\title{
Design and Management of Freight Transport Networks: Intermodal Transport and Externalities
}

\author{
Thèse présentée \\ en vue de l'obtention du grade \\ de Docteur en Sciences Economiques \\ et de Gestion par
}

\section{Martine Mostert}

\section{Promoteur:}

Sabine Limbourg, Université de Liège

Membres du comité:

An Caris, Hasselt University

Mario Cools, Université de Liège

Membres du jury:

Bart Jourquin, Université Catholique de Louvain Bruno F. Santos, Delft University of Technology

Jean-Sébastien Tancrez, Université Catholique de Louvain 

Table of contents

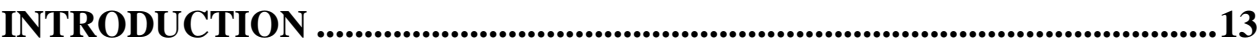

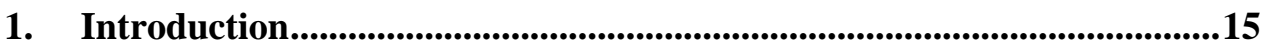

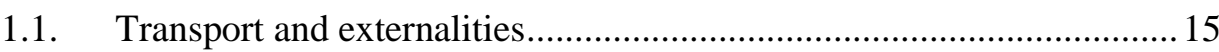

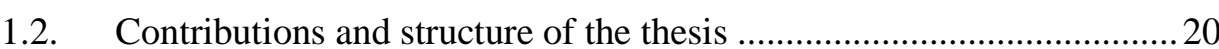

INTERMODAL FREIGHT TRANSPORT AND FREIGHT TRANSPORT

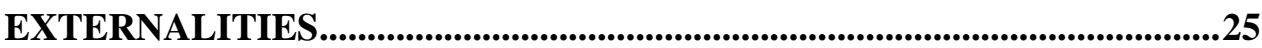

2. Intermodal freight transport ...........................................................27

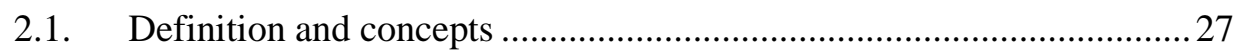

2.2. SWOT analysis of intermodal freight transport...................................29

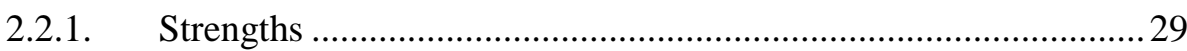

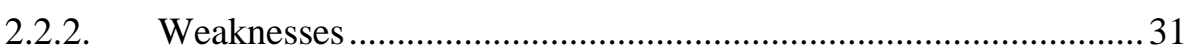

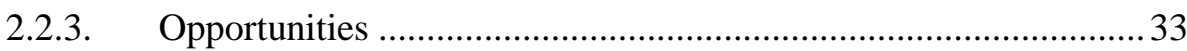

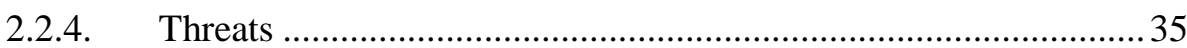

3. Freight transport externalities .............................................................37

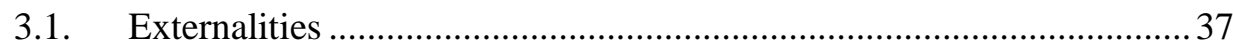

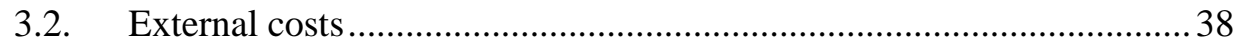

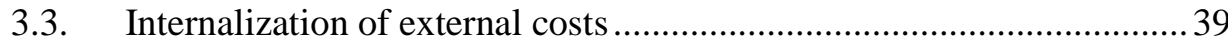

4. External costs as competitiveness factors for freight transport...............43

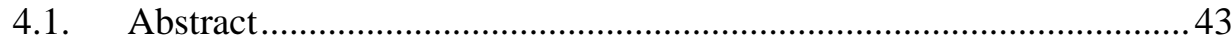

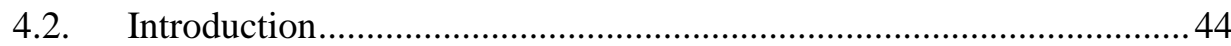

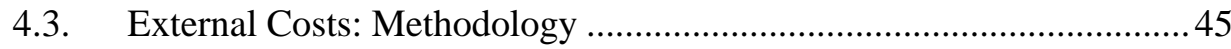

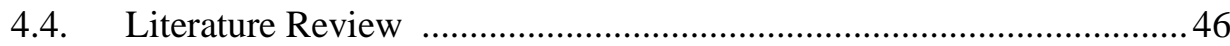

4.5. External Costs as Competitiveness Factors …………..........................50

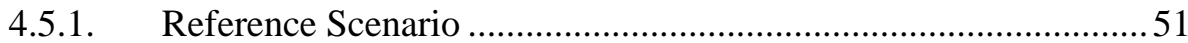




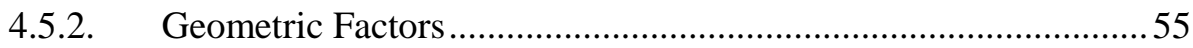

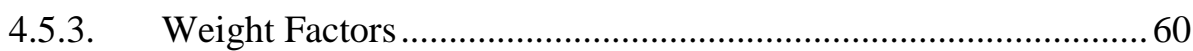

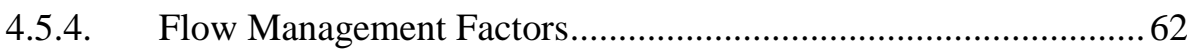

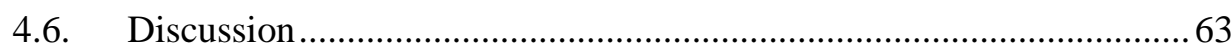

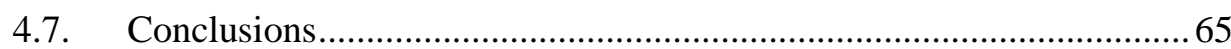

OPTIMIZATION MODELS AND APPLICATIONS.......................................67

5. Intermodal transport and climate change ..............................................73

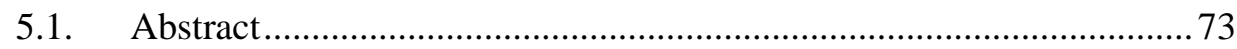

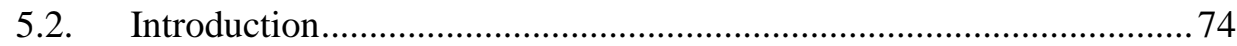

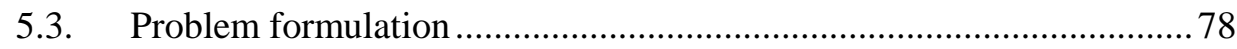

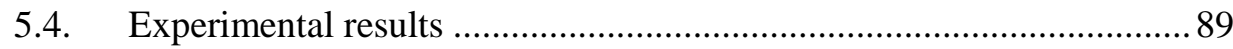

5.4.1. Discussion on calibration and validation .................................... 91

5.4.2. Without economies of scale - linear approach ............................... 94

5.4.3. With economies of scale - nonlinear approach ........................... 103

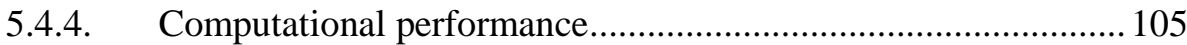

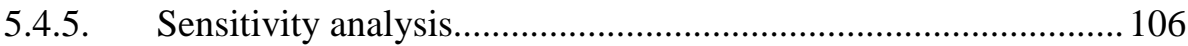

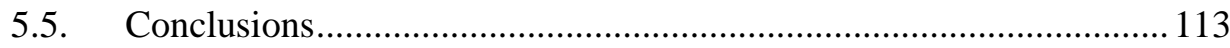

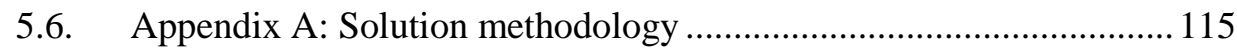

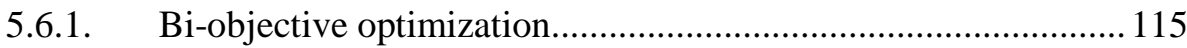

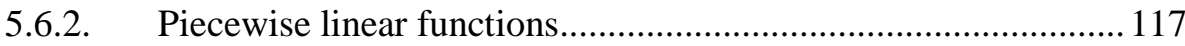

5.7. Appendix B: Cost and emission functions of the linear approach ...... 119

5.8. Appendix C: Cost and emission functions of the nonlinear approach 122

6. Intermodal transport and air pollution .........................................................127

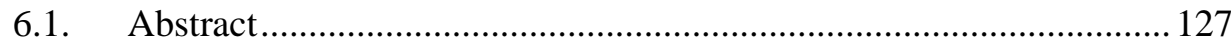

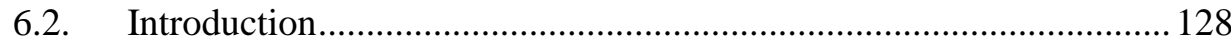

6.3. Freight transport, air pollution and human health impacts: what are the implications for business and stakeholders? 


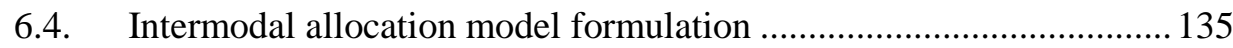

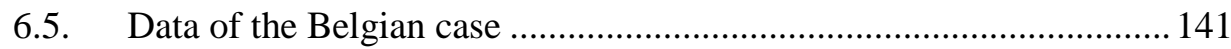

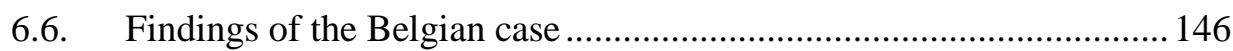

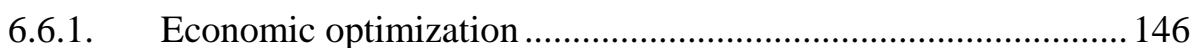

6.6.2. Air pollution optimization........................................................... 147

6.6.3. Economic optimization with taxation system ............................... 148

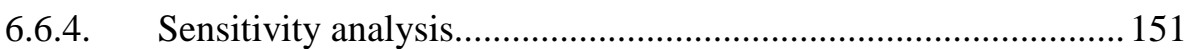

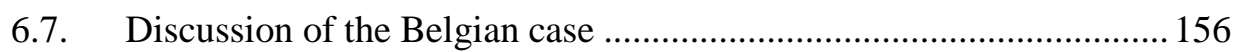

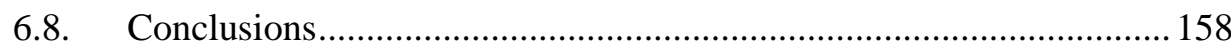

7. Several intermodal transport chains ......................................................161

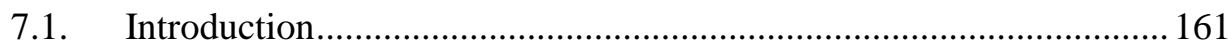

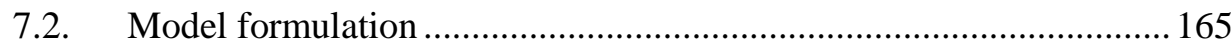

7.3. Experimental data at the European level............................................. 171

7.4. Experimental results at the European level......................................... 175

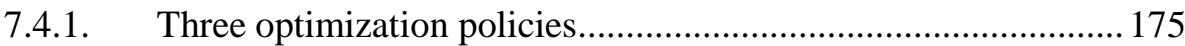

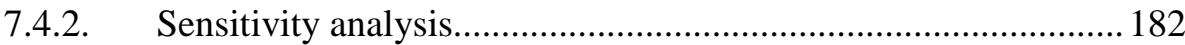

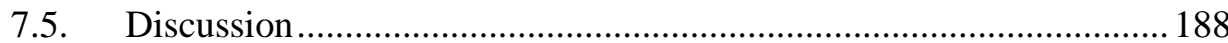

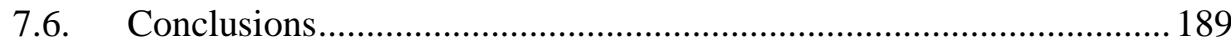

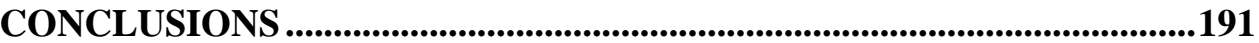

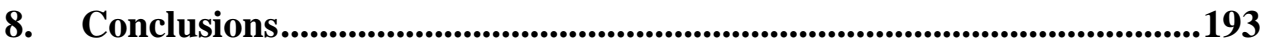

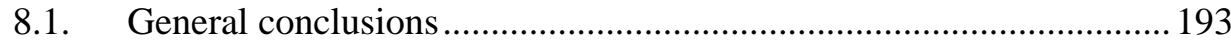

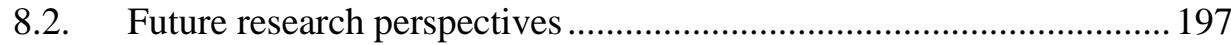

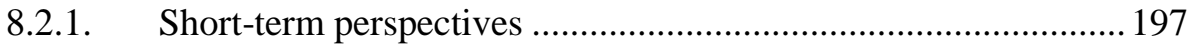

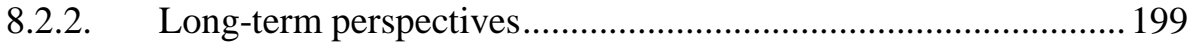





\section{List of figures}

Figure 1: Core network corridors (source: RailNetEurope)

Figure 2: Examples of the six theoretical models for transport design (source:

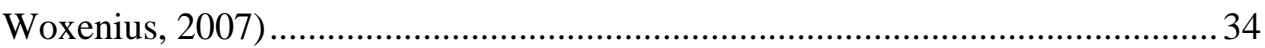

Figure 3: Demand-supply equilibrium in perfect competition............................. 40

Figure 4: Social and private marginal cost pricing ......................................... 41

Figure 5: Evolution of internal and full costs with the distance travelled, for road and intermodal using rail transport - Reference scenario....................................55

Figure 6: Comparison of road and intermodal external costs with different $\mathrm{PPH}$

Figure 7: Location of origin and destination nodes in relation to origin and

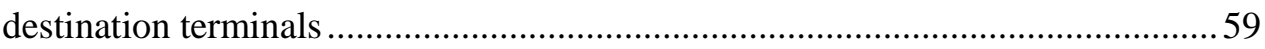

Figure 8: NUTS 3 regions considered in the Belgian case study.........................90

Figure 9: Pareto front for the bi-objective model in the linear case .................... 95

Figure 10: Flow distribution (t.km) for costs and emissions minimization in the

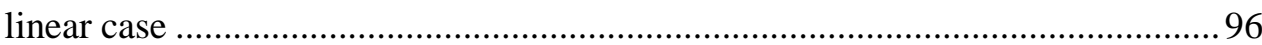

Figure 11: Flow distribution (t.km) for costs and emissions minimization in the nonlinear case 103

Figure 12: Map of the rail-IWW, IWW and rail terminals in Belgium (source:

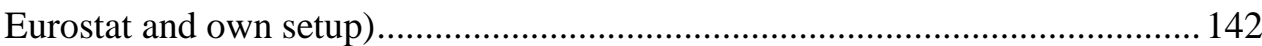

Figure 13: Flow distribution for operational costs minimization. …................... 147

Figure 14: Flow distribution for air pollution external costs minimization........ 148

Figure 15: Flow distribution for operational costs minimization with road tax on

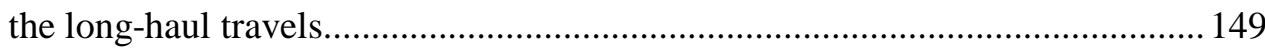

Figure 16: Flow distribution under different values of road tax ....................... 150

Figure 17: Flow distribution for operational costs minimization with road tax on

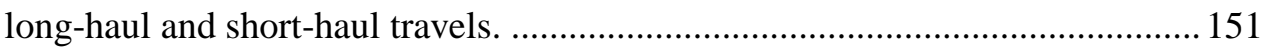

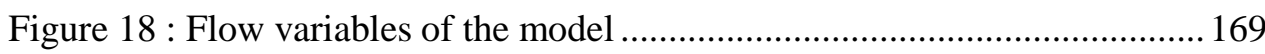

Figure 19: Flow distribution of intermodal transport through one terminal (a) and through two terminals (b) for operational costs min...................................... 178 Figure 20: Flow distribution of intermodal transport through one terminal (a) and through two terminals (b) for $\mathrm{CO}_{2}$ emissions min. .......................................... 179 Figure 21: Flow distribution of intermodal transport through one terminal (a) and through two terminals (b) for air pollution min.............................................. 180 Figure 22: Examples of flow distribution for the three optimization policies .... 182 



\section{List of tables}

Table 1: SWOT analysis of intermodal transport

Table 2: Summary of the main external costs characteristics studied in the

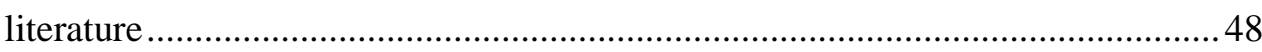

Table 3: Parameters and reference values of the internal and external cost

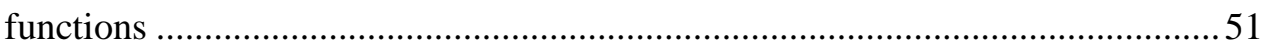

Table 4: Breakeven distances for internal and full costs ......................................56

Table 5: Sensitivity analysis of the breakeven distance for internal and full costs to the location scenario

Table 6: Sensitivity analysis of the breakeven distance for internal and full costs to the rail load factor.

Table 7: Overview of the characteristics of the three models and their application

Table 8 : Comparison of the research works of Zhang et al. $(2013,2015)$ and

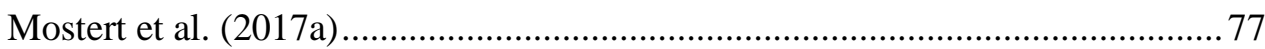

Table 9: Real and modeled modal split under the economic optimization approach that does not consider economies of scale ....................................................... 92

Table 10: Results of the optimal costs and emissions minimization cases ...........96

Table 11: $\mathrm{CO}_{2}$ avoidance costs for 2025 and 2050 ....................................... 100

Table 12: Marginal operational costs between the points of the Pareto curve.... 101

Table 13: Sensitivity analysis of the cost parameters .......................................... 107

Table 14 : Aggregate elasticities of road, rail and IWW .................................... 108

Table 15: Sensitivity analysis of the emission parameters ................................... 110

Table 16: References and comments related to the used parameters.................. 143

Table 17: EURO standards shares (Emisia, 2015) and costs (Ricardo AEA, 2014)

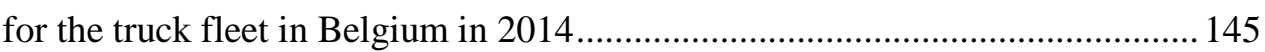

Table 18: Operational and external costs of transportation modes ...................... 146

Table 19: Sensitivity of flow distribution to truck fleet structure........................ 153

Table 20: Sensitivity of flow distribution to rail traction mix ............................ 154

Table 21: Sensitivity of flow distribution to IWW operational and air pollution

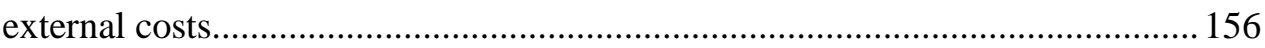

Table 22: Transportation possibilities for each origin-destination pair .............. 164

Table 23: Unit operational costs, $\mathrm{CO}_{2}$ emissions, and air pollution external costs

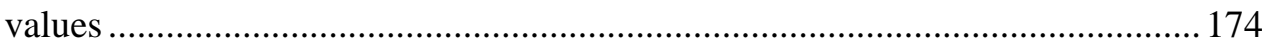

Table 24: Modal splits between road, rail and IWW flows .................................. 175 
Table 25: Modal split between direct and intermodal flows................................ 176

Table 26: Detailed modal split within direct transport ...................................... 177

Table 27: Detailed modal split within intermodal transport with two

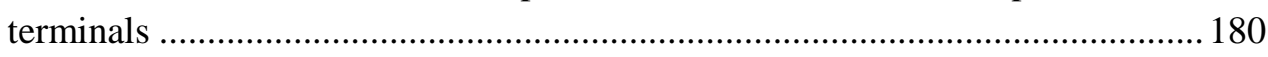

Table 28: Sensitivity analysis of flows to operational costs variations .............. 183

Table 29: Aggregate elasticities of road, rail and IWW - several intermodal

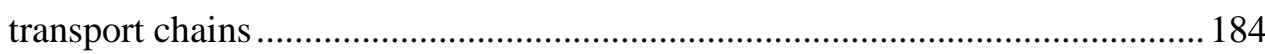

Table 30: Sensitivity analysis of flows to $\mathrm{CO}_{2}$ emissions variations................... 185

Table 31: Sensitivity analysis of flows to air pollution external costs variations 187 


\section{Acknowledgments}

This thesis is the result of the work that I performed during these last four years and a half, and has only been possible thanks to the participation, the support, and the involvement of several people around me.

First, I would like to thank my supervisor, Sabine Limbourg, who offered me the possibility to make a $\mathrm{PhD}$ thesis, and who supported me from the very beginning to the end of this project. Thanks for our successful collaboration, for the time spent in writing funding projects, for our technical discussions, for your feedback regarding papers, for showing me that programming was not impossible, for your deep involvement, and for your continuous enthusiasm. I learned a lot from you during these years, from a technical and from a human point of view. All of this would not have been possible without you!

I would like to warmly thank the members of my thesis committee, An Caris and Mario Cools, for their ideas and their guidance during my $\mathrm{PhD}$ studies. Thank you for believing in my project and for your useful comments throughout the process. Thank you also for the nice time that we had together in conferences and other scientific events.

I am very grateful to the members of my thesis jury, Bart Jourquin, Bruno F. Santos and Jean-Sébastien Tancrez, for having attentively read and commented this thesis. Thank you for helping me improving this work, based on your research expertise in your respective domains. Your useful and pertinent suggestions definitively improved the quality of this thesis.

I thank the University of Liège and the Fonds National pour la Recherche Scientifique (F.R.S-FNRS) for the funding of my $\mathrm{PhD}$ studies.

During this time at HEC, I was also very lucky to share moments with a super team of colleagues! It was a real chance to be part of such a nice group, and to be able to discuss about technical issues, but also about anything but research at the coffee breaks, lunch times, and restaurants that we had together. Thank you Christine, Eli, Hande, Frédéric, Sarah, Célia, Anne-Sophie, Stéphanie, Stefano, Virginie, Julien, Alessandro, Ashwin, Maud, Thierry, Reza, Yasemin, Guillaume, Véronique, Bart, Christian, Mr. Crama, \& Mr. Schyns for these good moments together. 
I would like to deeply thank my friends and my family, and in particular my Parents, who gave me the possibility to realize this $\mathrm{PhD}$. Thank you for all your Love, for your unconditional support, and for all these moments of happiness that we share. A special thanks to Aurélie, Anthony, Anne-Marie, Bruno, Aline, Sébastien, and my grand-parents for being always present and attentive. Thank you also to Audrey, Maud, Thomas, Mélanie, Julien, Valérie, Françoise, Adeline and Stéphan: these years would have not been the same without our meetings and celebrations all together.

Finally, I would like to thank Grégory, my Partner in Life for already more than 12 years. Thank you for believing in me, for always encouraging me, for your endless motivation, for your patience, for your Love, and for the wonderful projects that we are undertaking together. The Reason is You. 


\begin{abstract}
Transportation of goods contributes to the economic development of societies but it generates negative impacts on its environment called negative externalities. In its White Paper on Transport, the European Commission encourages the flow transfer from road to more environmentally friendly modes like rail or inland waterways (IWW). This objective can be reached by the development of intermodal transport, i.e. the transportation of goods using two or more modes of transport, in the same loading unit, without handling of the goods themselves.
\end{abstract}

A literature review on transport externalities and their valorization methods highlights the small number of studies related to the general modeling of transport externalities through dedicated mathematical formulas. However, the latter are important for identifying the key parameters that influence transport competitiveness in terms of externalities. This is demonstrated by analyzing two external cost functions for road and rail. The location of intermodal terminals, where the flow transfer between road and a more environmentally friendly mode occurs, stands out from the environmental perspective as one of the most important competitiveness factors of intermodal transport regarding road.

An innovative mathematical model for the location of terminals and allocation of flows between road and intermodal rail and IWW transport is developed. The model is based on a bi-objective formulation which evaluates the trade-offs between transport operational costs and $\mathrm{CO}_{2}$ emissions. Economies of scale of intermodal transport are integrated thanks to nonlinear functions. The model is applied to the Belgian network. Results indicate that terminal locations are relatively stable, whatever the optimized economic or environmental objective. The type of terminal located changes according to the followed strategy. Minimizing $\mathrm{CO}_{2}$ emissions leads to an increased use of intermodal transport.

The impact of transport on air pollution is also evaluated. On the Belgian case, an economic optimization of transport operational costs is compared to an environmental optimization of transport air pollution external costs. The intervention of public authorities through a taxation policy for trucks is also studied. Results show that the introduction of road taxes leads to a more intensive use of intermodal transport than in the absence of taxes. The maximum intermodal market share is observed when air pollution external costs are minimized. 
Finally, intermodal transport is often modeled as a "road-rail/IWW-road" combination. A new model which considers other intermodal chains is applied on experimental data at the European level. The model allows to choose between any direct transport by one mode (road, rail or IWW), and any intermodal transport of up to three modes. Results indicate that several connections may benefit from the use of other combinations of modes than the "road-rail/IWW-road" combination. 


\section{PART I}

\section{INTRODUCTION}

This thesis deals with freight transport systems. It focuses on intermodal transport and on its use as an alternative solution to road transport. The evaluation of the attractiveness of intermodal transport is performed in both economic and environmental terms, so as to reflect today's and tomorrow's expectations.

This first part develops the general context of the thesis subject and identifies the research contributions and the thesis structure. 



\section{Chapter 1}

\section{Introduction}

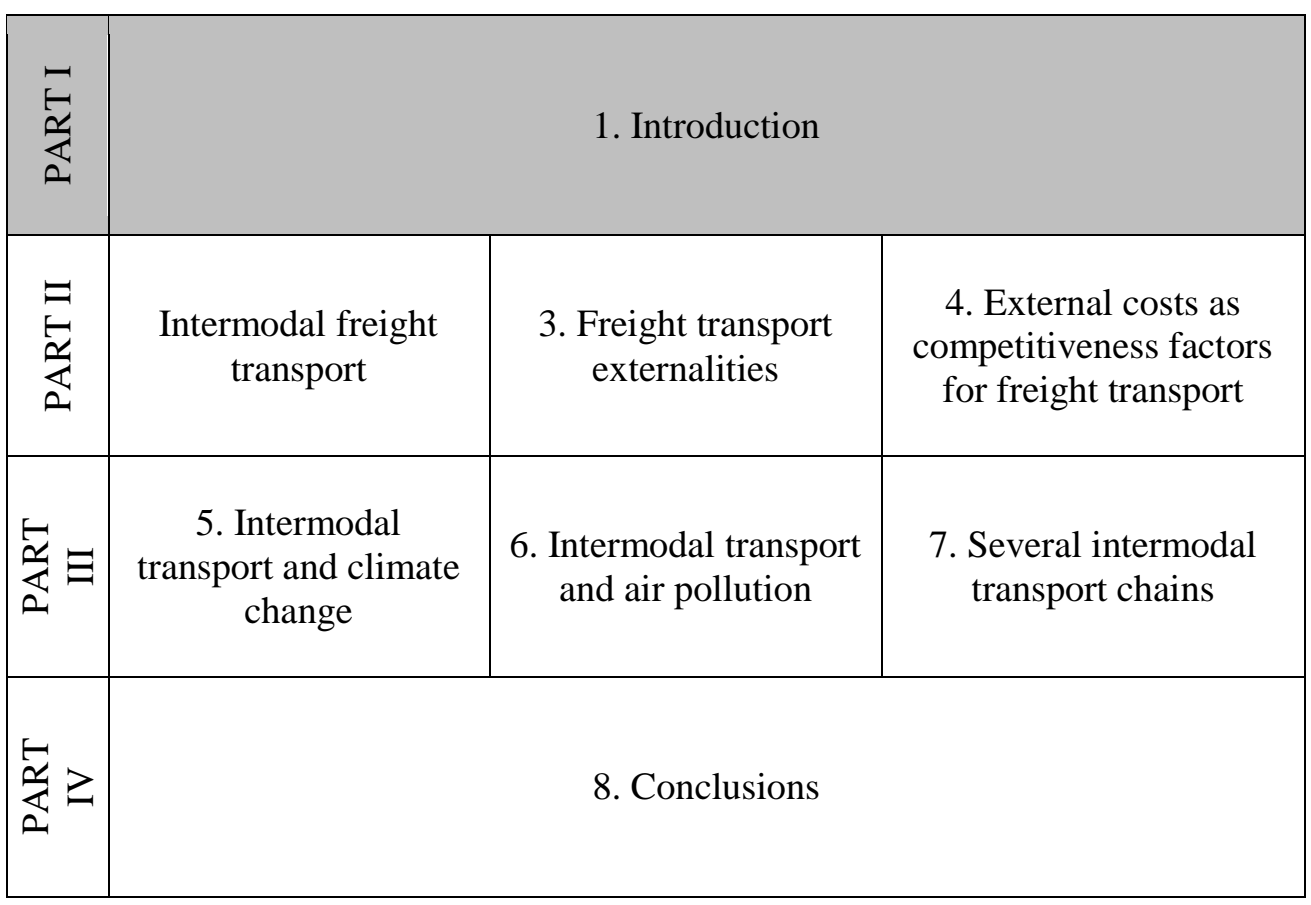

This introductory chapter is structured around two main parts. First, it presents the notions of transport and externalities, and how these two concepts are connected. Second, it elaborates on the thesis contributions and structure.

\subsection{Transport and externalities}

Freight transportation activities are necessary for the economic development of societies. Everybody is concerned with freight transportation. Who never goes to the supermarket or to a restaurant, buys new clothes, shoes or material for repairing a house or a car? All these activities require goods and raw material that are not necessarily produced in facilities close to the retailing companies in which 
they are sold. This implies the movement of freight between several origin and destination nodes using transportation modes.

Freight transportation brings positive contributions to societies, such as the possibility to beneficiate from exotic food or from products which are produced at a lower price in further economic regions.

Despite these positive impacts on the economy, transportation is responsible for a lot of negative effects on the environment, such as noise, air and water pollution, congestion, accidents and climate change. Some of these negative impacts happen at the local level and only affect the direct surroundings of the places where the transportation mode is employed (e.g. noise, road degradation, air pollution). Other negative impacts (e.g. climate change) have a more global influence on the environment. Indeed, the effects of global warming are not only observed in places where emissions are generated.

All the negative effects of transport that are generated by transportation companies but that are not economically supported by them are defined as transport externalities. These negative effects of transport are supported by other economic stakeholders such as public authorities, local residents, private companies, or even inhabitants of faraway regions. The costs of these externalities on society are known as transport external costs.

This thesis focuses on freight transportation and assesses the alternative intermodal transport solution in terms of economic and environmental impacts. Intermodal transport refers to the transportation of goods using several modes of transport in loading units, without handling of the goods themselves. Further discussion on the concept is developed in chapter 2.

Developing deeper knowledge regarding alternative solutions to road and their impact on the environment is necessary, in view of the willingness of the European Commission (2011) to go for more environmentally friendly modes and regarding the still dominant share of road in European land freight transport. In 2014, $75.5 \%$ of the freight t.km in Europe (28 countries) were transported by road, $18 \%$ by rail and $6.6 \%$ by inland waterways (IWW) (Eurostat, 2016). This dominant position of road on the freight transport market is explained by the advantages of this mode, such as its flexibility, its advantageous speed/price relationship and its direct connection between all origin and destination nodes, allowing a single door-to-door transportation mode. Nevertheless these 
advantages are counterbalanced by negative impacts on the environment, such as air pollution, emission of greenhouse gases, congestion, accidents and noise.

In the last decades, there has been an increasing trend to consider and try to reduce these negative effects of transport on the environment. Some of the main concerns of public authorities regarding transport externalities relate to the emissions generated by road vehicles. The latter are responsible for global warming, which induces climate change, and for air pollution which, in turn, implies negative effects on human health. Several tools have been used to limit these negative transport externalities. Some examples through legislative and policy measures are presented below.

The interest for climate change is illustrated by the organization of international conventions and events, such as the Kyoto Protocol or the regular United Nations Climate Change Conferences. In 2016, more than 55 Parties to the Paris Convention, accounting in total for more than $55 \%$ of the total global greenhouse gas emissions, ratified the Paris Agreement (UNFCCC, 2016). This shows the world willingness to contain the average global temperature increase under $2 \%$, compared to the pre-industrialized period. The main advantage and improvement of this Agreement, compared to the Kyoto Protocol, is the implication of all countries, including developing regions. The contribution to the global objective depends on each country, and a distinction is made between developed and developing countries. The main European objectives in terms of climate change can be summarized by the 20-20-20 objectives for 2020. Indeed, European authorities aim at reducing by $20 \%$ the greenhouse gases compared to 1990 , at achieving a proportion of $20 \%$ of renewable energies in the global energy consumption, and at increasing by $20 \%$ their energy efficiency. For 2030, these objectives are even higher; Europe expects a reduction of $40 \%$ of greenhouse gases compared to 1990, a use of $27 \%$ of renewable energies in global energy consumption, and an increase of $27 \%$ of the energy efficiency (European Commission, 2016c).

Besides climate change, air pollution matters at the world level are consolidated in the United Nation Economic Commission for Europe (UNECE) Convention on Long-range Transboundary Air Pollution (LRTAP). Dating from 1979, this convention is the first international legally binding tool developed to limit air pollution. It has been followed by a set of protocols aiming at enforcing the transboundary air pollution abatement (UNECE, 2015). At the European level, the 
National Emission Ceilings Directive sets national emission maximum values for four pollutants i.e. $\mathrm{NO}_{\mathrm{x}}, \mathrm{SO}_{2}, \mathrm{NMVOC}$ and $\mathrm{NH}_{3}$ for the year 2010. These ceilings are even more restrictive than the ones of the LRTAP convention (European Commission, 2015).

At the local level, different kinds of polices are also implemented in order to limit air pollution. In European city centers, the introduction of Low Emission Zones (LEZs) is becoming very common. Austria, Belgium, Czech Republic, Denmark, Finland, Germany, Greece, Italy, France, the Netherlands, Norway, Portugal, Sweden and United Kingdom all have implemented LEZs of various scopes and with different characteristics. LEZs consist in predetermined geographical areas in which road traffic is controlled and limited, based on the emission characteristics of the vehicles. LEZs can concern passenger or freight transportation, they can be regulated through national or local schemes (Cruz and Montenon, 2015), they can have different enforcement methods (manual versus technological through cameras), and a fee can also be asked to enter into the zone. LEZs clearly have an environmental objective and they can be completed by a charge zone for congestion, i.e. a zone in which additional fee should be paid, in order to reduce traffic jam and congestion. A well-known example of these charge zones of congestion is the city of London. For reducing air pollution and congestion, other measures such as the implementation of alternate traffic circulation based on license plate have been implemented earlier in city centers (i.e. Athens was a pioneer) but this model showed its weaknesses. Indeed, drivers found alternative solutions for driving every day, such as buying an additional car, in order to have two license plates: an even and an odd one. Road pricing in the form of a bonus or a malus, depending on the sustainable characteristics of the vehicles, as well as subsidies for alternative modes of transport are other examples of policies introduced at the local level to limit the externalities of transport.

The implementation of all these tools at the local, national, and supranational level reveal the importance accorded to the development and coordination of transport policies which take into account their impact on the direct and indirect environment.

The reduction of the negative impacts of transport is generally associated with a reduction of the tonne.kilometers (t.km) performed by road. One of the objectives of the European Commission (2011) in the White Paper for Transport, is to 
transfer $30 \%$ of the goods transported by road over $300 \mathrm{~km}$ to a more environmentally-friendly mode by 2030 , and $50 \%$ by 2050 . This objective can be achieved through the use of alternative modes like rail and IWW. However, the latter are not very efficient if they are used on their own, without combining them with road. Rail and IWW transport present the disadvantage of not connecting directly all possible origins and destinations because they require terminals where trains or barges can be welcomed.

A combination of road with another more environmentally friendly mode therefore appears as an interesting alternative solution to limit the negative effects of direct road transport. Combining several modes for delivering goods from an origin to a destination is the basic concept of multimodal, intermodal and synchromodal transport.

Multimodal transport is characterized by the use of several modes of transport for traveling from an origin to a destination node (SteadieSeifi et al., 2014).

Intermodal transport adds the notion of transportation in an intermodal loading unit without handling of the goods themselves (United Nations, 2001). Intermodal loading units mainly refer to containers or swap bodies. According to the European Commission (2004), a container is " a box to carry freight, strong enough for repeated use, stackable and fitted with devices for transfer between modes". From the same source, a swap body is a "freight-carrying unit, used in Europe, optimized to road vehicle dimensions and fitted with handling devices for transfer between modes, usually road/rail". The main difference between a container and a swap-body is that a container is stackable whereas a swap body is not. Moreover, swap body cannot be lifted thanks to top lifting castings but have to be lifted from the sides using castings along the bottom (The Intermodal Container Web Page, 2013).

Synchromodal transport implies the concept of transport flexibility. The idea is for the shipper to let the freedom to the logistics service provider (LSP) to choose the transport modes during the travel (DINALOG, 2013). The LSP is able to dynamically select the best way of traveling according to the current traffic, time, weather, service level, environmental or costs conditions (SteadieSeifi et al., 2014, Verweij, 2011). The main challenges are related to the coordination and optimal use of modalities. If this improved connection between modes is achieved, it allows for more sustainability because it helps reducing the number of 
operations and the storage time that are responsible for external costs (e.g. noise or pollutants). Synchromodality therefore refers to the efficient use of intermodal transport.

This dissertation focuses on intermodal freight transport as an alternative solution to road transport. The effects of economic and environmental planning policies on the modal split between road and intermodal transport are analyzed and discussed. The objectives and structure of the thesis are defined in the next section.

\subsection{Contributions and structure of the thesis}

The objective of this thesis is to develop additional knowledge regarding the viability of intermodal transport in terms of economic and environmental perspectives. For this purpose, a literature review on freight transport externalities provides an overview of the latest research studies in the domain, as well as an analysis of the main parameters which influence intermodal competitiveness. In order to make strategic transport decisions, realistic decision support models for freight transport networks must be developed, so that insights can be derived for the different stakeholders of the transportation chain. This thesis develops such innovative location-allocation and allocation models for road and intermodal freight transport. The models are applied on case studies, in order to highlight the similarities and differences between economic and environmental policies regarding flows, terminal locations and terminal types. This thesis enriches the current state of the art by providing contributions regarding

1) Freight transport external costs

a. The latest research studies regarding freight transport external costs are identified and are summarized based on their characteristics in terms of their perspective (academic or projectoriented), their objective (prescription, application, projection), the type of externality (air pollution, climate change, noise, accidents, congestion), and the type of cost (marginal, average, total) that is considered.

b. The competitiveness of intermodal transport in relation to road is assessed for economic and environmental objectives. The analysis of the breakeven distance between these two modes for operational and internalized full costs allows determining the 
main parameters which influence the competitiveness of land transport.

2) Intermodal transport and climate change

a. A new location-allocation model for intermodal and road transport is developed. This model takes into account three modes of transport and balances the economic and environmental objectives related to climate change in a bi-objective formulation. Economies of scale of intermodal transport can also be integrated using different sizes of vehicles or nonlinear cost and emission functions of the flows transported.

b. The model is solved using exact methods on the extended real Belgian case study, considering all the flow exchanges between Belgian, Luxembourg and some Dutch, German and French regions. The effects on modal split, terminal type and terminal location are analyzed for economic and climate change purposes.

3) Intermodal transport and air pollution

a. A simplification of the previous model is applied on the extended Belgian case study to evaluate the trade-offs between economic and air pollution objectives. The effect on modal split of the introduction of additional road taxes is compared to purely economic or environmental objectives. The evolution of the competitiveness of intermodal transport in relation to road is assessed when cleaner vehicles are introduced in the truck fleet, when the rail traction mix is modified and when inland waterways costs are varied.

4) Several intermodal chains

a. An innovative location-allocation model for road and intermodal transport is developed. This model allows choosing between any direct transport by road, rail or IWW, and any intermodal combination of up to three modes. The flow distribution can therefore be assessed between direct transport, intermodal transport passing through one terminal, and intermodal transport passing through two terminals.

b. The model is solved exactly using experimental data at the European level, in order to identify the behavior of flows between direct and intermodal combinations on long distances. The optimal flow exchanges between European regions are compared 
for policies aiming at minimizing economic (operational costs) and environmental objectives $\left(\mathrm{CO}_{2}\right.$ emissions and air pollution external costs).

The thesis is structured as follows.

Chapter 1 provides the general context of transport and externalities, and the thesis contributions and structure.

Chapter 2 investigates the concept of intermodal transport. The basic notions and definitions of intermodal transport are described. An analysis of the main strengths, weaknesses, opportunities and threats of intermodal transport (SWOT analysis) is then performed.

Chapter 3 focuses on freight transport externalities. The basic notions and definitions of transport externalities are explained. The theory of external costs internalization is also developed.

Chapter 4 develops a state of the art of external costs as competitiveness factors for freight transport.

Chapters 5, 6, and 7 compile on the results of chapters 2, 3 and 4 to combine intermodal transport and transport externalities in mathematical models of the operations research domain. The models take into account economic and environmental objectives so as to reflect today's and tomorrow's expectations.

Chapter 5 develops a new intermodal location-allocation model which allows assessing the impact on flow distribution, on intermodal terminal location, and on intermodal terminal type of policies aiming at restricting the impact of climate change. The model is solved for an application on the extended Belgian case study.

Chapter 6 provides an intermodal allocation model which assesses the impact on flow distribution of several policies aiming at optimizing air pollution external costs. The model is solved on the extended Belgian case study.

Chapter 7 focuses on an intermodal allocation model which allows the choice between direct transport and several intermodal chains. The model is solved using experimental data at the European level. 
Chapter 8 identifies the main conclusions retrieved from the analyses related to intermodal transport, externalities, and their combination in intermodal locationallocation or allocation models. Further research perspectives are also elaborated. 



\section{PART II \\ INTERMODAL FREIGHT TRANSPORT AND FREIGHT TRANSPORT EXTERNALITIES}

This second part develops the concepts of intermodal freight transport and freight transport externalities.

Chapter 2 focuses on intermodal freight transport. It describes intermodal freight transport and identifies its positive and negative characteristics.

Chapter 3 concentrates on freight transport externalities and explains the notions of externalities, external costs, and internalization of external costs.

Chapter 4 provides a state of the art of external costs as competitiveness factors for freight transport. 



\section{Chapter 2}

\section{Intermodal freight transport}

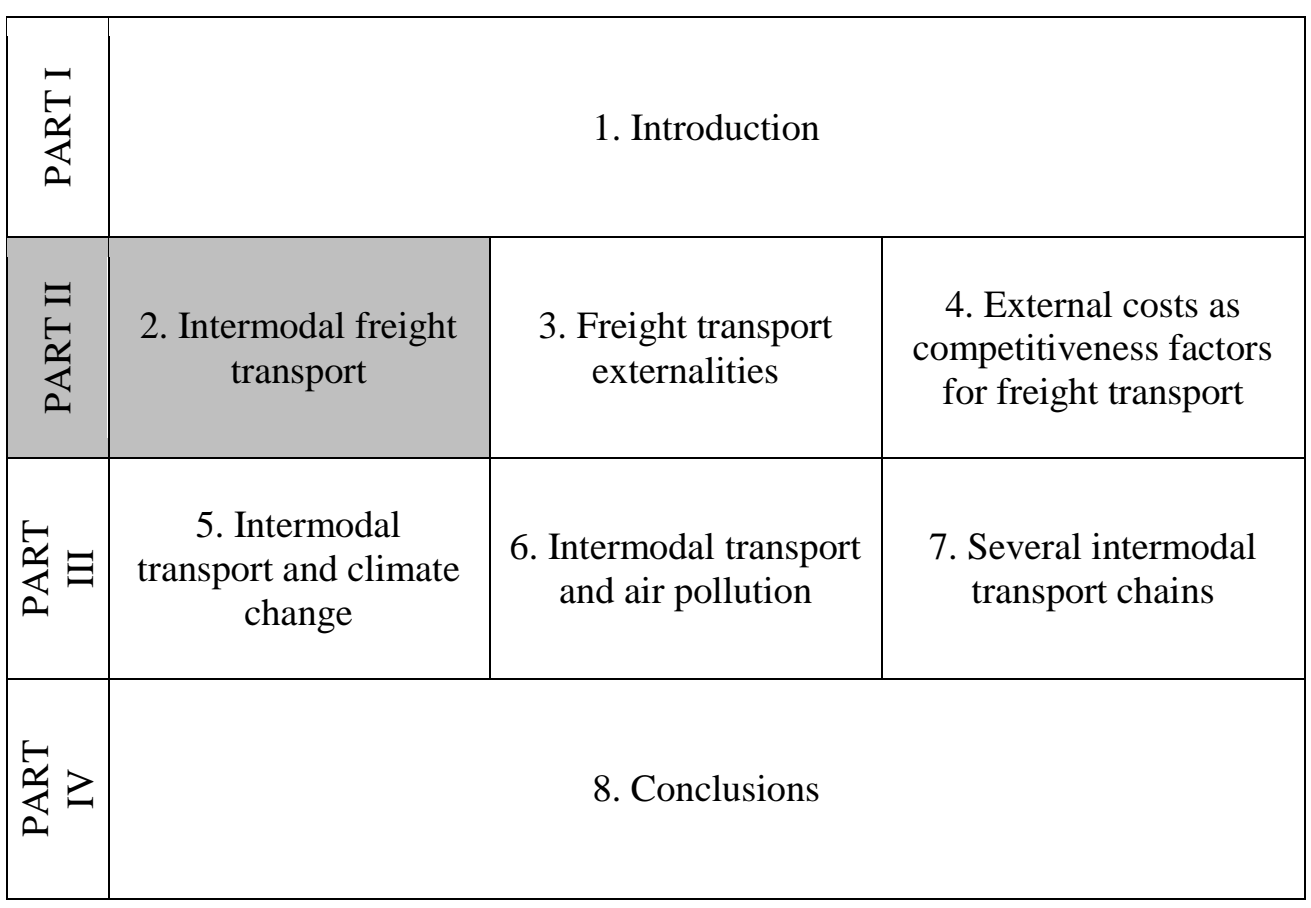

This chapter focuses on intermodal freight transport. The general definition and concepts of intermodal transport are first developed. A SWOT analysis of intermodal freight transport is then provided.

\subsection{Definition and concepts}

Intermodal transport is defined as the transportation of goods using two or more modes of transport, in the same loading unit, without handling of the goods themselves (United Nations, 2001). In this work, intermodal transport refers to the flows of goods transported in containers. 
In this work, it is assumed that intermodal transport is performed by the travel through at most two intermodal terminals. This is done to better match reality and to represent the fact that transferring freight from one mode to another is not free of charges. Indeed, moving goods requires equipment (terminal infrastructure, cranes, storage areas) and labor (people activating the cranes, planning the transfer schedules). In this thesis, intermodal transport is therefore constituted by at most five main phases:

1) Pre-haulage of the goods from the origin node to the first terminal

2) Transfer at the first terminal, between the pre-haulage mode of transport, and the long-haul mode of transport

3) Long-haul travel of the goods from the first to the second terminal

4) Transfer at the second terminal, between the long-haul mode of transport and the post-haulage mode of transport.

5) Post-haulage of the goods from the second terminal to the destination node.

The modeling of intermodal transport is often done with road for the pre and posthaulage (PPH) travels and with a more environmentally friendly mode like rail or IWW for the long-haul transport.

Other configurations of intermodal transport with fewer stages are also possible. When goods are leaving or arriving at a port node, the PPH travels by road can be removed out of the process, since ports are generally connected to the rail and IWW networks. If the intermodal transport is done through one single terminal, only two modes of transport are required and intermodal transport refers to three stages i.e. pre-haulage from the origin to the unique terminal, transfer from one mode to another, and post-haulage from the unique terminal to the destination node.

In order to be adopted by users, intermodal transport has to be efficient. It is therefore essential to identify the positive and negative features that characterize intermodal transport. This is the purpose of the following section. 


\subsection{SWOT analysis of intermodal freight transport ${ }^{1}$}

The SWOT analysis (table 1) identifies the positive and negative internal (strengths and weaknesses) and external (opportunities and threats) parameters that play a role on intermodal transport. Based on documents, scientific literature review, and interviews with experts in the field, the main elements related to the operational, macro-economic, sustainable, regulatory, and governance domains are pointed out.

\begin{tabular}{|c|c|}
\hline Strengths & Weaknesses \\
\hline 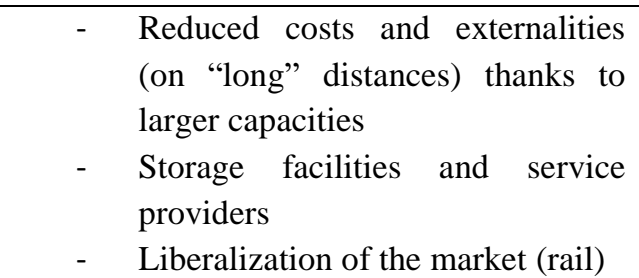 & $\begin{array}{ll}- & \text { Weak network access (rail) } \\
- & \text { Lack of flexibility } \\
- & \text { High fixed costs } \\
- & \text { High drayage operating costs } \\
- & \text { Missing links }\end{array}$ \\
\hline Opportunities & Threats \\
\hline $\begin{array}{ll}- & \text { Consolidation of flows } \\
\text { - } & \text { A single European } \\
\text { - } & \text { Market/Transport Area (rail) } \\
\text { - } & \text { Future road taxes } \\
& \text { Standardization }\end{array}$ & $\begin{array}{ll}- & \text { Cancellation of investments and } \\
& \text { subsidies } \\
- & \text { Interoperability problems } \\
- & \text { Passenger traffic (rail) } \\
- & \text { European Monopoly or duopoly } \\
& \text { (rail) }\end{array}$ \\
\hline
\end{tabular}

Table 1: SWOT analysis of intermodal transport

\subsubsection{Strengths}

Intermodal transport benefits from the advantages of its combined transportation modes. Rail and IWW transport on the long-haul travel enable economic and

\footnotetext{
${ }^{1}$ This section is partially based on results of the BRAIN-TRAINS project published under the references:

"Troch, F., Vanelslander, T., Sys, C., Belboom, S., Léonard, A., Limbourg, S., Merchan Arribas, A., Mostert, M., Stevens, V., Tawfik, C. M. F., \& Verhoest, K. (2015). Brain Trains: Intermodal Rail Freight Transport and Hinterland Connections - A Swot Analysis to Assess the Belgian Rail Practice. Proceedings of the IAME Annual Conference 2015."

"Troch, F., Vanelslander, T., Sys, C., Belboom, S., Léonard, A., Limbourg, S., Merchan Arribas, A., Mostert, M., Stevens, V., Tawfik, C. M. F., \& Verhoest, K. (2015). Brain Trains: Transversal assessment of new intermodal strategies: SWOT analysis."
} 
environmental savings. Indeed, these modes generate economies of scale (decrease of the average unit cost thanks to an increase of quantities/services produced) which imply reduced average costs/externalities per unit transported (Yevdokimov, 2000, Rodrigue et al., 2006).

The economic and environmental interest of intermodal transport is generally acknowledged on "long" distances. Intermodal transport implies additional transshipment operations between the different modes. These additional transshipment activities generate economic and environmental costs. The main benefits of intermodal transport are achieved on the long-haul travels by rail or IWW. If the distance with these modes is too short, compared to the PPH by truck, it is possible that the advantages obtained on the long-haul travel cannot compensate for the transshipment and road operational and external costs. The breakeven distance at which intermodal transport becomes more interesting than road differs according to the authors. Grosso (2011) states that, for operational costs, "according to experiences and common practice in transport, the minimum rail distance that allows a shift from road to rail is around 500-600 km". Janic (2007) determines the breakeven distance between road and intermodal rail transport at $900 \mathrm{~km}$ and $1050 \mathrm{~km}$, respectively for internal and full costs. Janic (2008) claims that using Long Intermodal Freight Trains (LIFTs) instead of Conventional Intermodal Freight Trains (CIFTs) reduces the breakeven distance for full costs to $700 \mathrm{~km}$. However, high volumes and short PPH distances can make intermodal transport attractive on short and medium distances (Bouchery and Fransoo, 2015).

Intermodal terminals can provide storage and service facilities to their users. Inland terminals can be referred to dry ports when they are directly connected to a sea port. Leveque and Roso (2002) define a dry port as "an inland intermodal terminal directly connected to seaport(s) with high capacity transport mean $(s)$, where customers can leave/pick up their standardized units as if directly to a sea port". In the literature, various terms have been used to define intermodal inland terminals. Please refer to Notteboom and Rodrigue (2009) for a detailed typology. Besides the transfer of goods between modes, inland terminals provide additional services to their users. One of their main advantages relates to storage facilities. Sea ports generally face problems of land availability. Since land prices are lower in dry ports than in sea ports, customers can store their goods at a reduced cost. Moreover, storing at the dry port reduces the inventory and congestion at the sea port. Several types of services can be handled at the intermodal terminal such as 
labeling and packaging of goods, customs clearance or container repair. The "Trilogiport" multimodal platform at Liege in Belgium is a good specific example of the willingness to incorporate services at the intermodal terminal. Indeed, 41.7 hectares of land (i.e. about $42 \%$ of the total available area) are dedicated to logistics services. This zone is devoted to European distribution centers that can provide added-values to the goods that are passing through the platform (Port Autonome de Liège, 2016).

The liberalization of the rail sector in Europe is a positive element for rail freight transport competitiveness. The liberalization process in Europe started in 2005 and was completely achieved in 2007. Before this process, the rail market in each country was characterized by a monopoly, where one national freight company was providing the whole offer to the network users. In economic theory, monopolies are responsible for market failure since producers (transport service providers in this case) hold some market power and do not price at the marginal cost but at a higher price (Gathon, 2013). It leads to inefficient systems where less quantity is produced (lower number of trips for instance) and at a higher price. Even if for rail experts in Belgium, the effects of the liberalization are not yet totally visible, positive impacts on the market development are expected, with increased competition at the borders, and the implementation of interoperability measures.

\subsubsection{Weaknesses}

Rail transport is characterized by a weak network access compared to road. Indeed, some obstacles, like slot attribution, establishment of new connections, expensive load wagons and network density, imply access restrictions such as the long lead times before operating a new service. These issues restrict the potential admission of new players on the network, and therefore limit the expansion of this mode of transport. The late deregulation of the rail sector compared to road also put barriers on the sector development. Difficult network access favors the system of one national company per country (Pham, 2013, Crozet et al., 2014) and the non-efficient economic theory of monopoly.

Intermodal transport suffers from a lack of flexibility. It is explained by several elements. First, intermodal transport requires high load factors to be able to generate economies of scale. Ensuring this full loading of trains or barges therefore implies longer waiting times before operating the transport and leads to 
services based on fixed schedules, which reduce transport flexibility. Second, few modifications can be performed in relation to the forecast schedules and flows. Indeed, in case of accidents on the rail and IWW network, it is difficult to find an alternative path. Other specific elements such as the priority of passenger over freight transport for trains, or variations of the water level due to the weather for barges reduce the flexibility of intermodal transport. In this context, the commitment of shippers to respect planned schedules and transported quantities is crucial for intermodal viability.

Intermodal transport has to support high fixed costs compared to road. Indeed, rail or IWW transport implies the use of expensive locomotives, wagons, barges, cranes, and the development of an adapted rail or IWW infrastructure. These costs are much higher than for road, which makes intermodal freight transportation only competitive if high quantities of goods are transported.

Intermodal transport implies the use of road and rail or IWW to deliver the goods from an origin to a destination node. This means that three main types of costs have to be supported: PPH by truck, long-haul transfer by train or barge, and transshipment costs at the terminal. Drayage operations costs consist in the movements by trucks between terminals and shippers or receivers, i.e. they refer to the PPH travels. Even if they are performed on short distances, drayage operations still consist in an important part of the total intermodal transportation costs. According to Macharis and Bontekoning (2004), they represent between $25 \%$ and $40 \%$ of an origin-destination intermodal travel. These operations may hamper the profitability and the competitiveness of intermodal transport. They must be carefully considered in the intermodal transport planning.

Intermodal transport is very dependent on its network and on the development of its infrastructure. At the European level, nine core network corridors (Scandinavian-Mediterranean Corridor, North Sea-Baltic Corridor, North SeaMediterranean Corridor, Baltic-Adriatic Corridor, Orient/East-Med Corridor, Rhine-Alpine Corridor, Atlantic Corridor, Rhine-Danube Corridor, and Mediterranean Corridor) have been defined. An illustration of these corridors is shown by figure 1 . 


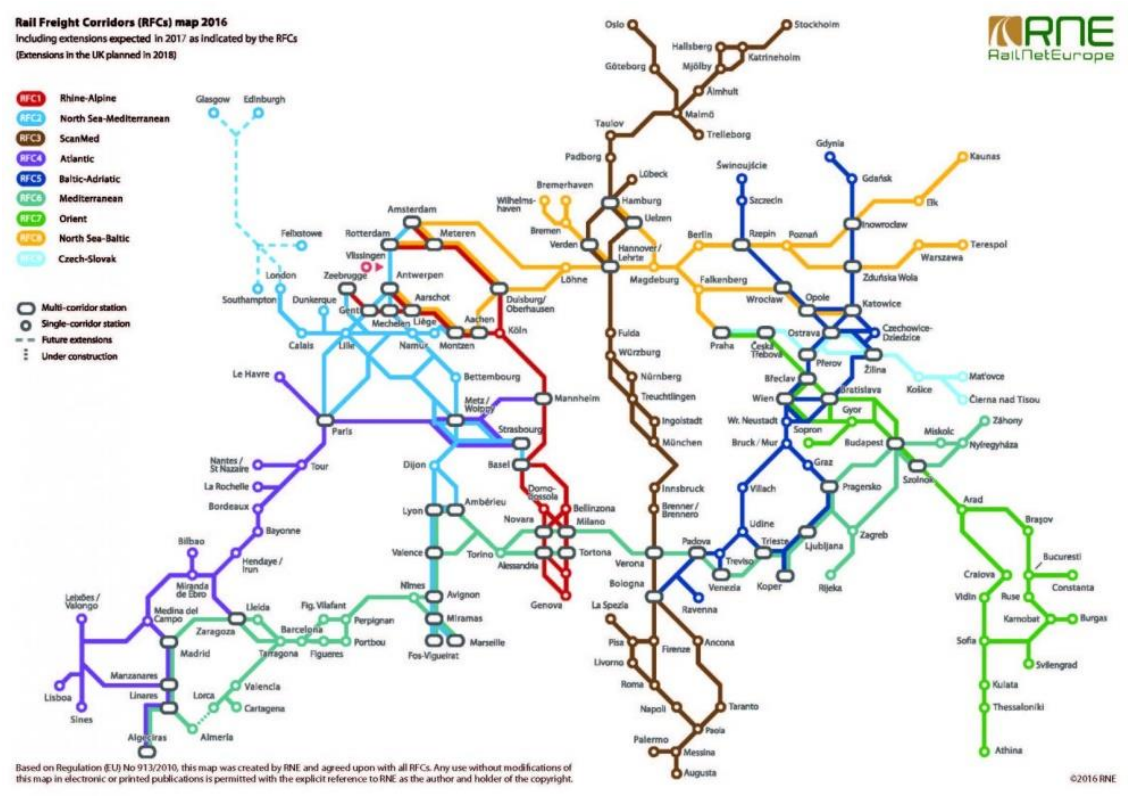

Figure 1: Core network corridors (source: RailNetEurope)

On each corridor, coordination between the intermodal stakeholders is promoted, in order to provide high quality service. Some of these corridors however suffer from missing links. Flows cannot therefore directly go through the corridors using intermodal transportation. Europe is working on the building of the missing links. By doing so, they specially address the need of developing connected, interoperable, intelligent and environmentally responsible infrastructure networks. Even if the process of connecting the different parts of the network is going on, intermodal transport is nowadays still suffering from the situation, since these current disconnections imply the use of alternative paths, which are generally longer, if they exist.

\subsubsection{Opportunities}

Unlike road transport, which is interesting for its flexibility and rapidity, intermodal transport bases its competitiveness advantage on the possibility of generating economies of scale by consolidating flows at intermodal terminals. Consolidation is defined by Bookbinder and Higginson (2002) as "an active effort to more efficiently utilize transportation resources". The term bundling is also interchangeably used to denote "the collection of goods to fill a transport unit" 
(Macharis et al., 2002). Consolidation happens to balance the mismatch between shipment sizes and transportation mode units' capacities. The decision to consolidate flows is based on different parameters: consignment size, transport distance, transport time demand, product characteristics and availability of other goods along the route (Woxenius, 2007). Different schemes of flow consolidation exist in intermodal transport. Six theoretical models implying different consolidation strategies are defined by Woxenius (2007): direct link, corridor, hub-and-spoke, connected hubs, static routes, and dynamic routes (figure 2).

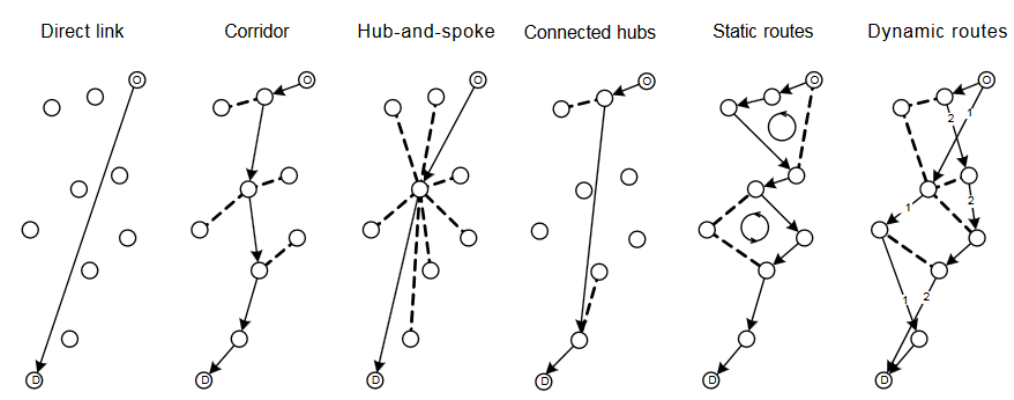

Figure 2: Examples of the six theoretical models for transport design (source:

Woxenius, 2007)

The creation of a single European transport area and market makes the intermodal transportation of goods easier and more efficient. Through the implementation of European rules which aim at standardizing economic and technical regulations, flows can travel more easily on the European territory. Technical standardization passes through the modification of vehicle fleets, of transportation units, and of the network infrastructure. Economic regulation refers to an open market, where no monopoly exists, and where as perfect as possible competition is encouraged. According to the European Commission (2011) in its White Paper, the main expected benefits of a single European open market are reduced costs, increased sustainability and safety, and increased economic development through the creation of high quality jobs and working conditions.

There is currently a political consent to shift the costs of the infrastructure to the user, i.e. through taxes on highways. These taxes can indirectly benefit to intermodal transport since it performs fewer kilometers on highways than when direct door-to-door road transport is used. If PPH distances are not too important 
compared to the total length of the travels, taxes for trucks mean higher costs for road transport and relatively more attractiveness for intermodal transport.

The standardization that is being established on the nine core freight corridors is an interesting opportunity of the intermodal sector since it allows the access to previously inaccessible markets. The development of interoperable services passes through the adaptation of gauges, safety, communication and signaling systems. Standard vehicles save time and money at borders. The standardization is paired with the increase use of information technology, such as freight tracking and tracing systems. The implementation of the European Rail Traffic Management System (ERTMS) in Europe, with its harmonized safety (European Train Control System - ETCS) and communication (Global System for Mobile communications - Railways - GSM-R) components is clearly going in this direction.

\subsubsection{Threats}

The rail and IWW freight sectors require important investments in terms of infrastructure and rolling stock. The European standardization of equipment and infrastructure is also expensive. For this reason, the financial support provided by the European Union and its member states is crucial in terms of business survival. Nevertheless, European budget restrictions limit the contribution of states in investments and subsidies for all sectors, including intermodal transport. The restriction of these financial helps may clearly hamper the development of the intermodal sector in its launch phase. The direct help from Europe, through funds like the Trans-European Transport Network (TEN-T) program and its related financial instrument, the Connecting Europe Facility, Structural Funds and Cohesion Funds as well as the European Fund for Strategic Investments (EFSI) is very welcome (UNIFE, 2016).

Intermodal transport is operated on long distances and may face some interoperability problems due to the crossing of borders between countries. Mulley and Nelson (1999), define interoperability as "the ability of two, or more, transport systems to operate effectively and efficiently together to fulfill consumers' requirements of a transport system". The objective is not only to connect different networks together but to ensure the invisibility of the boundaries between the networks. The principal requirements for achieving interoperability in the rail sector have been consigned in the "Technical Specifications for 
Interoperability" (European Railway Agency, 2011). Rail interoperability issues may concern languages, gauges, rail infrastructure (heights and widths of tunnels), electrification and signaling systems, train lengths, rolling stocks, directions of driving (left or right) and driving license characteristics. IWW also faces interoperability problems related to the various sizes and depths of waterways, due to different construction times or to the natural characteristics of their surroundings.

Rail freight transportation has to share the network with passenger transportation. They use the same tracks and rail freight transport generally suffers from the priority that is mostly given to passenger transport. Slots are often attributed first to passenger transport, and freight transport has to use what remains (European Commission, 2007). This priority to passenger transport may reduce the viability and competitiveness of intermodal freight transport.

The objective of the liberalization of the European market is to provide an open market on which operators can compete in a fair way, in order to ensure economic efficiency. However, derivatives of this system could bring the system back to its initial state of monopoly, this time not at the country but at the European level. Indeed, there is a risk that big and well-established players on the market like DB Schenker (Germany), SNCF (France), and Trenitalia (Italy) take over small other national companies, and then constitute a European monopoly or duopoly, on which competition almost does not exist.

The SWOT analysis has highlighted the interest of using intermodal transport regarding freight transport externalities. Chapter 3 further develops the concept of freight transport externalities and analyzes how externalities can be integrated in economic policies. Even if intermodal transport is attractive as to operational or external costs, the breakeven distance at which intermodal transport becomes more competitive than road varies according to the authors and is influenced by several parameters. Chapter 4 focuses on these aspects and provides a state of the art of external costs as competitiveness factors for freight transport. 


\section{Chapter 3}

\section{Freight transport externalities}

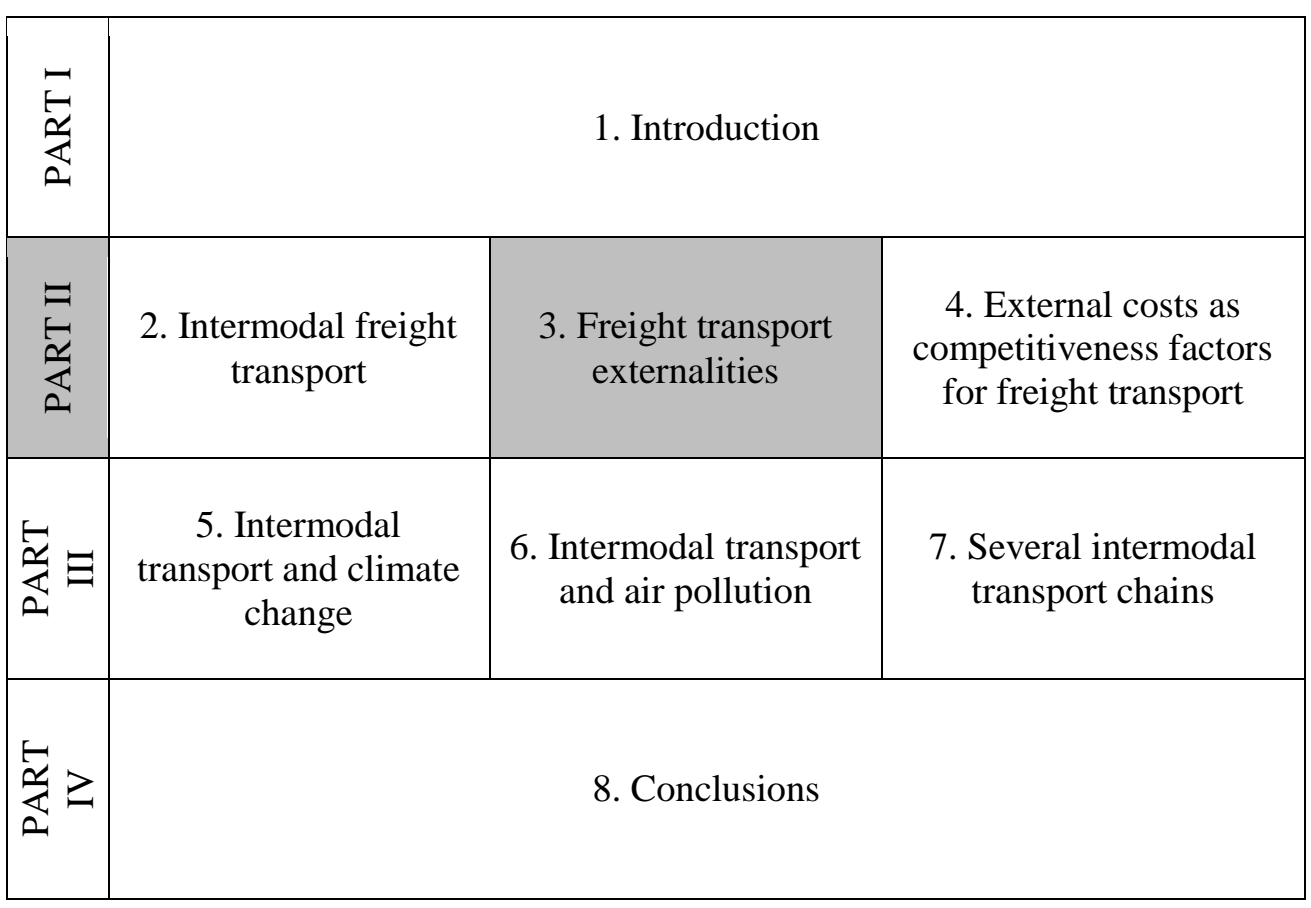

This chapter defines the general concepts of externalities, external costs, and internalization of external costs.

\subsection{Externalities}

Externalities of transport happen when the transportation users do not totally support the negative effects that they cause on their environment, or do not retrieve the whole benefit that they are generating out of their activities. Even if positive externalities of transport may happen (i.e. ability to provide emergency services or increases in land value), they are rare compared to the negative impacts of transport on societies. This is why this dissertation concentrates on negative externalities of freight transport. 
A lot of different types of transport negative externalities exist. The main categories of negative impacts relate to congestion, accidents, pollution, climate change and noise. Other externalities can also be identified such as scarcity of infrastructure or the impact on nature and landscape (Ricardo-AEA, 2014). Externalities can be grouped into general endpoint categories such as damage to human health, damage to ecosystem diversity and resource scarcity (Merchan et al., 2016).

Each mode of transport generates a different intensity of externalities. Indeed, road, rail and IWW do not produce the same amount of air emissions, or do not impact populations in the same way regarding noise. In a continuous perspective of reducing the impact of transport on its environment, it is interesting to be able to value these negative transport externalities.

Externalities happen with different time horizons. Some negative effects are directly linked to the transportation activities (emissions of pollutants during the driving of the vehicle), but others are produced at previous or further steps of the vehicle lifecycle (energy production, vehicle production, vehicle recycling). In order to fairly compare different objects or services, it is important to correctly determine the scope of the analysis.

When they are evaluated, the externalities of transport are expressed in their own units, e.g. the amount of tonnes of pollutants, the number of decibels, the number of accidents, the time losses in traffic jam, etc. These measures are reliable but they are provided in different units. In order to more easily compare externalities of several categories, externalities are often translated into monetary values, called external costs of transport.

\subsection{External costs}

External costs are side effects of transportation. According to Maibach et al. (2008), "they are costs to society and - without policy intervention - they are not taken into account by the transport users". External costs are the monetary valuation of externalities. They allow comparing different kinds of externalities in the same unit and are also important to take into account from an economic perspective. 
Transportation is characterized by social, private and external costs. Social costs refer to the total costs of transportation that the society must bear. They are composed of private and external costs (European Commission, 2008). Private costs are the direct costs related to a specific transportation mode (e.g. fuel cost, maintenance cost, infrastructure cost, insurance cost). External costs refer to the costs that are generated by an economic agent (user of transport) but that are supported by other stakeholders of the society. Pigou (1920) is the first author to mention the difference between marginal private and social costs. It is important to take into account external costs are important for pricing at the right social cost. This refers to the economic theory of internalization of external costs.

\subsection{Internalization of external costs}

The reference model for competition analysis in economics is perfect competition. Perfect competition remains the most used model for analyzing the positive and negative impacts of other complex systems.

A market is said to be in perfect competition, when two conditions are respected. First, no individual or group of individuals can, by his/her/their own action, influence the price of the good or service that he/she/they sell(s) or buy(s). Second, production factors, which are looking for the highest possible revenues, are free to change their utilization (Jurion, 2013).

The condition that nobody is able to influence the price on the market in a perfect competition scheme means that the price is a fixed parameter for any stakeholder. The optimal price and quantity of goods or services to produce are determined by the intersection between supply and demand curves. The illustration of the demand-supply equilibrium in a perfect competition market is illustrated by figure 3. This equilibrium leads to the selling a quantity $q$ of goods, at a price $p$. 


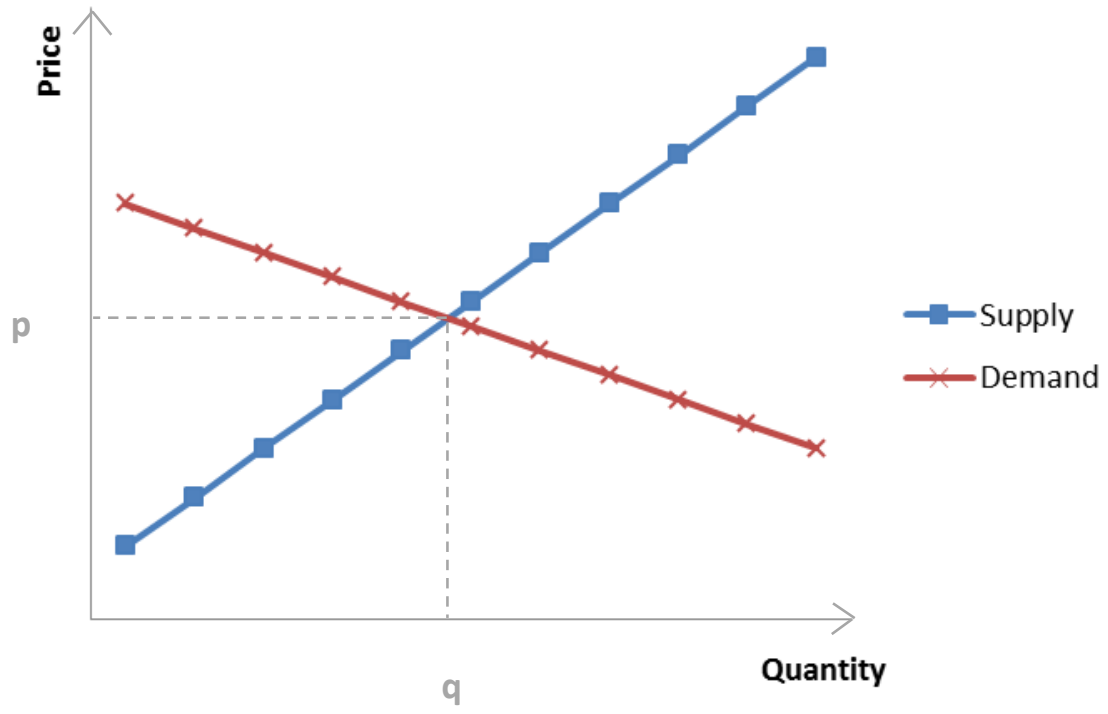

Figure 3: Demand-supply equilibrium in perfect competition

At the supplier level, the producer of transport services continues to provide transportation offers as long as the marginal revenue for this additional service is greater than the marginal cost that he/she has to support for ensuring this service. In a perfect competition scheme, the marginal revenue corresponds to the price of the goods/services, which is fixed for any stakeholder. At equilibrium, the price is therefore equal to the marginal cost of the transportation service provider.

Figure 4 identifies the effect on the market prices and quantities of the internalization of external costs.

When external costs are not internalized on the market, transportation price is set to a value $p 1$, with a resulting produced quantity $q 1$. This corresponds to the intersection of the marginal private cost curve with the demand. Transport providers offer services as long as they can cover the private cost that is generated by the production of an additional unit. 


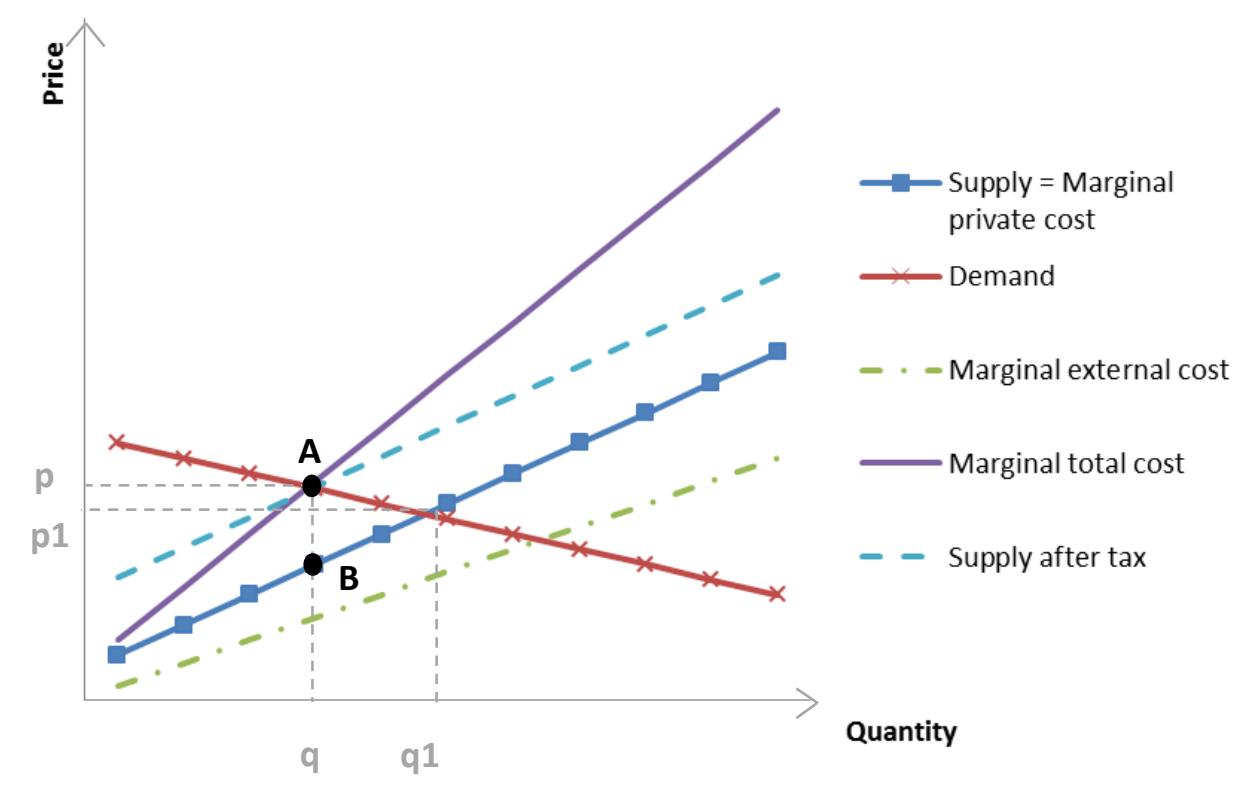

Figure 4: Social and private marginal cost pricing

When external costs are internalized, the marginal total cost corresponds to the sum of the marginal private costs and external costs. The optimal price is therefore equal to $p$, for a produced quantity $q$. This corresponds to the intersection of the marginal total cost curve with the demand. The quantity resulting from the equilibrium where external costs are not internalized is higher than the market social optimal quantity $q$, and allows the market to produce too much, in relation to its production costs. For this reason, external costs should be internalized.

This can be done in economic policies by public authorities, through the introduction of a Pigovian tax per unit produced, in order to bring back the production to the optimal quantity $q$. Introducing this tax pushes the initial marginal private cost curve to the left hand side, so that it crosses the demand curve at the equilibrium price $p$ and quantity $q$. On figure 4 , the value of this tax per unit produced should be equal to the vertical $A B$ segment.

External costs of transport have been studied a lot in the literature and are key elements that influence the competitiveness of intermodal transport in relation to road transport. This is shown in the following chapter. 



\section{Chapter 4}

\section{External costs as competitiveness factors for freight transport}

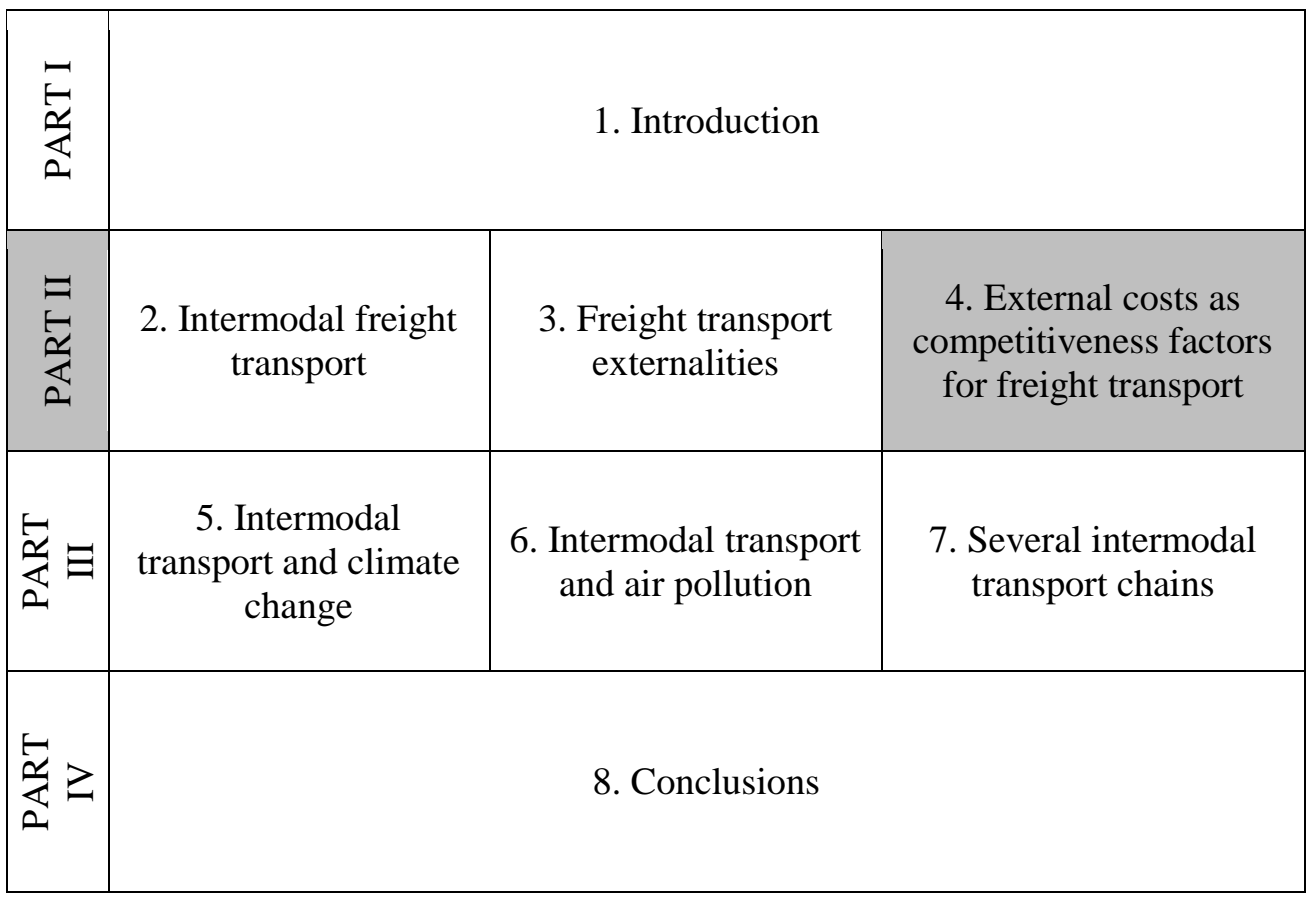

This chapter identifies the state of the art of external costs as competitiveness factors for freight transport.

\section{1. $\underline{\text { Abstract }}^{2}$}

External costs have been a key issue in the last years of transport research. In Europe, this trend is in line with the political willingness to internalize externalities in transport pricing policies. This paper has two purposes. It first

\footnotetext{
${ }^{2}$ This chapter is based on the paper published under the reference: "Mostert, M. \& Limbourg, S. (2016). External costs as competitiveness factors for freight transport: a state of the art. Transport Reviews, 36 (6), 692-712."
} 
identifies the recent work achieved in the field of external costs of road and intermodal freight transport, where each paper is assessed in terms of its perspective (academic or project-oriented), its objective (prescription, application, projection), the type of externality (air pollution, climate change, noise, accidents, congestion) and the type of cost (marginal, average, total) that is considered. The literature review reveals a gap in the development of generic mathematical functions for external costs of transport. The second objective of the paper is to highlight the usefulness of such functions by identifying the main parameters that influence freight transport competitiveness in terms of external costs, and by determining which of these parameters should be incorporated in further research works.

\subsection{Introduction}

Freight transport provides societal benefits but also generates costs. The sum of the private and external costs of transport corresponds to the total or social cost of transport (Pigou, 1920). Private (or operational or internal) costs refer to the costs that an economic agent has to support in order to perform his activities. External costs are side effects of transport and, "without policy intervention they are not taken into account by the transport users" (Maibach et al., 2008).

The objective of the European Union is to integrate external costs in transport pricing policies (European Commission, 2008). Internalizing external costs allows pricing at the right social cost, leading to an efficient allocation of resources. European authorities also aim at limiting the total amount of external costs and therefore encourage the transfer of freight flows from road to more environmentally friendly modes of transport (European Commission, 2011). Road transport is thus in competition with intermodal transport, in order to ensure this modal transfer.

In the recent years, external costs have become a key issue in transport studies. The broad variety of costs valuation methods, types and uses has led to the development of an extensive literature.

The aim of this paper is twofold. It first provides a literature review on external costs of freight transport, for the last 15 years, identifying for each paper its perspective (academic or project-oriented), its objective (prescription, application, projection), the type of externality (air pollution, climate change, noise, accidents, 
congestion) and the type of cost (marginal, average, total) that is considered. The second part of the paper aims at showing the practical interest of generic mathematical functions of external costs, for identifying the most important parameters that influence the competitiveness of road and intermodal freight transport. A sensitivity analysis of the external cost functions found in the literature review is therefore performed. A reference situation is compared to a worst-case and best-case scenario, for different parameters such as PPH distances, terminal locations, load and density of the goods. On the basis of this analysis, the main future research directions are identified.

Section 4.3 describes the basic concepts and methodology related to transport external costs. Section 4.4. provides a literature review of the different studies dealing with external costs in freight transport. The main parameters that influence the competitiveness of freight transport in terms of external costs are identified in section 4.5. Discussion of the results is performed in section 4.6. Conclusions are finally drawn in the last section.

\subsection{External Costs: Methodology}

It is now acknowledged that transport generates negative effects on society. External costs consist in five main categories: global warming, air pollution, noise, accidents and congestion.

External costs are not easy to evaluate and to monetize. Indeed it is difficult to measure physically the damage because the scope of the externality is not totally known, the effect is uncertain and can vary a lot from an individual to another, and externalities happen with different time horizons. Moreover, for the majority of externalities, there are no markets on which they can be exchanged at a commercial value (Nayes and Arnold, 2010).

Dealing with costs requires distinguishing between marginal and average costs. In transport, marginal cost refers to the additional cost provoked by the transport of one additional unit. Average cost refers to the total transport costs divided by the number of units transported. In the literature, this differentiation has led to the development of two main methodologies: the bottom-up and the top-down approach. 
The bottom-up strategy consists in starting the evaluation from the lowest level, i.e. the micro level. The analysis is based on the definition of the external effects of a particular element and how it affects its environment. This approach focuses on determining the marginal external cost. This method provides precise and detailed information on which specific parameters impact negative externalities. Nevertheless, since it focuses on very specific cases, it might be difficult to translate the obtained results into policy measures (Van Essen et al., 2007).

The top-down strategy relates to a macro vision and consists in evaluating the external effects of a wider system, for example a country or a sector. This leads to the definition of average costs, which makes it difficult to extract the marginal cost value (Maibach et al., 2008). The total externalities are then divided by a cost unit in order to obtain the external effects of specific items. This approach has the advantage to be simpler than the bottom-up methodology but leads to less precise values.

External costs thus deal with two main steps: determination and valuation of the impact. When there is no market price, different methods of evaluation exist: damage cost (Bickel et al., 2005, 2006a, Schmid et al., 2001), avoidance cost (Bickel et al., 2005, Schmid et al., 2001) or opportunity (or willingness-to-pay) cost method (Bickel et al., 2005, 2006a, OECD, 2005, Ortúzar et al., 2000, Schmid et al., 2001). The damage cost method consists in defining the real damages caused by the external costs. The avoidance cost method is based on scenarios and determines which costs are generated for avoiding a specific amount of externalities in the future. Finally, the opportunity cost method identifies the external cost value as the price that should be paid to an economic agent, who suffers from the externalities, in order to accept to support the external effect. The latter can be obtained through stated preference methods.

\subsection{Literature Review}

Several kinds of papers related to the identification and computation of external costs of road and intermodal transport can be found in the literature. Table 2 provides a summary of the different characteristics of each paper related to the computation of transport external costs. 


\begin{tabular}{|c|c|c|c|c|c|c|c|c|}
\hline \multirow[t]{2}{*}{ Author } & \multirow[b]{2}{*}{ 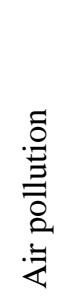 } & \multirow[b]{2}{*}{$\stackrel{\stackrel{\Xi}{\Xi}}{\leftrightarrows}$} & \multirow[b]{2}{*}{$\frac{.}{0}$} & \multirow[b]{2}{*}{$\frac{0}{0}$} & \multirow[b]{2}{*}{ 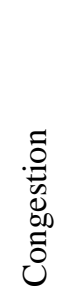 } & \multirow{2}{*}{$\begin{array}{l}\text { Costs: } \\
\text { Average } \\
\text { (A) } \\
\text { Marginal } \\
\text { (M) } \\
\text { Total (T) }\end{array}$} & \multirow{2}{*}{$\begin{array}{l}\text { Perspective: } \\
\text { Academic } \\
\text { Project }\end{array}$} & \multirow{2}{*}{$\begin{array}{l}\text { Objective: } \\
\text { Prescription } \\
\text { Application } \\
\text { Projection }\end{array}$} \\
\hline & & & & & & & & \\
\hline $\begin{array}{l}\text { Forkenbrock } \\
\text { (1999) }\end{array}$ & $\mathrm{X}$ & $\mathrm{X}$ & $\mathrm{X}$ & $\mathrm{X}$ & & A & Academic & Application \\
\hline $\begin{array}{l}\text { Forkenbrock } \\
\text { (2001) }\end{array}$ & $\mathrm{X}$ & $\mathrm{X}$ & $\mathrm{X}$ & $\mathrm{X}$ & & A & Academic & Application \\
\hline Sansom (2001) & $\mathrm{X}$ & $\mathrm{X}$ & $X$ & & $\mathrm{X}$ & $\mathrm{A}, \mathrm{M}$ & Project & Application \\
\hline Mayeres (2001) & $\mathrm{X}$ & $\mathrm{X}$ & & $X$ & $\mathrm{X}$ & M & Project & Application \\
\hline $\begin{array}{l}\text { RECORDIT } \\
(2001)\end{array}$ & $\mathrm{X}$ & $\mathrm{X}$ & $\mathrm{X}$ & $\mathrm{X}$ & $\mathrm{X}$ & M & Project & Application \\
\hline $\begin{array}{l}\text { Beuthe et al. } \\
\text { (2002) }\end{array}$ & $\mathrm{X}$ & $\mathrm{X}$ & $\mathrm{X}$ & $\mathrm{X}$ & $\mathrm{X}$ & M & Academic & Application \\
\hline $\begin{array}{l}\text { INFRAS/IWW } \\
\text { (2004) }\end{array}$ & $\mathrm{X}$ & $\mathrm{X}$ & $\mathrm{X}$ & $\mathrm{X}$ & $\mathrm{X}$ & $\mathrm{A}, \mathrm{M}, \mathrm{T}$ & Project & Application \\
\hline CAFE (2005) & $\mathrm{X}$ & & & & & M & Project & Application \\
\hline $\begin{array}{l}\text { HEATCO } \\
\text { (Odgaard et al., } \\
\text { 2005) }\end{array}$ & $\mathrm{X}$ & $\mathrm{X}$ & $\mathrm{X}$ & & $\mathrm{X}$ & $\mathrm{A}, \mathrm{M}, \mathrm{T}$ & Project & Prescription \\
\hline $\begin{array}{l}\text { ExternE (Bickel et } \\
\text { al., 2005) }\end{array}$ & $\mathrm{X}$ & $\mathrm{X}$ & & $\mathrm{X}$ & & M & Project & Prescription \\
\hline $\begin{array}{l}\text { HEATCO (Bickel } \\
\text { et al., 2006a, } \\
\text { 2006b) }\end{array}$ & $\mathrm{X}$ & $\mathrm{X}$ & $\mathrm{X}$ & & $\mathrm{X}$ & A & Project & Application \\
\hline $\begin{array}{l}\text { Bickel et al. - } \\
\text { UNITE(2006c) }\end{array}$ & $X$ & $\mathrm{X}$ & $\mathrm{X}$ & & & $\mathrm{M}, \mathrm{T}$ & Project & Application \\
\hline Janic (2007) & $\mathrm{X}$ & & $\mathrm{X}$ & $X$ & $\mathrm{X}$ & A & Academic & Projection \\
\hline Janic (2008) & $\mathrm{X}$ & & $\mathrm{X}$ & $\mathrm{X}$ & $\mathrm{X}$ & A & Academic & Projection \\
\hline
\end{tabular}




\begin{tabular}{|c|c|c|c|c|c|c|c|c|}
\hline $\begin{array}{l}\text { Maibach et al. } \\
\text { (2008) }\end{array}$ & $X$ & $\mathrm{X}$ & $\mathrm{X}$ & $X$ & $\mathrm{X}$ & $\mathrm{A}, \mathrm{M}$ & Project & Application \\
\hline $\begin{array}{l}\text { Van Essen et al. } \\
\text { (2008) }\end{array}$ & $\mathrm{X}$ & $\mathrm{X}$ & $X$ & $\mathrm{X}$ & $\mathrm{X}$ & M & Project & Prescription \\
\hline $\begin{array}{l}\text { Delucchi and } \\
\text { McCubbin (2010) }\end{array}$ & $\mathrm{X}$ & $\mathrm{X}$ & $\mathrm{X}$ & $\mathrm{X}$ & $\mathrm{X}$ & M & Academic & Prescription \\
\hline $\begin{array}{l}\text { Macharis et al. } \\
\text { (2010) }\end{array}$ & $\mathrm{X}$ & $\mathrm{X}$ & $X$ & $\mathrm{X}$ & $X$ & M & Academic & Application \\
\hline $\begin{array}{l}\text { Janic and Vleugel } \\
\text { (2012) }\end{array}$ & $\mathrm{X}$ & $\mathrm{X}$ & $\mathrm{X}$ & $\mathrm{X}$ & $\mathrm{X}$ & A & Academic & Application \\
\hline $\begin{array}{l}\text { Michiels et al. } \\
\text { (2012) }\end{array}$ & $\mathrm{X}$ & & & & & M & Academic & Application \\
\hline $\begin{array}{l}\text { Cravioto et al. } \\
\text { (2013) }\end{array}$ & $\mathrm{X}$ & $\mathrm{X}$ & $X$ & $\mathrm{X}$ & $\mathrm{X}$ & $\mathrm{A}, \mathrm{T}$ & Academic & Application \\
\hline $\begin{array}{l}\text { Moliner et al. } \\
\text { (2013) }\end{array}$ & & & $\mathrm{X}$ & & & A & Academic & Application \\
\hline $\begin{array}{l}\text { Pérez-Martínez } \\
\text { and Vassallo- } \\
\text { Magro (2013) }\end{array}$ & $\mathrm{X}$ & $\mathrm{X}$ & & $\mathrm{X}$ & & M & Academic & Application \\
\hline $\begin{array}{l}\text { Ricardo-AEA } \\
\text { (2014) }\end{array}$ & $\mathrm{X}$ & $\mathrm{X}$ & $\mathrm{X}$ & $\mathrm{X}$ & $\mathrm{X}$ & $\mathrm{A}, \mathrm{M}$ & Project & Application \\
\hline van Lier (2014) & $X$ & $\mathrm{X}$ & $X$ & $X$ & $X$ & M & Academic & Prescription \\
\hline $\begin{array}{l}\text { Agarwal et al. } \\
\text { (2015) }\end{array}$ & $\mathrm{X}$ & $\mathrm{X}$ & & & $\mathrm{X}$ & M & Academic & Application \\
\hline Austin (2015) & $\mathrm{X}$ & $X$ & & $\mathrm{X}$ & $\mathrm{X}$ & $\mathrm{A}, \mathrm{M}$ & Project & Application \\
\hline
\end{tabular}

Table 2: Summary of the main external costs characteristics studied in the literature

The papers differ in terms of their perspective (academic or project-oriented), the type of externality (air pollution, climate change, noise, accidents, congestion) and the type of cost (marginal, average, total) that they consider. A differentiation of these papers can also be performed based on their objective. Some papers focus 
on the development of the methods and tools to be used to determine the scope and value of external costs. Their aim is therefore to prescribe the right methodology (prescription). Another objective is to practically use and combine these methods for determining specific numerical values of external costs. This second objective consists in applying concretely the methodology on external costs (application). Finally other papers aim at formally generalizing the modelling of external costs, for instance for forecast purpose (projection).

Besides external costs computations, some studies concentrate more on internalization policies (e.g. Beuthe et al., 2002, Macharis et al., 2010, Moliner et al., 2013, Agarwal et al., 2015, Austin, 2015). Optimization objectives can also be attributed to external costs of transport (e.g. Musso and Rotengatter, 2013, Zhang et al., 2013). External cost papers can focus on a specific cost type, a particular mode, multimodal transport or a defined transport entity such as a port or a terminal.

The literature on external costs of road and intermodal freight transport does not only rely on academic production but is also considerably based on project-related papers. This shows the practical interest in tackling the issue of internalization of external costs of transport. The main objective of most of the papers is to determine the specific external costs values for different modes of transport. Indeed, more than $70 \%$ of the reviewed literature focuses on concrete evaluations of external costs, or on the impact on several internalization policies. Research on external costs of transport is therefore not only of theoretical scientific interest but has concrete applications in the real world. A smaller fraction of the analyzed papers concentrates on the methods that exist and that are appropriate to correctly evaluate the external costs of transport. This small amount of reference literature is not very surprising since these documents summarize all the current knowledge and best practices in the field. They are used by a lot of application papers in order to choose the correct methodology. Finally, only two papers define external costs functions that combine mathematically the different parameters that influence externalities. The lack of research in this specific area is damageable, since sensitivity analyses of these functions allow explicitly identifying the key parameters that ensure transport competitiveness, when external costs are internalized.

In the following section, we look more deeply at the mathematical external costs functions found in the literature and provide a sensitivity analysis of different 
parameters of these functions, in order to determine the main factors which influence the competitiveness of road and intermodal transport, in terms of external costs.

\subsection{External Costs as Competitiveness Factors}

The previous literature review shows that papers rarely focus on the development of generic mathematical functions that allow for determining the value of external costs. However, the use of these functions is very helpful to define the main parameters that ensure the competitiveness of transportation modes. This section aims at highlighting the interest of such functions in the identification of competitiveness factors of road and intermodal transport. A sensitivity analysis of the functions of Janic $(2007,2008)$ is provided in order to emphasize the key elements that have to be tackled in further research in the field. Best-case and worst-case scenarios are compared to the reference scenario, in order to determine the key issues that influence transport competitiveness.

A common tool to evaluate the competitiveness of transportation modes is to compare their breakeven distance, i.e. the distance at which two modes of transport have the same cost. Below and above this breakeven distance, one mode is more advantageous than the other one.

According to Kim and van Wee (2011), the elements that influence the breakeven distance of intermodal freight transport for operational costs can be classified into two categories: geometric and cost factors. These two categories are also valid for external costs. However, based on the sensitivity analysis of the generic costs functions of Janic $(2007,2008)$, we also identify a third category called weight factors. This class includes the load factor of the vehicle and the density of the transported goods. Finally, by reconsidering the classical hypothesis that demand for flows decreases with the distance, we highlight the importance of the management of flows on the breakeven distance. Flow management factors are thus grouped in a fourth category which tackles the issues of freight consolidation and transport reliability and flexibility. The analysis first focuses on geometric factors of intermodal transport and thus deals with PPH distances issues and terminal location scenarios. The effects of the weight (load and density) factors are then analyzed. We finally highlight the importance of freight consolidation and of the reliability and flexibility of transport services (flow management factors) in terms of external costs. 


\subsubsection{Reference Scenario}

We use the cost functions of Janic $(2007,2008)$ for analyzing the factors that influence transport external costs. The reference scenario reflects the main hypotheses assumed by Janic $(2007,2008)$ for the European case-study.

\begin{tabular}{|c|c|c|c|}
\hline Parameter & Definition & Value & Unit \\
\hline$n_{l}$ & $\begin{array}{l}\text { Number of locomotives per } \\
\text { train }\end{array}$ & 1 & locomotive \\
\hline$n_{w}$ & Number of flat wagons & 26 & flat wagon \\
\hline$s$ & Long-haul distance & $25-1600$ & $\mathrm{~km}$ \\
\hline$q$ & $\begin{array}{l}\text { Net weight of the goods } \\
\text { transported }\end{array}$ & 702 & tonne \\
\hline$W$ & Gross weight of the train & 1606 & tonne \\
\hline$l$ & $\begin{array}{l}\text { Number of segments } \\
\text { between origin and } \\
\text { destination terminal }\end{array}$ & 1 & segment \\
\hline$v_{l}$ & $\begin{array}{l}\text { Train commercial speed on } \\
\text { segment } l\end{array}$ & 60 & $\mathrm{~km} / \mathrm{h}$ \\
\hline$d_{l}$ & Distance of segment $l$ & $25-1600$ & $\mathrm{~km}$ \\
\hline$n_{d}$ & Number of drivers & 1 & driver \\
\hline$t_{d p}$ & $\begin{array}{l}\text { Driver's preparation and } \\
\text { finishing time before and } \\
\text { after the trip }\end{array}$ & 1 & hour \\
\hline$v$ & $\begin{array}{l}\text { Train commercial speed } \\
\text { along a given line }\end{array}$ & 60 & $\mathrm{~km} / \mathrm{h}$ \\
\hline$D$ & $\begin{array}{l}\text { Anticipated delay of a train } \\
\text { running between two } \\
\text { intermodal terminals }\end{array}$ & 1 & hour \\
\hline
\end{tabular}

Table 3: Parameters and reference values of the internal and external cost functions 
Door-to-door transport costs by road are determined thanks to internal and external cost functions for long-haul travels. Intermodal transport costs are constituted by internal and external (i) PPH costs by road, (ii) transshipment costs at the intermodal terminals and (iii) long-haul costs by rail.

For rail transport, we use the cost function of Janic (2008) but slightly modify the term which represents the transshipment external costs. This term is multiplied by a factor two for considering the transshipment that happens both at the origin and destination terminal. The parameters of the rail costs are detailed in table 3 .

The rail internal cost function for one train is provided by

$$
\begin{aligned}
& \left(4.60 n_{l}+0.144 n_{w}+0.3\right) s+12.98\left(n_{l}+n_{w}\right)+5.6 q+0.0019 W s \\
& +\sum_{l=1}^{L}\left[0.227 * \frac{10^{-6} v_{l}^{2}}{\ln \left(d_{l}\right)}+0.000774\right] W s+33 n_{d}\left(t_{d p}+\frac{s}{v}+D\right)
\end{aligned}
$$

and the rail external cost function by

$$
\begin{aligned}
0.000128 W s+ & 2 * 0.0549 q \\
& +\sum_{l=1}^{L}\left[1.889 * \frac{10^{-7} v_{l}^{2}}{\ln \left(d_{t}\right)}+0.00064\right] W s+0 W s \\
& +5.6 s \bar{D}_{m}
\end{aligned}
$$

The internal cost function (1) is constituted by six terms: the unit cost of depreciation and maintenance of the rolling stock and monitoring of the train, the unit cost of assembling/decomposing the train at both ends of the corridor, the unit transshipment cost at the intermodal terminals, the unit cost of using the rail infrastructure, the unit cost of the energy consumption along the line with $\mathrm{L}$ segments and finally the unit cost of the train's driver.

The external cost function (2) is composed of five principal terms: the unit cost of noise, the unit external cost of transshipment at the intermodal terminals, the cost of air pollution due to the energy consumption and production, the cost of traffic 
accidents and finally the unit external cost of congestion. This last term is omitted because we assume an uncongested rail network.

q stands for the net weight of the goods transported and is equal to 702 tonnes. W is the gross weight of the train and is equal to 1606 tonnes since the empty train is estimated at 724 tonnes and the train loading at 882 tonnes. We assume an average weight of 12 tonnes transported in one 20' container (Black et al., 2003 and Janic, 2007, 2008).

One train consists in 26 flatcars. Each flatcar contains three 20 foot load units. Each unit weighs 14.3 tonnes, i.e. 12 tonnes of freight and 2.3 tonnes of tare. A load factor of 0.75 is assumed (Black et al., 2003). The load factor is defined as the ratio of the average load to total vehicle freight capacity (EEA, 2010). The load factor represents the utilization of the available capacity in terms of weight.

Road external costs are split into short-haul (assumed average PPH distance of 50 $\mathrm{km}$ ) and long-haul (road-only) travels (Janic, 2007). A load factor $\lambda$ of 0.85 and 0.60 is respectively used for long-haul and short-haul journeys (Black et al., 2003). The internal and external cost functions are non-linear with the distance travelled and are expressed in $€ / \mathrm{t} . \mathrm{km}$. We assume that a full truck contains two 20 foot load units. Cost functions of Janic (2007) are provided by vehicle.km. The cost per t.km is obtained by dividing the coefficient of the cost function by a factor $14.4(2 * 12 * 0.60)$ for short-haul transport and by a factor $20.4(2 * 12 * 0.85)$ for long-haul transport. These amounts correspond to the number of tonnes effectively transported by a truck over short- or long-haul transport. For long-haul travels, the internal cost function is $0.2676 \mathrm{~d}^{-0,278} /(\mathrm{t} . \mathrm{km})$ and the external cost function is $0.4843 \mathrm{~d}^{-0,624} /(\mathrm{t} . \mathrm{km})$. For short-haul travels, the internal cost function is $0.3791 \mathrm{~d}^{-0,278} /(\mathrm{t} . \mathrm{km})$ and the external cost function is $0.6861 \mathrm{~d}^{-0,624} /(\mathrm{t} . \mathrm{km})$. These cost formulations imply that an increase in the handled quantities does not lead to economies of scale and therefore does not result in reduced average road costs per t.km.

Full costs of transport refer to the sum of internal and external costs.

Road and intermodal using rail transport are compared based on the assumption that the distance between two intermodal terminals on rail (s) is equal to the doorto-door distance by road (d). For comparing fairly intermodal and road transport, an additional PPH distance must thus be added to the total kilometres travelled 
using intermodal transport. For instance, a travel of $500 \mathrm{~km}$ by road is thus compared with a long-haul travel by rail of $500 \mathrm{~km}$ and a PPH of $50 \mathrm{~km}$ each. This assumption reflects an average situation for which the additional kilometre that must be performed when using intermodal transport are taken into account.

Costs and breakeven distances are computed for distances comprised between 25 and $1600 \mathrm{~km}$, distances for which the cost functions of Janic (2007) are valid. The breakeven distance has to be understood as the road distance (d) at which intermodal transport becomes more interesting than road transport.

According to the reference values of the cost functions of Janic $(2007,2008)$, the breakeven distance between road and intermodal transport for internal costs (925 $\mathrm{km})$ is lower than the breakeven distance for full costs $(1100 \mathrm{~km})$. In addition, there is a convergence of the internal and full costs, both for road and intermodal transport, meaning that unit external costs decrease with the distance. PPH distances of intermodal transport are assumed to be $50 \mathrm{~km}$. The values of PPH external costs thus remain the same, whatever the distance travelled. However, if the long-haul distance increases, these PPH road external costs can be split into more kilometers. For intermodal transport, it therefore leads to decreasing external costs with the distance travelled. The decrease of road transport external costs along with the distance is linked to the definition of the cost function, which reflects economies of distance (figure 5). 


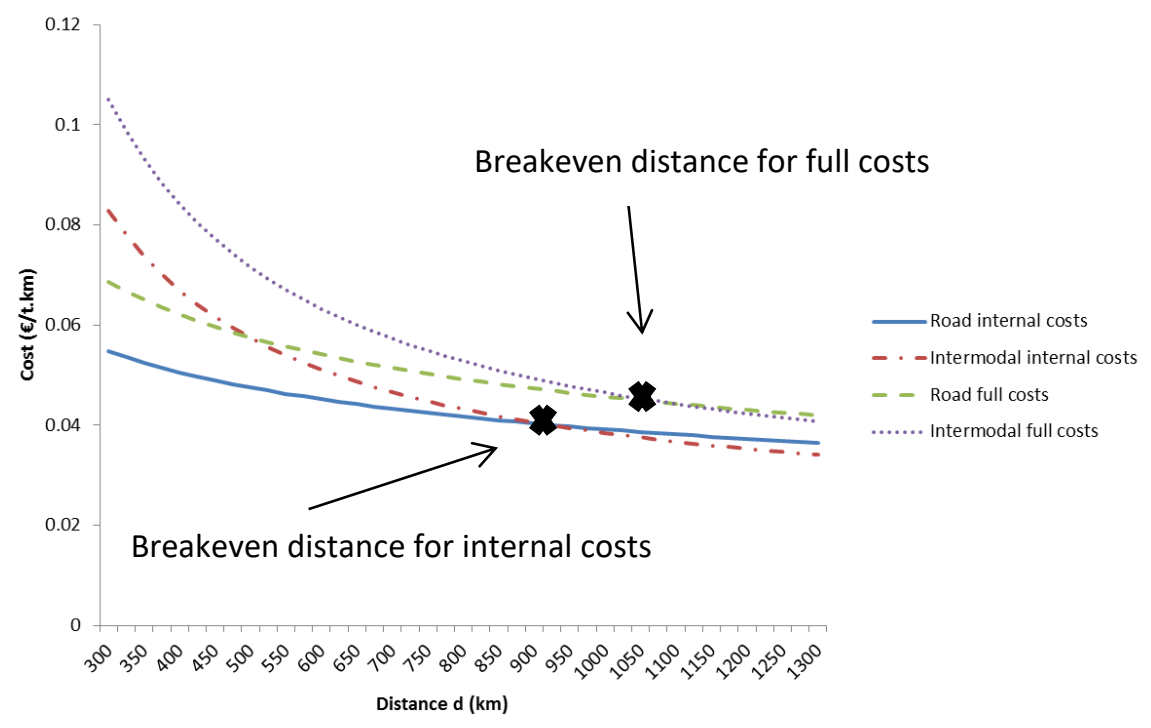

Figure 5: Evolution of internal and full costs with the distance travelled, for road and intermodal using rail transport-Reference scenario

Results of this reference scenario lead to a greater breakeven distance for full than for internal costs. This counter intuitive result is related to the structure of the cost functions of Janic (2007, 2008). This outcome is in contradiction with the willingness of the European Commission to internalize external costs and differs from the results of Macharis et al. (2010) which highlight that internalizing external costs increases the competitiveness of intermodal transport.

The results of a greater breakeven distance for full than for internal costs also depend on the hypotheses of the model, such as the assumed average PPH distance by truck. When the real PPH and long-haul distances are taken into account, the relative part of PPH in the global intermodal costs can be reduced, which can advantage intermodal transport when internalizing external costs. The following sections identify the impact on the breakeven distance for internal and full costs of a modification of the geometric and weight parameters of the cost functions.

\subsubsection{Geometric Factors}

This chapter analyses the effects on the breakeven distance of PPH distances and several location scenarios. The focus is therefore on drayage external costs. 
Intermodal drayage costs are generated during the road operations of the PPH travels by truck (Caris et al., 2013). Drayage external costs thus refer to the externalities that are generated during the road travel between the pick-up at the origin node and the delivery at the first intermodal terminal, or between the pickup at the second intermodal terminal and the delivery to the destination node.

\subsubsection{PPH distances.}

Considering a PPH distance of $50 \mathrm{~km}$ refers to the basic scenario of Janic (2008) and thus to an average European situation. However in some countries, the part of intermodal transport is higher than the average European one and PPH distances are thus smaller.

This is in particular the case in Belgium (Eurostat, 2013) where the modal share in t.km of road transport is $66.3 \%$ (75.5\% for Europe), the modal share of IWW is $18.5 \%$ (6.2\% for Europe) and the modal share of rail is $15.2 \%$ (18.4\% for Europe). Verhetsel et al. (2013) study the impact of accessibility on the location of logistics centres in Flanders. They observe that most of the 235 main logistics sites are located within $10 \mathrm{~km}$ of a rail and IWW terminal.

In this sensitivity analysis, we study the impact on the breakeven distance of PPH distances of $50 \mathrm{~km}$ (reference scenario), $10 \mathrm{~km}, 5 \mathrm{~km}$ (Verhetsel et al., 2013) and $0 \mathrm{~km}$. The latter case consists in comparing road versus rail-only transport, which represents the possibility of door-to-door travels by rail, thanks to private sidings. Table 4 summarizes the values of the breakeven distances for internal and full costs of the different scenarios.

\begin{tabular}{lcc}
\hline Scenario & $\begin{array}{c}\text { Breakeven distance for internal } \\
\text { costs }(\mathrm{km})\end{array}$ & $\begin{array}{c}\text { Breakeven distance for full costs } \\
(\mathrm{km})\end{array}$ \\
\hline $\mathrm{PPH}=50 \mathrm{~km}$ & 925 & 1100 \\
$\mathrm{PPH}=10 \mathrm{~km}$ & 300 & 300 \\
$\mathrm{PPH}=5 \mathrm{~km}$ & 225 & 200 \\
$\mathrm{PPH}=0 \mathrm{~km}$ & No cost convergence & No cost convergence \\
\hline
\end{tabular}

Table 4: Breakeven distances for internal and full costs

With a PPH of $50 \mathrm{~km}$, the breakeven distance increases between internal and full costs consideration. This means that intermodal transport becomes less quickly 
attractive if external costs are taken into account. On the contrary, a shorter PPH distance leads to an identical (for $\mathrm{PPH}=10 \mathrm{~km}$ ) or decreased (for PPH $=5 \mathrm{~km}$ ) breakeven distance from internal to full costs consideration. This tends to show that intermodal transport is more rapidly competitive if external costs are internalized. The comparison between rail-only (intermodal with $\mathrm{PPH}=0$ ) and road transport leads to no breakeven distance, since the costs of rail are always lower than the ones of road, both for internal and full costs. The results of this sensitivity analysis show the importance of the proportion of PPH costs in total costs of intermodal transport. The difference in trend between internal and full costs breakeven distances is explained by external costs variations between intermodal and road transport. If the PPH distances increase, road external costs of these PPH travels increase considerably the total full costs of intermodal transport, leading to a longer breakeven distance between road and intermodal transport. External costs of road transport are higher than external costs of rail transport. If the PPH distances of intermodal transport become too long, then the long haul travel by rail cannot compensate anymore for the higher external costs of the PPH costs by road. This means that the internalization of external costs leads to a longer breakeven distance for full costs than for internal costs. In order to allow rail transport to compensate for the negative impacts of road transport in terms of externalities, PPH distances must thus be reduced as much as possible.

Figure 6 shows the different external costs of transport, according to the considered scenario. The external costs of rail-only transport are always lower than the external costs of road transport (on an identical distance). For a PPH distance of $5 \mathrm{~km}$, intermodal transport external costs are lower than road transport external costs around a distance of $125 \mathrm{~km}$, against $300 \mathrm{~km}$ for a PPH distance of $10 \mathrm{~km}$. When considering a PPH distance of $50 \mathrm{~km}$, the external costs of intermodal transport are always higher than the ones of road transport. However intermodal external costs decrease more quickly with the distance travelled than road external costs.

The results of this analysis confirm that the PPH operations are very important for the competitiveness of intermodal to road transport. Indeed it comes out of the results that small PPH distances lead to lower external costs for intermodal than for road transport. In the case of small PPH and with the internalization of external costs, intermodal transport becomes more rapidly competitive in terms of distance than when only internal costs are taken into account. On the other hand, for longer PPH distances, external costs internalization leads to a lower 
competitiveness of intermodal transport, i.e. to a higher breakeven distance than when only internal costs are considered.

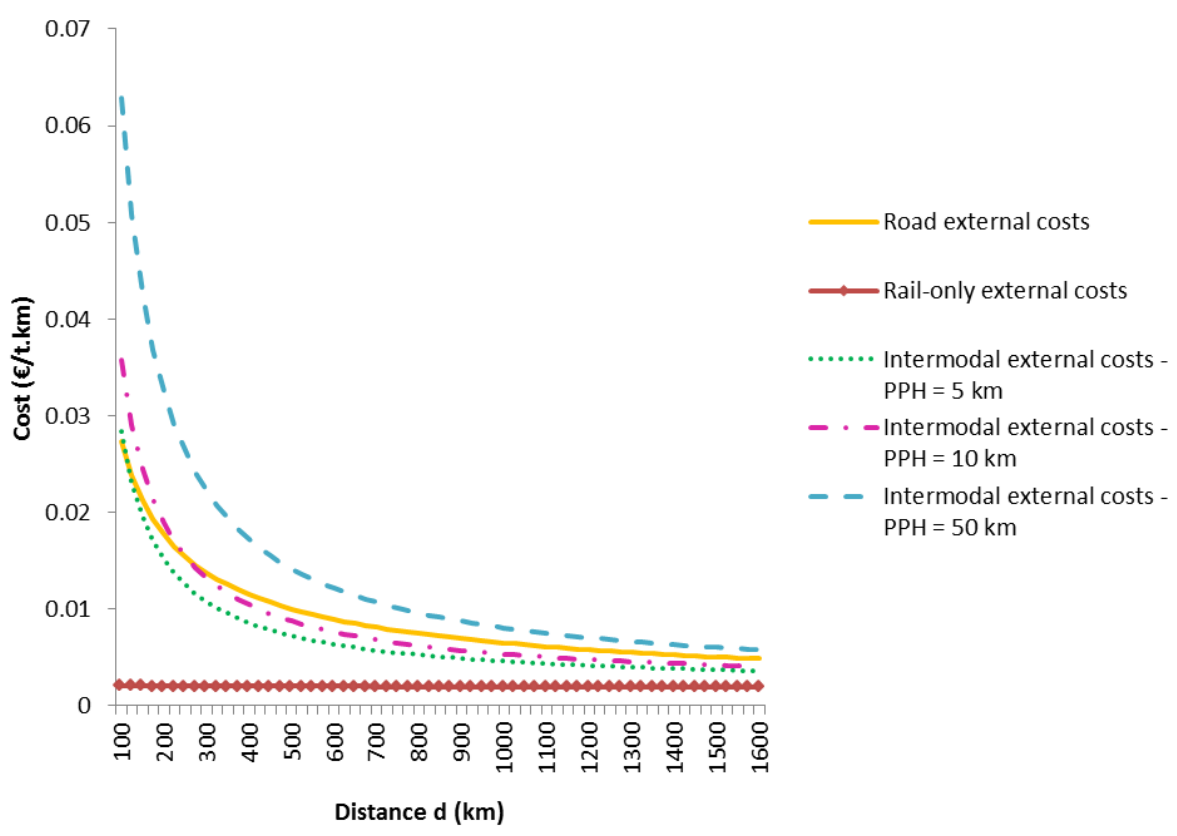

Figure 6: Comparison of road and intermodal external costs with different PPH

\subsubsection{Location scenarios.}

Until now we considered that the rail distance was equivalent to the door-to-door distance by road (i.e. between the origin and the destination nodes). Figure 7 illustrates the two extreme situations under the alignment condition. The origin A and destination $\mathrm{B}$ represent the best-case scenario for intermodal transport whereas the origin $\mathrm{C}$ and destination $\mathrm{D}$ represent the worst-case scenario for intermodal transport. T1 and T2 stand for the origin and destination terminals. 


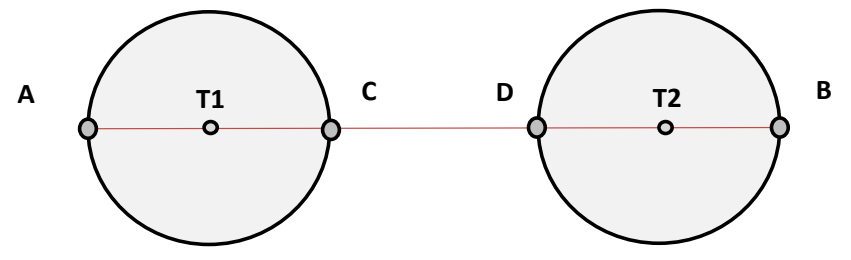

\section{Figure 7: Location of origin and destination nodes in relation to origin and destination terminals}

In this analysis, the circle around a terminal (determined by a specific average PPH distance) represents the potential origin/destination nodes that can be served by the terminal. It does not correspond to the rail market area defined as the set of all the points around the terminal for which intermodal transport using rail is less expensive than road-only transport. Contrary to figure 7 which represents by a circle the potential origin/destination nodes that can be served by the terminal, the shape of the terminal market area is part of the family of Descartes' ovals (Niérat, 1997) and its border represents all the points for which road and intermodal using rail transport have the same cost. Please refer to Limbourg and Jourquin (2010) for further discussions on the shape of the market area around intermodal terminals.

In the reference scenario, a comparison is made between road and intermodal using rail transport, based on the hypothesis that the long-haul transport by rail is equal to the door-to-door transport by road $(s=d)$. In the best-case scenario for intermodal transport, the transport distance by rail is determined as $\mathrm{s}=\mathrm{d}-2 * \mathrm{p}$, where $\mathrm{p}$ stands for the $\mathrm{PPH}$ distance. In the worst-case scenario for intermodal transport, the transport distance by rail is defined as $\mathrm{s}=\mathrm{d}+2 * \mathrm{p}$. This instance is very simple since it assumes that the road and rail network are equivalent in terms of pathway, which is generally not the case. 


\begin{tabular}{lcc}
\hline Scenario & $\begin{array}{c}\text { Breakeven distance for } \\
\text { internal costs }(\mathrm{km})\end{array}$ & $\begin{array}{c}\text { Breakeven distance for } \\
\text { full costs } \\
(\mathrm{km})\end{array}$ \\
\hline Reference scenario: $\mathrm{s}=\mathrm{d}$ & 925 & 1100 \\
Best-case scenario: $\mathrm{s}=\mathrm{d}-2 \mathrm{p}$ & 750 & 875 \\
Worst-case scenario: $\mathrm{s}=\mathrm{d}+2 \mathrm{p}$ & 1150 & 1375 \\
\hline Table 5: Sensitivity analysis of the breakeven distance for internal and full costs \\
to the location scenario
\end{tabular}

The relation between the door-to-door distance by road and the long-haul distance by rail impacts the competitiveness of intermodal transport (table 5). Both internal and external costs are affected by the relation between rail distance and door-todoor distance by road. The breakeven distances for internal and full costs are thus both modified. However the variation of the breakeven, in relation to the reference scenario, is a little bit higher for full costs than for internal costs. Indeed, for the best-case scenario, the variation is $-18.9 \%$ for internal costs against $-20.4 \%$ for full costs. For the worst-case scenario, a variation of $+24.3 \%$ is observed for internal costs against $+25 \%$ for full costs.

The location scenario, and therefore the distances on which road and intermodal using rail transport are compared, also impacts the external costs of transport and the full costs breakeven, but to a lesser extent than the PPH distances. These results confirm the importance of drayage operations for external costs generation and therefore transport competitiveness.

\subsubsection{Weight Factors}

This section focuses on how the competitiveness of transport is affected by the load and density aspects.

\subsubsection{Load factors.}

The load factor has been defined as the percentage of the available capacity of the vehicle that is effectively used. The load factor influences externalities of transport (Maibach et al., 2008) and therefore impacts the competitiveness of transport modes when external costs are internalized. The load factor of rail transport is varied in order to analyze its effects on external costs and breakeven 
distances. The best-case scenario for intermodal transport refers to a load factor of 1 , meaning that the full capacity of the train is used. The worst-case scenario is determined using a load factor of 0.5 (EEA, 2010). Table 6 provides the different breakeven distances.

\begin{tabular}{lcc}
\hline Scenario & $\begin{array}{c}\text { Breakeven distance for } \\
\text { internal costs }(\mathrm{km})\end{array}$ & $\begin{array}{c}\text { Breakeven distance for } \\
\text { full costs } \\
(\mathrm{km})\end{array}$ \\
\hline Reference scenario: $\lambda_{\text {rail }}=0.75$ & 925 & 1100 \\
Best-case scenario: $\lambda_{\text {rail }}=1$ & 675 & 750 \\
Worst-case scenario: $\lambda_{\text {rail }}=0.5$ & No cost convergence & No cost convergence \\
\hline Table 6: Sensitivity analysis of the breakeven distance for internal and full costs \\
to the rail load factor
\end{tabular}

The results show that the internal and external breakeven distances are sensitive to the rail load factor. As expected, an increased load factor for rail favours intermodal transport competitiveness. The comparison of the reference and bestcase scenario shows that the breakeven distance for full costs decreases more ($31.82 \%)$ than the breakeven distance for internal costs (-27.02\%). Again, external costs seem even more sensitive than internal costs to the load factor. When considering a load factor of 0.5 , no breakeven distance is found between intermodal and road freight transport since road transport is always cheaper. The load factor of rail transport is therefore an important element in the decision of using intermodal transport, both from the economic and sustainable point of view.

A half loaded train is thus not sufficient for achieving intermodal competitiveness. A deeper analysis determines that, under the reference scenario hypotheses, a minimum rail load factor of $67 \%$ is required for intermodal transport to become competitive from the full costs point of view. This rail load factor decreases to $63 \%$ for achieving intermodal competitiveness from the internal costs point of view.

\subsubsection{Density factors.}

The reference scenario assumes that a 20' container contains on average 12 tonnes of freight. This hypothesis stands for average density goods. However the weight can vary depending on the heaviness or lightness of goods (Black et al., 
2013). We analyse the effect on transport competitiveness of such a density modification. We assume that heavy goods have to be transported, meaning that an average load of 22 tonnes is considered. This corresponds to the maximum load of a 20' container according the ISO standards. As expected, the breakeven distances for both internal and full costs decrease respectively to 550 and $625 \mathrm{~km}$. The breakeven variation is again more important for internal $(-40.5 \%)$ than for full $(-43.3 \%)$ costs, meaning that external costs are more sensitive than internal costs to density. Nevertheless, the variation of external costs is not sufficient for reducing the breakeven for full costs to a distance lower than the breakeven for internal costs.

\subsubsection{Flow Management Factors}

The hypothesis of Janic (2007), stating that demand flows generally decrease while the distance increases, is in particular supported by the transport gravity generation model (Ortúzar and Willumsen, 2011, Rodrigue et al., 2006). However, consolidation of flows is one technique that allows for generating higher demand on long distances. Consolidation is a critical issue for transport actors and bundling strategies can be classified into five basic bundling types (Kreutzberger, 2010). For barge transport, bundling can be achieved through cooperation between inland terminals, which leads to aggregate flows generation (Caris et al., 2012, Konings et al., 2013). The use of freight corridors allows avoiding flow reductions over longer distances. Increased distances between origin and destination nodes are thus not necessarily synonym of reduced intermodal competitiveness.

Transport reliability must also be considered for comparing different modes of transport in a fair way. Reliability refers to transit/lead time variability (Dullaert and Zamparini, 2013). Reliability has effects on external costs and thus impacts the transport mode competitiveness. Indeed the unreliability of a mode of transport, especially in the case of intermodal transport, can lead to the missing of the connection with the following mode in the chain. This situation generates increased external costs that result, for instance, from the additional storage or handling operations that are required.

Transport flexibility is another element that influences the external costs of transport. This notion is related to the concept of synchromodal transport. The idea is for the shipper to let the freedom to the logistics service provider (LSP) to 
choose the transport modes during the travel (DINALOG, 2013). The LSP is thus able to dynamically select the best way of traveling according to the current traffic, time, weather, service level, environmental or costs conditions (SteadieSeifi et al., 2014, Verweij, 2011). The main challenges are related to the coordination and optimal use of modalities. If this improved connection between modes is achieved, it allows for more sustainability because it helps in reducing the number of operations and the storage time that are responsible for external costs (e.g. noise or pollutants). Synchromodality thus refers to the efficient use of intermodal transport. The design of such a transport system has recently been studied by Fan (2013).

\subsection{Discussion}

Based on the literature review and on the analysis in the last section, we discuss the use of externalities, marginal or average costs for integrating external effects. The cost functions studied in the previous section only refer to road and intermodal rail transport. However, intermodal IWW transport is also recognized for its benefits in terms of externalities. We thus give some insights for further research topics on this particular mode.

The literature review shows that external costs of transport are not only of academic but also of real-life and project-based interests. Most of the papers deal with the topic of concretely evaluating the external costs values of specific modes of transport, or the impact of different internalization policies in the competitiveness of modes. Very few studies focus on the identification of generic mathematical functions that define average costs of transport. However, these functions have been proven to be very useful to identify the main competitiveness factors in terms of external costs.

The analysis in the previous section deals with average costs estimations. Nevertheless, even if identifying the competitiveness of one mode of transport based on average costs is relatively easy and provides general recommendations, the use of average costs may lead to a lot of variations. External costs can appear in various situations such as different means of transport, vehicle technologies, road types, time periods, traffic conditions, geographical zones characteristics, population densities and standards of living. Some of these elements are related to the externality itself. A higher slope means for instance higher fuel consumption (Demir, 2012) and thus more emissions of pollutants. Other elements are linked to 
the valuation aspects. For instance an additional decibel in an already noisy environment will be valued less than in a very calm area (Bickel et al., 2006). The particular circumstances of the external costs generation cannot thus be totally reflected in average costs.

The choice for the type of considered costs must therefore carefully be achieved. For general strategic issues, i.e. for the identification of the main factors that influence the competitiveness of road transport, we recommend the use of average external costs functions.

If the focus is on a specific transport connection, the use of the marginal cost approach is possible and seems more relevant. Indeed, marginal costs provide more reliable results in the framework of a specific point-to-point or firm-to-firm configuration analysis. The comparison of the marginal effects of several modes of transport can for instance be performed on a specific geographic corridor. The marginal external cost analysis can focus on the emissions related to the use of the transport mode (tank-to-wheel analysis), on the production phase (well-to-tank analysis) or on both aspects (well-to-wheel analysis, e.g. Hoffrichter et al., 2012).

Instead of focusing on costs, one can also consider the externality itself, in nonmonetary units. Under this situation, it is easy to compare different modes of transport for a same type of external effect. For instance carbon dioxide emissions can simply be evaluated since they are virtually proportional to fuel consumptions (Kirby et al., 2000). However the use of the externality unit instead of its cost may lead to difficulties in comparing two different types of externality (e.g. noise and air pollution).

Externalities, average costs functions and marginal costs values should thus be used in a complementary way, depending on the specific issue that is addressed. Average costs functions better suit the objectives of identifying strategic competitive factors, while marginal costs values are more appropriate for application to specific case studies. The use of externalities in non-monetary units allows for less variation in the estimation, although it suffers from the difficulty to compare external costs of different units.

Also, the determination of external cost values or functions is generally an iterative procedure, based on related earlier studies. However, in order to account for the evolution of technologies (e.g. EURO norms for trucks), there is an important need for actualising these values and functions with up-to-date data. 
Finally, several studies deal with external costs of IWW transport (see for instance Beuthe et al., 2002, Brons and Christidis, 2012 in the framework of the European Marco Polo project, Caris et al., 2013, Ricci and Black, 2005 or van Lier and Macharis, 2010). The above analysis has been developed for the evaluation of road and intermodal using rail transport costs. In the literature, we did not find any similar cost functions to those provided by Janic $(2007,2008)$ for IWW transport. However, it has been showed for intermodal rail transport that these generic functions considerably help in identifying the main competitiveness factors of a specific mode. Some of the results obtained for rail transport should also be valid for IWW transport, such as results related to drayage distances and location scenarios. Further research work should nevertheless be performed in this direction, in order to confirm these statements.

\subsection{Conclusions}

This paper focuses on the identification of external costs as competitive factors of freight transport. After a review of the basic methodology and definitions related to the topic, an analysis of the recent literature is provided. Very few papers in this field focus on the development of generic mathematical functions of external costs. However, the latter are very useful to strategically identify the main factors that influence the competitiveness of transport in terms of external costs. For illustrating the usefulness of such functions, a sensitivity analysis of the parameters of the functions developed by Janic $(2007,2008)$ is provided in the context of the internalization of transport external costs.

The analysis of the functions of Janic $(2007,2008)$ highlights the importance of drayage operations external costs. Indeed, the PPH distances and location scenarios clearly influence the competitiveness of transport, when external costs are internalized. The load and density factors also impact transport competitiveness but to a lesser extent. Furthermore, the way in which flows are managed also influences the amount of generated externalities, and thus the competitiveness of different transportation modes.

Further research topics on freight transport and environmental effects clearly have to consider the decisions related to the location of intermodal terminals. Indeed, depending on the commercial density of their surrounding areas, terminal locations determine the level of consolidation and thus the load factor. Furthermore, terminal locations also define the PPH distances of the companies 
that they disserve. These factors have been identified as competitiveness attributes for intermodal transport full costs. Location decision problems have thus to integrate environmental issues and focus on both rail and IWW transport.

The use of generic mathematical functions dealing with average costs is useful for identifying the strategic competitiveness factors of freight transport. Nevertheless, this method should be considered in a complementary way with other approaches, such as the use of marginal costs. This solution is more appropriate for representing a particular case-study with all its specificities. In order to avoid errors in the monetization of costs, externalities themselves can also be directly taken into account. External cost values and functions require regular updates along time to account for the quick evolution of technologies.

Finally few articles deal with the definition of generic functions for external costs computation. In this study, the usefulness of such kinds of functions has been practically shown for road and intermodal rail transport. No formulation was found in the literature to determine the external costs of IWW transport. Some research should also be performed in that direction.

Disclosure statement:

No potential conflict of interest was reported by the authors.

Funding:

Martine Mostert acknowledges the financial support of FRS-FNRS (Fonds de la Recherche Scientifique). The project leading to the presented results was partially supported by the Interuniversity Attraction Poles Programme initiated by the Belgian Science Policy Office, Comex [grant P7/36]. The paper, however, only expresses the view of the authors. 
PART III

OPTIMIZATION MODELS AND APPLICATIONS

This third part combines intermodal freight transport and freight transport externalities through the development of optimization models and their application to case studies. 

Part II of the thesis (chapters 2, 3 and 4) has developed the topics of intermodal transport and transport externalities. The integration of the environmental component and the PPH distances of intermodal transport have been identified as key factors for improving intermodal transport development. Since PPH distances are determined by the position of intermodal terminals, it is necessary to correctly identify the location of intermodal facilities. The flow distribution between road and intermodal transport can then be deduced.

The following part III of the thesis (chapters 5, 6 and 7) combines intermodal transport and transport externalities in optimization models of the operations research domain. These chapters focus on the analysis of intermodal locationallocation or allocation models, taking into account economic and environmental perspectives. Each chapter provides a model with specific characteristics and its application to a transportation network.

Chapter 5 deals with a three-mode bi-objective intermodal location-allocation model which accounts for climate change. The formulation evaluates the effects on intermodal terminal location, type and modal split of optimizing operational costs and $\mathrm{CO}_{2}$ emissions. The model is applied to the Belgian case study and allows testing how results vary if intermodal economies of scale are integrated or not, if unit costs and emissions are modified, and if the number of terminals to locate changes.

Chapter 5 reveals that an increased intermodal market share is observed when economies of scale are considered, rather than when they are not. Indeed, taking into account economies of scale encourages a more intensive consolidation of flows, leading to reduced global costs and emissions for intermodal transport, with a higher use rate of this mode. Moreover, the phenomenon of selfcannibalization among intermodal terminals is observed when economies of scale are integrated. In chapter 5, economies of scale have been modeled using several vehicle sizes or nonlinear functions of the flows. These methodological issues add complexity to the resolution of the problem. Since the results of the approaches that integrate and that do not integrate economies of scale provide not too different modal splits, and for keeping reasonable computational times, the following chapters 6 and 7 deal with linear costs and emissions, without taking into account economies of scale of intermodal transport. 
Chapter 6 provides an intermodal allocation model which integrates the air pollution environmental impact. The model is applied to the Belgian case study and identifies the variations of flow allocation between a policy aiming at minimizing air pollution external costs (environmental perspective) and a policy aiming at minimizing operational costs (economic perspective). An intermediate policy consisting in the introduction of additional road taxes in an economic perspective is also evaluated.

Chapter 7 delivers an intermodal allocation model that allows the choice between direct transport and any intermodal chain of up to three modes. This formulation differs from the traditional modeling of intermodal transport as a road-rail/IWWroad combination. The formulation is tested on a network at the European level. The model identifies the effects on modal split of policies which optimize operational costs, $\mathrm{CO}_{2}$ emissions and air pollution external costs.

Table 7 summarizes the main characteristics of the three models and applications developed in chapters 5, 6 and 7. 
Characteristics

Climate change

Air pollution

Several intermodal

chains

\begin{tabular}{llll}
\hline Three modes & $\mathrm{X}$ & $\mathrm{X}$ & $\mathrm{X}$ \\
$\begin{array}{l}\text { Any intermodal } \\
\text { combination of up to } \\
\text { three modes }\end{array}$ & & $\mathrm{X}$ \\
$\begin{array}{l}\text { Direct road transport } \\
\begin{array}{l}\text { Direct rail and IWW } \\
\text { transport }\end{array}\end{array}$ & $\mathrm{X}$ & $\mathrm{X}$ \\
$\begin{array}{l}\text { Intermodal transport } \\
\text { with one terminal }\end{array}$ & & $\mathrm{X}$ \\
$\begin{array}{l}\text { Intermodal transport } \\
\text { with two terminals }\end{array}$ & $\mathrm{X}$ & $\mathrm{X}$ & $\mathrm{X}$ \\
$\begin{array}{l}\text { Bi-objective } \\
\text { Economies of scale }\end{array}$ & $\mathrm{X}$ & \\
$\begin{array}{l}\text { Belgian case study } \\
\begin{array}{l}\text { Experimental results } \\
\text { at the European level }\end{array}\end{array}$ & $\mathrm{X}$ & $\mathrm{X}$ & \\
Operational costs & $\mathrm{X}$ & $\mathrm{X}$ & $\mathrm{X}$ \\
CO ${ }_{2}$ emissions & $\mathrm{X}$ & $\mathrm{X}$ & $\mathrm{X}$ \\
$\begin{array}{l}\text { Air pollution external } \\
\text { costs }\end{array}$ & & & $\mathrm{X}$ \\
\hline Table 7: Overview of the characteristics of the three models and their application
\end{tabular}

Table 7: Overview of the characteristics of the three models and their application 



\section{Chapter 5}

\section{Intermodal transport and climate change}

\begin{tabular}{|l|c|c|c|}
\hline \multicolumn{3}{|c|}{ 1. Introduction } \\
\hline
\end{tabular}

This chapter identifies the links between intermodal transport and climate change through an intermodal location-allocation model. The model is applied to the Belgian case study.

\subsection{Abstract $^{3}$}

Freight transport planning is nowadays encouraged to align with environmental objectives. Among those, climate change is of particular interest for many countries. In its White Paper on Transport, the European Commission (2011)

\footnotetext{
${ }^{3}$ This chapter is based on the paper published under the reference: "Mostert, M., Caris, A. \& Limbourg, S. (2017). Intermodal network design: A three-mode bi-objective model applied to the case of Belgium. Flexible Services and Manufacturing Journal, In Press"
} 
considers intermodal transport as a potential solution for reducing environmental impacts. In order to make good strategic transport decisions, realistic decision support models for freight transport networks must be developed, so that insights can be derived for the different stakeholders of the transportation chain. This research provides a bi-objective mathematical formulation which takes into account economic and environmental objectives, on a road and intermodal network with three modes of transport (road, intermodal rail, and intermodal IWW), and in which economies of scale of intermodal transport can be considered. With this model better fitting reality, an application to the Belgian case study provides practical information on how flows, terminal types and locations vary depending on the chosen policy, on the integration or not of economies of scale, on costs or emissions modifications and on the number of terminals to locate. Results show that the chosen policy influences the terminal type and the intermodal market share. The study also highlights the interest of intermodal transport on short distances, and the risk of flow exchanges inside the intermodal market share, rather than between road and intermodal transport.

\subsection{Introduction}

One of the most negative impacts of transport on climate change is the release of $\mathrm{CO}_{2}$ emissions. Road transport represents around $20 \%$ of the total carbon dioxide emissions in Europe (European Commission, 2015a). Nowadays, European authorities clearly encourage the transfer of freight flows from road to more environmentally friendly modes of transport such as IWW or rail (European Commission, 2011). Intermodal transport is identified as an interesting solution for achieving the required transfer from road to less polluting modes of transport.

Intermodal transport is defined as the transportation of goods using two or more modes of transport, in the same loading unit, without handling of the goods themselves (United Nations, 2001). For ensuring intermodal competitiveness both in terms of economic and environmental issues, it is of strategic importance to correctly locate intermodal terminals (Mostert and Limbourg, 2016). The location of terminals determines the PPH distances of trucks between the terminals and the origin/destination nodes. If terminals are wrongly located, i.e. if the PPH distances are too long, the benefits obtained on the intermodal travel cannot compensate anymore for the higher costs and emissions of road transport. 
Intermodal transport has been studied according to different perspectives (Bontekoning et al., 2004, Mathisen and Sandberg Hanssen, 2014) in the literature and an important part of research is concentrated on supporting the decisionmaking process (Macharis and Bontekoning, 2004, Caris et al., 2008, Caris et al., 2013, SteadieSeifi et al., 2014).

In particular, network design problems have been addressed using several methodologies: agent-based models (Sirikijpanichkul et al., 2007) , GIS-based models (Macharis and Pekin, 2009, Macharis et al., 2010, Zhang et al., 2013, Meers and Macharis, 2014) or mathematical programming models (Arnold et al., 2001, Arnold et al., 2004, Racunica and Wynter, 2005; Ishfaq and Sox, 2011, Sörensen et al., 2012, Sörensen and Vanovermeire, 2013, Lin et al., 2014, Bouchery and Fransoo, 2015, Santos et al., 2015, Zhang et al., 2015).

Studies on intermodal network design mostly focus on a single objective. Most of the research concentrates on the minimization of the operational costs on the network (Arnold et al., 2004, Racunica and Wynter, 2005, Ishfaq and Sox, 2011, Sörensen et al., 2012, Ghane-Ezabadi et al., 2016). Some models focus on generalized costs of transport, including transport externalities (Zhang et al., 2013, Santos et al., 2015, Zhang et al., 2015). Single-objective optimization can also be applied to emissions minimization or modal split maximization (Bouchery and Fransoo, 2015). Few articles of bi-objective modeling are available in intermodal transport applications. Sörensen and Vanomermeire (2013) use biobjective optimization for balancing the network users' costs and the terminal operators' opening costs. In order to consider the environmental impact of trucks at maritime railroad terminals, Chen et al. (2013) apply a bi-objective queuing model that minimizes both the number of shifted truck arrivals and the total waiting time of trucks in the queue.

With the exception of Ghane-Ezabadi et al. (2016), who develop a path-based formulation allowing the use of several modes of transport, and Zhang et al. (2015), who focus on bi-level programming, the traditional location-allocation mathematical programming models in the literature are generally developed on a network which does not exceed two modes of transport (Arnold et al., 2001, Arnold et al., 2004, Racunica and Wynter, 2005, Ishfaq and Sox, 2011, Limbourg and Jourquin, 2009, Söresen et al., 2012, Santos et al., 2015). Some papers however include road, rail and IWW transport (Macharis and Pekin, 2009, Macharis et al., 2010, Meers and Macharis, 2014) but in the framework of a GIS- 
based approach. The introduction of more than two modes of transport is important for better matching reality.

Intermodal transport provides the advantage of moving large quantities of goods and thus to possibly benefit from scale effects. Economies of scale can happen at several levels of the intermodal chain, i.e. during the long-haul transportation by a more environmentally friendly mode (Racunica and Wynter, 2005, Ishfaq and Sox, 2011, Ghane-Ezabadi et al., 2016) or at the intermodal terminal, during the transshipment process (Limbourg and Jourquin, 2009, Zhang et al., 2013, Zhang et al., 2016). Economies of scale can be translated mathematically using different methods, e.g. nonlinear functions, discount factors, different values for different vehicle sizes or functions constituted by fixed and variables parts.

The objective of this research is to help closing the gap between freight transport network design and its impact on the environment, especially on climate change. This is done by proposing an innovative bi-objective intermodal locationallocation optimization model. The model evaluates the balance between economic (operational costs) and environmental ( $\mathrm{CO}_{2}$ emissions) objectives, in the framework of a network with three modes: road, intermodal rail, and intermodal IWW transport. The economies of scale of intermodal transport are incorporated using different vehicle sizes and piecewise linear approximations of nonlinear cost and emission functions. The integration of these characteristics contributes to the development of a more realistic formulation of transportation planning, in a political context where transportation strategies have to be aligned with environmental objectives. To highlight the practical usefulness of the model, it is applied to the Belgian case study. Thanks to its strategic perspective, the model gives insights to various actors of the freight transport network, in a societal context which focuses more and more on environmental issues. Policymakers, intermodal terminal operators, road and intermodal transport companies and infrastructure managers can indeed gain insight on the strategies to follow, in terms of policy measure analysis, capacity, infrastructure design and transport flow planning. Indeed, the behavior of road and intermodal flows may vary depending on the followed transportation strategy, in terms of the objective to pursue, or the number of terminals to locate. Sensitivity analysis is used to evaluate the evolution and robustness of the results, when the parameters related to costs, emissions, or to the number of terminals are modified. 
The papers of Zhang et al. (2013) and Zhang et al. (2015) are the closest to this research work since they also deal with intermodal network design by integrating environmental issues. The differences between this research work (Mostert et al., 2017a) and the studies of Zhang et al. $(2013,2015)$ are presented in table 8.

\begin{tabular}{|l|l|l|}
\hline & Zhang et al. (2013, 2015) & Mostert et al. (2017a) \\
\hline Methodology & Bi-level programming & $\begin{array}{l}\text { Bi-objective } \\
\text { optimization }\end{array}$ \\
\hline Resolution method & Genetic algorithm & Exact branch and cut \\
\hline Economies of scale & At the terminal level & $\begin{array}{l}\text { At the transportation } \\
\text { mode level (train and } \\
\text { barge) }\end{array}$ \\
\hline $\mathrm{CO}_{2}$ emissions & $\begin{array}{l}\text { Monetized and internalized } \\
\text { in a single objective function }\end{array}$ & $\begin{array}{l}\text { One separate objective } \\
\text { of the bi-objective } \\
\text { formulation }\end{array}$ \\
\hline Terminal location & $\begin{array}{l}\text { Selection of a terminal } \\
\text { configuration among several } \\
\text { terminal configuration } \\
\text { scenarios }\end{array}$ & $\begin{array}{l}\text { Selection of the best } \\
\text { possible terminal } \\
\text { configuration among all } \\
\text { accessible locations }\end{array}$ \\
\hline
\end{tabular}

Table 8: Comparison of the research works of Zhang et al. $(2013,2015)$ and

Mostert et al. (2017a)

The papers of Meers and Macharis (2014), Bouchery and Fransoo (2015), Santos et al. (2015) are also close to this research but they are based on different tools or integrate other aspects of transportation planning. Meers and Macharis (2014) focus on the terminal operator's perspective using a GIS-based approach, while we formulate the mixed integer nonlinear model at a global level and provide decision-making tools to different stakeholders. We also explicitly take environmental issues into account, whereas Meers and Macharis (2014) only consider them implicitly. Bouchery and Fransoo (2015) locate a single terminal. Alternatively, this work focuses on the location of several terminals between many origin and destination nodes. Bouchery and Fransoo (2015) focus on the Euclidian and Manhattan distances, and on approximated continuous demands, while we concentrate on the real distance and historical record of flow exchanges. We also offer the possibility to choose between road and two intermodal solutions, whereas Bouchery and Fransoo (2015) permit to select either road or intermodal transport. Our model is also subject to different constraints, not only related to demand satisfaction. Santos et al. (2015) focus on road and rail transport, while we consider three modes and economies of scale of intermodal 
transport. We do not take into account subsidies and global external costs in a single objective function, but we solve a bi-objective model, in order to highlight the opposition between costs and $\mathrm{CO}_{2}$ emissions minimization, in terms of terminal location and type.

The next section develops the problem formulation and the proposed mathematical model. Section 5.4 presents the experimental results of the application to the Belgian case. The last section highlights the main conclusions of the research work.

\subsection{Problem formulation}

The objective of the model is to provide a global vision of the impact of operational costs and $\mathrm{CO}_{2}$ emissions on terminal location and type, and on the allocation of flows between road and intermodal transport. Even if a lot of stakeholders are involved in the decision process of intermodal network design, this paper assumes a single decision maker at the strategic level (Arnold et al., 2004, Limbourg and Jourquin, 2009, Santos et al., 2015) in order to provide decision-making support for different stakeholders of the system. Policy makers can gain insight by assessing the interest of locating new terminals inside their political zone of decision. They can also use the model to analyze the impact of policy measures such as the introduction of subsidies or the internalization of external costs. Intermodal terminal operators can benefit from improved information on the predicted volumes passing through their facilities and thus adapt the related services inside the terminal. Road and intermodal transport companies can be interested in identifying how the adoption of one or another policy could modify their market share. Information on flow distribution can also be used by rail, road and IWW infrastructure managers to determine the future transported volumes and thus plan the required capacities of the network.

The formulation allows determining the modal split between three modes: road, intermodal rail and intermodal IWW transport. Transport network design models often only focus on a specific intermodal transport mode (Arnold et al., 2004, Racunica and Wynters, 2005, Ishfaq and Sox, 2011) using the hub location theory (Alumur and Kara, 2008, Farahani et al., 2013) without considering the possible direct door-to-door road travel. Our modelling differs from the traditional hub system in the sense that non-hubs (i.e. non-terminal nodes) can be connected directly to each other using road transport, two intermodal terminals (hubs) are 
not necessarily connected, and finally the non-hub nodes can be connected to more than one terminal. The relaxation of these hypotheses better reflects reality (Lin et al., 2014).

The minimization of operational costs and $\mathrm{CO}_{2}$ emissions mainly refers to energy optimization. Instinctively, we presume that the terminal locations do not differ too much from costs to emissions optimization. However, we also expect some diverging factors between both functions. For instance, repair and maintenance costs may be lower for road than for rail, whereas emissions are expected to be higher for road than for rail. This possible opposition between costs and emissions is taken into account by including both functions in a bi-objective optimization model.

For the environmental aspect, the focus is on climate change, using $\mathrm{CO}_{2}$ emissions as its indicator. Only one type of externality is selected in order to identify its specific environmental impact on the terminal location problem. The choice for climate change is justified by the worldwide willingness to reduce the anthropic global warming effect. This is observed through big conventions and events such as the Kyoto Protocol or the regular United Nations Climate change conferences. Limiting the global warming effect is also part of the priorities of Europe (European Commission, 2015a) since heavy duty vehicles are responsible for $25 \%$ of road transport and $6 \%$ of total transport $\mathrm{CO}_{2}$ emissions. $\mathrm{CO}_{2}$ emissions are chosen as the environmental indicator because they represent the main greenhouse gas which influences climate change.

The model takes train and barge capacity into account. For rail transport, a single train size is considered. The number of trains to be used on each arc is optimized and the related load factor is then deduced. Rail cost and emission values are computed on the basis of this load factor. For IWW transport, the number and size of barges to be used on each arc are optimized and the related load factor is then deduced. Similarly to rail, IWW cost and emission values are computed on the basis of this load factor.

The formulation of the model which allows taking into account economies of scale of intermodal transport is developed hereunder.

The transportation units used for expressing costs are tonne.kilometers (t.km), barge.kilometers (barge.km) and tonnes (t). 


\section{$\underline{\text { Sets }}$}

$T \quad$ set of types of barges, according to their size, indexed by $t \in\{1, \ldots, d\}$

$V \quad$ set of trains indexed by $v \in\{1, \ldots, f\}$

$N \quad$ node set consisting of $n$ demand nodes, indexed by $i, m \in\{1, \ldots, n\}$

$H \quad$ existing and potential terminal (hub) set, $(H \subseteq N)$ consisting of $h$ nodes, indexed by $j, k \in\{1, \ldots, h\}$

These sets are divided into various subsets:

$\mathrm{N}_{0} \quad$ set of port nodes, inside the studied geographical area. These nodes are assumed to have rail and IWW connections. They are therefore considered as existing intermodal terminals.

$\mathrm{N}_{1} \quad$ set of demand nodes inside the studied geographical area, potential railroad terminals

$\mathrm{N}_{2} \quad$ set of demand nodes inside the studied geographical area, potential IWWroad terminals

$\mathrm{N}_{3} \quad$ set of railroad terminals located outside the studied geographical area

$\mathrm{N}_{4} \quad$ set of IWW-road terminals located outside the studied geographical area

$\mathrm{N}_{5} \quad$ set of demand nodes outside the studied geographical area

Thus $\mathrm{N}=\mathrm{U}_{\mathrm{i}=0}^{5} \mathrm{~N}_{\mathrm{i}} ; \mathrm{H}=\mathrm{U}_{\mathrm{i}=0}^{4} \mathrm{~N}_{\mathrm{i}} ; \mathrm{H}_{\mathrm{R}}=\mathrm{N}_{0} \cup \mathrm{N}_{1} \cup \mathrm{N}_{3}$ and $\mathrm{H}_{\mathrm{W}}=\mathrm{N}_{0} \cup \mathrm{N}_{2} \cup \mathrm{N}_{4}$

\section{$\underline{\text { Parameters }}$}

$p \quad$ number of intermodal terminals to locate inside the studied geographical area

$d_{i m} \quad$ road distance between demand nodes $i$ and $m$ (in $\mathrm{km}$ )

$s_{j k} \quad$ rail distance between terminals $j$ and $k$ (in $\mathrm{km}$ )

$l_{j k} \quad$ IWW distance between terminals $j$ and $k$ (in $\mathrm{km}$ ) 
$D_{i m} \quad$ cargo demand from demand node $i$ to demand node $m$ (in $\mathrm{t}$ )

$C_{i m}^{L} \quad$ long-haul road transportation costs for travelling from node $i$ to node $m$ (in $€ /$ t.km)

$C_{i j}^{P} \quad$ collection/distribution road transportation costs for travelling from node $i$ to terminal $j$ (in $€ /$ t.km)

$C_{j k}^{R} \quad$ long-haul rail transportation costs for travelling from terminal $\mathrm{j}$ to terminal $\mathrm{k}$ (in $€ / \mathrm{t} . \mathrm{km}$ )

$C_{j k}^{W} \quad$ long-haul IWW transportation costs for travelling from terminal $\mathrm{j}$ to terminal $\mathrm{k}$ (in $€ / \mathrm{t} . \mathrm{km}$ )

$C_{j k}^{t W} \quad$ long-haul IWW transportation costs for travelling from terminal $\mathrm{j}$ to terminal $\mathrm{k}$ using a barge of size $\mathrm{t}$ (in $€ /$ barge.km)

$E_{i m}^{L} \quad$ long-haul road transportation emissions for travelling from node $i$ to node $m$ (in $\mathrm{kg}$ of $\mathrm{CO}_{2} / \mathrm{t} . \mathrm{km}$

$E_{i j}^{P} \quad$ collection/distribution road transportation emissions for travelling from node $i$ to terminal $j$ (in $\mathrm{kg}$ of $\mathrm{CO}_{2} / \mathrm{t} . \mathrm{km}$ )

$E_{j k}^{v R} \quad$ transportation emissions for travelling from terminal $j$ to terminal $k$ using the $v^{\text {th }}$ train for the long-haul travel by rail (in $\mathrm{kg}$ of $\mathrm{CO}_{2} / \mathrm{t} . \mathrm{km}$ )

$E_{j k}^{t W} \quad$ transportation emissions of a barge of size $t$ for travelling from terminal $j$ to terminal $k$ for the long-haul travel by IWW (in $\mathrm{kg} \mathrm{of} \mathrm{CO}_{2} /$ barge.km)

$C_{j}^{T} \quad$ handling operational costs at the terminal $j$ (in $€ / \mathrm{t}$ )

$E_{j}^{T} \quad$ handling emissions at the terminal $j$ (in $\mathrm{kg}$ of $\mathrm{CO}_{2} / \mathrm{t}$ )

$K_{T} \quad$ maximum capacity of a barge of size $t$ (in t)

A maximum capacity of a train (in $\mathrm{t}$ ) 


\section{$\underline{\text { Decision variables }}$}

$y_{k} \quad=1$ if a terminal is located at $\mathrm{k} \forall k \in N_{1} \cup N_{2}$

$=0$ otherwise

$W_{i m}$ road flows from demand origin $i$ and destination $m$ (in tonnes), $\forall i, m \in$ $N$

$X_{j k}^{i} \quad$ flows from node $i$ firstly routed through origin rail terminal $j$ and then through destination rail terminal $k$ (in tonnes), $\forall i \in N, \forall j, k \in H_{R}$

$X_{j k}^{v i} \quad$ flows from node $i$ firstly routed through origin terminal $j$ and then through destination terminal $k$, using the $v^{\text {th }}$ train for the long-haul travel by rail (in tonnes), $\forall v \in V, \forall i \in N, \forall j, k \in H_{R}$

$Q_{k m}^{i}$ flows from origin $i$ to destination $m$ that are routed through rail destination terminal in $k$ (in tonnes), $\forall i, m \in N, \forall k \in H_{R}$

$F_{j k}^{i} \quad$ flows from node $i$ firstly routed through origin IWW terminal $j$ and then through destination IWW terminal $k$ (in tonnes), $\forall i \in N, \forall j, k \in H_{W}$

$V_{k m}^{i} \quad$ flows from origin $i$ to destination $m$ that are routed through IWW destination terminal in $k$ (in tonnes), $\forall i, m \in N, \forall k \in H_{W}$

$M_{t} \quad$ number of barges of size $t, \forall t \in T$ 
Objective functions to minimize

$$
\begin{gathered}
f_{\text {costs }}= \\
\sum_{i \in N} \sum_{m \in N} d_{i m \cdot} \cdot C_{i m}^{L} \cdot W_{i m} \\
+\sum_{i \in N_{0}} C_{i}^{T} \cdot W_{i m}+\sum_{m \in N_{0}} C_{m}^{T} \cdot W_{i m} \\
+\sum_{i \in N} \sum_{j \in H_{R}} \sum_{k \neq j \in H_{R}}\left(d_{i j} \cdot C_{i j}^{P}+C_{j}^{T}\right) \cdot X_{j k}^{i} \\
+\sum_{i \in N} \sum_{j \in H_{R}} \sum_{k \neq j \in H_{R}} s_{j k} \cdot C_{j k}^{R} \cdot X_{j k}^{i} \\
+\sum_{i \in N} \sum_{k \in H_{R}} \sum_{m \in N}\left(d_{k m} \cdot C_{k m}^{P}+C_{k}^{T}\right) \cdot Q_{k m}^{i} \\
+\sum_{i \in N} \sum_{j \in H_{W}} \sum_{k \neq j \in H_{W}}\left(d_{i j} \cdot C_{i j}^{P}+C_{j}^{T}\right) \cdot F_{j k}^{i} \\
+\sum_{t \in T} \sum_{j \in H_{W}} \sum_{k \neq j \in H_{W}} l_{j k} \cdot C_{j k}^{t W} \cdot M_{t} \\
\sum_{i \in N}\left(d_{k m} \cdot C_{k m}^{P}+C_{k}^{T}\right) \cdot V_{k m}^{i}
\end{gathered}
$$




$$
\begin{gathered}
f_{\text {emissions }}= \\
\sum_{i \in N} \sum_{m \in N} d_{i m} \cdot E_{i m}^{L} \cdot W_{i m} \\
+\sum_{i \in N_{0}} E_{i}^{T} \cdot W_{i m}+\sum_{m \in N_{0}} E_{m}^{T} \cdot W_{i m} \\
+\sum_{i \in N} \sum_{j \in H_{R}} \sum_{k \neq j \in H_{R}}\left(d_{i j} \cdot E_{i j}^{P}+E_{j}^{T}\right) \cdot X_{j k}^{i} \\
+\sum_{v \in V} \sum_{i \in N} \sum_{j \in H_{R}} \sum_{k \neq j \in H_{R}} s_{j k} \cdot E_{j k}^{v R} \cdot X_{j k}^{v i} \\
+\sum_{i \in N} \sum_{k \in H_{R}} \sum_{m \in N}\left(d_{k m} \cdot E_{k m}^{P}+E_{k}^{T}\right) \cdot Q_{k m}^{i} \\
+\sum_{i \in N} \sum_{j \in H_{W}} \sum_{k \neq j \in H_{W}}\left(d_{i j} \cdot E_{i j}^{P}+E_{j}^{T}\right) \cdot F_{j k}^{i} \\
+\sum_{t \in T} \sum_{j \in H_{W}} \sum_{k \neq j \in H_{W}} l_{j k} \cdot E_{j k}^{t W} \cdot M_{t} \\
\sum_{i \in N} \sum_{k \in H_{W}}\left(d_{k m} \cdot E_{k m}^{P}+E_{k}^{T}\right) \cdot V_{k m}^{i}
\end{gathered}
$$

Subject to:

$$
\begin{aligned}
& \sum_{k \in N_{1} \cup N_{2}} y_{k} \leq p \\
& y_{k}=1
\end{aligned}
$$$$
\forall k \in N_{0} \cup
$$$$
N_{3} \cup N_{4} \cup N_{5} \cup N_{6}
$$ 


$$
\begin{aligned}
& D_{i m}=W_{i m}+\sum_{k \in H_{R}} Q_{k m}^{i}+\sum_{k \in H_{W}} V_{k m}^{i} \\
& \forall i, m \in N \\
& \sum_{m \in N} D_{i m}=\sum_{m \in N} W_{i m}+\sum_{j, k \in H_{R}} X_{j k}^{i} \\
& +\sum_{j, k \in H_{W}} F_{j k}^{i} \\
& \sum_{k \in H_{R}} X_{j k}^{i} \leq y_{j} \sum_{m \in N} D_{i m} \\
& \sum_{j \in H_{R}} X_{j k}^{i} \leq y_{k} \sum_{m \in N} D_{i m} \\
& \sum_{k \in H_{W}} F_{j k}^{i} \leq y_{j} \sum_{m \in N} D_{i m} \\
& \sum_{j \in H_{W}} F_{j k}^{i} \leq y_{k} \sum_{m \in N} D_{i m} \\
& \sum_{j \in H_{R}} X_{j k}^{i}=\sum_{m \in N} Q_{k m}^{i} \\
& \sum_{j \in H_{W}} F_{j k}^{i}=\sum_{m \in N} V_{k m}^{i} \\
& \sum_{t} M_{t} \cdot K_{t} \geq \sum_{i \in N} \sum_{j \in H_{W}} \sum_{k \neq j \in H_{W}} F_{j k}^{i} \\
& X_{j k}^{i}=\sum_{v \in V} X_{j k}^{v i} \\
& X_{j k}^{v i} \leq A \\
& W_{m}^{i} \geq 0 \\
& \forall i \in N, \forall j \in H_{R} \\
& \forall i \in N, \forall k \in H_{R} \\
& \forall i \in N, \forall j \in H_{W} \\
& \forall i \in N, \forall k \in H_{W} \\
& \forall i \in N, \forall k \in H_{R} \\
& \forall i \in N, \forall k \in H_{W} \\
& \forall v \in V, \\
& \forall i \in N, \forall j, k \in H_{R} \\
& \forall i, m \in N
\end{aligned}
$$


$X_{j k}^{i} \geq 0$

$$
\forall i \in N, \forall j, k \in H_{R}
$$

$Q_{k m}^{i} \geq 0$

$\forall i, m \in N, \forall k \in H_{R}$

$F_{j k}^{i} \geq 0$

$\forall i \in N, \forall j, k \in H_{R}$

$V_{k m}^{i} \geq 0$

$\forall i, m \in N, \forall k \in H_{R}$

$\forall k \in H$

Equations (3) and (4) respectively stand for the total operational costs and emissions of transport companies. These equations are divided into: (i) door-todoor road costs/ emissions, (ii) transshipment costs/emissions between sea and road, (iii) railroad intermodal costs/emissions and (iv) IWW-road intermodal costs/emissions. Elements (iii) and (iv) are again subdivided into (a) pre-haulage costs/emissions by road, (b) transshipment costs/emissions at origin intermodal terminal, (c) long-haul travel costs/emissions by rail or IWW, (d) transshipment costs/emissions at the destination terminal and (e) post-haulage costs/emissions by road.

Constraint (5) suggests that a maximum of $p$ terminals can be located. This constraint reflects that building intermodal terminals is not free of charge so that only a certain number of terminals can be constructed, with respect to the available budget. Constraints (6) ensure that the already existing terminals are open. Constraints sets (7) and (8) respectively guarantee that the demand between each origin $i$ and destination $m$ pair is satisfied either by road, railroad or IWWroad transport and that all the flows are leaving their origin by one of the three modes. Constraints (9) to (12) state that no flow can pass through an intermodal terminal if this terminal is not open. Constraints (13) and (14) ensure flow conservation for rail and IWW transport. Constraint (15) ensures that, at the global level, the number of available barges of all types is sufficient for satisfying the demand transported by IWW. This assumption implies that enough barges are available in total and that all barges are not used at the same moment. Constraints (16) guarantee flow conservation between road transport by truck and rail transport by train. Constraints (17) ensure that the capacity of the train is not exceeded. Finally constraints (18) to (22) are non-negativity constraints for flows, while constraints (23) define variables $y_{k}$ as binary variables. 
The proposed model is bi-objective and can account for economies of scale of intermodal transport. The bi-objective formulation is solved using the exact $\varepsilon$ constraint resolution technique of Chankong and Haimes (1983). The method consists in transforming a multi-objective problem into single-objective optimization, by only keeping one objective function to optimize. Other objective functions are introduced as constraints of the model, lower or equal to a value $\varepsilon$ (Rangaiah, 2009). In this study, the $\mathrm{CO}_{2}$ emission function is introduced as a constraint of the cost minimization problem. Economies of scale of intermodal transport are modeled using nonlinear functions of the weight. The latter are approximated by a piecewise linear function, so as to permit the use of linear programming solvers for the problem resolution. Detailed explanations on the solution methodology can be found in section 5.6 (Belotti et al., 2013; Chankong and Haimes, 1983; Jeroslow and Lowe, 1984; Kimms, 2006; Rangaiah, 2009).

This model is based on an all-or-nothing assignment of flows when it comes to select the best transportation mode between an origin and a destination node. The choice for the transportation mode is therefore restricted to one mode for any origin-destination pair, only depending on the cost criteria for the economic optimization and on the emission criteria for the environmental optimization. This assumption influences the resulted flow distribution since either all or none of the flows between a specific origin-destination pair (i.e. all of the flows between NUTS 3 regions) is transported using a single specific mode. Based on the aggregation level of data, it is therefore assumed that all the flows between NUTS 3 regions are sent using the same mode of transport.

Even if the all-or-nothing assignment is a simplification of reality, this method has the advantage to provide information on the "desire line" (Ortúzar and Willumsen, 2011), i.e. what is the expected trajectory of flows, without any congestion on the network.

An all-or-nothing assignment does not account for capacity issues neither for stochastic effects related to the perception and knowledge of available routes (Ortúzar and Willumsen, 2011).

Congestion is not taken into account in our formulation since the model is applied at a strategic level of decision. The application of the all-or-nothing assignment of flows allows understanding the preferred choices of modes between the available possibilities in absence of congestion. The maximum wished capacities on the 
network links can be evaluated and it can be assessed if these required capacities correspond to existing and available capacities. This provides information to infrastructure managers regarding the need to potentially increase or improve the transportation infrastructure of specific modes of transport.

The stochastic aspects related to the perception of routes are not considered in the all-or-nothing assignment but are included in modal choice analysis. The all-ornothing assignment of flows has the advantage to be simpler than discrete choice analysis which takes into account several parameters which influence the probability of choosing one mode or another (i.e. through utility functions based on several attributes). Indeed, modal choice modeling requires good data based on surveys and these data are difficult to obtain, in particular for revealed preferences/choices (Ortúzar and Willumsen, 2011).

Even if it is not the only driver of modal choice, the cost attribute of the transportation mode remains one of the main parameters which influence the modal choice (Cullinane and Toy, 2000, Garcia-Menendez et al., 2004, Danielis and Marcucci, 2007, Ravibabu, 2013, Larranaga et al., 2016). The all-or-nothing assignment approach at the strategic level simplifies reality since it assumes that all aggregated flows are sent using the same mode of transport. However, this approach gives interesting information on the flow preferences at the strategic level and it offers "extreme" modal split results in terms of cost or emissions minimization. These results provide a range in which modal splits can vary on the network. All-or-nothing algorithms are commonly used in freight transportation models of operations research (Racunica and Wynter, 2005, Ishfaq and Sox, 2009, Sörensen et al., 2012, Sörensen and Vanovermeire, 2013, Lin et al., 2014, Santos et al., 2015).

The following sections develop the results of the approaches which do not take into account economies of scale of intermodal transport (linear approach) and which do take into account economies of scale of intermodal transport (nonlinear approach). A sensitivity analysis of the parameters related to costs, emissions, and number of terminals is then performed to check the robustness of the model. 


\subsection{Experimental results}

The model is tested on the Belgian network and its neighboring regions. This is done for several reasons. First, the country has a high density of road, rail and IWW infrastructure. Then, new intermodal terminals are still currently being added to the network, e.g. with the development of the new Trilogiport intermodal platform in Liege. Thanks to its strategic location at the heart of Europe, important quantities of freight flows are also transiting through the country. Moreover, Belgium has one of the worst European performances in terms of air quality (European Commission, 2015b), which makes this case interesting in terms of environmental analysis. The use of intermodal transport is often recommended on medium and long distances. This case study allows analyzing the performance of road and intermodal transport on shorter distances. Finally, the analysis of the development of intermodal transport on the Belgian network is supported by the Belgian government, for instance through the subvention of research projects aiming at enhancing intermodal transport in Belgium (i.e. the BRAIN-TRAINS project by Troch et al. (2015) for intermodal rail transport). Belgium has already been used as a case study by several authors to identify the impact of policy measures on the modal shift (Macharis and Pekin, 2009, Macharis et al., 2010, Santos et al., 2015), and to evaluate if opening additional intermodal terminals is still desirable from the terminal operator's perspective (Meers and Macharis, 2014).

Demand data related to intermodal flows are hard to obtain and to gather and are not really up-to-date. In the present paper, the demand data originates from the Worldnet database (Newton 2009). It consists in the flows transported in containers by road, rail and IWW from and to 88 third-level Nomenclature of Territorial Units for Statistics (NUTS 3) regions in Belgium and its neighboring countries (France, the Netherlands, Luxembourg, Germany). The matrix takes into account the flows exchanges related to the Standard Goods Nomenclature for Transport Statistics (NST/R) 9 class of commodities which are transported in containers. Demand data consists in an origin-destination matrix of size $88 * 88$. The original 2005 database has been extrapolated to 2010 based on aggregated flow values available from Eurostat and from Belgian ports' annual outlooks. The original flows at the NUTS 2 level are disaggregated to a NUTS 3 level, using the number of companies of productive sectors in each region as the proxy indicator. The studied region is presented in figure 8 . 


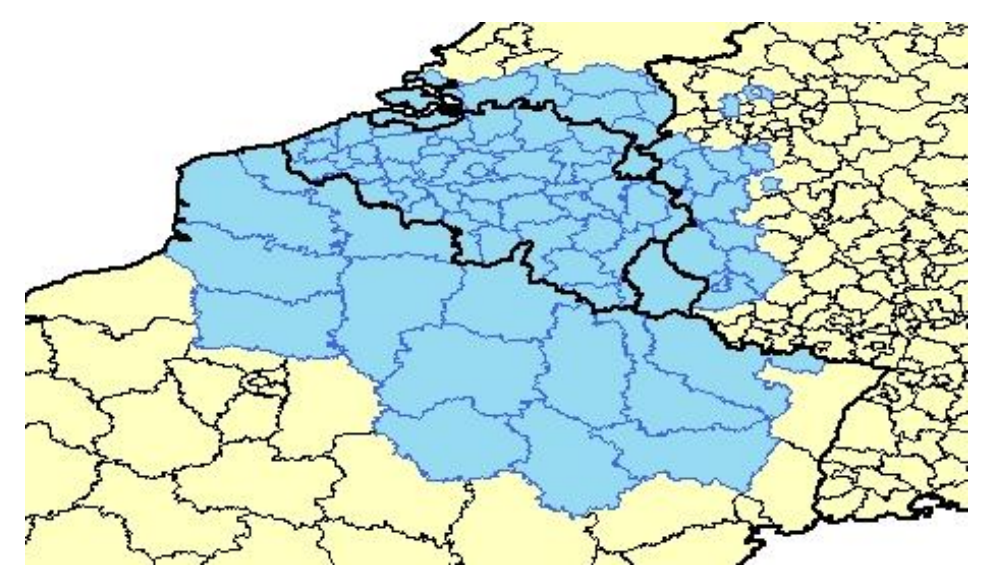

Figure 8: NUTS 3 regions considered in the Belgian case study

The demand for each region is concentrated on a single generation node, called centroid and chosen for the importance of the cities in the NUTS 3 region and the existence of a rail/IWW platform nearby. The already existing terminals for rail and IWW outside Belgium, as well as the already existing sea terminals in Belgium (Antwerp, Zeebrugge and Ghent) are taken into account. These sea terminals in Belgium both have rail and IWW connections. They can therefore be assimilated to intermodal terminals.

Supply data consists in the real road, rail and IWW transport distances between two nodes. Road and rail distances are based on GIS networks detained by Carreira et al. (2012). IWW distances are computed based on the Periskal route planning tool (Promotie Binnenvaart Vlaanderen, 2015) networks of transport, and their associated costs.

In the reference case, the maximum number of IWW and rail terminals to be located is fixed to 15. It corresponds to the sum of the most important rail, IWW and three-mode terminals currently available in Belgium. Sea terminals of Antwerp, Ghent and Zeebruge are not considered for determining the total number of terminals to open, as they are already assumed to be open, both for IWW and rail. The limit between short-haul and long-haul travel is fixed to 300 $\mathrm{km}$, which is the accepted distance by the European Commission (2011).

The next section discusses calibration and validation issues of the model. Since the intermodal location-allocation model developed in this chapter allows integrating economies of scale of intermodal transport, detailed experimental 
results are then analyzed for two approaches. The first one does not take into account economies of scale of intermodal transport, which makes the model formulation linear. The second approach takes into account economies of scale of intermodal transport and leads to a nonlinear formulation.

\subsubsection{Discussion on calibration and validation}

Calibration and validation issues deal with the evaluation of the level of adequacy between the results of the model and reality. The difficulty to obtain real accurate data limits the possibility to confront the results of the model with reality. Indeed, flow demands of the model are based on values of 2010. Moreover, real data at the level of terminals or at the level of link between two terminals is generally only available for larger geographical regions than the case under study. The calibration and validation steps of the modeling are therefore not easy to perform.

Calibration and validation issues in freight transportation models have been treated by Jourquin (2005), Yamada et al. (2009), Zhang (2013) and Jourquin (2016). Jourquin (2005) validates his model by comparing the resulted modal shares of the model by road, rail, and IWW transport with the real observed modal shares, for several categories of goods. Yamada et al. (2009) validate the modal split of their model by comparing the modelled link flows with the real link traffic counts but do not perform calibration at the node flows level. Zhang et al. (2013) calibrate their multimodal multi-commodity flow assignment model at the mode, route and node levels. Jourquin (2016) analyzes the validity of strategic freight transport planning models on the European case study at three levels: a highly aggregated level (global modal shares of each transport mode for each group of commodity) and two disaggregated levels (node and link perspectives).

The results of the model should be validated in order to see if they correspond to real transport observations. The validation of the model can be done by comparing the resulting values of flows at the intermodal terminals or between some terminal connections with the observed real values on the case study.

Few flow data are available for the specific geographical region under study. Some comparisons of the results of the model with data related to Belgium are nevertheless given to highlight that the model provides reasonable results. 


\begin{tabular}{ccc}
\hline Mode & $\begin{array}{c}\text { Modal split (\%) for the } \\
\text { economic optimization of } \\
\text { the model }\end{array}$ & Real modal split (\%) \\
\hline Road & 76 & 68 \\
Rail & 15 & 15 \\
IWW & 9 & 18 \\
\hline
\end{tabular}

Table 9: Real and modeled modal split under the economic optimization approach that does not consider economies of scale

Table 9 compares the real and resulted modal split given by the model. The rail market share for the economic optimization of the model corresponds to the real observed market share on the case study (Belgium, the Netherlands, Germany, France and Luxembourg). The IWW market share of the model is underestimated compared to the real flows. This is partially explained by the fact that real statistics focus on all kinds of flows whereas our model only refers to containerized transport. Since IWW is often used for bulk transport, this may explain the underestimation of the IWW market share in the model, for which only containerized flows are analyzed.

In 2010, a little bit less than 8,500,000 TEUs have been transshipped through the Port of Antwerp, for an estimated amount of 102,000,000 tonnes. Among these TEUs, $37 \%$ were originating from or destined to Europe, i.e. 38,000,000 tonnes. $43 \%$ of these tonnes were transported using intermodal rail and IWW transport. In $2010,16,350,000$ tonnes of containerized flows therefore transshipped by rail and by IWW through the Port of Antwerp for the European market (Port of Antwerp, 2015).

Under the economic optimization of costs, our results highlight that 9,050,000 tonnes of goods are handled using rail and IWW at the Port of Antwerp. This corresponds to around 55\% of the European 16,350,000 tonnes that transshipped through the Port of Antwerp in 2010 (Port of Antwerp, 2015). The result of the model seems reasonable compared to the statistics of the Port since the model only focuses on the flows within Belgium and between Belgium and some NUTS 3 regions of its neighboring countries, whereas statistics correspond to flow exchanges on the whole European territory.

Under the economic optimization, the connection between the Port of Antwerp and the terminal located in Arlon (close to the existing terminal in Athus) ensures the transport of 325,000 tonnes of goods. Based on the load factor of trains, this 
corresponds to between 12 and 13 trains of goods sent weekly. This is a little bit more than the current 8 to 10 trains transferred in reality each week between Antwerp and Athus (Terminal Container Athus, 2017). The results of the model are based on 2010 demands and should be balanced with the evolution of flows between 2010 and 2017. An annual average growth of around 2\% is expected for the tonnes transported between 2008 and 2030 in Belgium (Bureau Fédéral du Plan, 2012).

The flows transiting through the Port of Zeebrugge (Port of Zeebrugge, 2017) in containers in $2011(22,500,000$ tonnes $)$ correspond to $21 \%$ of the flows transported through the Port of Antwerp (105,000,000 tonnes). In our model this proportion is also respected since $1,800,000$ tonnes of goods pass through the Port of Zeebrugge, which represents around $20 \%$ of the tonnes transiting through Antwerp (9,050,000 tonnes).

The Port of Ghent is the third most important port in Belgium. In 2011, 500,000 tonnes of containerized goods have been transshipped through the Port of Ghent (Port of Ghent, 2017). The model also identifies the Port of Ghent as the third biggest port in terms of flows $(1,500,000$ tonnes $)$.

Under the optimization of operational costs, the two most important inland terminals in terms of transshipped flows are Hasselt (2,445,000 tonnes) and Liège $(1,500,000$ tonnes). The flows transshipped at these terminals are comparable to the ones identified in Santos et al. (2015) for Hasselt (1,811,000 tonnes) and for Liège $(1,454,000$ tonnes) under the optimal terminal locations. More important flows are transshipped at these terminals in our model than in Santos et al. (2015), since we consider the IWW flows and paths. The results of the model overstate the statistical flows of tonnes transported in TEUs at Liège $(684,000$ tonnes in 2016) but are coherent with the expectations related to the implementation of the Trilogiport platform which lie between 160,000 and 200,000 TEUs, i.e. between $1,920,000$ and 2,400,000 tonnes (RTBF, 2014).

The restricted availability of up-to-date data related to the flows passing through the extended Belgian case study makes difficult the comparison of the results of the model with reality. Indeed, information related to the amount of flows transshipped at the terminals is global and not disaggregated at the studied level of Belgium and its neighborhood. The validation step is therefore not easy to perform in an exact way. If more data was available, specifically related to the 
flows transiting through the terminals in the studied case on Belgium and its neighborhood, better comparisons could be performed. Moreover, if good and upto-date data are available, calibration issues could be dealt with by modifying the level of subsidies and taxes in the model, to propose a formulation which is really adjusted to reality. One solution to perform a more efficient calibration and validation of the model is to apply it to a core network corridor, where flows can be better evaluated. However, data might be missing and the size of the problem may be too large to be solved using an exact method.

The model developed in this study assumes that the decision makers are rational and that they are only driven by cost objectives. In reality, other objectives also play a role such as reliability, traveling time, or availability of services with added-value. These various objectives, in addition to the awarding of subsidies and to different negotiation powers (lobbying) may explain the differences that happen between our results and the statistical flows. Moreover, the translation between the tonnes transported and the number of TEUs in our model is based on average values (12 tonnes per container) whereas containers may have higher or lower load factors in reality, depending on the density of goods. Finally, the allor-nothing characteristic of the model implies that all the flows of a specific origin-destination are transported through the same mode of transport. Since flows are aggregated, the all-or-nothing assignment of the model may easily increase the t.km of one mode over another if the volume exchanged in this origin-destination pair is high.

\subsubsection{Without economies of scale - linear approach}

This section aims at presenting the results of the bi-objective linear model.

The definition of the linear cost and emission functions can be found in section 5.7 (European Commission, 2001; Hoen et al. 2010; Hoen et al., 2014; Janic, 2007; Janic, 2008; te Loo, 2009; PWC, 2003). Figure 9 shows the Pareto front for the bi-objective model under the linear approach in terms of relative values. The relative optimal costs-emissions pairs for 11 solutions varying from the minimum cost scenario (reference value) to the minimum emission scenario are presented. 


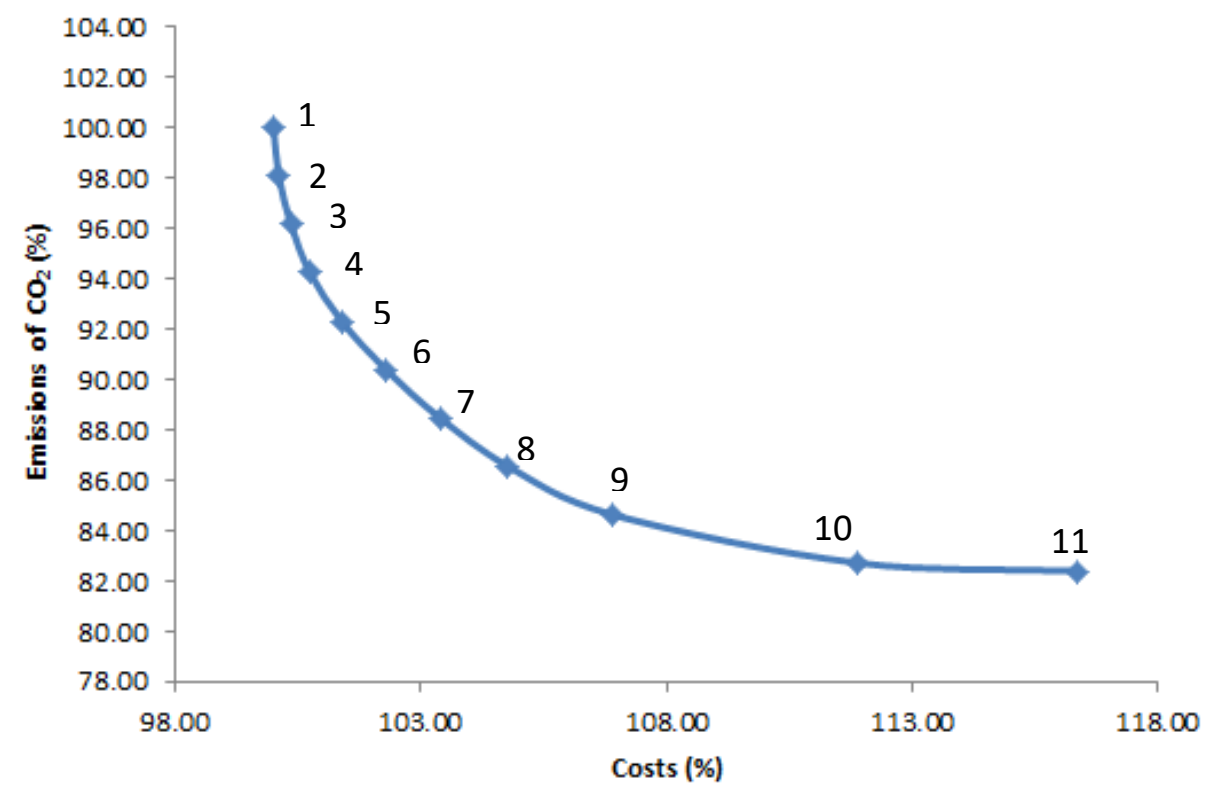

Figure 9: Pareto front for the bi-objective model in the linear case

The Pareto front shows that emphasizing more environmentally friendly transport implies additional financial means. The two next sections further analyze the Pareto curve by providing specific results for the two extreme points of the Pareto front and by identifying how one point of the Pareto front can be selected from a policy perspective, using marginal costs and benefits analysis.

\subsubsection{Extreme points of the Pareto front}

This subsection analyzes the results of the two extreme points of the Pareto curve in terms of flow distribution, terminal types and terminal locations.

Table 10 provides the flow distribution values and the number of located terminals, for the two extreme points of the Pareto curve. 


\begin{tabular}{llllll}
\hline $\begin{array}{l}\text { Reference } \\
\text { scenario }\end{array}$ & $\begin{array}{l}\text { Absolute } \\
\text { road flow } \\
\text { values }\end{array}$ & $\begin{array}{l}\text { Absolute } \\
\text { rail flow } \\
\text { values }\end{array}$ & $\begin{array}{l}\text { Absolute } \\
\text { IWW flow } \\
\text { values }\end{array}$ & $\begin{array}{l}\text { Number of } \\
\text { located rail } \\
\text { terminals }\end{array}$ & $\begin{array}{l}\text { Number of } \\
\text { located } \\
\text { IWW } \\
\text { terminals }\end{array}$ \\
\hline Costs min & $76 \%$ & $15 \%$ & $9 \%$ & 10 & 5 \\
$\begin{array}{l}\text { Emissions } \\
\text { min }\end{array}$ & $26 \%$ & $24 \%$ & $50 \%$ & 6 & 9 \\
\hline
\end{tabular}

Table 10: Results of the optimal costs and emissions minimization cases

Figure 10 illustrates the flow distribution of the extreme cases of the Pareto curve, i.e. the situation, with the minimum possible costs and the minimum possible emissions.

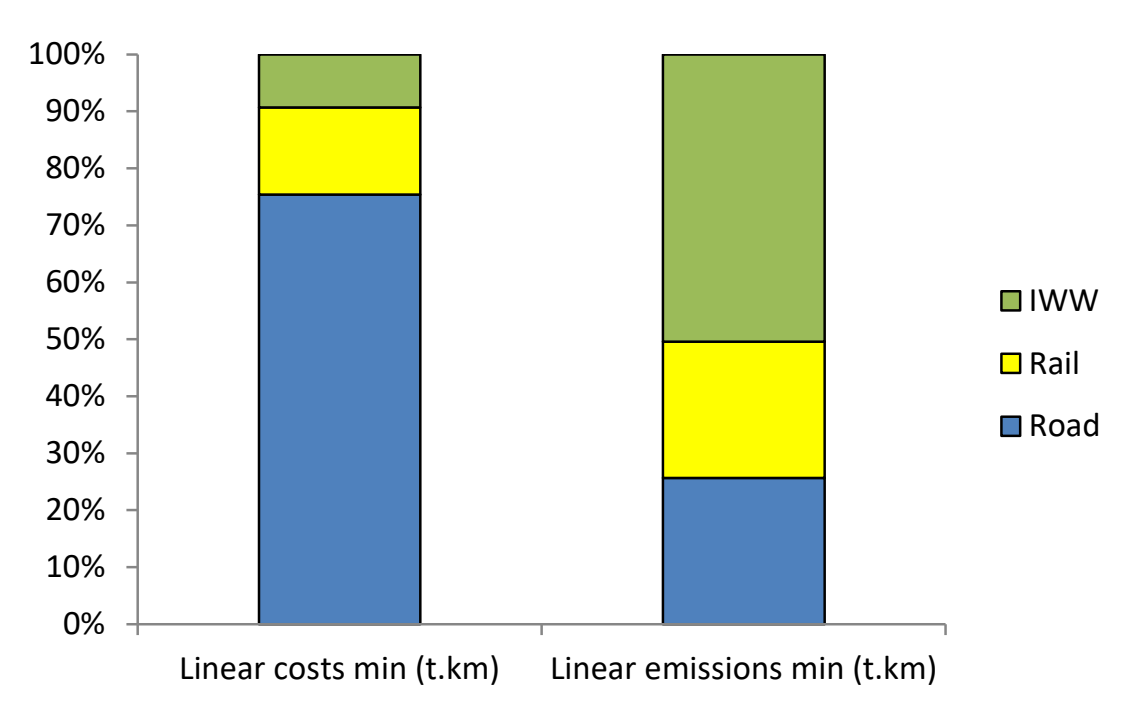

Figure 10: Flow distribution (t.km) for costs and emissions minimization in the linear case

In the cost minimization case, compared to the real modal split of the studied region, IWW flows are underestimated in favor of road flows. For 2011, the flow distribution in Belgium and in its neighboring countries (mainly the Netherlands, Germany and France), is on average $68 \%$ for road, $15 \%$ for rail and $18 \%$ for IWW transport (Eurostat, 2015). The difference between statistics data and the modal split of the model is explained by the fact that our origin-destination matrix 
only takes into account containerized flows, whereas IWW is generally used for bulk transportation (Central Commission for the Navigation of the Rhine, 2014). The actual modal split is also influenced by the awarded subsidies (Santos et al., 2015) which are not included in the current particular analysis. Furthermore, since the objective of the model is to minimize costs, only the cheapest mode of transport is used for transporting goods for a specific origin-destination pair. For origin-destination pairs with high volumes, the modal choice greatly influences the general market share distribution in t.km.

The predominance of rail transport under costs minimization is explained by the low value of the used rail cost function compared to IWW. In addition, there are not as many IWW as rail potential locations for terminals, which leads to increased distances using barges compared to trains. Under emissions minimization, the switch to more IWW transport is also explained by the values of the emission functions. Even if the distance by barge is longer than the distance by train, the small unit IWW emissions can compensate for the larger distances.

When costs are minimized, 5 IWW and 10 rail terminals are located. When emissions are minimized, 9 IWW and 6 rail terminals are open. Even if the type of terminal may change from costs to emissions minimization, more than half of the terminals are located exactly at the same place. This means that the policies aiming at optimizing costs and emissions are not totally in opposition, in terms of terminal location.

The model locates 15 terminals in 44 possible NUTS 3 regions. Most of the locations found by the model correspond to the real implementations of the main intermodal terminals in Belgium. However, some minor changes can also be noticed. These differences can be explained by the model's focus only on costs and emissions efficiency. However, other parameters also influence the location of terminals, such as political issues, land availability and equipment. The current model assumes as a potential terminal location any centroid of a region that can physically be accessed by train and IWW, which does not necessarily correspond to an already existing terminal.

Results of the model can be used by several stakeholders for retrieving policy information, among which infrastructure managers, intermodal terminal operators, intermodal transport operators, public authorities. 
Infrastructure managers can use the model to evaluate the flows between two intermodal terminals and to identify the potentially related capacity issues. The economic optimization highlights that a little bit more trains than the current situation are necessary for ensuring the optimal flow distribution between the terminal of Athus and the Port of Antwerp. This information is interesting to practically identify the possibilities at the operational level to deal with increased traffic of trains. Results of the model identify that around 180,000 tonnes (i.e. more or less 15,000 TEUs) of containerized goods should optimally be transported between Charleroi and Antwerp, compared to the 6,000 TEUs transshipped in 2015 between the terminal of Garocentre and the Port of Antwerp. This result can support infrastructure managers in their choice for developing and investing in this connection. These results can be compared with existing infrastructure capacities in order to identify if an infrastructure adaptation is necessary or possible. Nevertheless, it should be reminded that the results provided here above are based on 2010 flows and that the evolution of the demand since then should be taken into account.

Intermodal terminal operators can also gain insight from the results of the model in terms of flows, in order to compare the effects of economic and environmental objectives. Indeed, when the focus is on environmental issues related to climate change, the intermodal flows at the Port of Antwerp increase to 17,750,000 tonnes transported yearly. This means that the flows should be almost doubled compared to the optimal economic situation $(9,050,000$ tonnes). This result is interesting for terminal operators since they show that a policy focusing on $\mathrm{CO}_{2}$ emissions may increase the attractiveness of the terminal. However, it also shows that capacities of the terminal should be adapted consequently. Knowing terminal flow values under a specific policy is therefore useful to get advice on the possibility to support these flows from an infrastructural point of view.

Intermodal transport operators can also benefit from the results of the model by identifying how the flows that they transport vary if economic or climate change objectives are taken into account. This can be done at the terminal and at the link level between two terminals. For instance, at the Port of Antwerp (=terminal level), 4,740,000 tonnes of goods are transported by rail when operational costs are minimized against 7,510,000 tonnes when $\mathrm{CO}_{2}$ emissions are optimized. This implies the transportation of two times more flows than under the economic situation and requires thinking about the availability of enough vehicle capacities to transport these flows. IWW flows at the Port of Antwerp vary from 4,308,000 
tonnes when operational costs are optimized to $10,245,000$ tonnes when $\mathrm{CO}_{2}$ emissions are optimized. The variation of the IWW flows is even greater than the variation of the rail flows, which may lead to increased benefits for terminal transport operators. These values should nevertheless be compared to existing or possible extensions of the vehicle fleet. Another example consists in the connection between the Port of Antwerp and the region of Arlon. Under the minimization of operational costs, 335,000 tonnes of goods should optimally be transported by rail on this connection. When $\mathrm{CO}_{2}$ emissions are minimized, 387,000 tonnes of goods should use this rail connection. The difference between the flows under economic and environmental optimizations corresponds to two trains a week. The availability of this additional capacity can then be evaluated in practice by transport operators.

For public authorities, the optimizations in terms of economic and environmental objectives show that different kinds of intermodal terminal types should be located, depending on the followed objectives. These results provide a range of terminal locations and types when going from economic to environmental objectives. Our results show that more rail terminals (10/15) are located when operational costs are minimized, whereas more IWW terminals (9/16) are chosen when $\mathrm{CO}_{2}$ emissions are optimized. These outcomes may be useful for public authorities when deciding on supporting the development and implementation of additional rail or IWW terminal infrastructure, for instance with the awarding of public funding like subsidies for the building of terminals.

The application of the linear model to the Belgian case study shows that the cost effort for achieving a same amount of reduction of $\mathrm{CO}_{2}$ emissions becomes larger as one approaches the emissions optimality scenario. The chosen policy (costs or emissions minimization) leads to the location of different types of intermodal terminals (rail or IWW) and also influences the intermodal market share. Regardless of the pursued objective, intermodal transport is always used, even on small networks with reduced distances like Belgium. Finally, most of the locations found by the model correspond to the 15 main existing terminals in Belgium, or are located in the same region, which highlights the realism of the modeling approach. 


\subsubsection{Pareto front analysis}

The objective of the Pareto curve (figure 9) is to provide a set of Pareto optimal solutions but in practice and from the policy perspective, a specific solution has to be chosen among this set.

From the economic perspective, choosing one solution among the set of solutions provided by the Pareto front can be done by identifying the point until which the marginal operational costs resulting from the $\mathrm{CO}_{2}$ emissions decrease are lower than the marginal benefits obtained from reducing these emissions. Indeed, at this point, the economic gains resulting from the avoidance of $\mathrm{CO}_{2}$ emissions (and therefore the improvement of the impact on climate change) can compensate for the economic losses related to operational costs on the transportation system network.

In our model, the value of the externality itself has been taken into account (i.e. $\mathrm{CO}_{2}$ emissions) for building the Pareto curve. In order to make the cost-benefit analysis in relation to operational costs and $\mathrm{CO}_{2}$ emissions, the values of $\mathrm{CO}_{2}$ emissions have to be translated into monetary terms. Reference $\mathrm{CO}_{2}$ costs per tonne of $\mathrm{CO}_{2}$ equivalent are given by Ricardo AEA (2014). These outcomes originate from the meta-study of Kuik et al. (2009) which is based on the analysis of 26 models of available estimates of abatement costs. The avoidance costs are computed with the target to stabilize global warming at $2^{\circ} \mathrm{C}$ (maximum $\mathrm{CO}_{2}$ equivalent concentration in the atmosphere of $450 \mathrm{ppm}$ ), which corresponds to the goal currently supported and formalized in the 2016 Paris Agreement of the United Nations Framework Convention on Climate Change (UNFCCC). Table 11 provides the $\mathrm{CO}_{2}$ costs for avoidance objectives for the time horizons 2025 and 2050 .

\begin{tabular}{cccc}
\hline Time horizon & $\begin{array}{c}\text { Low value } \\
\left(€ / \mathrm{t} \text { of } \mathrm{CO}_{2}\right. \\
\text { equivalent })\end{array}$ & $\begin{array}{c}\text { Central value } \\
€ / \mathrm{t} \text { of } \mathrm{CO}_{2} \\
\text { equivalent }\end{array}$ & $\begin{array}{c}\text { High value } \\
€ / \mathrm{t} \text { of } \mathrm{CO}_{2} \\
\text { equivalent }\end{array}$ \\
\hline 2025 & 48 & 90 & 168 \\
2050 & 90 & 158 & 277 \\
\hline
\end{tabular}

Table 11: $\mathrm{CO}_{2}$ avoidance costs for 2025 and 2050

The marginal operational costs related to reductions of $\mathrm{CO}_{2}$ emissions are identified in table 12 . 


\begin{tabular}{ccr}
\hline From & To & $\begin{array}{r}\text { Marginal operational } \\
\text { costs } \\
\text { (in } € \text { ) }\end{array}$ \\
\hline Point 1 & Point 2 & 864,201 \\
Point 2 & Point 3 & $1,949,091$ \\
Point 3 & Point 4 & $3,081,668$ \\
Point 4 & Point 5 & $5,103,868$ \\
Point 5 & Point 6 & $7,108,696$ \\
Point 6 & Point 7 & $8,740,899$ \\
Point 7 & Point 8 & $10,954,746$ \\
Point 8 & Point 9 & $16,803,790$ \\
Point 9 & Point 2 & $39,446,017$ \\
\hline
\end{tabular}

Table 12: Marginal operational costs between the points of the Pareto curve

If the low and central values of the 2025 time horizon are used, marginal benefits resulting from the decrease of $\mathrm{CO}_{2}$ emissions from one point to another of the Pareto curve respectively have a value of $288,000 €\left(48 € / \mathrm{t} \mathrm{CO}_{2} * 6,000 \mathrm{t} \mathrm{CO}_{2}\right)$ and $540,000 €\left(90 € / \mathrm{CO}_{2} * 6,000 \mathrm{t} \mathrm{CO}_{2}\right)$. These marginal benefits obtained from the reduction of $\mathrm{CO}_{2}$ emissions are never high enough to compensate for the marginal operational costs due to the reduction of emissions. This means that under these $\mathrm{CO}_{2}$ pricings, it is economically more interesting for policy makers to focus on the extreme left point of the Pareto curve, i.e. the minimization of the operational costs on the network.

If the high value of the 2025 time horizon is used, marginal benefits resulting from the decrease of $\mathrm{CO}_{2}$ emissions have a value of $1,008,000 €(168 € / \mathrm{t}$ $\mathrm{CO}_{2} * 6,000 \mathrm{t} \mathrm{CO}_{2}$ ). The equilibrium solution happens at point 2 of the Pareto front. Indeed, going from point 1 to point 2 ensures higher benefits retrieved from the $\mathrm{CO}_{2}$ emissions reductions, than the related increase of operational costs on the transport network. Nevertheless, going further down on the Pareto curve is not economically interesting since the benefits of reducing emissions from point 2 to point 3 are lower than the required operational costs increase for making the transition.

Comparisons between marginal operational costs and marginal benefits of reducing $\mathrm{CO}_{2}$ emissions for the 2050 time horizon have been done in the same way as for the 2025 horizon. 
If the low value of the 2050 time horizon is used, the equilibrium solution is at point 1 , i.e. the solution which optimizes operational costs. This solution is the same as the solution selected for the 2025 time horizon with the low and central values of avoidance costs.

If the central and high values of the 2050 time horizon are used, the equilibrium solution is at point 2 . This point corresponds to the solution to select if high avoidance cost values of the 2025 time horizon are taken into account.

These results tend to show that for $\mathrm{CO}_{2}$ avoidance objectives related to the 2025 and 2050 time horizons, the economic optimal solutions among the set of solutions proposed by the Pareto front are more situated on the left side of the Pareto curve, i.e. next to the solution which optimizes operational costs.

These outcomes should to be balanced with several elements. First, the model only takes $\mathrm{CO}_{2}$ emissions into account for identifying the impact on climate change, whereas, even if $\mathrm{CO}_{2}$ is the main greenhouse gas, other emissions also contribute to the global warming effect. The inclusion of these emissions may lead to solutions closer to the right side of the Pareto curve. Second, the results of the choice for one or another solution of the Pareto curve is strongly related to the assumption regarding the value of $\mathrm{CO}_{2}$ emissions. Indeed, when different values of the reference ranges are used, different results regarding the solution to select are provided. This has been shown using the lowest, middle and highest values of the avoidance objectives related to $\mathrm{CO}_{2}$ avoidance costs for the time horizons 2025 and 2050.

Even if balancing the marginal costs and benefits of reducing $\mathrm{CO}_{2}$ emissions may be a useful tool for policy makers to select a specific solution on the Pareto curve, the uncertainty related to the valuation of avoidance costs of $\mathrm{CO}_{2}$ emissions should be carefully considered when dealing with this method. Indeed, the values attributed to $\mathrm{CO}_{2}$ have already considerably evolved between 2008 and 2014, and are still subject to potential quick modifications, because of the uncertainty in the process of estimation of the carbon price (Ricardo AEA, 2014).

This uncertainty is one of the reasons why we focused on the values of the externality itself $\left(\mathrm{CO}_{2}\right.$ emissions) in a bi-objective formulation, instead of dealing with the monetary valuation of the externalities (external costs). 


\subsubsection{With economies of scale - nonlinear approach}

This section identifies how the integration of economies of scale of intermodal transport impacts the results of the linear approach. The definitions of the cost and emission functions are described in section 5.8 (Eurostat, 2014; Janic, 2007; Janic, 2008; Mostert and Limbourg, 2016; PWC, 2003). The focus is on the two extreme cases of the Pareto curve, i.e. costs minimization and emissions minimization. The terminal configurations obtained under the linear approach are tested using the nonlinear parameters, in order to compare the flows obtained in the linear and nonlinear cases.

Figure 11 details the flow distribution between the different modes of transport under the nonlinear parameters.

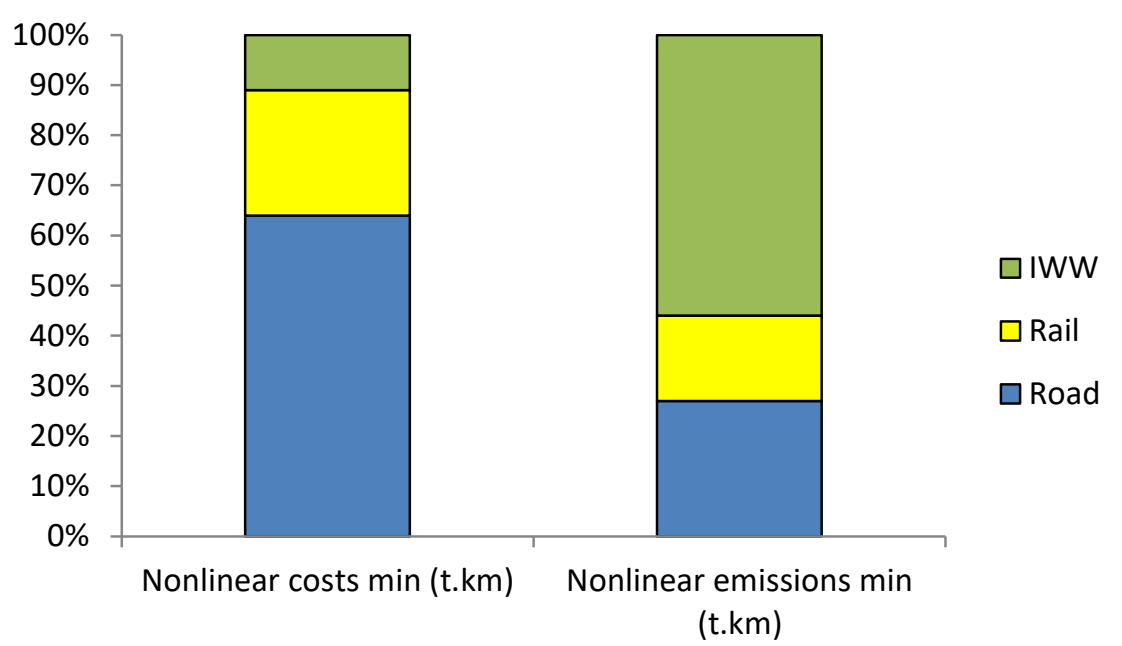

Figure 11: Flow distribution (t.km) for costs and emissions minimization in the nonlinear case

In the nonlinear case, going from costs to emissions minimization also leads to an increase of the use of intermodal transport. Inside intermodal transport, rail transport is preferred for achieving cost efficiency, but IWW is favored when it comes to optimize the environmental perspective. The chosen policy therefore influences the actual modal split. 
Between the linear and nonlinear approach, a market share increase of $10 \%$ for rail and $2 \%$ for IWW is observed under the costs minimization case. When economies of scale are integrated, $12 \%$ of the road flows are thus transferred to the intermodal market share. For the emissions minimization case, a market share decrease of $7 \%$ for rail and an increase of $6 \%$ for IWW are identified when taking into account economies of scale, i.e. a transfer of $1 \%$ from road to intermodal market share. In the minimum emissions case, the main flow transfer between the linear and nonlinear approach is observed inside the intermodal market share, rather than between road and intermodal transport.

Taking into account economies of scale in the model encourages a more intensive consolidation of flows, leading to reduced global costs and emissions for intermodal transport, with a higher use rate of this mode. This explains the increased intermodal market share, when going from the linear to the nonlinear approach.

The number and size of barges used under the nonlinear approach differs from costs to emissions minimization. Indeed, around three times more barges are used when emissions are minimized than when costs are minimized. This is coherent with the observed increase of IWW market share from costs to emissions minimization. Moreover, the split between the different types of barges is also different. Under costs minimization, $3 \%$ of the barges are small, $71 \%$ are medium and $26 \%$ are large. Under emissions minimization, small barges represent $47 \%$ of the IWW flows, medium barges correspond to $37 \%$ and large barges have $16 \%$ of the IWW market.

Under the emission minimization policy, more IWW terminals are open, all of which not necessary accessible through medium barges (geographical constraints), which may explain the larger part of used small barges. These results are interesting for infrastructure managers and barge operators, since they show that the chosen policy (economic or environmental) influences the way in which networks and vehicles should be planned in the future.

For both objective functions, in the linear and nonlinear cases, the model advises the use of intermodal transport. This result shows that, to the contrary of what is recommended by the European Commission in its White Paper (European Commission, 2011), intermodal transport is also viable and could therefore also be used on short distances. Indeed, most of the distances of the case study on 
Belgium are below $300 \mathrm{~km}$. This insight has already been highlighted by Bouchery and Fransoo (2015) who state that high volumes and short PPH distances make intermodal transport attractive on short and medium distances. The importance of short PPH distances in terms of intermodal competitiveness, especially from the perspective of externalities, has also been underlined in Mostert and Limbourg (2016). The conclusions of Janic (2008) showing that, in some cases, the internalization of external costs may lead to a lower attractiveness of intermodal transport, rather than when only operational costs are considered, reinforces the need for particularly considering short PPH distances. As Zhang et al. (2013) and Zhang et al. (2015), our results also show the strong link between the terminal network configuration and the amount of $\mathrm{CO}_{2}$ emissions.

To summarize, in the limited case of Belgium and its neighborhood, the nonlinear and linear approaches both encourage more intermodal transport in order to reduce the environmental impact of transport. Furthermore, introducing economies of scale of intermodal transport in the modeling modifies the modal split, favoring intermodal transport both for costs and emissions minimization.

\subsubsection{Computational performance}

The optimization steps were performed on a workstation (Windows 10 Pro, Intel Xeon $2.1 \mathrm{GHz}, 32 \mathrm{~GB}$ of RAM) with CPLEX 12.63.

The problem developed in this paper is complex to solve. The model uses an origin destination matrix constituted by 88 origin and 88 destination nodes. The number of flow variables is $88^{2}$ for road, $2 * 88^{3}$ for intermodal rail, and $2 * 88^{3}$ for intermodal IWW transport. As Ernst and Krishnamoorthy (1998), the model uses variables of maximum size $O\left(n^{3}\right)$. The problem size, in terms of the number of variables, is thus reduced by a factor $\mathrm{n}$, compared to most of the hub location models Farahani et al. (2013), where flows are expressed using variables with four indices.

For the example under study, the linear single cost minimization problem is easier to solve than the linear single emission minimization problem. The single cost minimization location-allocation model is solved in 69 seconds. The single emission minimization location-allocation problem is solved in about 80 times the time required for the single cost case. The difference in computational times may be explained by the unit emission values, which allow for more use of the three 
modes of transport in the emission rather than in the cost minimization case, in which road transport is clearly favored. Whatever the optimized objective, we therefore expect shorter computational times, as long as the differences between the unit modal parameters increase.

Solving the cost minimization problem, and then determining the corresponding optimal emission value (i.e., defining the Pareto optimal solution) results in a computational time of 983 seconds. It is 14 times the time required for finding a solution which is optimal in terms of cost.

Having generated the starting point of the Pareto curve, the inclusion of the additional epsilon-constraint leads to run times varying between 2 and 14 times the time required for the optimization without the additional constraint on the emissions. Each point of the Pareto curve is generated in times between 1,912 and 14,069 seconds. The average time for solving one point of the Pareto curve is 7,339 seconds. The standard deviation of the solving times is 4.06 .

When dealing with economies of scale, a single allocation problem is solved and the resolution times are less than 450 seconds.

Since our model solves a problem at the strategic level of transport planning, the resolution times do not limit its usefulness for decision makers. At the NUTS 3 level, the model allows solving location-allocation problems for a small geographical region like Belgium. In order to obtain similar computational performances for bigger geographical areas, the level of aggregation of flows should be increased. If larger instances with the same degree of disaggregation are analyzed, further solution methods (Sörensen et al., 2012) will be needed.

\subsubsection{Sensitivity analysis}

The goal of this section is to test the robustness of the model, by identifying whether the results change substantially, when the input parameters are modified. Sensitivity analysis is performed on the parameters related to costs, emissions and the number of terminals.

\subsubsection{Costs}

Table 13 compares the results of the linear cost minimization case analyzed here above (table 10) with scenarios of $10 \%$ increase and decrease of the initial parameter values. 


\begin{tabular}{|c|c|c|c|c|c|c|c|}
\hline Cost min & $\begin{array}{l}\text { Relative } \\
\text { cost } \Delta\end{array}$ & $\begin{array}{l}\text { Absolute } \\
\text { road flow } \\
\Delta\end{array}$ & $\begin{array}{l}\text { Absolute } \\
\text { rail flow } \\
\Delta\end{array}$ & $\begin{array}{l}\text { Absolute } \\
\text { IWW } \\
\text { flow } \Delta\end{array}$ & $\begin{array}{l}\text { Rail } \\
\text { termi- } \\
\text { nal }\end{array}$ & $\begin{array}{l}\text { IWW } \\
\text { termi- } \\
\text { nal }\end{array}$ & $\begin{array}{l}\text { Same } \\
\text { locations }\end{array}$ \\
\hline $\begin{array}{l}\text { Transsh.: } \\
+10 \%\end{array}$ & $+1.16 \%$ & $+2.89 \%$ & $-1.36 \%$ & $-1.53 \%$ & 10 & 5 & $15 / 15$ \\
\hline $\begin{array}{l}\text { Transsh.: } \\
-10 \%\end{array}$ & $-1.23 \%$ & $-0.91 \%$ & $+0.75 \%$ & $+0.16 \%$ & 10 & 5 & $14 / 15$ \\
\hline $\begin{array}{l}\text { IWW } \\
\text { cost: } \\
+10 \%\end{array}$ & $+0.17 \%$ & $+1.16 \%$ & $+1.49 \%$ & $-2.65 \%$ & 11 & 4 & $14 / 15$ \\
\hline $\begin{array}{l}\text { IWW } \\
\text { cost: } \\
-10 \%\end{array}$ & $-0.34 \%$ & $-1.39 \%$ & $-6.24 \%$ & $+7.63 \%$ & 9 & 6 & $14 / 15$ \\
\hline $\begin{array}{l}\text { Road } \\
\text { cost: } \\
+10 \%\end{array}$ & $+8.01 \%$ & $-3.05 \%$ & $+3.22 \%$ & $-0.17 \%$ & 11 & 4 & $14 / 15$ \\
\hline $\begin{array}{l}\text { Road } \\
\text { cost: } \\
-10 \%\end{array}$ & $-8.23 \%$ & $+5.05 \%$ & $-1.98 \%$ & $-3.07 \%$ & 11 & 4 & $13 / 15$ \\
\hline $\begin{array}{l}\text { Rail } \\
\text { cost: } \\
+10 \%\end{array}$ & $+0.36 \%$ & $+0.03 \%$ & $-7.15 \%$ & $+7.12 \%$ & 9 & 6 & $14 / 15$ \\
\hline $\begin{array}{l}\text { Rail } \\
\text { cost: } \\
-10 \%\end{array}$ & $-0.56 \%$ & $-0.38 \%$ & $+3.02 \%$ & $-2.64 \%$ & 11 & 4 & $14 / 15$ \\
\hline
\end{tabular}

\section{Table 13: Sensitivity analysis of the cost parameters}

The cost and flow variations are the respective relative and absolute differences in total costs and flows, compared to the cost minimization scenario. For instance, an increase of $10 \%$ of the transshipment cost leads to total costs relatively $1.16 \%$ higher than the ones obtained in the cost minimization scenario. Regarding flows, an increase of $10 \%$ of the transshipment cost leads to an absolute increase of $2.89 \%$ of the road market share, compared to the cost minimization scenario. The relative variation of the total costs is smaller than the relative variation of the cost parameters. Road external cost is the parameter that mostly influences the modification of total costs (respectively $+8.01 \%$ and $-8.23 \%$ when road costs are 
increased and decreased). This is expected since road activities have the greater modal share in the initial scenario and they influence the model in direct road transfers, but also during the PPH stages of intermodal transport.

When road costs are modified, most of the flow distribution changes are observed between road and intermodal market shares. However, when the costs of intermodal long-haul modes are varied, a transfer of flows inside the intermodal market share is observed. This result highlights the risk of switch of modes inside the intermodal market share, rather than between intermodal and all-road transport (Macharis and Pekin, 2009). As expected, the general flow distribution is affected by changes in cost factors. However, the absolute variation never exceeds $8 \%$. The terminal locations mainly remain the same, in each of the studied scenarios. However, some slight switch in terminal type is noticed, depending on the cost variation under study. At most two terminals are different from the initial solution. When a different terminal is located, only two different locations are chosen, whatever the scenario. The terminal location, type and flow distribution thus seem robust to cost variations.

Table 14 provides the aggregate elasticities for an increase of $10 \%$ of the road, rail and IWW transport costs (flows in t.km).

\begin{tabular}{lllll}
\hline & \multicolumn{4}{l}{ Cost increase of 10\% } \\
\cline { 2 - 5 } & & Road & Rail & IWW \\
\hline t.km & Road & -0.51 & 0.25 & 0.07 \\
& Rail & 1.93 & -6.37 & 0.89 \\
& IWW & -0.26 & 6.20 & -3.60 \\
\hline
\end{tabular}

Table 14 : Aggregate elasticities of road, rail and IWW

These elasticities confirm the previous results showing that increasing the cost of one mode decreases the use of this mode in t.km. Results highlight the important link between the rail and the IWW sector. Indeed, an increase of the rail cost has a significant impact on the flows transported by IWW. The elasticity related to the impact of rail costs on rail demand is high compared to the elasticities observed in most papers of the literature (see Beuthe et al., 2014 for a review of elasticities in multi-mode studies). These strong elasticities may be explained by the all-ornothing characteristic of the model and the aggregation level of the data which imply that important flows of goods can be transferred from one mode to the least expensive mode in case of cost variations. 
Results show that increasing road costs may reduce the intermodal flows transported by IWW, highlighting that the pre- and post-haulage distance values by road play a more significant role in intermodal IWW than in intermodal rail transport. This can be explained by the fact that under the economic optimization, more rail than IWW terminals are located, which reduces the PPH distances of intermodal rail compared to intermodal IWW transport.

Elastic demands are observed for rail and IWW when rail costs are modified, for rail when road costs are modified, and for IWW when IWW costs are modified. As several studies in the literature (Beuthe et al., 2014), inelastic demand is observed for road transport.

\subsubsection{Emissions}

Table 15 compares the results of the linear emission minimization case analyzed here above (table 10) with scenarios of $10 \%$ increase and decrease of the initial parameter values.

The relative variation of the total emissions is smaller than the relative variation of the emission parameters. The greatest gap is also observed for the scenarios where road emissions are modified. Global emissions are thus more sensitive to road than to other modes of transport. The flow distribution varies according to the scenario but the changes are limited in most of the cases. Larger market share variations are only observed in the scenario where rail emissions are decreased. Flow transfers mainly occur inside the intermodal market share, between rail and IWW transport. These results highlight again the risk of flow transfers inside the intermodal market share, rather than between road and a more environmentally friendly mode. Most of the terminal locations and types remain the same, whatever the scenario. The identical structure of terminal locations and types is observed in three out of eight scenarios. In four other cases, only one rail terminal is placed at another location (identical for each of these four scenarios). When rail emissions are reduced, three IWW terminals are replaced by rail terminals, which is coherent with the observed market share variation. The terminal location, type and flow distribution thus seem robust to emission variations. 


\begin{tabular}{|c|c|c|c|c|c|c|}
\hline $\begin{array}{l}\text { Emission } \\
\text { min }\end{array}$ & $\begin{array}{l}\text { Relative } \\
\text { emission } \\
\Delta\end{array}$ & $\begin{array}{l}\text { Absolute } \\
\text { road flow } \\
\Delta\end{array}$ & $\begin{array}{l}\text { Absolute } \\
\text { rail flow } \\
\Delta\end{array}$ & $\begin{array}{l}\text { Absolute } \\
\text { IWW } \\
\text { flow } \Delta\end{array}$ & $\begin{array}{l}\text { Identical } \\
\text { rail } \\
\text { terminals }\end{array}$ & $\begin{array}{l}\text { Identical } \\
\text { IWW } \\
\text { terminals }\end{array}$ \\
\hline $\begin{array}{l}\text { Transsh.: } \\
+10 \%\end{array}$ & $+0.58 \%$ & $+1.66 \%$ & $-0.34 \%$ & $-1.32 \%$ & $5 / 6$ & $9 / 9$ \\
\hline $\begin{array}{l}\text { Transsh.: } \\
-10 \%\end{array}$ & $-0.61 \%$ & $-1.69 \%$ & $+1.98 \%$ & $-0.29 \%$ & $6 / 6$ & $9 / 9$ \\
\hline $\begin{array}{l}\text { IWW } \\
\text { emission: } \\
+10 \%\end{array}$ & $+1.06 \%$ & $+1.97 \%$ & $+0.30 \%$ & $-2.27 \%$ & $5 / 6$ & $9 / 9$ \\
\hline $\begin{array}{l}\text { IWW } \\
\text { emission: } \\
-10 \%\end{array}$ & $-1.12 \%$ & $-0.43 \%$ & $-1.17 \%$ & $+1.60 \%$ & $6 / 6$ & $9 / 9$ \\
\hline $\begin{array}{l}\text { Road } \\
\text { emission: } \\
+10 \%\end{array}$ & $+6.96 \%$ & $-3.10 \%$ & $+3.24 \%$ & $-0.14 \%$ & $6 / 6$ & $9 / 9$ \\
\hline $\begin{array}{l}\text { Road } \\
\text { emission: } \\
-10 \%\end{array}$ & $-7.23 \%$ & $+3.54 \%$ & $-2.61 \%$ & $-0.93 \%$ & $5 / 6$ & $9 / 9$ \\
\hline $\begin{array}{l}\text { Rail } \\
\text { emission: } \\
+10 \%\end{array}$ & $+1.11 \%$ & $+2.64 \%$ & $-3.27 \%$ & $+0.63 \%$ & $5 / 6$ & $9 / 9$ \\
\hline $\begin{array}{l}\text { Rail } \\
\text { emission: } \\
-10 \%\end{array}$ & $-1.38 \%$ & $-2.30 \%$ & $+12.97 \%$ & $-10.67 \%$ & $6 / 6$ & $6 / 9$ \\
\hline
\end{tabular}

Table 15: Sensitivity analysis of the emission parameters

\subsubsection{Number of terminals}

The model assumes that the number of terminals is given and that it is a fixed parameter. This assumption has implications on the resulted terminal locations and types and on the modal split. In order to test the implications of this assumption, sensitivity analysis of the results to variations of the maximum number of allowed terminals is performed. 
In order to test the parameter $p$ and its effect on the model, we varied its value from 10 to 16 terminals, both on the linear and nonlinear approaches. We also tested two extreme cases, i.e. a very small (2) and a very high (24) number of located terminals. Results show that the model is robust in terms of terminal locations. Indeed, when allowing $p+1$ terminals to be opened, the model locates exactly the same terminals as in the $p$-configuration, and opens an additional terminal. The locations and types of terminals are thus consistent, whatever the value of $p$.

Under the linear cost optimization, the road market share progressively decreases with the increasing number of terminals. This behavior is understandable since locating more terminals reduces the PPH costs of intermodal transport, and thus increases its competitiveness. A maximum of $8 \%$ of the road flows are transferred to the intermodal market share, between the location of 2 and 24 terminals. This means that, on several connections, even by increasing the number of terminals, i.e. by decreasing the PPH distances, the long-haul costs of rail and IWW are not low enough to compensate for the transshipment and PPH costs of intermodal transport. This modal transfer of $8 \%$ from road to more environmentally-friendly modes is far from the targeted flow transfers of $30 \%$ or $50 \%$ expressed in the European White Paper on Transport (European Commission, 2011).The main absolute transfers of flows happen between road and rail transport. Intermodal IWW and rail transport are similar in terms of cost structure. Flows are thus transferred from road to rail and not IWW, because rail long-haul costs are more attractive. In addition, rail terminals can be implemented at much more locations than IWW terminals (due to geographical constraints), which enhances their accessibility.

For the nonlinear cost optimization, a decrease of the road market share to the benefit of intermodal transport is observed until $p=13$, i.e. less than the number of currently existing main terminals in Belgium. For every further additional terminal, the ratio between the intermodal and road market share remains the same. In the nonlinear case, there is thus some limitation in the flow exchange between road and intermodal transport. At some point, flows are simply transferred from one to another terminal, highlighting the self-cannibalization issue of intermodal transport. Results show that this phenomenon can happen either between the same type of terminals or between rail and IWW terminals. The absolute difference of road market share between the smallest and the highest amount of located terminals is bigger for emission (22\%) than for cost 
optimization (8\%). The modal split between road and intermodal transport is thus more sensitive to the number of terminals, when emissions are optimized, rather than when costs are optimized.

In the linear emission optimization, the flow exchanges happen between the three modes of transport. Flows are first mainly transferred from road to IWW, but when reaching a number of 15 terminals, only additional rail terminals are open. Some IWW flows are thus replaced by rail flows, which increases the rail market share to the detriment of IWW. Again, this underlines the risk of flow exchange inside intermodal transport rather than between road and intermodal transport.

For the nonlinear emission minimization, the intermodal market share also increases with the increasing number of terminals. An increase of the IWW market share is observed until $p=14$, where this market share starts to decrease. This is explained by reduced flows passing through certain terminals, which leads to barges less charged and thus to reduced economies of scale.

It might be expected that changing the maximum number of terminals when fewer terminals are located modifies more significantly the results. For this purpose, an analysis of the outcomes when at most 1, 2 or 3 terminals can be located is also studied.

The terminal location is stable when few terminals are located. As when a large number of terminals is located, allowing $p+1$ terminals to be opened implies the location of the same terminals as in the $p$-configuration with the opening of an additional terminal.

In the cost minimization, the same kinds of results are observed for a small number as for a large number of terminals. Indeed, allowing more terminals progressively decreases the road market share to the benefit of intermodal transport.

For the emission minimization, other results are observed. Indeed, when going from 1 to 2 terminals, a decrease of the relative market share of intermodal transport in t.km is observed (from 58\% to 55\%) whereas the proportion of tonnes transported by intermodal transport increases (from 50\% to 53\%). This means that the reduction of the intermodal market share in t.km (flows vary from $5,155^{*} 10^{6}$ to $4,243^{*} 10^{6}$ t.km) is due to the reduction of the kilometers rather than to the reduction of the tonnes (flows vary from $56^{*} 10^{6}$ to $61 * 10^{6}$ t) transported by 
intermodal transport. This result demonstrates that adding terminals allows decreasing the long-haul travel by intermodal transport. This contradictory behavior between intermodal market share in tonnes and in t.km is observed when modifying a small number but not a large number of terminals. As expected, this means that increasing the number of terminals has a larger effect on distance reductions by rail or IWW when a small rather than when a large number of terminals is located.

\subsection{Conclusions}

This research develops and solves a new bi-objective location-allocation optimization model for intermodal transport under economies of scale. The model includes three modes: road, intermodal rail and intermodal IWW transport. It focuses on a bi-objective formulation, for identifying the trade-off between economic and environmental goals. The latter are estimated through $\mathrm{CO}_{2}$ emissions, main greenhouse gas responsible for climate change. The economies of scale of intermodal transport can also be taken into account, using different sizes of vehicles for IWW and nonlinear cost and emission functions for rail.

The characteristics of the model allow a better matching with reality, and provide interesting insights to the stakeholders of the freight transportation chain. Indeed, the obtained results in terms of modal split and intermodal terminal location and type can be used by public authorities, infrastructure and terminal managers, or road, rail and IWW carriers to plan their strategic future decisions in alignment with environmental perspectives.

A case study on Belgium reveals interesting information regarding the impact on flow distribution, terminal type, and terminal location, of the followed economic or environmental policy, of the consideration or not of economies of scale, of the structure of costs and emissions, and of the number of located terminals.

The case study shows that different terminal types and modal splits are obtained, depending on the economic- or environmental-oriented policy that is considered. Similarly, the chosen policy affects the modal split inside the intermodal market share. Locations may change according to the economic or environmental desired outcome, but generally most of the terminals remain the same. 
No matter if economies of scale are integrated or not, an increase of the intermodal market share is observed going from cost to emission minimization. An increased use of intermodal transport is thus suggested for achieving the environmental objectives related to climate change. Results of the linear and nonlinear cases underline the viability and interest of using intermodal transport on short distances. When economies of scale are integrated, more road flows are transferred to the intermodal market share, compared to the linear case.

Slight modifications of the unit costs and emissions of the different modes of transport do not provide significant impacts on the terminal location and flow distribution. This shows the robustness of the model but also highlights the issue that modifying slightly the performance of one mode in terms of costs or emissions (for instance through improved technologies) does not necessary lead to an important modification of the modal split. Moreover, results of the sensitivity analysis also illustrate that modifying road costs or emissions leads to flow transfers between road and intermodal transport, whereas modifications of rail or IWW costs or emissions generate flow exchanges between rail and IWW, inside the intermodal market share.

The terminal locations remain stable when the maximum number of allowed terminals is modified. The modal split behavior is however different, when economies of scale are taken into account or not. Indeed, with linear costs and emissions, increasing the number of terminals continuously increases the intermodal market share, due to reduced PPH distances. When economies of scale are modelled, the decrease of the road market share is observed only until a certain number of terminals. After this ceiling, flows are transferred from one to another terminal, highlighting the risk of self-cannibalization of terminals. Indeed, more terminals means less flows through them, lower possibilities of consolidation, and thus lower economies of scale.

The tests on the Belgian case study reveal that intermodal transport should be more used when environmental goals are followed. These outcomes confirm and support the usefulness of the European policies which encourage the transfer of road freight to more environmentally friendly modes such as rail or IWW. However, the results also underline the risk of flow transfers inside the intermodal market share, rather than between road and intermodal transport. 
This research can be extended in future studies, by using other types of externalities to represent the environmental impact. Other applications of the model can also be developed, such as the analysis of new policy scenarios and the assessment of the impact of improvement in environmental friendliness of specific modes. The model can also be applied to another geographical area, where intermodal network design is still in progress. The strategic evaluation in terms of economic and environmental perspective of a new terminal location makes thus full sense in these areas in need of intermodal network design expertise.

\subsection{Appendix A: Solution methodology}

This section aims at presenting the methodological issues used in the solution of the bi-objective model with economies of scale of intermodal transport. The resolution method of the bi-objective model is first presented. The way in which nonlinear economies of scale are dealt with is then explained.

\subsubsection{Bi-objective optimization}

The bi-objective terminal location-allocation model is a particular multi-objective problem. The resolution of such kinds of problems leads to the generation of socalled Pareto optimal (or non-dominated) solutions, i.e. solutions for which none objective function value can be improved without worsening the value of another one.

We solve the bi-objective problem by improving the exact $\mathcal{E}$-constraint resolution technique of Chankong and Haimes (1983). The method consists in transforming a multi-objective problem into single-objective optimization by only keeping one objective function to optimize, and introducing the other objective function as constraints of the model, lower or equal to a value $\varepsilon$ (Rangaiah, 2009). In this study, we introduce the $\mathrm{CO}_{2}$ emission function as a constraint of the costs minimization problem. Instead of classically generating the $\varepsilon$ values by determining a range of values in which it should vary, we generate the next $\varepsilon$ value, directly based on the previous obtained optimal solution. 
Algorithm 1 represents the methodology used for obtaining the different Paretooptimal solutions of the bi-objective model thanks to the exact $\mathcal{E}$-constraint method. Here are some details about its content:

- $\mathrm{MC}(\mathrm{E})$ (respectively $\mathrm{MC}(\mathrm{E}))$ is the following model:

Min $f_{\text {costs }}$

s.t. $\quad(3)-(21)$

$f_{\text {emissions }}<E$ (respectively $f_{\text {emissions }} \leq E$ )

- $\mathrm{ME}(\mathrm{C})$ is the model:

Min $f_{\text {emissions }}$

s.t. $\quad(3)-(21)$

$f_{\text {costs }} \leq C$

- $\quad i$ is the index of the step of the algorithm.

Solve $\operatorname{ME}(\infty)$

if $\mathrm{ME}(\infty)$ has a solution then

$\operatorname{minE} \leftarrow$ Value $\left[f_{\text {emissions }}\right]$

Solve MC'(minE)

$\mathrm{C}^{\prime} \leftarrow$ Value $\left[f_{\text {costs }}\right]$

$\mathrm{i}=0$

$\mathrm{E}[0]=\infty$

while $(\mathrm{E} \geq \min \mathrm{E})$ do

Solve $\mathrm{MC}(\mathrm{E})$

if $\mathrm{MC}(\mathrm{E}[\mathrm{i}])$ has a solution then

$\mathrm{C}[\mathrm{i}] \leftarrow$ Value $\left[f_{\text {costs }}\right]$

Solve $\operatorname{ME}(\mathrm{C}[\mathrm{i}])$

$\mathrm{E}[\mathrm{i}] \leftarrow$ Value $\left[f_{\text {emissions }}\right]$

$\mathrm{P}[\mathrm{i}]=(\mathrm{C}[\mathrm{i}], \mathrm{E}[\mathrm{i}])$

$\mathrm{i} \leftarrow \mathrm{i}+1$

end if

$\mathrm{E}[\mathrm{i}] \leftarrow$ Value $\left[f_{\text {emissions }}\right]-\mathrm{s}$

end while

$\mathrm{P}[\mathrm{i}]=\left(\mathrm{C}^{\prime}, \min \mathrm{E}\right)$

else

Stop

end if

Algorithm 1: Generation of Pareto optimal solutions

A minimization of emissions is performed, with costs set to infinite. The resulting emission value is assigned to the variable minE. The minimum cost related to this minimum amount of emissions minE is then computed and assigned to the variable $C^{\prime}$. We thus have one of the two extreme points of the Pareto curve 
$\left(C^{\prime}, \min E\right)$, which corresponds to the minimum possible emissions. The algorithm then initializes the value of the emissions to infinite. The loop starts with the generation of the other extreme point of the Pareto curve, with the minimum possible costs. For this purpose, costs are minimized and no constraints are applied on the emissions. Even if this solution is optimal in terms of costs, it is not necessarily optimal for the minimization of emissions. To ensure Pareto optimality, the model where emissions are minimized subject to the fact that costs are equal to or lower than the obtained cost value is thus solved. The other extreme point of the Pareto curve $(C[0], E[0])$ is thus generated. $E[0]$ is the first value of epsilon that is identified. Based on the optimal solution at the previous iteration, another Pareto optimal solution is generated by solving the model where the costs are minimized, subject to the fact that the emission values should be strictly lower than the ones obtained at the preceding iteration of the optimization (E[0]). Solving this model gives a cost value $C[1]$. To ensure the Pareto optimality, the same model is again solved by minimizing emissions, subject to the fact that the costs are less or equal to $C[1]$. A second Pareto optimal solution $(C[1], E[1])$ is then generated. $E[1]$ is the second identified epsilon value. The value of $C[1]$ is higher than the one of $C[0]$ but the value of $E[1]$ is smaller than the one of $E[0]$. One thus goes down along the Pareto front.

The loop goes on until the minimum value of emissions by the step size $s$ is reached. This step size is used in order to avoid generating infinity of Pareto optimal solutions.

\subsubsection{Piecewise linear functions}

In the literature, economies of scale of transport are generally represented using a classical discount factor for the axes with high quantities of flows. The problem of this modeling is that this discount factor is often fixed, whatever the quantity transported, and does not really reflect the benefits generated for different levels of utilization (Kimms, 2006). There is therefore a need to integrate economies of scale in a different way. To account for economies of scale of rail transport, we use nonlinear functions of the weight transported. The concave increasing cost terms are approximated by a piecewise-linear function so as to permit the use of linear programming solvers for its resolution. 
Two methodological steps must be performed in order to generate the piecewise linear function: identification of the piecewise linear function and modeling of the piecewise linear function.

Identifying the piecewise linear function consists in determining the different segments that define the piecewise linear function, by isolating several breakpoints. The piecewise linearization is done in the simplest way (Belotti et al., 2012), by cutting the function in segments of equal size. This is performed by choosing a set of breakpoints, uniformly distributed in the interval, between the minimum and maximum flows that are transported yearly.

The piecewise linear function is modeled using the multiple choice model introduced by Jeroslow and Lowe (1984).

$\sum_{k=1}^{d} w^{k}=x$

$\sum_{k=1}^{d} z_{k}=1$

$b^{k-1} z_{k} \leq w_{k} \leq b^{k} z_{k} \quad ; \quad \forall k=1, \ldots, d$

$\sum_{k=1}^{d}\left(m_{k} w_{k}+a_{k} z_{k}\right)=y$

$z_{k} \in\{0,1\} ; \forall k=1, \ldots, d$

The modeling is based on the introduction of two additional sets of variables. The value of $w^{k}$ is equal to $x$, if $x$ lies in the $k^{\text {th }}$ interval and 0 otherwise. The value of $z_{k}$ is equal to 1 if $x$ lies in the $k^{\text {th }}$ interval and 0 otherwise. The combination of constraints (24) and (26) ensures that only one $w^{k}$ is equal to $x$, and that this happens only if $x$ is in the $k^{\text {th }}$ interval. The combination of (25) and (28) makes sure that only one $z_{k}$ is equal to 1 and that this happens when $x$ is in the $k^{\text {th }}$ interval. Finally, constraint (27) determines the value of $y$ as the linear combination of $m_{k}$ and $a_{k}$, where $m_{k}$ is the slope of the $k^{\text {th }}$ segment and $a_{k}$ is the interception of this segment with the $y$-axis, when it is extended until reaching the $y$-axis. 


\subsection{Appendix B: Cost and emission functions of the linear approach}

Unit costs functions for road are based on Janic (2007) and Janic (2008). Unit road operational costs for long-haul travels $\left(C_{i m}^{L}\right)$ are computed as $0.2676 d_{i m}^{-0.278} / \mathrm{t} . \mathrm{km}$, where $d_{i m}$ stands for the road distance between origin $i$ and destination $j$ and an average load factor of 0.85 (European Commission, 2001) is assumed. Unit road operational costs for collection/distribution travels $\left(C_{i j}^{P}\right)$ are equal to $0.3791 d^{-0,278}$, with a considered load factor of 0.6 (European Commission, 2001). Unit road costs are nonlinear with the distance traveled.

Unit IWW costs $\left(C_{j k}^{t W}\right)$ for a barge of size $t$ are based on a study of PWC (2003). In this approach, a single type of barge is considered. In this approach, a single type of barge is considered. The capacity of this boat is determined as the maximum capacity of the European Conference of the Ministers of Transport (ECMT) class Va of barges, i.e. 3,000 t. The IWW costs for this average size barge are estimated to $0.02285 € /$ t.km., i.e. $68.55 € /$ barge.km.

Unit rail costs $\left(C_{j k}^{R}\right)$ in $€ /$ t.km are given in Janic (2008) and are estimated using the following formula (29).

$$
\frac{0.8899+0.0275 s_{j k}+0.0024\left(\frac{s_{j k}}{\ln \left(s_{j k}\right)}\right)}{s_{j k}}
$$

$s_{j k}$ refers to the rail distance between terminals $j$ and $k$. This function has been obtained by considering several hypotheses such as an average load factor of 0.5 per train (Hoen et al., 2010, Hoen et al., 2014). Please refer to Janic (2008) for the detailed explanation of the numerical values of other parameters.

Transshipment costs $\left(C_{j}^{T}\right)$ are based on Janic (2007) and are assumed, for both rail and IWW, equal to $2.8 € / \mathrm{t}$ (Janic, 2007).

Emission functions are based on the NTM methodology. They are obtained from the work of Hoen et al. (2010) and Hoen et al. (2014) for road, rail and water transportation. 
Unit road transport emissions $\left(E_{i m}^{L}\right)$ for long-haul travels and for collection/distribution travels $\left(E_{i j}^{P}\right)$ are expressed in $\mathrm{kg}$ of $\mathrm{CO}_{2} / \mathrm{t} . \mathrm{km}$ and are determined by expression (30).

$$
\frac{\gamma \cdot C^{F} \cdot E^{F}}{K^{T} \cdot \lambda}
$$

$K^{T}$ is the maximum capacity of one truck and $\lambda$ is the load factor of the truck. Emissions also depend on the fuel consumption $\left(C^{F}\right)$, on a terrain factor $(\gamma)$ which reflects the different consumption levels over hilly or flat terrains, and on the fuel emissions $\left(E^{F}\right)$. It is assumed that a single truck transports two twenty feet equivalent units ( 2 TEU). Since a TEU contains on average 12 tonnes of freight, $K^{T}$ is thus equal to 24 tonnes. A load factor of 0.85 is considered for long-haul travels and 0.6 for short-haul travels (European Commission, 2001). Fuel consumption is assumed to be equal to $0.33991 / \mathrm{km}$ for long-haul travels and $0.4175 \mathrm{l} / \mathrm{km}$ for short-haul travels. A terrain factor of 1.05 is considered. Fuel emissions are taken as $2.621 \mathrm{~kg}$ of $\mathrm{CO}_{2} / 1$ of fuel. The unit road emissions are thus computed as $2.7440 * 10^{-2} \mathrm{~kg}$ of $\mathrm{CO}_{2} / \mathrm{t} . \mathrm{km}$ for long-haul travels and as $4.788610^{-2} \mathrm{~kg}$ of $\mathrm{CO}_{2} / \mathrm{t} . \mathrm{km}$ for collection/distribution travels.

Unit IWW emissions of a barge of size $t\left(E_{j k}^{t W}\right)$ in $\mathrm{kg}$ of $\mathrm{CO}_{2} /$ barge. $\mathrm{km}$ are based on the NTM methodology developed in the paper of Hoen et al. (2014). According to this methodology, unit IWW emissions are obtained using equation (31).

$$
C^{F} \cdot E^{F}
$$

Fuel consumption of $0.007 \mathrm{t} / \mathrm{km}$ and fuel emissions of $3,178 \mathrm{~kg}$ of $\mathrm{CO}_{2} / \mathrm{t}$ are taken into account. Considering that a medium barge has a maximum capacity of 3,000 $\mathrm{t}$, the unit IWW emissions for this barge size are thus equal to $7.145 * 10^{-3} \mathrm{~kg}$ of $\mathrm{CO}_{2} / \mathrm{t} . \mathrm{km}$.

Unit rail emissions $\left(E_{j k}^{v R}\right)$ of a train $v$, loaded with a predetermined amount of freight, are expressed in $\mathrm{kg}$ of $\mathrm{CO}_{2} /$ ton.km using equation (32) for electrical trains 
and equation (33) for diesel trains. Rail emissions are also based on the NTM methodology.

$$
\begin{gathered}
\frac{T * \gamma * E^{E}}{1000 * \lambda *(1-L) * \sqrt{g}} \\
\frac{T * \gamma * E^{F}}{10^{6} * \lambda * \sqrt{g}}
\end{gathered}
$$

$T$ stands for the energy consumption for a flat region. As for road transport, $\gamma$ reflects the topography of the studied area. $E^{E}$ represents the energy efficiency i.e. the quantity of $\mathrm{CO}_{2}$ emissions required for producing one $\mathrm{kWh} . \lambda$ is the load factor of the train and $L$ is a percentage representative of the energy loss, when transferring the energy from the power plant to the train. $g$ is the gross weight of a full train. Finally, $E^{F}$ stands for the amount of $\mathrm{CO}_{2}$ released in the atmosphere for one unit of fuel burnt.

In this section, we assume that there is only one type of loaded train $v$. We consider a load factor of 0.5 , a gross weight of the train of 1,371 tonnes and a topography factor equal to 1.25 (Hoen et al., 2010, Hoen et al., 2014). For electrical trains, the energy consumption for a flat region is assumed to be 540 $\mathrm{Wh} / \mathrm{km}$ and the energy efficiency is set to $0.41 \mathrm{~kg} / \mathrm{kWh}$ (average value for Europe). The energy loss factor is fixed to 0.1. For diesel trains, the fuel consumption factor is taken as 122.46 and the fuel emissions as $3,175 \mathrm{~g} \mathrm{of} \mathrm{CO}_{2} / \mathrm{kg}$ of diesel consumed. Results of equations (32) and (33) are finally weighted by the average proportion of train technology in Europe for obtaining the emission ratio by t.km. $75.4 \%$ of the European rail network operates using electricity whereas $24.6 \%$ uses the diesel technology. This leads to unit rail emissions for an average train of $1.638 * 10^{-2} \mathrm{~kg}$ of $\mathrm{CO}_{2} / \mathrm{t} . \mathrm{km}$

Transshipment emissions at the terminal are based on te Loo (2009). They are estimated at 0.002 tonnes of $\mathrm{CO}_{2}$ /handling of a container with cranes.

In the following analysis, we assume that there is no storage at the terminal and that goods only have to be transshipped using cranes. Considering that a container 
contains on average 12 tonnes of freight (Janic, 2007), one determines the transshipment emissions $\left(E_{j}^{T}\right)$ at the terminal as $1.67 * 10^{-4} \mathrm{t}$ of $\mathrm{CO}_{2} / \mathrm{t}$ of handled goods.

\subsection{Appendix C: Cost and emission functions of the nonlinear approach}

Cost functions for road are still based on the work of Janic (2007, 2008). Unit road operational costs for long-haul $\left(C_{i m}^{L}\right)$ and collection/distribution travels $\left(C_{i j}^{P}\right)$ are determined as in the NES approach. Indeed, we neglect the potential economies of scale related to road transport since we consider that a truck either transports its TEUs or it does not travel.

In the literature, no general nonlinear formulation for IWW costs has been found, which was modelling IWW costs as a nonlinear function of the weight transported (Mostert and Limbourg, 2016). In order to remain coherent in the formulation of IWW functions, we modelled IWW economies of scale through the use of three different barge sizes, both for costs and emissions.

Unit IWW costs $\left(C_{j k}^{t W}\right)$ of a barge of size $t$ are computed as in the linear approach. In this first scenario, only one average medium barge is taken into account whereas three sizes of barges are considered in the current nonlinear approach, which leads to three different costs. PWC (2003), based on data from Voies Navigables de France, assumes that the unit costs of barges vary between 0.0076 (large barges) and 0.0381 (small barges) $€ / t . \mathrm{km}$. One can therefore deduct that the cost for an average medium barge is $0.02285 € /$ t. km.

Small ships are represented by the ECMT class IV boats, i.e. Johann Welker type (maximum capacity of 1,500 t). Medium barges correspond to the ECMT class Va, i.e. large Rhine ships (maximum capacity of 3,000 t). Finally large barges are assumed to be part of the ECMT class VIIb, i.e. pushed convoys (maximum capacity of 12,000 t). These specific vessels' sizes have been chosen as reference for the representation of small, average and large barges because they correspond to the most often IWW capacities encountered in Belgium. Therefore, we assume a barge capacity of 1,500, 3,000 and 12,000 t, respectively for small, medium and large size barges. Taking into account these capacities, we determine that unit 
IWW costs are around $57 € /$ barge.km for small ships, $69 € /$ barge.km for medium ships and $91 € /$ barge.km for large ships.

Transshipment costs $\left(E_{j}^{T}\right)$ are valued as in the linear approach.

Unit rail operational costs $\left(C_{j k}^{R}\right)$ in $€ /$ t.km come from Janic (2007) and are determined by equation (34).

$$
\frac{\sqrt{2}}{2 X_{j k}^{i} \cdot s_{j k}} \cdot 0.58\left(g \cdot s_{j k}\right)^{0,74} \cdot\left[\frac{X_{j k}^{i} \cdot T \cdot\left(\alpha_{b 1}+\alpha_{b 2}\right.}{0.58\left(g \cdot s_{j k}\right)^{0,74}+0.57\left(g \cdot s_{j k}\right)^{0,6894}}\right]^{0,5}
$$

$X_{j k}^{i}$ refers to the amount of goods (in tonnes) that is really transported from origin node $i$ and that passes though rail terminals $j$ and $k . s_{j k}$ represents the rail distance between terminals $j$ and $k . g$ is the gross weight of a full train and is equal to 1,371 tonnes (Janic, 2007). Given the cost function formulation, it is to notice that an increase of the transported quantity $X_{j k}^{i}$ leads to economies of scale and therefore to reduced average costs per tonne.kilometer. Rail costs thus take into account economies of scale related to the bundling of flows in terms of weight. Parameter $T$ represents the network operating time. It is fixed and supposed equal to five days a week multiplied by 52 weeks a year, i.e. 6,240 hours. Finally, $\alpha_{b 1}$ and $\alpha_{b 2}$ stand for the unit cost of time per units in zones 1 and 2 and are assumed to be $0.028 € /$ hour.tonne.

Unit road transport emissions $\left(E_{i m}^{L}\right)$ for long-haul travels and for collection/distribution travels $\left(E_{i j}^{P}\right)$ are expressed as in the linear approach. As for road costs, we neglect potential economies of scale in terms of emissions for road transport.

IWW emissions of a barge $\left(E_{j k}^{t W}\right)$ in $\mathrm{kg}$ of $\mathrm{CO}_{2} /$ barge.km are based on the NTM methodology. Three emission levels are considered for small, medium and large size barges, which reflects the potential economies of scale obtained when using larger vehicles, on different sizes of IWW.

As in the linear approach, medium barges are supposed to emit $7.145 * 10^{-3} \mathrm{~kg}$ of $\mathrm{CO}_{2} / \mathrm{t} . \mathrm{km}$. We assume that small size barges have a unit emission rate $20 \%$ 
higher, while we consider that that large size boats generate $20 \%$ less emissions than medium barges. Knowing the capacities of each boat, we can deduct the values of emissions as $12.86 \mathrm{~kg}$ of $\mathrm{CO}_{2} / \mathrm{t} . \mathrm{km}$ for small barges, $21.43 \mathrm{~kg}$ of $\mathrm{CO}_{2} / \mathrm{t} . \mathrm{km}$ for medium barges, and $68.52 \mathrm{~kg}$ of $\mathrm{CO}_{2} / \mathrm{t} . \mathrm{km}$ for large barges.

Unit rail emissions $\left(E_{j k}^{v R}\right)$ are expressed in $\mathrm{kg}$ of $\mathrm{CO}_{2} /$ ton.km using equation (35) for electrical trains and (36) for diesel trains.

$$
\begin{gathered}
\frac{T * \gamma * E^{E}}{1000 *(1-L) * \sqrt{W_{e m p t y}+X_{j k}^{v i}}} \\
\frac{T * \gamma * E^{F}}{10^{6} * \sqrt{W_{\text {empty }}+X_{j k}^{v i}}}
\end{gathered}
$$

Compared to the linear approach, by $W_{\text {empty }}$ and $X_{j k}^{v i}$. $W_{\text {empty }}$ refers to the tare of the train, i.e. the weight of a train, i.e. the weight of a train with no merchandise loaded on it. It is assumed equal to 903 tonnes (Janic, 2007, Janic, 2008). $X_{j k}^{v i}$ is the net weight of freight transported by train $v$ between terminals $j$ and $k$. This amount is limited to the maximum capacity of one train $(A)$ i.e. 468 tonnes (Janic, 2007, Janic, 2008).

Finally, transshipment emissions at the terminal $\left(E_{j}^{T}\right)$ are valued exactly as in the linear approach.

The nonlinear functions presented here above are approximated using piecewise linear functions, to permit the use of linear programming solvers for the resolution of the model. The next paragraphs detail how this piecewise linearization is practically performed.

Janic (2007) states that one train a day, i.e. five trains a week, is the most common train frequency in many trans-European intermodal markets-corridors. One train a day is thus the unit chosen as the increment between two segments of the piecewise linear function for rail that approximates the nonlinear costs. Using 
this method thus allows cutting the function between the minimum and maximum flows, according to the benchmark situation.

The first segment of the function therefore contains the annual flows which correspond to zero trains a day until one train a day. The second segment focuses on the annual flows equivalent to one train until two trains a day. And the cut is iteratively continued, until reaching the last segment, which contains the additional capacity required for achieving the maximum flows value.

In this case study, the cost function is divided into seven segments. The first six ones are equal and their size corresponds to the annual flows transported if one train a day is used. The last segment of the function contains the annual flows corresponding to more than six trains a day.

Rail emissions are computed thanks to equations (35) and (36), respectively for electrical and diesel trains.

The specificity of these functions is that the value of $X_{j k}^{v i}$, the weight transported, cannot exceed the maximum amount transportable in a single train. The emissions generated are thus nonlinear with the weight transported inside a specific train. However, the total emissions generated by a flow equivalent to an integer number of trains are linear with the number of trains. In this work, we determine the different segments of the piecewise linear function using breakpoints equivalent to an integer multiple of trains. Since the economies of scale are developed inside a specific train and not from one train to another, the obtained piecewise linear function is thus simply linear.

In Belgium, in 2008 and 2009, around $80 \%$ of the travels were performed using electric locomotives whereas $20 \%$ of these travels were done with the help of diesel machines (Eurostat, 2014).

The nonlinear emissions functions for electrical and diesel trains are thus reduced to a linear emission value, based on an 80-20 repartition key.

\section{Acknowledgements:}

Martine Mostert acknowledges the financial support of FRS-FNRS (Fonds de la Recherche Scientifique). The authors thank Annick Sartenaer and Thibaut Lust for their valuable advice. The authors are also grateful to the two anonymous 
reviewers who provided constructive comments which definitely improved the paper. The project leading to the presented results was partially supported by the Interuniversity Attraction Poles Programme initiated by the Belgian Science Policy Office, Comex, Grant P7/36. The paper, however, only expresses the view of the authors. 


\section{Chapter 6}

\section{Intermodal transport and air pollution}

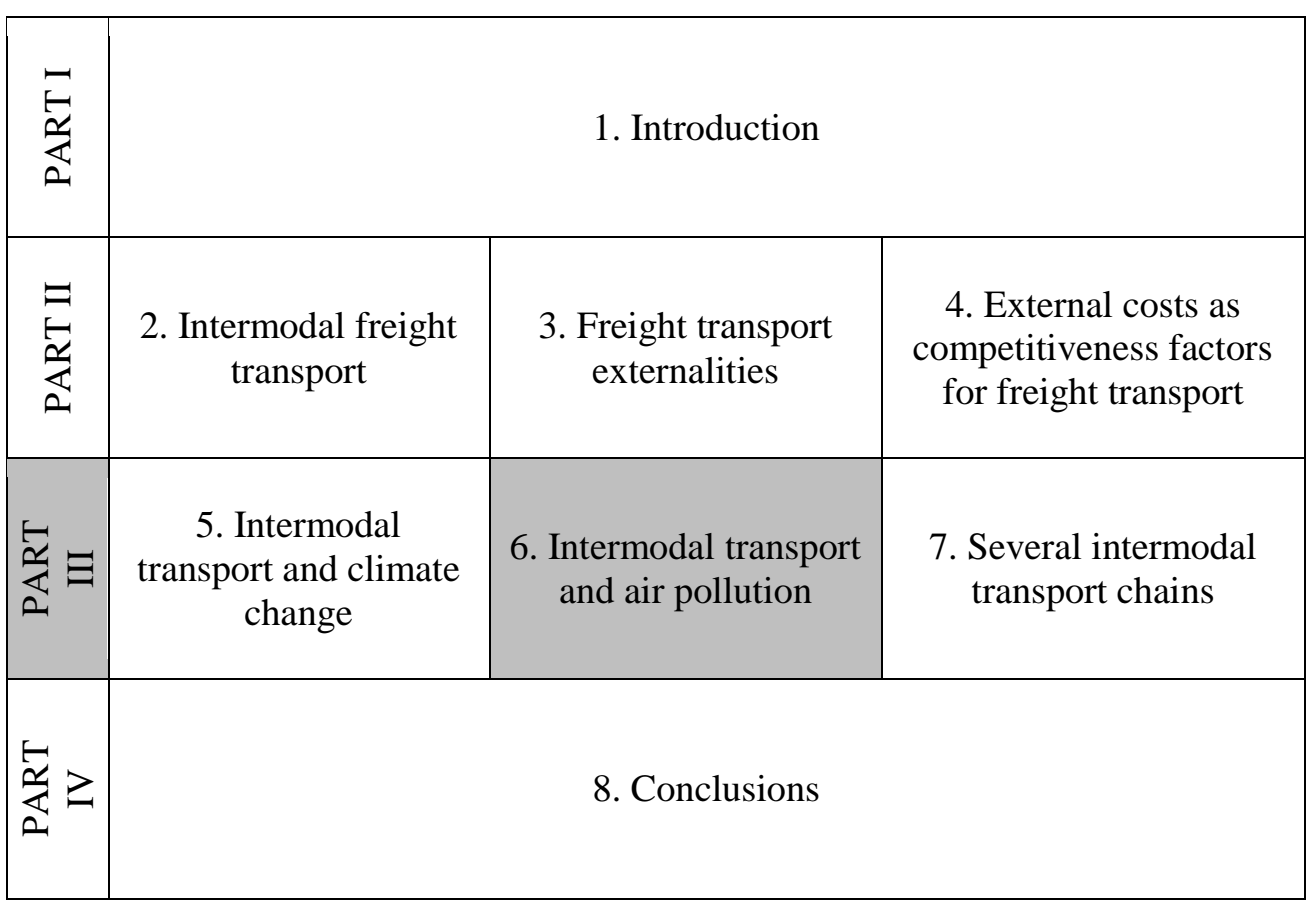

In a complementary approach to chapter 5, this chapter identifies the links between intermodal transport and another type of externality: air pollution. It evaluates the flow distribution between road and intermodal transport under economic and environmental policies on the Belgian case study.

\subsection{Abstract $^{4}$}

The transportation of goods is essential for the economy, but it also contributes to air pollution which, in turn, affects human health. These negative impacts

\footnotetext{
${ }^{4}$ This chapter is based on the paper published under the reference: "Mostert, M., Caris, A. \& Limbourg, S. (2017). Road and intermodal transport performance: the impact of operational costs and air pollution external costs. Research in Transportation Business and Management, In Press."
} 
generate additional costs for society that are not necessarily taken into account in public transportation policies and in private transportation decisions of companies and individuals. This leads to inefficient transportation systems where the social equilibrium is not reached. Intermodal transport is promoted by the European Commission to reduce these negative externalities. The objective of this research is to analyze at a strategic level the effect on modal split between road, intermodal rail and intermodal IWW transport of several economic or environmental policies. An intermodal allocation model is applied to the Belgian case in order to identify the modal split changes between the single minimization of costs (operational or health-related external) and the introduction of additional road taxes.

\subsection{Introduction}

Transportation activities have been increasing in the last years. Between 1995 and 2010, an annual transportation growth rate of $1.5 \%$ for freight (road, rail, IWW, oil pipelines, intra-EU air, intra-EU sea) and $1.3 \%$ for passengers has been observed in the European Union's 27 countries (European Commission, 2012).

Transportation of goods and people brings several advantages to society, both from the personal and the economic side. Freight transportation in particular allows access to previously unreachable goods, but also enables cost reduction for products developed in further regions at a lower price. Unfortunately, these benefits are also counterbalanced by undesirable features. Ricardo AEA (2014) states that "when side effects of a certain activity impose a cost upon society, economists speak of such a cost as an external cost". The negative effects generated by transport but not directly supported by the related sector are therefore known as transport external costs. The latter can be of various types such as climate change, air pollution, water pollution, congestion, accidents or noise.

Among these externalities, air pollution is receiving increasing interest. This is observable through several policy measures applied at different levels of decision. Some examples of these measures to mitigate air pollution are the development of European air pollutant standards, the introduction of low emissions zones or alternate traffic circulation in European city centers, the introduction in some countries of stronger speed limitations on highways when pollutant thresholds are reached, or the development and encouragement to use alternative transportation modes like rail or IWW (European Commission, 2011). 
The World Health Organization (WHO) estimates that air pollution is now "the world's largest single environmental risk." In 2012, one out of eight people who passed away died because of air pollution exposure (WHO, 2014). Indeed, the emissions generated during the movement of goods directly affect air quality. A higher level of exposure to these chemical components increases the percentage of disease development and aggravation. Heart attacks, cancers and respiratory system illnesses are some of the negative impacts on human health generated by transport.

Human health external costs are divided into two categories: mortality and morbidity costs. Mortality costs reflect the reduction in life expectancy due to acute and chronic effects and are often computed through values of statistical lives (Ricardo AEA, 2014). The monetization of mortality costs is important since they represent the most important part of human health external costs (Ricardo AEA, 2014). Morbidity costs refer to the other costs generated by air pollution, such as costs of curing, costs of hospitalization, and costs of restricted activity days (Ricardo AEA, 2014). These consequences of transportation are not supported by transportation companies and impose a cost on society. For this reason, the limitation and reduction of transport air pollution are encouraged by the European Commission in its White Paper on Transport (European Commission, 2011).

Road is currently the most used mode for freight transport in Europe. Europe is willing to decrease its modal share and to go for more environmentally friendly modes in order to restrict the negative impacts of transport on its environment (European Commission, 2011). This objective can be achieved by the use of rail and IWW in the framework of an intermodal transport. Intermodal transport is defined as the transportation of goods using two or more modes of transport, in the same loading unit, without handling the goods themselves (United Nations, 2001).

Intermodal transport is generally composed of five main stages. Goods are first transported by truck for the pre-haulage from the origin node to the first intermodal terminal. At this first terminal, goods are transferred from truck to train or to barge. The long-haul transport by the more environmentally friendly mode is then performed on rail or IWW. At the second terminal, freight is transferred from train or barge to truck. The post-haulage, i.e. the last part of the travel, is done by truck until the final destination node. The main benefits of 
intermodal transport lie in the reduced costs and externalities of the environmentally friendly long-haul transport (Mostert and Limbourg, 2016).

Analyses of the relation between transport, air pollution, and human health are often performed at the urban level (de Leeuw et al., 2001, Costabile and Allegrini, 2008, Bagienski, 2015, Lozhkina and Lozkhin, 2015, Tainio, 2015, Aggarwal and Jain, 2015). The focus is often, therefore, on a restricted mode and case study. However, a wider perspective of analysis at the strategic level is also needed to develop long-term transportation policies which account for human health impacts.

How do different modes of transport perform regarding human health external costs? Does the modal split between road and intermodal transport vary, when economic or human health objectives are followed? In an economic optimization strategy, can the intervention of states (for instance through the implementation of taxes) lead to the same modal split, as an environmental optimization strategy? Which modes of transport should be promoted in order to ensure reduced human health external costs? In which infrastructure projects should public authorities invest? What is the implication on modal split of external costs variations, resulting, for instance, from technological improvement or traction mix modifications?

This research aims to respond to these questions by filling the gap which exists in linking transport and human health external costs at a strategic level of decision making. This is done with tools of the operations research domain. For this purpose, an intermodal allocation model is used to compare the modal split between road, intermodal rail and intermodal IWW transport, under economic and environmental optimization strategies. An intermediate policy between economic and environmental optimization is also studied. This policy consists of public intervention through additional road taxes in a system which follows an economic optimization strategy.

The resulting flow distribution under operational costs or human health external costs minimization is analyzed. Sensitivity analysis of transportation external costs is also performed in order to evaluate how modifications of these costs influence the market shares of road and intermodal transport. The mathematical model is applied to the case of Belgium in order to practically emphasize which kinds of policy-related decisions can be provided. 
The next section provides a literature review on the links between the modeling of freight transport and its impact on air pollution and human health, and a positioning of our research in this framework. Section 6.4 details the model formulation and elaborates on the used methodology. Section 6.5 concentrates on the used data for the case study. Section 6.6 focuses on the case study findings. Discussion of these results is provided in Section 6.7. Conclusions are drawn in section 6.8 .

\subsection{Freight transport, air pollution and human health impacts: what are the implications for business and stakeholders?}

Transportation directly influences human health through the emission of chemical components which affect air quality. According to the Update of the Handbook on External Costs of Transport (Ricardo AEA, 2014), the most important emissions related to transport are sulfur dioxide (SO2), nitrogen oxides (NOx), NonMethane Volatile Organic Compounds (NMVOCs) and particulate matters (PM). Particulate matters are divided into two categories: PM2.5 and PM10, representing the particles of a diameter size of less than 2.5 and 10 micrometers, respectively.

These gases emitted by transport are responsible for several harmful impacts such as asthma, inflammation of the respiratory system, headaches, anxiety, cardiovascular diseases, effects on the central nervous system, lung diseases, cancers and premature mortality (EEA, 2013a). The combination of some of these emissions also contributes to the generation of ground-level ozone (O3), leading to breathing difficulties, especially for young, old or sensitive (for instance, asthmatic) people.

Since these emissions are generated by the transportation companies, but impose a cost on other economic actors of society, they are recognized as externalities or external costs. The non-consideration of externalities on the economic market leads to the production of a higher quantity of transport services than the optimal societal one. As transport externalities can be considered to be market failures, they might provide a rationale for government intervention (for instance through the introduction of additional taxes) in order to reach the societal optimal level of transport. 
Several stakeholders like shippers, public authorities, private individuals and private companies may benefit from introducing external costs in transportation planning policies.

Shippers may take advantage of an improvement in their transportation mode attractiveness. This can increase the market share revenues of owners of more environmentally friendly modes.

Government and public authorities mainly support the costs of public health care and hospitals. By ensuring a restricted amount of transport externalities, public authorities could reduce the budget assigned to these services. In Europe, between $46 \%$ and $66 \%$ of total healthcare expenses were used for curative and rehabilitative care in the different states in 2012 (European Commission, 2015c). Limiting health-related externalities may thus help states better control healthcare expenditures. This is still a major problem in all types of healthcare systems (Wendt, 2009). Some public deficits may thus be recovered, or some money could be transferred to other areas of expenses. These savings are welcome in times of economic crisis when the European Union encourages the reduction of public debt of the member states (European Commission, 2016d).

Private individuals also benefit from transport externalities being taken into account in transportation policies. The potential advantages happen at two levels. First, by explicitly making decisions related to the restriction of these external effects, people may enjoy a healthier way of life. Second, households need to invest less money in healthcare expenses, which alleviates their global budget.

Finally, private companies may also benefit from reduced externalities through transportation policies. Indeed, air pollution is responsible for the development of serious health problems such as cancers or heart attacks. The latter often imply sickness absences for employees who do not work anymore. This has a cost for companies which pay sick leave to their members (Gimeno et al., 2014). In addition, new employees might need to be hired and trained to replace the sick person, which also represents an indirect cost to support. Consequently, even if the effects of air pollution related to transport are not directly noticeable, their impact on society is not marginal and concerns a lot of economic actors.

The enhancement of human health preservation is currently done through the setting of global reduction targets for air pollutant emissions. At the world level, air pollution matters are consolidated in the United Nation Economic Commission 
for Europe (UNECE) Convention on Long-range Transboundary Air Pollution (LRTAP). Introduced in 1979, this convention is the first international legally binding tool developed to limit air pollution. It has been followed by a set of protocols aiming at enforcing the transboundary air pollution abatement (UNECE, 2015). At the European level, the National Emission Ceilings Directive sets national emission objective values for four pollutants, i.e. NOx, SO2, NMVOC and NH3 for the year 2010. These maximum ceilings are more restrictive than those of the LRTAP convention (European Commission, 2015d).

According to Ricardo AEA (2014), the best-known and recommended method for evaluating the impact of emissions of air pollutant is the Impact Pathway Approach developed in the context of the ExternE project (Bickel et al., 2005). This method follows a bottom-up approach, which evaluates the external effect from the lowest level, i.e. the micro level. The analysis is based on the definition of the external effects of a particular object and how it affects its direct environment. This approach focuses on determining the marginal external costs. The specific parameters related to externalities (e.g. the speed of a vehicle or the slope on which it evolves for emissions) can be taken into account precisely. Nevertheless, since this method focuses on very specific cases, it might be difficult to translate the obtained results into policy measures (Van Essen et al., 2007). The Impact Pathway Approach is constructed around five main steps: identification and quantification of the emissions, evaluation of the dispersion of the pollutants around its source, determination of the extent to which a population is exposed to the burdens, identification of the impact in terms of premature deaths and ill health, and finally monetary evaluation of the damage using the damage cost approach (EEA, 2014). The latter defines the real damages caused by the externalities to its surrounding environment.

As the Impact Pathway Approach suggests an evaluation of external costs at the micro-level, the evaluation of the impact of land transportation on air pollution is often considered in urban contexts. The particular attention to these zones mainly lies in the higher concentration of both gases and human beings in these areas. The intensity of exposition as well as the number of people exposed are increased, which generates a higher interest in these regions.

Road transport is the most concerning mode in urban zones. According to EEA (2013b), $10.8 \%$ of the PM10 and $16.1 \%$ of the PM2.5 emissions are attributed to 
road transport. As a comparison, only 1.7 and $2.9 \%$ of emissions can be attributed to non-road transport, for PM10 and PM2.5, respectively.

Air pollution deterioration in cities may be performed by evaluating a posteriori how pollutant values exceed the legal sanitary thresholds that are imposed by authorities (de Leeuw et al., 2001). A more proactive approach consists of better understanding the source-receptor relationship related to traffic air pollution (Costabile and Allegrini, 2008). The traffic density is not the only parameter influencing air quality. Indeed, the interaction between road transport emissions and street structures also plays an important role (Bagienski, 2015). The correct modeling of transport emissions and their effects on air pollution remains one of the most challenging and important issues (Sen et al., 2010, van Lier and Macharis (2014), Lozhkina and Lozkhin, 2015).

The relationship between transport, air pollution and its effect on human health is modeled through various statistical tools, for instance for determining the impact of transport pollution on breast cancers (Hystad et al., 2015), on non-elective hospitalizations for pneumonia (Devos et al., 2015) or on cardio-respiratory risk (Aggarwal and Jain, 2015). Expression of transport impact on human health can also be assessed through exposure-response functions, with a disease burden evaluated in terms of Disability Adjusted Life Years (Tainio, 2015).

Beyond the direct analysis between transportation emissions, air pollution, and human health, other studies focus on the impact of transportation policies on air pollution and human health. Policy recommendations for reducing the human health impact of transport in urban areas often concern passenger transport (Smith et al., 2013, Aggarwal and Jain, 2015, Perez et al., 2015, Xia et al., 2015).

In a complementary approach to research methodologies which concentrate on dose-response functions, GIS-based models (Macharis and Pekin, 2009, Macharis et al., 2010, Meers and Macharis, 2014) or tools of the operations research domain can be used to identify the effect of different freight transportation policies on the flow distribution between several modes of transport. For decision support tools relating to optimization, this analysis is performed through network design models which determine the flow distribution between road and intermodal transport, as well as the location of intermodal terminals. Most of the research concentrates on the minimization of the operational costs on the network (for instance Arnold et al. 2004, Racunica and Wynter, 2005, Limbourg and 
Jourquin, 2009, Limbourg and Jourquin, 2010, Ishfaq and Sox, 2011, Sörensen et al., 2012, Sörensen and Vanovermeire, 2013, Ghane-Ezabadi and Vergara, 2016); however, some models focus on $\mathrm{CO}_{2}$ emissions (Mostert et al., 2017a) or on generalized costs of transport, including transport externalities (Iannone, 2012, Zhang et al., 2013, Santos et al., 2015, Zhang et al., 2015).

The impact of transport on human health is an important topic of research in the framework of urban passenger transportation. However, freight transportation is also responsible for negative human health effects and even if pollution is generated at a local and operational level, it is not restricted to urban areas. Many other areas can be impacted by the transportation travels that happen with longer distances. It is, therefore, interesting to identify how air pollution can be dealt with at a more global and strategic level. As highlighted here above, not only are stakeholders who are related to the transport sector concerned with transport air pollution. Private individuals and companies are concerned as well, as they face an economic impact due to the non-integration of air pollution externalities in transport policies.

Some contributions in the literature define models that focus on all kinds of externalities (e.g. Macharis et al., 2010 and Santos et al., 2015), providing a global insight but making it impossible to assess the specific impact of each specific external cost (congestion, accident, air pollution, water pollution, noise, etc.). Others account mainly for $\mathrm{CO}_{2}$ emissions (Zhang et al., 2013, Mostert et al., 2017a, Zhang et al., 2015) in order to analyze how the integration of global warming influences the location of intermodal terminals, and the allocation of flows. However, no study was found that specifically focused on the trade-offs between economic and human health interests of freight transport at a strategic level of decision making, using an optimization approach. This paper therefore aims at closing this gap by proposing a model which allows assessing at the global level the effect on modal split of economic or human health transportation policies.

\subsection{Intermodal allocation model formulation}

The following formulation is based on the intermodal location-allocation model developed by Mostert et al. (2017a). In this paper, we consider that intermodal terminals are already located on the studied geographical zone. This formulation 
is thus an intermodal allocation model, i.e. a simplification of the intermodal location-allocation model developed by Mostert et al. (2017a).

The model minimizes the total operational or external costs of air pollution of transport companies. These costs are divided into four main parts: door-to-door road operational/external costs, transshipment operational/external costs between sea and road, rail-road intermodal operational/external costs and IWW-road intermodal operational/external costs. Rail-road and IWW-road operational and external costs are subdivided into (a) pre-haulage operational/external costs by road, (b) transshipment operational/external costs at origin intermodal terminal, (c) long-haul travel operational/external costs by rail or IWW, (d) transshipment operational/external costs at the destination terminal and (e) post-haulage operational/external costs by road. The focus is on containerized flows of transport between several origin-destination pairs.

The main decisions that are made concern the choice of the mode for achieving the best objective value, subject to several constraints. The decision variables are the amount of flows transported directly by road, by intermodal rail transport, and by intermodal IWW transport. Classically, intermodal flows passing through two terminals are modelled using one variable with four indices (indicating origin, first terminal, second terminal, and destination). We use another approach (based on Ernst and Krishnamoorthy, 1998) which models intermodal flows using two variables with three indices each. The first variable indicates origin, first terminal, and second terminal of the origin-destination pair. The second variable indicates origin, second terminal, and destination of the origin-destination pair. The joint reading of these two variables describes the total travel of the flows, with origin, first terminal, second terminal, and destination. This formulation allows reducing the size of the problem to solve.

The mathematical formulation of the model is described hereafter. 
Sets:

$N \quad$ node set consisting of $n$ demand nodes, indexed by $i, m \in\{1, \ldots, n\}$

$H \quad$ existing terminal (hub) set, $(H \subseteq N)$ consisting of $h$ nodes, indexed by $j, k \in\{1, \ldots, h\}$

$\mathrm{N}_{0} \quad$ set of port nodes, existing rail and IWW terminals, inside the studied geographical area

$\mathrm{N}_{1} \quad$ set of demand nodes, with rail-road terminals inside the studied geographical area

$\mathrm{N}_{2} \quad$ set of demand nodes, with IWW-road terminals inside the studied geographical area,

$\mathrm{N}_{3} \quad$ set of demand nodes, with rail-road terminals located outside the studied geographical area

$\mathrm{N}_{4} \quad$ set of demand nodes, with IWW-road terminals located outside the studied geographical area

$\mathrm{N}_{5} \quad$ set of demand nodes inside the studied geographical area

$\mathrm{N}_{6} \quad$ set of demand nodes outside the studied geographical area

Thus $\mathrm{N}=\mathrm{U}_{\mathrm{i}=0}^{6} \mathrm{~N}_{\mathrm{i}} ; \mathrm{H}=\mathrm{U}_{\mathrm{i}=0}^{4} \mathrm{~N}_{\mathrm{i}} ; \mathrm{H}_{\mathrm{R}}=\mathrm{N}_{0} \cup \mathrm{N}_{1} \cup \mathrm{N}_{3}$ and $\mathrm{H}_{\mathrm{W}}=\mathrm{N}_{0} \cup \mathrm{N}_{2} \cup \mathrm{N}_{4}$

Parameters:

$d_{i m} \quad$ road distance between demand nodes $i$ and $m$ (in $\mathrm{km}$ )

$s_{j k} \quad$ rail distance between terminals $j$ and $k$ (in $\mathrm{km}$ )

$l_{j k} \quad$ IWW distance between terminals $j$ and $k$ (in km)

$D_{i m} \quad$ cargo demand from demand node $i$ to demand node $m$ (in t)

$\beta_{k} \quad=1$ if a terminal is located at $k$

$=0$ otherwise 
The value of the following parameters depends on the type of optimization that is performed. If the focus is on economic optimization, the following parameters take the value of operational costs. If the focus is on environmental optimization, the following parameters take the value of external costs.

$C_{i m}^{L} \quad$ long-haul road transportation operational or external costs for travelling from node $i$ to node $m$ (in $€ /$ t.km)

$C_{i j}^{P} \quad$ collection/distribution road transportation operational or external costs for travelling from node $i$ to terminal $j$ (in $€ /$ t.km)

$C_{j k}^{R} \quad$ long-haul rail transportation operational or external costs for travelling from terminal $j$ to terminal $k$ (in $€ /$ t.km)

$C_{j k}^{W} \quad$ long-haul IWW transportation operational or external costs for travelling from terminal $j$ to terminal $k$ (in $€ /$ t.km)

$C_{j}^{T} \quad$ handling operational or external costs at terminal $j($ in $€ / \mathrm{t})$

Variables:

$W_{i m}$ road flows from demand origin $i$ and destination $m$ (in tonnes), $\forall i, m \in N$

$X_{j k}^{i} \quad$ flows from node $i$ firstly routed through origin rail terminal $j$ and then through destination rail terminal $k$ (in tonnes), $\forall i \in N, \forall j, k \in H_{R}$

$Q_{\mathrm{km}}^{i}$ flows from origin $i$ to destination $m$ that are routed through rail destination terminal in $k$ (in tonnes), $\forall i, m \in N, \forall k \in H_{R}$

$F_{j k}^{i} \quad$ flows from node $i$ firstly routed through origin IWW terminal $j$ and then through destination IWW terminal $k$ (in tonnes), $\forall i \in N, \forall j, k \in H_{W}$

$V_{k m}^{i} \quad$ flows from origin $i$ to destination $m$ that are routed through IWW destination terminal in $k$ (in tonnes), $\forall i, m \in N, \forall k \in H_{W}$ 
Mathematical formulation:

\section{Minimize}

$$
\begin{gathered}
f= \\
\sum_{i \in N} \sum_{m \in N} d_{i m} \cdot C_{i m}^{L} \cdot W_{i m} \\
+\sum_{i \in N_{0}} C_{i}^{T} \cdot W_{i m}+\sum_{m \in N_{0}} C_{m}^{T} \cdot W_{i m} \\
+\sum_{i \in N} \sum_{j \in H_{R}} \sum_{k \neq j \in H_{R}}\left(d_{i j} \cdot C_{i j}^{P}+C_{j}^{T}\right) \cdot X_{j k}^{i} \\
+\sum_{i \in N} \sum_{j \in H_{R}} \sum_{k \neq j \in H_{R}} s_{j k} \cdot C_{j k}^{R} \cdot X_{j k}^{i} \\
+\sum_{i \in N} \sum_{k \in H_{R}} \sum_{m \in N}\left(d_{k m} \cdot C_{k m}^{P}+C_{k}^{T}\right) \cdot Q_{k m}^{i} \\
+\sum_{i \in N} \sum_{j \in H_{W}} \sum_{k \neq j \in H_{W}}\left(d_{i j} \cdot C_{i j}^{P}+C_{j}^{T}\right) \cdot F_{j k}^{i} \\
+\sum_{i \in N} \sum_{j \in H_{W}} \sum_{k \neq j \in H_{W}} l_{j k} \cdot C_{j k}^{W} \cdot . F_{j k}^{i} \\
+\sum_{i \in N} \sum_{k \in H_{W}} \sum_{m \in N}\left(d_{k m} \cdot C_{k m}^{P}+C_{k}^{T}\right) \cdot V_{k m}^{i}
\end{gathered}
$$


Subject to

$$
\begin{aligned}
& D_{i m}=W_{i m}+\sum_{k \in H_{R}} Q_{k m}^{i}+\sum_{k \in H_{W}} V_{k m}^{i} \\
& \forall i, m \in N \\
& \sum_{m \in N} D_{i m}=\sum_{m \in N} W_{i m}+\sum_{j, k \in H_{R}} X_{j k}^{i}+\sum_{j, k \in H_{W}} F_{j k}^{i} \\
& \forall i \in N \\
& \sum_{k \in H_{R}} X_{j k}^{i} \leq \beta_{j} \sum_{m \in N} D_{i m} \\
& \forall i \in N, \forall j \in H_{R} \\
& \sum_{j \in H_{R}} X_{j k}^{i} \leq \beta_{k} \sum_{m \in N} D_{i m} \\
& \sum_{k \in H_{W}} F_{j k}^{i} \leq \beta_{j} \sum_{m \in N} D_{i m} \\
& \sum_{j \in H_{W}} F_{j k}^{i} \leq \beta_{k} \sum_{m \in N} D_{i m} \\
& \sum_{j \in H_{R}} X_{j k}^{i}=\sum_{m \in N} Q_{k m}^{i} \\
& \sum_{j \in H_{W}} F_{j k}^{i}=\sum_{m \in N} V_{k m}^{i} \\
& W_{m}^{i} \geq 0 \\
& X_{j k}^{i} \geq 0 \\
& Q_{k m}^{i} \geq 0 \\
& \forall i \in N, \forall k \in H_{R} \\
& \forall i \in N, \forall j \in H_{W} \\
& \forall i \in N, \forall k \in H_{W} \\
& \forall i \in N, \forall k \in H_{R} \\
& \forall i \in N, \forall k \in H_{W} \\
& \forall i, m \in N \\
& \forall i \in N, \forall j, k \in H_{R} \\
& \forall i, m \in N, \forall k \in H_{R} \\
& F_{j k}^{i} \geq 0 \\
& \forall i \in N, \forall j, k \in H_{W} \\
& V_{k m}^{i} \geq 0 \\
& \forall i, m \in N, \forall k \in H_{W}
\end{aligned}
$$

The model structure can be summarized as follows: 


\section{Minimize}

Operational or air pollution external costs (37)

\section{Subject to}

Demand should be satisfied for each origin-destination pair (38)

All the flows should leave their origin (39)

Flows cannot go through a closed terminal (40)-(43)

Flows should be conserved between the intermodal variables of a specific origindestination pair (44)-(45)

Flow variables should be nonnegative (46)-(50)

The model is applied to the Belgian case and considers all flow exchanges at the third-level of Nomenclature of Territorial Units for Statistics (NUTS 3) represented in figure 11. Sea flows originating from or leaving the country at maritime ports are also taken into account. The problem is solved on a personal computer (Windows 10 Dual-Core $2.5 \mathrm{GHz}, 8 \mathrm{~GB}$ of RAM) and with CPLEX 12.61 .

\subsection{Data of the Belgian case}

The model presented above is applied to the Belgian case for analyzing how economic and health objectives impact the modal split between road and intermodal freight transport. Belgium is chosen for its very dense network of road, rail and IWW, as well as for its characteristic of being one of the least performant European countries in terms of air quality (European Commission, 2015b). The strategic location of Belgium at the heart of Europe also makes it an interesting case regarding flow volumes passing through it. A map of the Belgian terminals and NUTS 3 regions is presented in figure 12.

The Belgian case has already been analyzed several times in the literature. Besides other studies focusing on the Belgian flows from and to the port of Antwerp (Macharis and Pekin, 2009, Macharis et al., 2010, Meers and Macharis, 2014), this research evaluates the flow distribution between NUTS 3 regions in Belgium. Flow exchanges between Belgian NUTS 3 regions and some NUTS 3 regions of neighboring countries (the Netherlands, Germany, France and Luxembourg) are also taken into account. Our study differs from the analysis of 
Santos et al. (2015) since it allows the intermodal IWW option, whereas Santos et al. (2015) focus on road and intermodal rail transport.

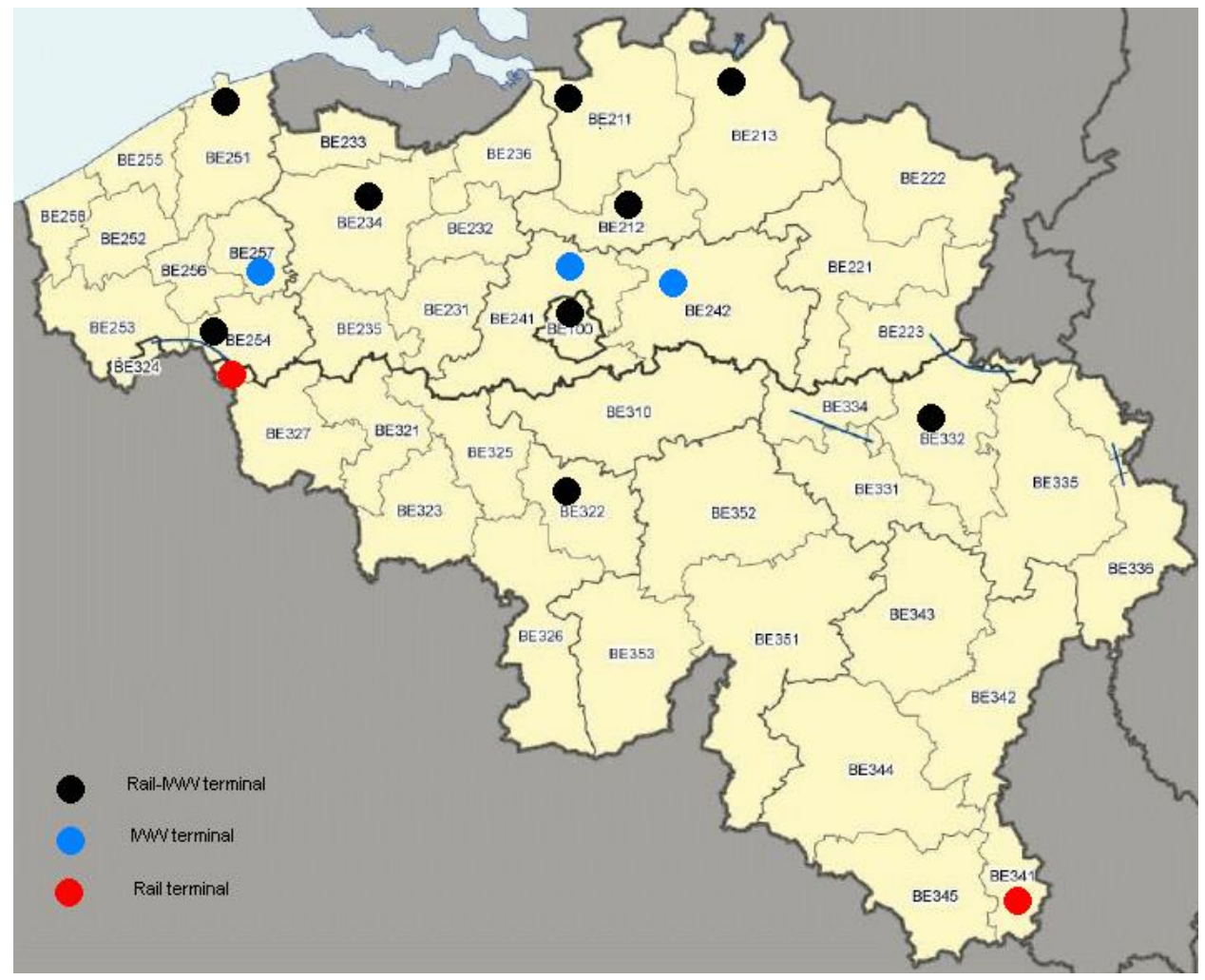

Figure 12: Map of the rail-IWW, IWW and rail terminals in Belgium (source: Eurostat and own setup)

The analysis of this application should provide insights on the relationship between economic or human health goals and the allocation of containerized flows between the different modes of transport. The study identifies the distribution of the total containerized flows sent to and from the considered NUTS 3 regions by road, rail and IWW. The demand of each region is concentrated on a single generation node, i.e. a city of this region which is chosen for its economic and population importance, and for the existence of a rail/IWW platform nearby. References and additional comments related to the parameters used in this case study are listed in table 16. 


\begin{tabular}{|c|c|c|}
\hline Data & Source & Comment \\
\hline $\begin{array}{l}\text { Demand for } \\
\text { containerized road, rail } \\
\text { and IWW flows }\end{array}$ & Mostert et al. (2017a) & $\begin{array}{l}\text { The original } 2005 \text { database has been } \\
\text { extrapolated to 2010, based on } \\
\text { aggregated flow values available from } \\
\text { Eurostat and from Belgian ports' annual } \\
\text { outlooks. Data at the NUTS } 2 \text { level } \\
\text { have been disaggregated to a NUTS } 3 \\
\text { level within Belgium and the } \\
\text { neighboring regions, using the number } \\
\text { of companies of productive sectors in } \\
\text { these regions as the proxy indicator. An } \\
\text { origin-destination pair is constituted by } \\
\text { any combination of two nodes in } \\
\text { Belgium or in its surrounding NUTS } 3 \\
\text { regions. }\end{array}$ \\
\hline
\end{tabular}

Road and rail network Carreira et al. (2012)

IWW network Promotie Binnenvaart

Vlaanderen (2015)

Road, rail, IWW and transshipment operational costs

BRAIN-TRAINS study (Troch et al., 2015)

Road, rail and transshipment operational costs originate from Janic (2007, 2008). IWW costs are based on PWC (2003). Road and rail operational costs are nonlinear with the distance traveled, assuming economies of distance.

Road, rail and IWW external costs of air

Ricardo-AEA (2014)

Damage cost values of air pollutants for road and rail are based on the European New Energy Externalities Development for Sustainability (NEEDS) study (Preiss and Klotz, 2007). IWW values originate from CE Delft (2011) and Brons and Christidis (2013).

Transshipment external costs of air

Baccelli et al. (2001)

Marginal external costs related to the transshipment of goods from one mode to another are small and negligible compared to other externalities of intermodal transport. They are equal to zero both for intermodal rail and IWW transport.

Table 16: References and comments related to the used parameters 
One particularity of this research is to account for human health external costs related to air pollution. Air pollution external cost values of this case study are computed based on a tank-to-wheel approach. More detailed information regarding road, rail and IWW external costs calculations is provided in the following paragraphs.

Road external costs related to air pollution are differentiated according to the size of the truck, the Euro norms of the diesel technology, and the region in which pollutants are emitted (urban, suburban, interurban or highways). Urban external costs are considered for short-haul travels whereas highway external costs are used for long-haul travels by trucks. PPH travels of intermodal transport are considered to be short-haul travels. It is assumed that most of these travels happen in urban zones, leaving companies/intermodal terminals or arriving at customers/intermodal terminals that are located in cities. This assumption is supported by the fact that an important part of economic activities happens in cities. Moreover, since the model aims at minimizing costs, it tries to reduce as much as possible the road PPH travels. It is, therefore, common to observe flows sent through terminals located in the same city as its origin or destination, implying urban travels.

In order to avoid underestimating intermodal PPH costs, all short-haul travels are considered with urban external cost values. Average road external costs are computed as air pollution costs of the different EURO standard categories, weighted by the proportion of vehicles in each category for 2014 (Emisia, 2015). These costs are presented in Table 17. Road costs provided in Ricardo AEA (2014) are expressed in vehicle-kilometer. The translation into t.km is based on load factors of 0.85 for long-haul and 0.6 for short-haul travels (Janic, 2007) for a truck transporting two TEUs of 12 tonnes each. 


\begin{tabular}{llll}
\hline EURO Standard & $\begin{array}{l}\text { Share of } \\
\text { the fleet } \\
(\%)\end{array}$ & $\begin{array}{l}\text { Long-haul air } \\
\text { pollution external } \\
\text { costs } \\
(€ \text { cents/vehicle.km) })\end{array}$ & $\begin{array}{l}\text { Short-haul air } \\
\text { pollution external } \\
\text { costs } \\
(€ c e n t s / v e h i c l e . k m)\end{array}$ \\
\hline $\begin{array}{l}\text { HD Euro I - 91/542/EEC } \\
\text { Stage I }\end{array}$ & 4.53 & 11.06 & 26.66 \\
$\begin{array}{l}\text { HD Euro II - 91/542/EEC } \\
\text { Stage II }\end{array}$ & 17.43 & 11.10 & 22.07 \\
HD Euro III - 2000 Standards & 25.49 & 8.82 & 18.41 \\
HD Euro IV - 2005 Standards & 20.63 & 5.97 & 10.43 \\
HD Euro V - 2008 Standards & 26.67 & 2.40 & 7.98 \\
HD Euro VI & 5.26 & 0.49 & 1.75 \\
\hline
\end{tabular}

Table 17: EURO standards shares (Emisia, 2015) and costs (Ricardo AEA, 2014) for the truck fleet in Belgium in 2014

Rail external costs related to air pollution are given for different categories of technology (diesel versus electricity traction). Air pollution external costs for diesel traction contain exhaust and non-exhaust emission costs. Since electric traction does not generate exhaust emissions during the transportation of goods, only non-exhaust costs of wear and tear PM emissions are taken into account. Air pollution external costs are $0.7 €$ cents/t.km for diesel traction and $0.1 €$ cents $/ \mathrm{t} . \mathrm{km}$ for electric traction, considering trains loaded with 500 tonnes of goods. The diesel-electric traction ratio is $17 \%-83 \%$ (Eurostat, 2016a).

IWW external costs related to air pollution are expressed for motor vessels and barges of freight capacity between 1,000 and 3,000 tonnes.

The already existing terminals in Belgium and in its neighboring countries are considered to be open in the model. Based on the references described in Table 12 , the values given to each operational and external unit cost are provided in Table 18. 


\begin{tabular}{lll}
\hline Mode & $\begin{array}{l}\text { Operational costs } \\
(€ / t . k m)\end{array}$ & $\begin{array}{l}\text { Air } \\
\text { pollution } \\
\text { external } \\
\text { costs } \\
(€ / t . k m)\end{array}$ \\
\hline Road - short-haul & From 0.04 to 0.1 & 0.00692 \\
Road - long-haul & From 0.02 to 0.07 & 0.00323 \\
Rail & From 0.019 to 0.025 & 0.00202 \\
IWW & 0.02285 & 0.00229 \\
\hline
\end{tabular}

Table 18: Operational and external costs of transportation modes

\subsection{Findings of the Belgian case}

This section details the findings of the application of the model to the Belgian case study. It focuses on the analysis of the resulting flow distribution of goods between road and intermodal transport when different policies are followed. The economic optimization of transport operational costs is first analyzed. The environmental optimization of transport human health external costs related to air pollution is then evaluated. An intermediate policy consisting of the economic optimization of transport operational costs with the introduction of additional road taxes is then assessed. Finally, sensitivity analysis of the main hypotheses of the Belgian case study is also performed.

\subsubsection{Economic optimization}

When operational costs are minimized, one notices that most of the flows are transported by road (figure 13), which is what currently happens in Belgium and in Europe. The intermodal modal share provided by the model is around $27 \%$. This is 5\% lower than the observed rail and IWW market share in 2013 for Belgium and its surrounding countries (Eurostat, 2016b). Within the intermodal market, and compared to reality, the model underestimates the IWW share in relation to the rail component. This might be explained in several ways. First, regarding flows, we only took containerized transport into account. However, a lot of travels performed by IWW are bulk transport. Moreover, the initial model does not account for the different policies introduced by public authorities. Nevertheless, the attribution of taxes or subsidies for specific transportation 
modes impacts the modal choice and thus influences the general flow distribution (Santos et al., 2015).

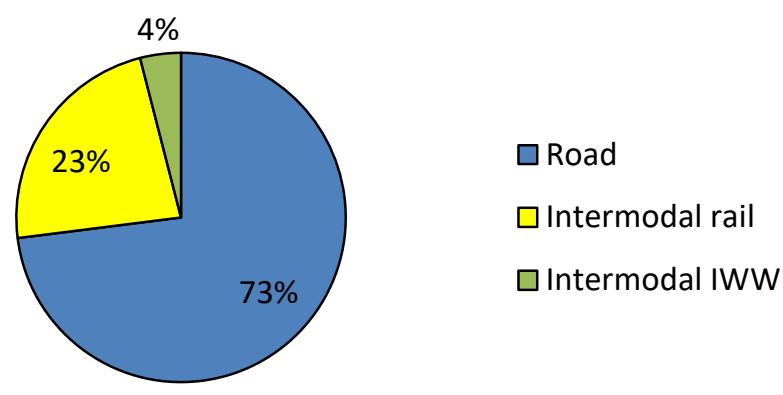

Figure 13: Flow distribution for operational costs minimization.

\subsubsection{Air pollution optimization}

When human health external costs related to air pollution are considered to be the objective to minimize, the optimal solution suggests a more intensive use of intermodal transport, to the detriment of road (figure 14). Market shares of both rail and IWW increase. The predominance of rail is explained by its lower external costs compared to IWW. Nevertheless, this predominance should be balanced, since this model considers a tank-to-wheel approach, and therefore does not reflect the externalities related to the production of electricity for running trains. In practice, this high modal share for rail could be limited by technical issues, such as capacity restrictions of rail lines and terminals. Capacity restrictions on the network may in particular be encountered because of the priority rule of passenger over freight trains. Road transport becomes the second mode of transport. According to the cost data used in the model, a minimization of the human health external costs of transport would, therefore, be achieved with a higher proportion of intermodal than road transport. Similar to the results of Macharis et al. (2010), this shows that taking into account externalities in transportation policies increases the use of intermodal transport. 


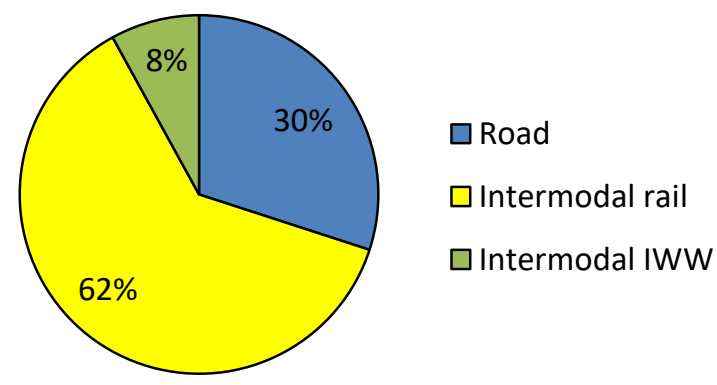

Figure 14: Flow distribution for air pollution external costs minimization.

\subsubsection{Economic optimization with taxation system}

This section analyzes the impact on flows of the introduction of an additional tax on the road network, when operational costs are optimized. This analysis takes its sources from the recent introduction of the "Viapass" road tax on highways and denser roads by the Belgian public authorities (April 2016). The objective of this tax is to allocate fairly the different damages provoked by trucks to the infrastructure and to the environment (Viapass, 2015). The Viapass road tax replaces the Eurovignette system, which was previously in place in Belgium. It is a kilometer-based charge for trucks only. The paid tax thus reflects the intensity of use of the vehicles. Different kilometric tax rates are applied based on the weight and EURO norm of the vehicle.

The tax per kilometer is applied to each truck with a permissible weight greater than 3.5 tonnes. A Viapass tariff of $0.14 € / \mathrm{km}$ is assumed, which corresponds to the average existing rates, weighted by the number of vehicles in each category for 2014 (Emisia, 2015). The Walloon/Flemish fees are considered in this case, since their respective highways represent the major part of the Belgian network. Supposing that an average truck carries 20.4 tonnes ( 2 TEU*12 tonnes/TEU*0.85 of load factor), this leads to a tax of $0.007 € / \mathrm{t} . \mathrm{km}$. The flow distribution when operational costs are minimized under the introduction of the Viapass road tax for the long-haul travels by road is given by figure 15 . 


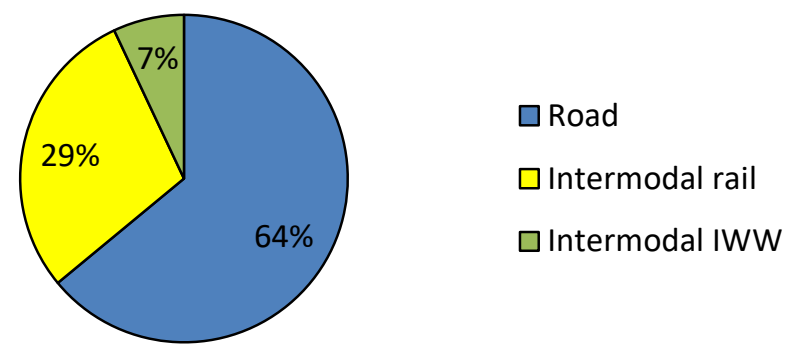

Figure 15: Flow distribution for operational costs minimization with road tax on the long-haul travels.

Compared to the operational costs minimization policy, an increase of intermodal flows is noticed. By charging an additional cost to the direct road transport, more flows are transported using the rail and IWW infrastructure. The amount of t.km transported by IWW is almost doubled while a relative increase of around $25 \%$ is observed for intermodal rail transport. With this additional tax, road transport still remains the most used mode.

Sensitivity analysis has been performed in order to identify how flows are distributed if the value of the road tax is increased. Figure 16 compares the modal split of the economic and environmental objectives, as well as the resulted modal split when the road tax is increased compared to the initial tax scenario. 


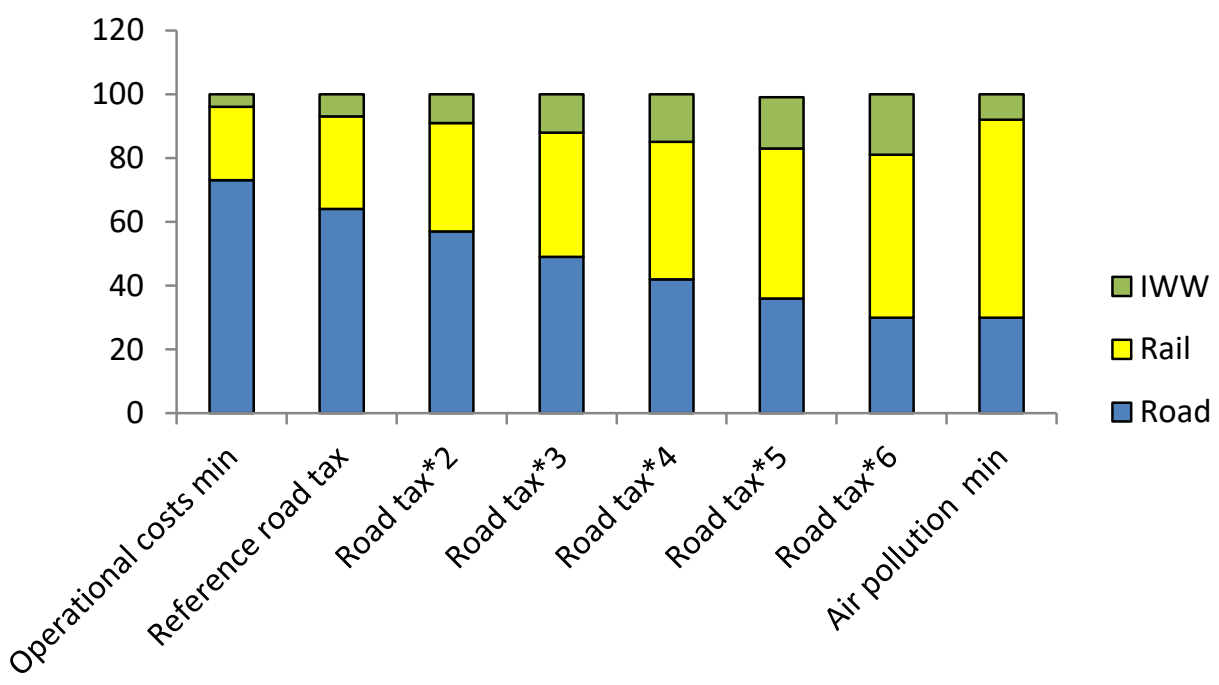

Figure 16: Flow distribution under different values of road tax

Results show that the current value of the road tax should be multiplied by six, in order to obtain the same intermodal market share as in the case of the minimization of air pollution external costs. This result underlines that the current road tax is still low compared to the optimal tax needed for ensuring a purely environmental optimization. In practice, the implementation of such an important increase of the tax value seems difficult, in view of the already high number of protests from the road sector related to the implementation of the current Viapass tax. Results also underline that implementing an additional road tax does not necessarily lead to the same modal split between intermodal rail and intermodal IWW transport. The intermodal market share of the situation in which the road tax is multiplied by six is equal to the intermodal market share under environmental optimization. However, more flows are sent by IWW under the implementation of the tax than under the environmental optimization. This is explained by the fact that the road tax favors rail and IWW in the same way, whereas rail is favored in the environmental optimization, due its low value of air pollution external costs. If the road tax is also included for short-haul travels of the intermodal transport, the flow distribution is as given in Figure 17. Applying the road fees on the short-haul travel corresponds to the assumption that all urban travels are affected by the tax, whereas this is presently only the case for the urban area of Brussels. This situation does not correspond to the current reality but the results of this analysis are interesting since they show that, even if this 
short part of the trip is impacted by the Viapass tax, more intermodal transport would nevertheless be used when compared to the single operational cost minimization problem. Indeed, the kilometers performed by road inside the intermodal travel are much fewer than the kilometers for door-to-door transport by truck. Intermodal transport is, therefore, less impacted by the Viapass fee per kilometer than road-only transport.

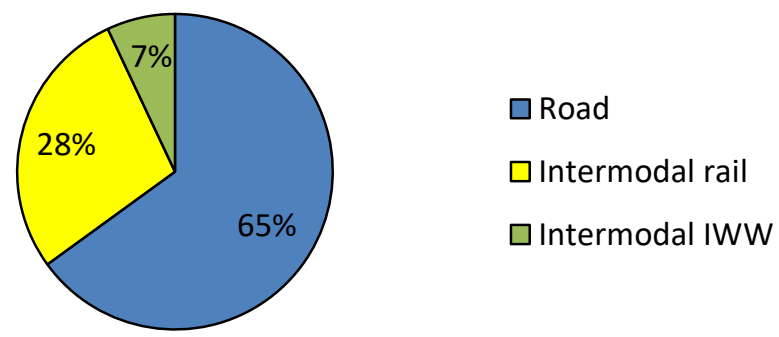

Figure 17: Flow distribution for operational costs minimization with road tax on long-haul and short-haul travels.

\subsubsection{Sensitivity analysis}

This section identifies the impact on the modal split of variations of some of the main hypotheses related to the Belgian case study. The effects of road, rail and IWW external costs changes are evaluated. A comparison between the effects of IWW operational and external costs variation is also provided.

\subsubsection{Road external costs}

This section analyzes the effects on modal split of a variation of road air pollution external cost parameters. In particular, the effect of truck fleet structure on flow distribution is evaluated.

The fleet constitution influences the average air pollution external cost value. Fleets are evolving with technological improvement. Progressively, old and more polluting trucks are replaced with cleaner vehicles. This sensitivity analysis evaluates the change of modal split when cleaner vehicles of EURO VI type are progressively replacing the oldest trucks in the Belgian territory. The reference case is compared to three scenarios: EURO VI proportion of 10\%, 15\% and $20 \%$ of the fleet. These scenarios reflect potential increases of the EURO VI vehicle 
share in the fleet. This progressive replacement of old vehicles with new vehicles is indeed expected in the future. The fleet structure of these scenarios as well as their resulted modal split are given in Table 19.

Results show that fleet structure affects modal split in terms of environmental perspective. The road market share increases with a greater proportion of EURO VI vehicles in the fleet. The introduction of cleaner road vehicles leads to solutions in which road transport is more and more included. Both rail and IWW lose market share when the road fleet becomes cleaner. A replacement of older trucks for reaching a $25 \%$-share of EURO VI vehicles (starting from a 5\%-share in the reference scenario) leads to an increase of $8 \%$ of the road market share. Therefore, improving the technology of trucks makes road transport more competitive on certain connections, from the perspective of air pollution external costs minimization. If the technology of trains and barges remains constant, intermodal rail and IWW attractiveness can subsequently be limited by an environmental improvement in truck technology. This scenario is plausible since renewal rates for barges and trains are much slower than for trucks. Truck technology is therefore more quickly adapted on the market than rail and IWW technological improvements.

\begin{tabular}{llrl}
\hline Scenario & $\begin{array}{l}\text { EURO } \\
\text { Standard }\end{array}$ & $\begin{array}{l}\text { Share of the } \\
\text { fleet }(\%)\end{array}$ & $\begin{array}{l}\text { Modal split of air } \\
\text { pollution external } \\
\text { cost min. } \\
\text { intermodal rail - } \\
\text { intermodal IWW in } \\
\%)\end{array}$ \\
\hline $\begin{array}{l}\text { EURO VI = 5\% - Reference } \\
\text { scenario }\end{array}$ & HD Euro I & 4.53 & $30-62-8$ \\
& HD Euro II & 17.43 & \\
HD Euro III & 25.49 \\
HD Euro IV & 20.63 \\
HD Euro V & 26.67 & \\
HD Euro VI & 5.26 &
\end{tabular}




\begin{tabular}{|c|c|c|c|}
\hline \multirow[t]{6}{*}{ EURO VI $=10 \%$} & HD Euro I & 0.00 & $31-62-7$ \\
\hline & HD Euro II & 17.21 & \\
\hline & HD Euro III & 25.49 & \\
\hline & HD Euro IV & 20.63 & \\
\hline & HD Euro V & 26.67 & \\
\hline & HD Euro VI & 10.00 & \\
\hline \multirow[t]{6}{*}{ EURO VI $=15 \%$} & HD Euro I & 0.00 & $33-59-8$ \\
\hline & HD Euro II & 12.21 & \\
\hline & HD Euro III & 25.49 & \\
\hline & HD Euro IV & 20.63 & \\
\hline & HD Euro V & 26.67 & \\
\hline & HD Euro VI & 15.00 & \\
\hline \multirow[t]{6}{*}{ EURO VI $=20 \%$} & HD Euro I & 0.00 & $35-59-7$ \\
\hline & HD Euro II & 7.21 & \\
\hline & HD Euro III & 25.49 & \\
\hline & HD Euro IV & 20.63 & \\
\hline & HD Euro V & 26.67 & \\
\hline & HD Euro VI & 20.00 & \\
\hline \multirow[t]{6}{*}{ EURO VI $=25 \%$} & HD Euro I & 0.00 & $38-57-5$ \\
\hline & HD Euro II & 2.21 & \\
\hline & HD Euro III & 25.49 & \\
\hline & HD Euro IV & 20.63 & \\
\hline & HD Euro V & 26.67 & \\
\hline & HD Euro VI & 25.00 & \\
\hline
\end{tabular}

Table 19: Sensitivity of flow distribution to truck fleet structure

6.6.4.2. Rail external costs

This section presents the effects on modal split of a variation of rail air pollution external cost parameters. In particular, the impact on modal split of a modification of the electric-diesel traction ratio is studied. 
Two scenarios are compared to the reference scenario. These scenarios show the potential evolution of the traction mix in Belgium, where most diesel traction is used for shunting activities at the intermodal terminals. The choice for electric or diesel traction may be driven by various criteria such as physical (some slopes on the network imply the use of electric locomotives) or financial (diesel locomotives are cheaper than electric locomotives) constraints. The modal split of the scenarios is presented in Table 20.

\begin{tabular}{ll}
\hline Scenario & $\begin{array}{l}\text { Modal split of air pollution external cost } \\
\text { min. (road - intermodal rail - intermodal } \\
\text { IWW in \%) }\end{array}$ \\
\hline $\begin{array}{l}17 \% \text { diesel }-83 \% \text { electric - Reference } \\
\text { scenario }\end{array}$ & $30-62-8$ \\
$15 \%$ diesel $-85 \%$ electric & $29-64-7$ \\
$10 \%$ diesel $-90 \%$ electric & $26-69-5$ \\
\hline
\end{tabular}

Table 20: Sensitivity of flow distribution to rail traction mix

The train traction mix between diesel and electricity influences the flow distribution. As expected, an increase of electricity use implies a bigger rail market share, since rail air pollution external costs decrease. The rail market share increase happens with a reduction of both IWW and road market shares. However, the road is a little bit more impacted than intermodal IWW transport. Consequently, reductions in the average unit external costs, through a higher use of electric traction, may be a solution to achieving part of the flow transfer from road to more environmentally friendly modes, as expected by the European Commission in its White Paper on Transport (European Commission, 2011).

\subsubsection{IWW operational and external costs}

This section develops the effects on modal split of a variation of IWW operational and air pollution external cost parameters.

In the literature, usually only the road and intermodal rail transport are compared. This is not surprising since a lot of regions are connected through road and rail, but are not necessarily equipped with waterways. This paper includes the intermodal IWW option. Belgium is well-connected through IWW, with around $1,500 \mathrm{~km}$ of waterways for a total surface of $31,000 \mathrm{~km}^{2}$ (Eurostat, 2016c). 
In order to identify how the flow distribution is impacted by the specific costs of IWW in this region, we perform a sensitivity analysis by increasing and decreasing successively the operational and external IWW costs by $10 \%, 20 \%$ and $30 \%$. These theoretical variations aim at estimating the flow distribution when the IWW input parameter varies. This helps assess the robustness of the model and also provides information on how results could evolve with other IWW cost values. The flow distribution for these different scenarios is given in Table 21. The first column provides the results of the operational/external cost minimization, whereas the second column shows the results of the external cost minimization when the operational/external IWW costs are modified.

Results show that variations of the operational and external costs of IWW play a role in modal split. Road market share seems more sensitive to IWW operational than external costs variations. Focusing on air pollution's external costs would lead to a higher proportion of intermodal transport than focusing on operational costs. However, reductions in IWW external costs, resulting from, for instance, technological improvement, would lead to flow transfers from rail to IWW, inside the intermodal market share, rather than from road to intermodal transport. This risk of flow transfer within the intermodal market share has also been highlighted by Macharis and Pekin (2009) and Mostert et al. (2017a).

In terms of operational costs, intermodal IWW transport never exceeds $18 \%$ of the market share, remaining the least used mode in most of the scenarios. However, intermodal IWW transport may reach $41 \%$ of the market share when external costs are optimized. In this case, intermodal IWW transport is the most used mode in only one out of the seven analyzed scenarios. These results are explained by the lower values of rail air pollution external costs. 


\begin{tabular}{lcc}
\hline IWW cost value & $\begin{array}{l}\text { Modal split of } \\
\text { operational } \\
\text { cost min. } \\
\text { (road- } \\
\text { intermodal } \\
\text { rail-intermodal } \\
\text { IWW in } \% \text { ) }\end{array}$ & $\begin{array}{l}\text { Modal split of } \\
\text { air pollution } \\
\text { external cost } \\
\text { min. (road- } \\
\text { intermodal } \\
\text { rail- } \\
\text { intermodal } \\
\text { IWW in } \%)\end{array}$ \\
\hline $0.7 *$ IWW cost & $67-15-18$ & $28-31-41$ \\
$0.8^{*}$ IWW cost & $68-18-14$ & $29-40-31$ \\
$0.9 *$ IWW cost & $72-19-9$ & $30-50-20$ \\
$1.0^{*}$ IWW cost - Reference scenario & $73-23-4$ & $30-62-8$ \\
$1.1 *$ IWW cost & $74-23-3$ & $30-65-5$ \\
$1.2^{*}$ IWW cost & $74-24-2$ & $30-66-4$ \\
$1.3^{*}$ IWW cost & $75-24-1$ & $30-67-3$
\end{tabular}

Table 21: Sensitivity of flow distribution to IWW operational and air pollution external costs

\subsection{Discussion of the Belgian case}

The analysis of the Belgian case study shows that the optimal flow distribution differs according to the objective that is pursued and according to the policies that are implemented. Following an economic optimization strategy by considering only operational costs leads to a high proportion of direct door-to-door road transport. On the contrary, optimizing human health external costs of transport related to air pollution provides a system where intermodal transport has the largest market share. Economic and health objectives thus lead to different trends in terms of flow allocation.

Introducing an additional road tax per kilometer allows a slight reduction in the road market share. Even when the additional tax is introduced for both short-haul and long-haul travels, an increase in the intermodal market share is noticed. Of course, this increase is greater when no tax is applied for the PPH travels by truck in the framework of an intermodal trip. Nevertheless, the introduction of a tax on roads never allows reaching the intermodal market share of the external costs minimization strategy.

The introduction of cleaner vehicles in the truck fleet increases the road market share under the air pollution external cost minimization strategy. The development of improved environmental technologies for trucks therefore makes 
road transport competitive regarding air pollution optimization. This trend tends to reduce the rail and IWW market shares and the transfer from road to intermodal solutions.

Variations in rail external costs imply changes in the modal split. Some road flows are transferred to rail, which increases the intermodal market share. Reducing rail external costs also slightly reduces the market share of intermodal IWW transport. Decreasing rail pollution external costs by increasing the electricity share in rail traction mix is, therefore, a potential solution for transferring goods from road to intermodal transport.

This case shows that road market share seems more sensitive to IWW operational than external costs variations. If policies were focusing on air pollution external costs, rather than on operational costs, decreases of IWW external costs (for instance, resulting from technological improvement) would have a low impact on flow distribution between road and intermodal transport. On the contrary, changes in unit IWW external costs would lead to flow transfers between rail and IWW, within the intermodal market share, rather than between road and intermodal transport. This switch between two intermodal modes is not aligned with the willingness of the European Commission to transfer freight flows from road to other environmentally-friendly transportation means by 2030 et 2050 (European Commission, 2011). If an air pollution costs minimization strategy is followed, policy makers should be aware that reducing unit IWW external costs will not contribute to major flow transfers from road to intermodal transport.

More generally, results of the sensitivity analysis show that modal split depends on the value of the respective operational and external costs of transportation modes. Consequently, the precise valuation of these costs is necessary for ensuring good results of the model. The valuation of operational costs is easier than the valuation of external costs since operational costs are more tangible. Mortality external costs related to air pollution are based on statistical tools such as value of statistical life or value of a life year (Ricardo AEA, 2014). The current recommended studies evaluate morbidity external costs related to air pollution through stated preference surveys (Ricardo AEA, 2014). The continuous development of such valuation methods is necessary for ensuring accurate decision support systems for long-term transportation planning policies. 
Several intermodal stakeholders can gain insight from the results of this case. First, intermodal operators are able to identify the effect on their market share of a potential improvement of their technology, reflected in a decrease of their operational or external costs. Public leaders can assess the impact of their transportation policies on the flow distribution, and thus identify how a taxation system would, for instance, support the development and extension of intermodal transport. Terminals managers are also concerned with the results. Indeed, they can evaluate the evolution of the flows passing through their terminals, and therefore determine the potential investments for matching the terminal capacity with its future demand. Finally, infrastructure managers are also able to determine the modal split and thus, for instance, to forecast which further railway or IWW connections should be developed or removed, according to the decided policy for transport planning.

\subsection{Conclusions}

In a complementary approach to studies focusing on the effects of transport in urban contexts, this paper develops an analysis of the flow distribution between road and intermodal transport at the strategic level. This study contributes to the development of decision-support tools for long-term transportation policies, by allowing the identification of the effects of current (economic) and expected future (human-health) objectives. The performance of road and intermodal transport regarding operational costs and human health external costs related to air pollution can be identified. This study improves the understanding of the impact that public authorities can have on modal split using taxation systems. The trends in the evolution of flow distribution under technological improvement or modifications of traction mix can also be deduced.

An intermodal allocation model is applied to the Belgian case in order to highlight which kinds of policy measures can be evaluated. The outcome is interesting for public authorities, terminal operators, intermodal carriers, and shippers, as well as for infrastructure managers.

Results show that intermodal transport performs better than road regarding human health external costs. The modal split between road and intermodal transport is affected by the followed economic or environmental policy. Indeed, the external costs' minimization strategy leads to a configuration where intermodal transport 
has the most important market share. On the contrary, the operational costs minimization strategy defines road transportation as the most competitive mode.

The introduction of road taxes under economic optimization decreases the road market share in relation to intermodal transport. Nevertheless, this decrease leads to an underuse of intermodal transport, compared to the environmental optimization strategy.

Under an environmental optimization strategy, sensitivity analyses demonstrate that modifications of external cost values of the three modes imply variations of the modal split.

An improvement in the environmental friendliness of road transport through the introduction of cleaner vehicles in the truck fleet makes road competitive regarding human health external costs. The environmental improvement in truck technology, therefore, restricts the potential for flow transfer from road to rail or IWW. A reduction in rail air pollution external costs, through an increased use of electricity in the traction mix, increases the intermodal market share.

Sensitivity analysis of IWW external costs underlines the possibility of flow transfers within the intermodal market share between rail and IWW rather than between road and intermodal transport. This effect is in contradiction to the willingness of the European Commission to transfer freight flows from road to more environmentally friendly modes. Therefore, this topic should be carefully analyzed when implementing measures aimed at reducing road freight flows.

The chosen transport policy definitely influences the modal split. This implies that, according to the environmental or economic strategy that is followed, different kinds of investments might need to be performed. If the focus is on environmental optimization, money should be spent on rail or IWW infrastructure, to support intermodal development. If the focus remains on economic optimization, or if cleaner trucks progressively replace older technology vehicles, road investments should be reinforced.

This research compares the economic and air pollution external costs minimization strategies. Further research work should be performed regarding the analysis of other intermediate policies such as the introduction of subsidies or the economic optimization with an internalization of external costs. This study only analyzes the effects of human health external costs related to air pollution. 
However, other external costs like noise could also be integrated in policy analysis. Results of the model are influenced by the value given to external costs and other studies focusing on the precise valuation of these costs are, therefore, necessary. This paper does not account for intermodal terminal capacity. This helps intermodal stakeholders identify the most important connections in terms of flows. However, further work should also be done to identify the match between flows and terminal capacity. 


\section{Chapter 7}

\section{Several intermodal transport chains}

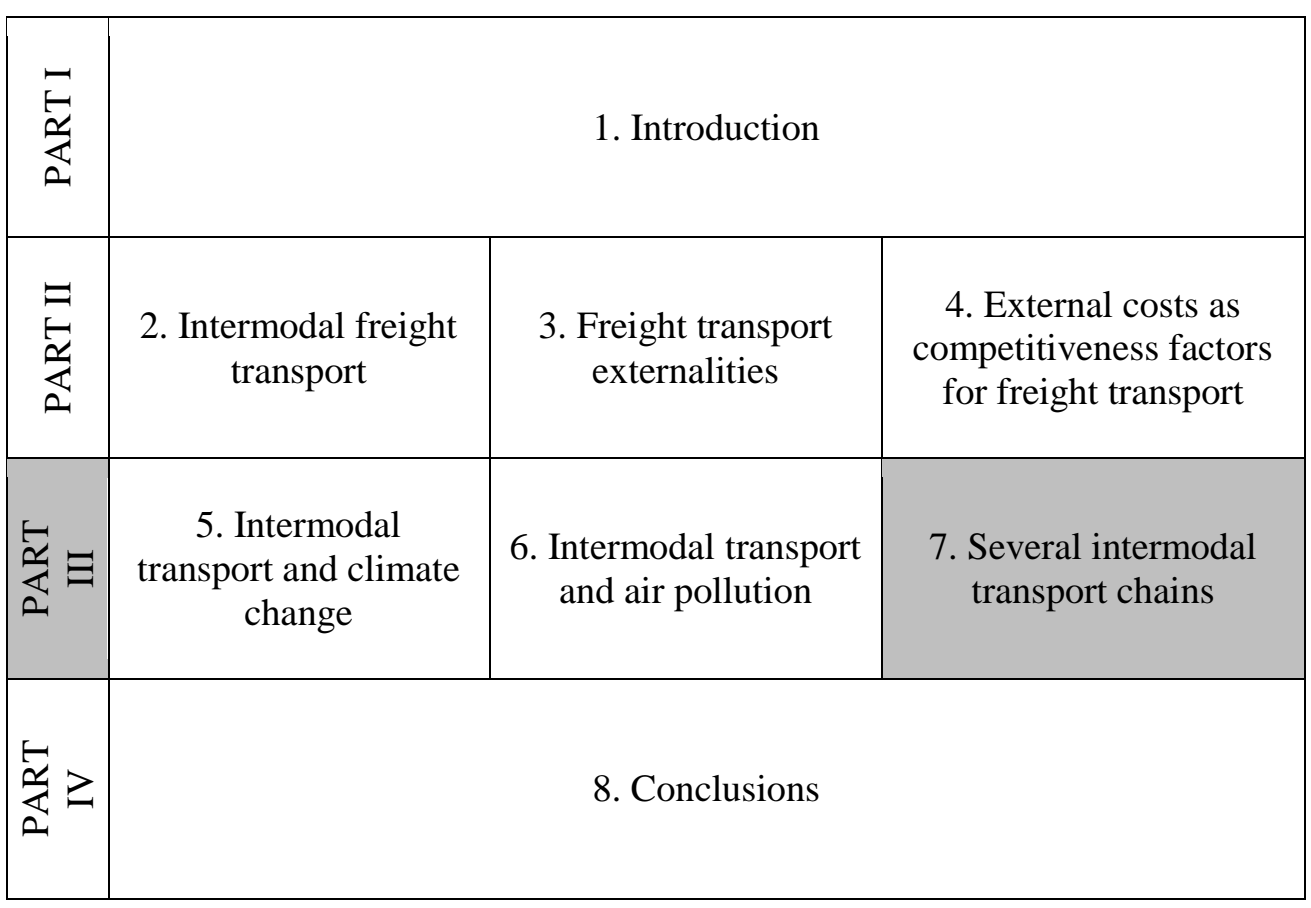

This chapter enlarges the modeling of intermodal transport developed in chapters 5 and 6, and provides an intermodal allocation formulation that allows the choice between direct transport and intermodal chains of up to three modes. The model identifies the effects on modal split of policies which optimize operational costs, $\mathrm{CO}_{2}$ emissions and air pollution external costs. The formulation is applied for experimental results on a case at the European level.

\subsection{Introduction}

With the opening of borders and the always greater decentralization of production, the transportation of goods increased a lot in the last years. In Europe, road remains the most used mode for freight transportation (Eurostat, 2016). Even 
if it is appreciated for its responsiveness, flexibility, and quickness, road transport is however responsible for negative impacts on its environment like air pollution or climate change. In order to reduce these damages of road transport, there is an increasing interest in sustaining alternative transport solutions like intermodal freight transport (European Commission, 2011).

Intermodal transport requires intermodal terminals, where the transfer from one mode to another can be achieved. Intermodal terminals can act as dry ports of sea ports, offering services such as stuffing, stripping and repair of containers, customs clearance or even storage areas (Roso et al., 2009).

Intermodal transport can be analyzed at several levels and according to different perspectives (Bontekoning et al., 2004; Mathisen and Sandberg Hanssen, 2014). The correct location of intermodal terminals and allocation of flows on an intermodal network have been studied using various methods: agent-based models (Sirikijpanichkul et al., 2007), GIS-based models (Macharis and Pekin, 2009; Macharis et al., 2010; Zhang et al., 2013; Meers and Macharis, 2014) or programming models (Arnold et al., 2001; Arnold et al., 2004; Racunica and Wynter, 2005; Ishfaq and Sox, 2011; Sörensen et al. 2012; Sörensen and Vanovermeire, 2013; Lin et al., 2014; Bouchery and Fransoo, 2015; Santos et al., 2015, Mostert and Limbourg, 2016).

In the traditional modeling of intermodal transport, pre- and post-haulage travels are supposed to be short, and to be performed by road transport, whereas the longhaul travel is done using rail or IWW (SteadieSeifi et al., 2014). Intermodal allocation or location-allocation models generally consider intermodal terminals with two modes of transport (Arnold et al., 2001, Arnold et al., 2004, Racunica and Wynter, 2005, Ishfaq and Sox, 2011, Limbourg and Jourquin, 2009, Sörensen et al., 2012, Santos et al., 2015, Mostert et al., 2017a, Mostert et al., 2017b).

Some works deal with intermodal network design with more than two modes (Zhang et al. 2015, Ghane-Ezabadi and Vergara, 2016, Mostert et al., 2017a, Mostert et al., 2017b). Zhang et al. (2015) analyze the effects on $\mathrm{CO}_{2}$ emissions and total (internal and external) network costs of several policies in a bi-level intermodal network model applied to the Dutch hinterland, while this work identifies the resulting behavior of flows when allowing any combination of up to three modes on a case at the European level with several origins and destinations. Ghane-Ezabadi and Vergara (2016) provide a path-based formulation of 
intermodal network design. This approach differs from Ghane-Ezabadi and Vergara (2016) since it does not determine feasible paths in advance and it decides on the transportation mode between any combinations of up to three modes. An application is provided based on European data whereas GhaneEzabadi and Vergara (2016) apply a decomposition-based search algorithm for solving randomly generated instances. Mostert et al. (2017a, 2017b) consider "road-rail-road" or "road-WW-road" intermodal travels, while this study allows for other combinations of modes.

The environmental impact of freight transportation is increasingly considered in decision-making related to transport (Bouchery and Fransoo, 2015, Zhang et al., 2013 , Mostert et al., 2017a, Mostert et al., 2017b) or supply chain network design (Wang et al., 2011, Chaabane et al., 2012, Martí et al., 2015).

This work develops a new mathematical intermodal allocation model applied to a network at the European level. This model questions the "road-rail/IWW-road" modeling of intermodal transport and evaluates the effects on modal split of economic and environmental policies when several intermodal chains are available. The model is based on the theory of intermodal network design, and aims at identifying how the flows are distributed, when all possible combinations of up to three modes are allowed for intermodal transport. Three main transportation formulas are included in the model, considering flow exchanges between road, rail, and IWW transport:

- A direct door-to-door transport using one single mode (road, rail or IWW)

- An intermodal transport passing through one intermodal terminal, and thus using two different modes of transport

- An intermodal transport passing through two intermodal terminals, and thus using at most three different modes of transport.

The transportation solution between an origin and a destination is constituted by one or several legs. A direct transport is constituted by one leg. An intermodal transport with one terminal has two legs. An intermodal transport with two terminals has three legs. Two consecutive legs of an intermodal transport cannot be performed by the same mode of transport.

The various possibilities that are evaluated by the model in terms of flow transportation between each origin and destination are given in table 22 . 


\begin{tabular}{lll}
\hline Direct Transport & $\begin{array}{l}\text { Intermodal transport } \\
\text { one terminal }\end{array}$ & $\begin{array}{l}\text { with } \\
\text { Intermodal transport with } \\
\text { two terminals }\end{array}$ \\
\hline Road & Road-Rail & Road-Rail-Road \\
Rail & Road-IWW & Road-Rail-IWW \\
IWW & Rail-Road & Road-IWW-Road \\
& Rail-IWW & Road-IWW-Rail \\
& IWW-Road & Rail-Road-Rail \\
& IWW-Rail & Rail-IWW-Road \\
& & Rail-IWW-Rail \\
& & IWW-Road-Rail \\
& & IWW-Road-IWW \\
& & IWW-Rail-Road \\
& IWW-Rail-IWW \\
\hline
\end{tabular}

Table 22: Transportation possibilities for each origin-destination pair

Even if intermodal transport provides several benefits compared to the current transportation system mainly driven by road, transshipping goods from one mode of transport to another has a cost, both in terms of operations and externalities. In the model, intermodal transport is assumed to pass through a maximum of two terminals to better match reality. This restriction reflects the cost of transshipment activities, which should not be repeated too many times, in order to remain efficient and competitive regarding a direct transportation mode.

Allowing any combination of modes on the network may remind the concept of synchromodality (Zhang and Pel, 2016). However, this approach differs from synchromodal transport, since it relates to the strategic and not to the operational level of decision, and therefore does not focus on the dynamic choice of a transport service provider between several transportation opportunities at a precise moment in time.

This research provides a new tool to identify the impact of economic (operational costs) and environmental ( $\mathrm{CO}_{2}$ emissions and air pollution external costs) policies on the modal split between transportation solutions which account for several intermodal chains. The objective is to reflect the possibilities to use a combination of the three inland modes (road, rail, and IWW) on different legs of the intermodal path, for a same origin-destination pair. This concept could for instance be applied between a sea port and its hinterland, i.e. the "continental area of origin and destination of traffic flows through a port" (van Klink and van den Berg, 1998). The model allows analyzing the flow distribution of an already established network, by taking the open terminals into account. On the contrary of 
what is generally done in the literature, the model accounts for intermodal terminals where two and three modes of transport are available. Terminal can be classified into three categories: road-rail, road-IWW, and road-rail-IWW. In the model, no terminal rail-IWW is accounted for, since in real life, intermodal terminals always have a road access. This work aims at identifying whether different combinations than the "road-rail/IWW-road" modeling of intermodal transport are used, in order to reach an economic or an environmental optimum. This study compares the results of intermodal structure in terms of operational costs, $\mathrm{CO}_{2}$ emissions, and human health external costs related to air pollution. This research therefore extends the studies developed in chapter 5 (Mostert et al., 2017a) and chapter 6 (Mostert et al., 2017b) of the thesis.

In addition to the mathematical formulation, this paper provides some first experimental results on a case at the European level to evaluate the potential flow transfers between direct and intermodal transport. These experimental results aim at providing a first overview of the behavior of the flow distribution between direct transport and intermodal transport with one and with two terminals, when any combination of modes is allowed. The objective is therefore not to provide precise policy-oriented advice on a specific case study, but rather to identify and illustrate the general behavior and potential insights of the model using data on an extended territory.

The next section details the mathematical formulation of the model. Section 7.3 elaborates on the experimental data at the European level. Section 7.4 analyzes the types of insights that can be provided by the model, through the evaluation of the results of three different policies in terms of modal split between direct transport, intermodal transport with one terminal, and intermodal transport with two terminals. Section 7.5 discusses the results provided by the model. Finally, section 7.6 provides the main conclusions.

\subsection{Model formulation}

In this model, flows are aggregated at NUTS 2 level and the demand for each region is concentrated on a single generation node, called centroid, chosen for the importance of the cities in the NUTS 2 region and the existence of a rail/IWW platform nearby. The centroids are always connected to the road network and, depending on their geographical location, can also be connected to the rail and to 
the IWW network. The origin and destination centroids are however not the initial origin and final destination of goods.

Two categories of initial/final nodes within the zone represented by the centroid can be identified: initial/final nodes that can be reached only by road and initial/final nodes that be reached by road and rail or IWW. To ensure that goods can always be delivered between their initial origin node and their initial centroid, or between their final centroid and their final destination node, it is assumed that all the deliveries from initial or to final nodes are performed by road. Since a centroid city is always connected to the road network, there is no need to introduce additional road transport connectors to virtually link the centroid to the closest node of the road network.

Since all initial/final deliveries are assumed to be transported by road, these deliveries represent fixed costs and can be omitted because they do not influence the resulting modal split. However, if goods are leaving an origin centroid or arriving at a destination centroid by rail or IWW, additional transshipment costs have to be included in the objective function.

The mathematical formulation of the model is developed here below.

\section{$\underline{\text { Sets }}$}

$N \quad$ node set consisting of $n$ demand nodes, indexed by $i, j, k, m \in\{1, \ldots, n\}$

$S \quad$ set of modes, indexed by $c, l \in\{1, \ldots, s\}$, where the mode 1 of the set is road

\section{$\underline{\text { Parameters }}$}

$\beta_{\text {ic }} \quad=1$ if a terminal is located at $k$ with mode $c \neq 1$ available,

$=0$ otherwise

$s_{i m l} \quad$ distance between demand nodes $i$ and $m$ using mode $l$ (in $\mathrm{km}$ )

$D_{i m} \quad$ cargo demand from demand node $i$ to demand node $m$ (in $\mathrm{t}$ ) 
The following parameters represent the value of operational costs, of $\mathrm{CO}_{2}$ emissions, or of human health external costs related to air pollution, depending on the optimization under study (operational costs, $\mathrm{CO}_{2}$ emissions or air pollution external costs respectively).

$a_{l}^{R} \quad$ transportation operational costs or $\mathrm{CO}_{2}$ emissions or air pollution external costs for travelling with mode $l$ (in $€ /$ t.km)

$a^{T} \quad$ transshipment operational costs or $\mathrm{CO}_{2}$ emissions or air pollution external costs (in $€ / t)$

Decision variables

$W_{i m l}$ direct flows from demand origin $i$ and destination $m$ with mode $l$ (in tonnes), $\forall i, m \in N, \forall l \in S$

$X_{i j k}^{c l} \quad$ intermodal flows from origin $i$ routed through first terminal $j$ with mode $c$ (first leg) and then through second terminal $k$, with mode $l$ (second leg) (in tonnes), $\forall i, j, k \in N, \forall c, l \in S$

$Q_{i k m}^{l c}$ intermodal flows from origin $i$ to destination $m$ routed through second terminal $k$ with mode $l$ (second leg) and with mode $c$ (third leg) (in tonnes), $\forall i, k, m \in N, \forall c, l \in S$

$U_{i k m}^{c l}$ intermodal flows from origin $i$ to destination $m$ that are routed through single terminal $k$ with mode $c$ (first leg) and with mode $l$ (second leg) (in tonnes), $\forall i, k, m \in N, \forall c, l \in S$ 
Objective function

$$
\begin{aligned}
& \sum_{i \in N} \sum_{m \in N} \sum_{l \in S} s_{i m l} * a_{l}^{R} * W_{i m l} \\
& +\sum_{i \in N} \sum_{j \in N} \sum_{k \in N} \sum_{c \in S}\left(s_{i j c} * a_{c}^{R}+a^{T}\right) * X_{i j k}^{c l} \\
& +\sum_{i \in N} \sum_{j \in N} \sum_{k \in N} \sum_{c \in S} \sum_{l \in S} s_{j k l} * a_{l}^{R} * X_{i j k}^{c l} \\
& +\sum_{i \in N} \sum_{k \in N} \sum_{m \in N} \sum_{l \in S} \sum_{c \in S}\left(s_{k m c} * a_{c}^{R}+a^{T}\right) * Q_{i k m}^{l c} \\
& +\sum_{i \in N} \sum_{k \in N} \sum_{m \in N} \sum_{c \in S} \sum_{l \in S}\left(s_{i k c} * a_{c}^{R}+s_{k m l} * a_{l}^{R}+a^{T}\right) * U_{i k m}^{c l} \\
& +\sum_{i \in N} \sum_{m \in N} \sum_{l \neq 1 \in S}^{2} * a^{T} * W_{i m l} \\
& +\sum_{i \in N} \sum_{j \in N} \sum_{k \in N} \sum_{c \neq 1 \in S} \sum_{l \in S} a^{T} * X_{i j k}^{c l} \\
& +\sum_{i \in N} \sum_{k \in N} \sum_{m \in N} \sum_{l \in S} \sum_{c \neq 1 \in S} a^{T} * Q_{i k m}^{l c} \\
& +\sum_{i \in N} \sum_{k \in N} \sum_{m \in N} \sum_{m \in N} \sum_{c \neq 1 \in S} a^{T} * U_{i k m}^{c l} \\
& +\sum_{i \in N} \sum_{k \in N} \sum_{m \in N} \sum_{c \in S} a_{l \neq 1 \in S}^{T} * U_{i k m}^{c l}
\end{aligned}
$$

Subject to

$$
\begin{array}{lr}
D_{i m}=\sum_{l \in S} W_{i m l} & \forall i, m \in N \\
+\sum_{k \in N} \sum_{c \in S} \sum_{l \in S}\left(Q_{i k m}^{l c}+U_{i k m}^{c l}\right) & \forall i, j \in N, \forall c \neq 1 \in S \\
\sum_{k \in N} \sum_{l \in S}^{c l} X_{i j k}^{c l} \leq \beta_{i c} \beta_{j c} \sum_{m \in N} D_{i m} & \forall i, j, k \in N, \forall l \neq 1 \in S \\
\sum_{c \in S} X_{i j k}^{c l} \leq \beta_{j l} \beta_{k l} \sum_{m \in N} D_{i m} & \forall i, k, m \in N, \forall c \neq 1 \in S
\end{array}
$$




$$
\begin{aligned}
& \sum_{j \in N} \sum_{c \in S} X_{i j k}^{c l}=\sum_{m \in N} \sum_{c \in S} Q_{i k m}^{l c} \\
& \sum_{l \in S} \sum_{m \in N} U_{i k m}^{c l} \leq \beta_{i c} \beta_{k c} \sum_{m \in N} D_{i m} \\
& \sum_{c \in S} U_{i k m}^{c l} \leq \beta_{k l} \beta_{m l} \sum_{m \in N} D_{i m} \\
& W_{i m l} \leq \beta_{i l} \beta_{m l} D_{i m} \\
& W_{i m l} \geq 0 \\
& X_{i j k}^{c l} \geq 0 \\
& Q_{i k m}^{l c} \geq 0 \\
& U_{i k m}^{c l} \geq 0
\end{aligned}
$$

$$
\begin{array}{r}
\forall i, k \in N, \forall l \in S \\
\forall i, k \in N, \forall c \neq 1 \in S \\
\forall i, k, m \in N, \forall l \neq 1 \in S \\
\forall i, m \in N, \forall l \neq 1 \in S \\
\forall i, m \in N, \forall l \in S \\
\forall i, j, k \in N, \forall c, l \in S \\
\forall i, k, m \in N, \forall c, l \in S \\
\forall i, k, m \in N, \forall c, l \in S
\end{array}
$$

Figure 18 illustrates the flow variables of the model. Direct flows are modeled using variables $W_{i m l}$. Intermodal flows through one terminal are modeled using variables $U_{i k m}^{c l}$. Intermodal flows through two terminals are modeled using variables $X_{i j k}^{c l}$ and $Q_{i k m}^{l c}$.

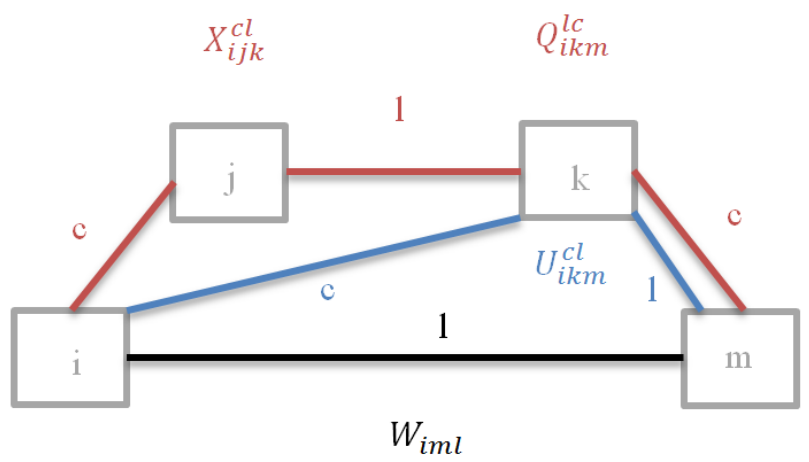

Figure 18: Flow variables of the model

The objective function (51) consists in the total transportation costs or $\mathrm{CO}_{2}$ emissions or air pollution external costs between all the origin-destination pairs. They are constituted by four main categories of transportation costs: (i) costs for direct transport through a unique mode, (ii) costs for intermodal transport with one terminal, (iii) costs for intermodal transport with two terminals, and (iv) additional transshipment costs if goods leave an origin node or arrive at a destination node using another mode of transport than road. 
- For direct transport (i), costs include the travel between the origin and the destination, with the unique mode.

- For intermodal transport with one terminal (ii), costs include the travel from the origin to the terminal with the first mode, the transshipment at the terminal, and the travel from the terminal to the destination with the second mode.

- For intermodal transport with two terminals (iii), costs include the prehaulage travel from the origin to the first terminal with the first mode, the transshipment at the first terminal, the long-haul travel between the two terminals with a second mode, the transshipment at this second terminal, and the post-haulage travel between the second terminal and the destination with a mode different from the second one.

- Additional transshipment costs for goods leaving an origin or arriving at a destination node with another mode of transport than road (iv) are introduced to take into account the aggregation of flows.

Several issues constrain the objective function. Demand should be satisfied, either through a direct transport, an intermodal transport with one terminal, or an intermodal transport with two terminals (52). When intermodal transport with two terminals is used, flows cannot go through two consecutive terminals if these terminals are not open and if they do not own the same mode of transport (53)(55). A constraint similar to (55) regarding the availability of mode $l$ at terminal $k$ for variables $Q_{i k m}^{l c}$ is not needed thanks to constraints (54) and (56). When intermodal terminal with two terminals is chosen, flows between the terminals should be conserved (56). In the case of an intermodal travel with one terminal, flows cannot transit through two consecutive terminals if they are not open and if they do not own the same mode of transport (57)-(58). If direct transport is used, flows cannot go from the origin to the destination terminal if they are not open and if do not own the same mode of transport (59). Non-negativity constraints have to be respected for the flows sent using direct transportation (60), for intermodal flows using two terminals (61)-(62) and for intermodal flows transiting through one terminal (63). 


\subsection{Experimental data at the European level}

The objective of this section is to detail the data used to test the model. The experimental results related to the used data aim at providing a first overview of the behavior of the flow distribution between direct transport and intermodal transport with one and with two terminals, when any combination of modes is allowed. The objective is therefore to illustrate how the model can be used, and which kinds of results can be retrieved. These experimental tests aim at identifying how the model works on a network with medium to long distances and with already existing terminals. To this effect, data rely on values retrieved from the European network.

Europe is a vast territory connected through an important number of links on the road, rail and IWW networks. Several intermodal terminals already exist on the land. Since intermodal transport is often recommended for medium to long distances (European Commission, 2011), the European territory allows analyzing the variations of flow distribution, when any possible combination of up to three modes is available.

The choice for the analysis at the European level is driven by several elements, which allow considering Europe as a unique entity, rather than a simple combination of different countries which cooperate from time to time.

The political willingness of creating an open market on the European territory is clearly observed through different policies put into practice. The first and most important one is the free circulation of goods in Europe. It is one of the four fundamental freedoms that define the single market of the European Commission, besides the freedom of movement for workers, the right of establishment and the freedom to provide services, and the free movement of capital (European Policy Center, 2016). The free circulation of goods has come into effect on the $1^{\text {st }}$ July 1968, by suppressing customs duties and quantitative restrictions (contingents) between the member states (European Parliament, 2016). The elimination of physical and technical barriers between countries (such as interoperability issues, please refer to section 2.2 SWOT analysis of intermodal freight transport) is also part of the measures taken for ensuring the free circulation of goods. In addition, legislative barriers have been removed, by harmonizing as much as possible the rules between the different member states. 
The development of the single market in terms of freight flows is highlighted by the definition of the nine TEN-T core network corridors, which cover the whole European territory from North to South and from East to West. The objective of the definition of these corridors is to facilitate the coordinated implementation of the core network. Each corridor brings together public and private actors who aim at removing bottlenecks, building missing cross-border connections, and promoting modal integration and interoperability (European Commission, 2016).

Specific measures related to the willingness of creating a single European market can be identified for the road, rail, and IWW networks.

On the road network, harmonization measures have taken place, such as the introduction of European rules for the maintenance of the security patterns of the vehicles and road infrastructure. This implies, for instance, the regular technical control of vehicles and their trailers, the introduction of cruise control systems for vehicles heavier than 3.5 tonnes, and the introduction of directives related to security measures for road tunnels. The development of the European Agreement concerning the International Carriage of Dangerous Goods by Road (ADR) also defines specific rules to follow on the whole European territory, concerning the transportation of hazardous goods by road. Even if some standardization trend is observed on the road market, the member states remain sovereign, i.e. they can still decide to adhere or not to the propositions made by Europe. This characteristic explains the remaining differences in different policies from one country to another. Some examples are the authorization or not of circulation of longer and heavier trucks (Eco-combi) on the different networks of the European countries, the fees to pay to use the national highway network, as well as the authorizations/interdictions for trucks to drive on highways during specific days or periods of time. Despite these differences, the European road market is quite accessible by any member of the Union, and remains the most used of transport for the transfer of goods. Indeed, in 2014, 75.5\% of the freight t.km in Europe (28 countries) were transported by road (Eurostat, 2016).

The opening of the European rail network to international freight services started in 2008. Some standardization willingness is clearly observed since then. This passes through the introduction of interoperable systems, with the replacement of the national systems by a unique and coherent European Rail Traffic Management system. The objective is to standardize rail in terms of signaling systems, security and braking rules, rolling stock, maximum speed limits, communication 
technology, and traction electricity. The use of information technology has an important role to play in the standardization procedure of rail. Indeed, it allows more fluidity on the network, through the improvement of the communication capacities.

Some approaches have also been undertaken on the IWW network, in order to allow a better communication between the different axes throughout the European territory. Contrary to the road network, where axes are generally standardized and normalized, IWW axes suffer from very diverse sizes and depths, due to their different times of construction, or to the natural characteristics to which they are constrained. European IWWs have been classified by the European Conference of Ministers of Transport (CEMT) into several classes, according to their capacity of welcoming barges and ships of specific dimensions and weights. This has been done to provide better information on the kind of ships and barges that could be transported on specific axes, based on dimension and load restrictions. The access to locks and bridges is also established based on these references. At the IWW level, the development of River Information Services, "the information technology designed to optimize traffic and transport processes in inland navigation" (Schilk and Seemann, 2012), also contributes to the unification of the European IWW market.

Since the European willingness is to create a unique open market which ensures the freedom of movement of goods, and due to the adequacy of the use of intermodal transport on medium to long distances, the European network is an interesting application to study.

The experimental results of the model have been tested at the European level on the basis of flows exchanges between NUTS 2 regions close to the nine European TEN-T core network corridors. The origin/destination matrix is constituted by these NUTS 2 regions that are crossed by the corridors.

The rail and IWW terminals have been retrieved from Agora (2016). The distances by road between any origin-destination pair has been computed using GoogleMaps (2016). The IWW network distances are obtained through Periskal (Promotie Binnenvaart Vlaanderen, 2016). The rail segments originate from TENTec Interactive Map Viewer developed by the European Commission (2016b). Demand for total containerized flows by road, rail, and IWW originates from the Worldnet database (Newton, 2009). 
Table 23 provides the values and sources of unit operational costs, $\mathrm{CO}_{2}$ emissions, and human health external costs related to air pollution used for the European data.

\begin{tabular}{|c|c|c|c|c|}
\hline Parameter & $\begin{array}{l}\text { Operational } \\
\text { costs }\end{array}$ & $\mathrm{CO}_{2}$ emissions & $\begin{array}{c}\text { Air } \\
\text { pollution } \\
\text { external } \\
\text { costs }\end{array}$ & Source \\
\hline Road & $\begin{array}{l}0.045 \\
€ / \text { t.km }\end{array}$ & $\begin{array}{c}0.027440 \\
\mathrm{~kg} \mathrm{CO}_{2} / \mathrm{t} . \mathrm{km}\end{array}$ & $\begin{array}{c}0.00323 \\
€ / \mathrm{t} . \mathrm{km}\end{array}$ & $\begin{array}{l}\text { Operational costs: Janic } \\
(2007,2008) \\
\mathrm{CO}_{2} \text { emissions: Hoen et } \\
\text { al. }(2010,2014) \\
\text { External costs: Ricardo- } \\
\text { AEA }(2014)\end{array}$ \\
\hline Rail & $\begin{array}{c}0.032 \\
€ / \mathrm{t} . \mathrm{km}\end{array}$ & $\begin{array}{c}0.01638 \\
\mathrm{~kg} \mathrm{CO}_{2} / \mathrm{t} . \mathrm{km}\end{array}$ & $\begin{array}{c}0.00202 \\
€ / \mathrm{t} . \mathrm{km}\end{array}$ & $\begin{array}{l}\text { Operational costs: Janic } \\
(2007,2008) \\
\mathrm{CO}_{2} \text { emissions: Hoen et } \\
\text { al. }(2010,2014) \\
\text { External costs: Ricardo- } \\
\text { AEA }(2014)\end{array}$ \\
\hline IWW & $\begin{array}{c}0.02285 \\
€ / \mathrm{t} . \mathrm{km}\end{array}$ & $\begin{array}{c}0.007145 \\
\mathrm{~kg} \mathrm{CO} / \mathrm{t} . \mathrm{km}\end{array}$ & $\begin{array}{c}0.00229 \\
€ / \mathrm{t} . \mathrm{km}\end{array}$ & $\begin{array}{l}\text { Operational costs: PWC } \\
(2003) \\
\mathrm{CO}_{2} \text { emissions: Hoen et } \\
\text { al. (2010, 2014) } \\
\text { External costs: Ricardo- } \\
\text { AEA (2014) }\end{array}$ \\
\hline Transshipment & $\begin{array}{l}2.8 \\
€ / \mathrm{t}\end{array}$ & $\begin{array}{c}0.167 \\
\mathrm{~kg} \mathrm{CO}_{2} / \mathrm{t}\end{array}$ & $\begin{array}{c}0 \\
€ / \mathrm{t}\end{array}$ & $\begin{array}{l}\text { Operational costs: Janic } \\
(2007,2008) \\
\mathrm{CO}_{2} \text { emissions: te Loo } \\
(2009) \\
\text { External costs: Baccelli } \\
\text { et al., } 2001\end{array}$ \\
\hline
\end{tabular}

Table 23: Unit operational costs, $\mathrm{CO}_{2}$ emissions, and air pollution external costs values 


\subsection{Experimental results at the European level}

The application at the European level has been solved on a workstation (Windows 10 Pro, Intel Xeon $2.1 \mathrm{GHz}, 32 \mathrm{~GB}$ of RAM) with CPLEX 12.63. The objective of this section is twofold. First it is to test the model in order to identify which kinds of results can be retrieved from the model (evolution of flow exchanges). Second, it is to provide insights on methodological issues related to the structure of the model and its application. This section is therefore focused on testing the model and identifying its behavior rather than analyzing precisely a case study in order to provide policy oriented decision support.

For illustrating how the model can be used, three optimization policies are compared: operational costs, $\mathrm{CO}_{2}$ emissions, and human health external costs related to air pollution. The distribution of flows when any combination of up to three modes is allowed on the intermodal travel is studied. A sensitivity analysis of the results to variations of the unit operational costs, $\mathrm{CO}_{2}$ emissions, air pollution external costs and transshipment parameters is then developed.

\subsubsection{Three optimization policies}

This section analyzes the general flow behavior when operational costs, $\mathrm{CO}_{2}$ emissions or human health external costs related to air pollution are optimized. Table 24 gives an overview of the modal split between road, rail, and IWW transport.

\begin{tabular}{lccc}
\hline Minimization & $\begin{array}{c}\text { Road flows } \\
\text { (t.km) }\end{array}$ & $\begin{array}{c}\text { Rail flows } \\
\text { (t.km) }\end{array}$ & $\begin{array}{c}\text { IWW flows } \\
\text { (t.km) }\end{array}$ \\
\hline $\begin{array}{l}\text { Operational } \\
\text { costs }\end{array}$ & $50 \%$ & $40 \%$ & $10 \%$ \\
$\begin{array}{l}\mathrm{CO}_{2} \\
\text { emissions }\end{array}$ & $25 \%$ & $43 \%$ & $32 \%$ \\
$\begin{array}{l}\text { Air pollution } \\
\text { external costs }\end{array}$ & $32 \%$ & $63 \%$ & $5 \%$ \\
\hline Table 24: Modal splits between road, rail and IWW flows
\end{tabular}

The economic optimization favors road, followed by rail and IWW. The environmental optimizations define rail transport as the preferred mode. This is explained by the lower unit environmental parameters of rail compared to road and IWW. The minimization of $\mathrm{CO}_{2}$ emissions gives a higher market share for IWW compared to the minimization of operational costs and $\mathrm{CO}_{2}$ emissions. $\mathrm{CO}_{2}$ 
emissions for IWW are computed based on the assumption that 3,000 tonnes of goods are transported by a medium barge, while air pollution external costs are given for boats transporting goods within a range of 1,000 and 3,000 tonnes. This assumption favors IWW in the $\mathrm{CO}_{2}$ emissions optimization case and explains why its use is increased compared to the air pollution external costs minimization. The share of IWW is lower in the optimization of air pollution external costs than in the optimization of operational costs. This comes from the fact that rail and IWW unit parameters are closer for air pollution external costs than for operational costs. It results that rail attracts most of the flows under the air pollution external costs optimization, to the detriment of IWW.

\begin{tabular}{lcc}
\hline Minimization & $\begin{array}{c}\text { Direct flows } \\
\text { (t.km) }\end{array}$ & $\begin{array}{c}\text { Intermodal } \\
\text { flows (t.km) }\end{array}$ \\
\hline $\begin{array}{l}\text { Operational } \\
\text { costs }\end{array}$ & $6 \%$ & $94 \%$ \\
$\mathrm{CO}_{2}$ & $2 \%$ & $98 \%$ \\
$\begin{array}{l}\text { emissions } \\
\text { Air pollution } \\
\text { external costs }\end{array}$ & $2 \%$ & $98 \%$ \\
\hline
\end{tabular}

Table 25: Modal split between direct and intermodal flows

Table 25 identifies the flow distribution between direct transport and intermodal transport.

Intermodal transport is preferred to direct transport in both economic and environmental optimizations. This is explained by three main factors: (i) the aggregation level of the data and the all-or-nothing characteristic of the model, (ii) the structure of the model which allows any mode of transport on any intermodal leg, and (iii) the structure of the data which considers regions located next to intermodal terminals.

(i) The model is run with aggregate flows at the NUTS 2 level. Since a region is relatively large (in Belgium, a NUTS 2 level of aggregation corresponds to the provinces), this means that more centroids are assumed to have a rail or an IWW access. Hence, the relative number of rail and IWW terminals compared to the total number of nodes considered is increased. More nodes can be accessed by rail or IWW. Since rail and IWW unit parameters are lower than road parameters, more flows are sent using a combination of modes, to the detriment of direct transport. The all-or-nothing characteristic of the model also 
impacts the flow distribution since all the flows between a single origin-destination pair are sent through the same path. If intermodal transport is the cheapest mode, all the flows will be sent through this mode. At the considered level of aggregation, it may clearly influence the proportion of flows transferred using a specific transport solution.

(ii) Unlike the formulations developed in chapters 5 and 6 of the thesis, rail and IWW can be used for the first and last legs of an intermodal travel. There is therefore much more possibilities to use rail and IWW in combinations, which reduces the proportion of direct transport.

(iii) The data consists in the NUTS 2 regions crossed by the core network corridors. The NUTS 2 centroids are close to intermodal terminals, which enhances the use of intermodal transport. The more intensive use of direct transport for the economic than for the environmental optimizations is explained by the relatively higher values for transshipment economic than environmental parameters.

Within the intermodal market share, the three optimization policies provide similar flow distribution between intermodal transport with one terminal (59\%) and intermodal transport with two terminals (41\%). Intermodal transport with one terminal is preferred to intermodal transport with two terminals. This flow distribution highlights the preference for transportation solutions with fewer transshipments but also underlines that, for some connections, combining three modes of transport can compensate for the additional transshipment costs or emissions related to the transfer of goods between modes.

For the three optimization policies, table 26 summarizes the flow distribution within direct transport between road, rail and IWW.

\begin{tabular}{lccc}
\hline Minimization & $\begin{array}{c}\text { Direct road } \\
\text { flows (t.km) }\end{array}$ & $\begin{array}{c}\text { Direct rail } \\
\text { flows (t.km) }\end{array}$ & $\begin{array}{c}\text { Direct IWW } \\
\text { flows (t.km) }\end{array}$ \\
\hline $\begin{array}{l}\text { Operational } \\
\text { costs }\end{array}$ & $59 \%$ & $35 \%$ & $6 \%$ \\
$\begin{array}{l}\mathrm{CO}_{2} \\
\text { emissions }\end{array}$ & $34 \%$ & $41 \%$ & $25 \%$ \\
$\begin{array}{l}\text { Air pollution } \\
\text { external costs }\end{array}$ & $41 \%$ & $57 \%$ & $2 \%$ \\
\hline
\end{tabular}

Table 26: Detailed modal split within direct transport

Road is mostly chosen for direct transport under the optimization of operational costs. Rail is the preferred mode for direct transport for environmental 
optimizations. The direct IWW market share is relatively low except for the $\mathrm{CO}_{2}$ emissions minimization, which provides a more competitive unit value for IWW transport.

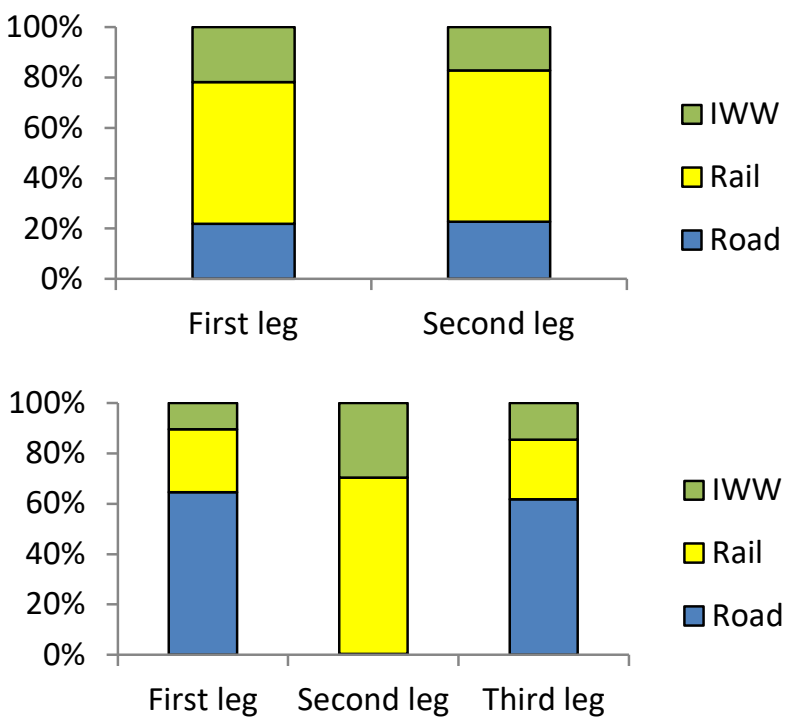

Figure 19: Flow distribution of intermodal transport through one terminal (a) and through two terminals (b) for operational costs min.

Under the operational costs minimization policy, the intermodal flows through one single terminal are mostly transported by rail on the first and second legs of the intermodal path (figure 19a). This contributes to the relatively high market share of rail. For intermodal flows through two terminals, most of the flows are transported by road on the first and third legs of the intermodal path, while the second leg of the transport is mainly performed by rail (figure 19b). 


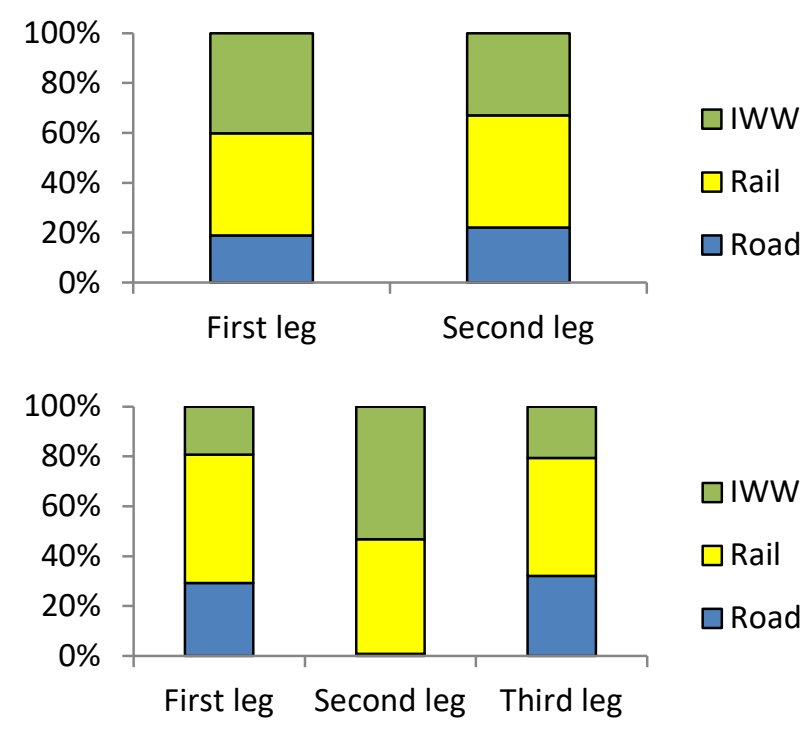

(a)

(b)

Figure 20: Flow distribution of intermodal transport through one terminal (a) and through two terminals (b) for $\mathrm{CO}_{2}$ emissions min.

Under the $\mathrm{CO}_{2}$ emissions minimization policy, the first and second legs of intermodal transport with one terminal are dominated by rail and by IWW (figure 20a). For intermodal transport with two terminals, the first leg is mainly performed by rail, followed by road and IWW (figure 20b). The second leg is shared by rail and IWW. The last leg is mostly done using rail, followed by road and IWW. These results explain the increased market share of IWW compared to the operational costs optimization policy. 


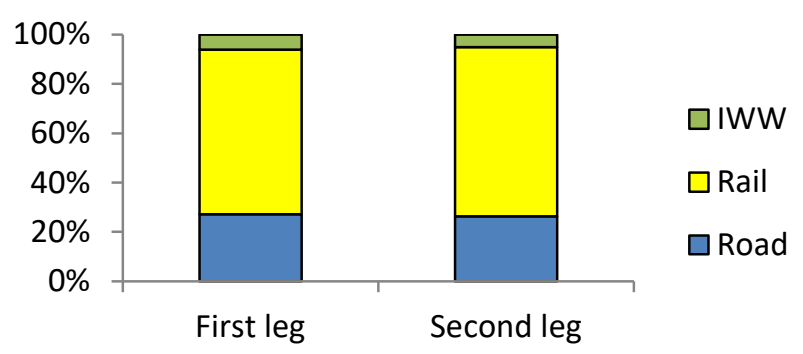

(a)

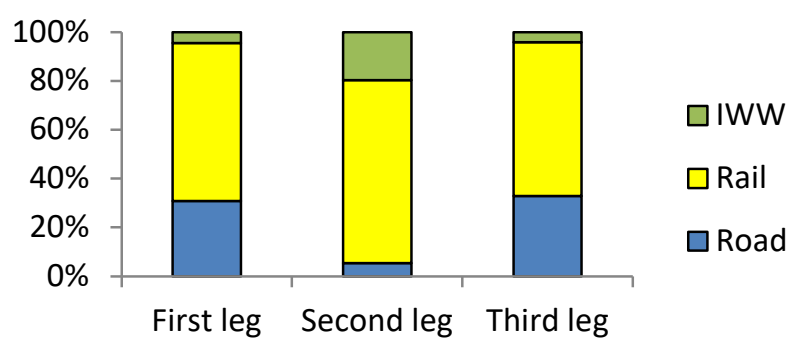

(b)

Figure 21: Flow distribution of intermodal transport through one terminal (a) and through two terminals $(b)$ for air pollution min.

Under the air pollution external costs minimization policy, the first and second legs of the intermodal transport with one terminal are characterized by high rail flows (figure 21a). For intermodal transport with two terminals, rail is the dominant mode for the first and last legs, followed by road (figure 21b). The second leg of the intermodal transport is also mostly performed by rail, followed by IWW.

Table 27 provides the flow distribution between "road-rail-road", "road-IWWroad" and "other" intermodal chains.

\begin{tabular}{lccc}
\hline Minimization & $\begin{array}{c}\text { Intermodal chain } \\
\text { "road-rail-road" } \\
\text { (t.km) }\end{array}$ & $\begin{array}{c}\text { Intermodal chain } \\
\text { "road-IWW- } \\
\text { road" (t.km) }\end{array}$ & $\begin{array}{c}\text { Intermodal chain } \\
\text { "other" (t.km) }\end{array}$ \\
\hline Operational & $52 \%$ & $18 \%$ & $30 \%$ \\
costs & $24 \%$ & $15 \%$ & $61 \%$ \\
$\mathrm{CO}_{2}$ emissions & $37 \%$ & $5 \%$ & $58 \%$ \\
$\begin{array}{l}\text { Air pollution } \\
\text { external costs }\end{array}$ & & & \\
\hline
\end{tabular}

Table 27: Detailed modal split within intermodal transport with two terminals 
Other paths than the "road-rail/IWW-road" intermodal chain are effectively observed when up to three modes of transport are allowed for intermodal transport.

The policy that optimizes operational costs reveals that most of the flows follow the "road-rail/IWW-road" modeling of intermodal transport. The predominance of this intermodal combination coincides with the previous results showing that most of the flows on the first and third legs of the intermodal chains are transported by road, while the second leg of the intermodal path is generally performed by rail.

When $\mathrm{CO}_{2}$ emissions are optimized, the modal split between the intermodal chains is modified and more flows are transported using other combinations than the "road-rail/IWW-road" intermodal path. Compared to the operational costs optimization and thanks to the more advantageous unit values of IWW, the model increases the use of the other intermodal combinations, to the detriment of the "road-rail-road" intermodal chain.

Under the optimization of air pollution external costs, most of the flows are transported using other combinations than the "road-rail/IWW-road" combination. These outcomes are similar to the results obtained for the optimization of $\mathrm{CO}_{2}$ emissions.

Figure 22 provides an example of the flow distribution under the three optimization policies for the transportation of goods between two intermodal terminal centroids (Antwerp-Milan), two non-terminal centroids (Lyon-Florence) and one intermodal terminal and one non-terminal centroid (Antwerp-Florence). These particular results correspond to the general trends of modal split detailed in the previous paragraphs. 

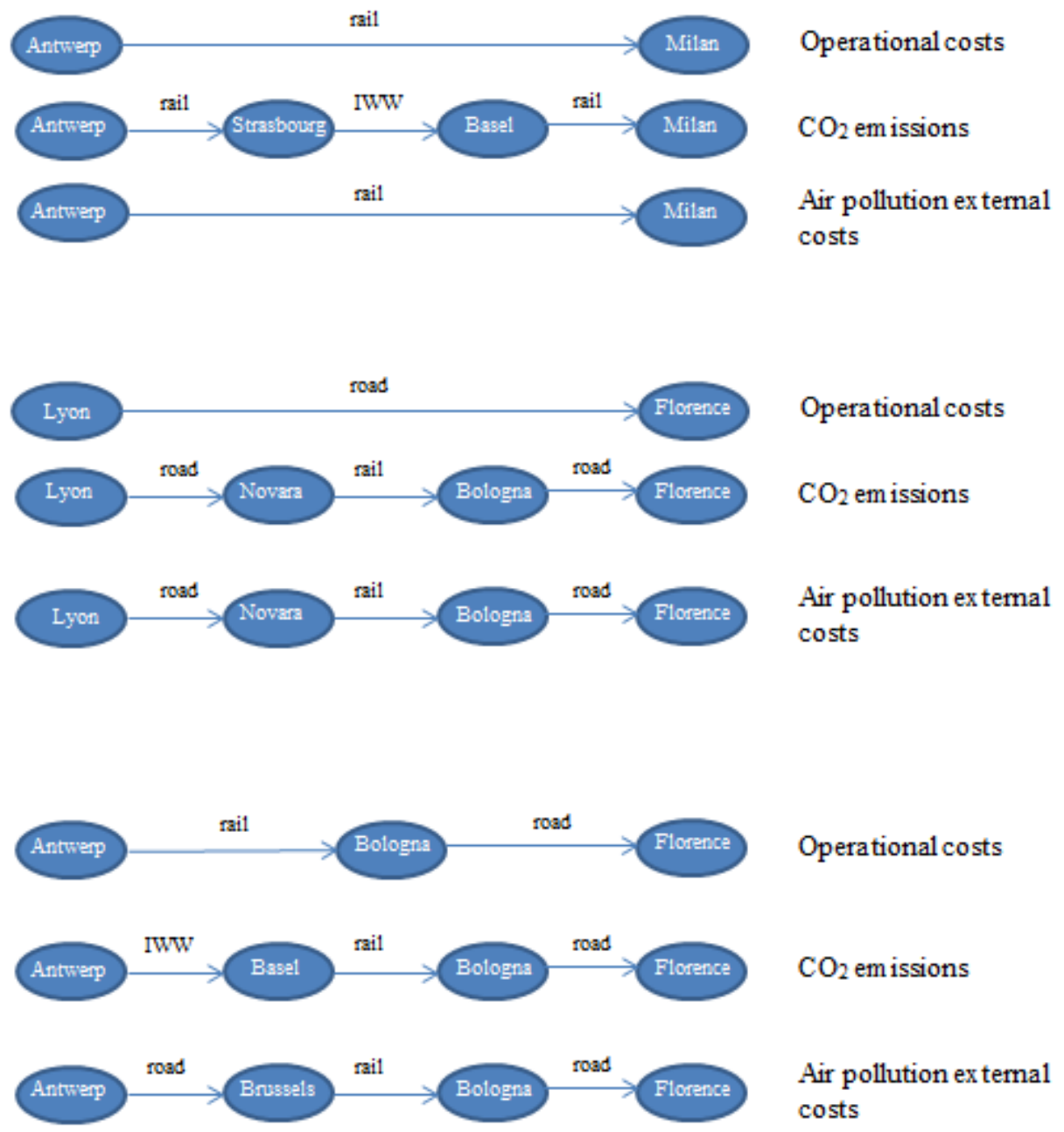

Figure 22: Examples of flow distribution for the three optimization policies

Results demonstrate that, depending on the followed economic or environmental policy, allowing several combinations of modes for an intermodal transport may lead to other intermodal chains than the traditional "road-rail/IWW-road" modeling of intermodal transport.

\subsubsection{Sensitivity analysis}

This part of the study identifies the effects on flow distribution of theoretical variations of the unit operational (op.) costs, $\mathrm{CO}_{2}$ emissions, air pollution external 
(ext.) costs and transshipment (transship.) parameters. The analysis is performed separately for the three optimization policies: operational costs minimization, $\mathrm{CO}_{2}$ emissions minimization, and air pollution external costs minimization.

\subsubsection{Operational costs}

This section focuses on the relative (rel.) and absolute (abs.) variations of operational costs and modal split when the initial unit operational costs parameters are respectively increased and decreased by 20\% (table 28). The analysis of this theoretical variation aims at determining which parameters most influence the flow distribution.

\begin{tabular}{|c|c|c|c|c|c|c|c|c|}
\hline & $\begin{array}{c}\text { Rel. op. } \\
\text { cost } \Delta\end{array}$ & $\begin{array}{c}\text { Abs. } \\
\text { road } \\
\text { flow } \Delta\end{array}$ & $\begin{array}{c}\text { Abs. rail } \\
\text { flow } \Delta\end{array}$ & $\begin{array}{c}\text { Abs. } \\
\text { IWW } \\
\text { flow } \Delta\end{array}$ & $\begin{array}{c}\text { Abs. } \\
\text { direct } \\
\text { flow } \Delta\end{array}$ & $\begin{array}{c}\text { Abs. } \\
\text { direct } \\
\text { flow } \Delta\end{array}$ & $\begin{array}{c}\text { Abs. } \\
\text { inter- } \\
\text { modal } \\
\text { flow } \\
\text { with } 1 \\
\text { terminal } \\
\Delta\end{array}$ & $\begin{array}{c}\text { Abs. } \\
\text { inter- } \\
\text { modal } \\
\text { flow } \\
\text { with } 2 \\
\text { terminals } \\
\Delta\end{array}$ \\
\hline $\begin{array}{l}\text { Trans- } \\
\text { ship.: } \\
+20 \%\end{array}$ & $1.40 \%$ & $3.76 \%$ & $-2.11 \%$ & $-1.65 \%$ & $1.01 \%$ & $-1.01 \%$ & $-0.36 \%$ & $0.36 \%$ \\
\hline $\begin{array}{l}\text { Trans- } \\
\text { ship.: } \\
-20 \%\end{array}$ & $-1.70 \%$ & $-4.04 \%$ & $2.59 \%$ & $1.45 \%$ & $-0.99 \%$ & $0.99 \%$ & $1.38 \%$ & $-1.38 \%$ \\
\hline $\begin{array}{l}\text { IWW: } \\
+20 \%\end{array}$ & $0.79 \%$ & $2.47 \%$ & $3.52 \%$ & $-5.99 \%$ & $1.29 \%$ & $-1.29 \%$ & $4.63 \%$ & $-4.63 \%$ \\
\hline $\begin{array}{l}\text { IWW: } \\
-20 \%\end{array}$ & $-1.68 \%$ & $-4.22 \%$ & $-4.45 \%$ & $8.67 \%$ & $-1.66 \%$ & $1.66 \%$ & $-4.07 \%$ & $4.07 \%$ \\
\hline $\begin{array}{l}\text { Road: } \\
+20 \%\end{array}$ & $9.31 \%$ & $-13.85 \%$ & $10.97 \%$ & $2.88 \%$ & $-0.50 \%$ & $0.50 \%$ & $7.79 \%$ & $-7.79 \%$ \\
\hline $\begin{array}{l}\text { Road: } \\
-20 \%\end{array}$ & $-13.74 \%$ & $31.73 \%$ & $-26.22 \%$ & $-5.51 \%$ & $2.55 \%$ & $-2.55 \%$ & $-14.90 \%$ & $14.90 \%$ \\
\hline $\begin{array}{l}\text { Rail: } \\
+20 \%\end{array}$ & $4.81 \%$ & $14.79 \%$ & $-18.56 \%$ & $3.77 \%$ & $-1.00 \%$ & $1.00 \%$ & $-12.12 \%$ & $12.12 \%$ \\
\hline $\begin{array}{l}\text { Rail: } \\
-20 \%\end{array}$ & $-7.86 \%$ & $-11.66 \%$ & $16.90 \%$ & $-5.24 \%$ & $1.78 \%$ & $-1.78 \%$ & $12.82 \%$ & $-12.82 \%$ \\
\hline
\end{tabular}

Table 28: Sensitivity analysis of flows to operational costs variations

Results highlight that the most important variations of the objective function (operational costs) are observed when road and rail unit costs are modified. The importance of the road parameters had already been underlined in chapters 5 and 6 . The emergence of the rail parameter as a determining factor of the objective 
function is new and is explained by the increased possibilities of using rail, due to the model structure formulation (any combination of modes is allowed) and to the level of aggregation of data (relatively more rail terminals are open compared to a higher level of disaggregation).

The distribution of flows between road, rail and IWW transport depends on the values of the unit cost parameters. Transshipment costs influence the modal split but to a lower extent than the unit operational costs of the different modes. Modifications of the road and rail costs induce the most important modal split variations for which most of the flow transfers happen between road and rail transport. When IWW unit costs are modified, flows are transferred to the rail and to the IWW market shares.

The choice between a direct and an intermodal transport is affected by the unit costs of each mode and by the value of the transshipment costs.

The choice for intermodal transport with one or two terminals is also affected by the transshipment cost value but higher flow variations are observed when the unit costs of the modes are modified. Increasing transshipment costs surprisingly leads to more intermodal flows through two terminals. Intermodal transport with one terminal is often done by rail and IWW, while the first and last legs of intermodal transport with two terminals are often performed by road. Intermodal flows passing through one terminal and leaving an origin node or arriving at a destination node by rail or IWW imply additional transshipment cost to road. This reduces the attractiveness of intermodal transport with one terminal, compared to intermodal transport with two terminals.

Table 29 provides the aggregate elasticities related to the three modes of transport.

\begin{tabular}{lllll}
\hline & & \multicolumn{3}{l}{ Cost increase of 20\% } \\
\cline { 3 - 5 } & & Road & Rail & IWW \\
\hline t.km & Road & -3.07 & 2.67 & 0.39 \\
& Rail & 2.91 & -6.57 & 0.75 \\
& IWW & 2.96 & 3.19 & -9.22 \\
\hline
\end{tabular}

Table 29: Aggregate elasticities of road, rail and IWW-several intermodal transport chains 
As in chapter 5, relatively high values of elasticities are obtained. Again, the allor-nothing characteristic of the model and the aggregation level of the data imply high sensibilities of the demand when costs are modified. IWW is very sensitive to variations of its own cost and its use also varies when rail and road costs are modified. Road, rail and IWW flows are mostly influenced by modifications of the road and rail costs. Variations of the IWW costs have high impacts on the level of use of IWW transport but little effects on the demand for transport by road and rail.

\subsubsection{2. $\mathrm{CO}_{2}$ emissions}

This section identifies the variations of $\mathrm{CO}_{2}$ emissions and modal split when the initial unit $\mathrm{CO}_{2}$ emissions parameters are respectively increased and decreased by $20 \%$ (table 30).

\begin{tabular}{|c|c|c|c|c|c|c|c|c|}
\hline & $\begin{array}{c}\text { Rel. } \\
\text { emis- } \\
\text { sion } \Delta\end{array}$ & $\begin{array}{c}\text { Abs. } \\
\text { road } \\
\text { flow } \Delta\end{array}$ & $\begin{array}{l}\text { Abs. rail } \\
\text { flow } \Delta\end{array}$ & $\begin{array}{c}\text { Abs. } \\
\text { IWW } \\
\text { flow } \Delta\end{array}$ & $\begin{array}{c}\text { Abs. } \\
\text { direct } \\
\text { flow } \Delta\end{array}$ & $\begin{array}{l}\text { Abs. } \\
\text { inter- } \\
\text { modal } \\
\text { flow } \Delta\end{array}$ & $\begin{array}{c}\text { Abs. } \\
\text { inter- } \\
\text { modal } \\
\text { flow } \\
\text { with 1 } \\
\text { terminal } \\
\Delta\end{array}$ & $\begin{array}{c}\text { Abs. } \\
\text { inter- } \\
\text { modal } \\
\text { flow } \\
\text { with } 2 \\
\text { termi- } \\
\text { nals } \Delta\end{array}$ \\
\hline $\begin{array}{l}\text { Trans- } \\
\text { ship.: } \\
+20 \%\end{array}$ & $0.47 \%$ & $0.02 \%$ & $-0.01 \%$ & $-0.01 \%$ & $0.01 \%$ & $-0.01 \%$ & $0.08 \%$ & $-0.08 \%$ \\
\hline $\begin{array}{l}\text { Trans- } \\
\text { ship.: - } \\
20 \%\end{array}$ & $-0.47 \%$ & $-0.04 \%$ & $-0.06 \%$ & $0.10 \%$ & $-0.05 \%$ & $0.05 \%$ & $-0.61 \%$ & $0.61 \%$ \\
\hline $\begin{array}{l}\text { IWW: } \\
+20 \%\end{array}$ & $2.51 \%$ & $0.96 \%$ & $3.14 \%$ & $-4.10 \%$ & $0.06 \%$ & $-0.06 \%$ & $-0.65 \%$ & $0.65 \%$ \\
\hline $\begin{array}{l}\text { IWW: } \\
-20 \%\end{array}$ & $-2.96 \%$ & $-1.19 \%$ & $-4.02 \%$ & $5.21 \%$ & $-0.15 \%$ & $0.15 \%$ & $2.38 \%$ & $-2.38 \%$ \\
\hline $\begin{array}{l}\text { Road: } \\
+20 \%\end{array}$ & $7.94 \%$ & $-2.68 \%$ & $2.66 \%$ & $0.02 \%$ & $-0.09 \%$ & $0.09 \%$ & $-0.21 \%$ & $0.21 \%$ \\
\hline $\begin{array}{l}\text { Road: } \\
-20 \%\end{array}$ & $-9.05 \%$ & $6.31 \%$ & $-5.64 \%$ & $-0.67 \%$ & $-0.15 \%$ & $0.15 \%$ & $-5.03 \%$ & $5.03 \%$ \\
\hline $\begin{array}{l}\text { Rail: } \\
+20 \%\end{array}$ & $7.79 \%$ & $2.99 \%$ & $-8.46 \%$ & $5.47 \%$ & $-0.17 \%$ & $0.17 \%$ & $-0.89 \%$ & $0.89 \%$ \\
\hline $\begin{array}{l}\text { Rail: } \\
-20 \%\end{array}$ & $-9.12 \%$ & $-2.17 \%$ & $6.48 \%$ & $-4.31 \%$ & $0.08 \%$ & $-0.08 \%$ & $-0.58 \%$ & $0.58 \%$ \\
\hline
\end{tabular}

Table 30: Sensitivity analysis of flows to $\mathrm{CO}_{2}$ emissions variations 
As for the optimization of operational costs, the objective function related to $\mathrm{CO}_{2}$ emissions is mostly influenced by the emission values of road and rail transport.

Variations of the transshipment $\mathrm{CO}_{2}$ emissions have almost zero effect on the modal split between road, rail and IWW. When rail or IWW unit emissions are varied, the largest flow transfers occur between rail and IWW transport. This result is different from the operational costs minimization, in which the main flow exchanges in case of rail emission variations happen between road and rail transport. Climate change optimization therefore increases the risk of flow transfer between environmentally friendly modes rather than between road and environmentally friendly mode. This is explained by the unit values of IWW, that are more competitive regarding $\mathrm{CO}_{2}$ emissions than regarding operational costs.

Transshipment emission values are small compared to the unit emission values per mode. It results that a variation of $20 \%$ of these transshipment emissions does not modify a lot the modal split between direct and intermodal transport. Increases or decreases of the unit emissions of each mode have also little influence on the modal split between direct and intermodal transport.

Finally, increasing or decreasing transshipment emissions by $20 \%$ does not really modify the modal split between intermodal transport with one terminal and intermodal transport with two terminals. The maximum transfers of flows between intermodal transport with one terminal and intermodal transport with two terminals happen when road emissions are modified. Decreasing the unit emissions of road allows more combinations of road with other modes of transport and leads to an increase of the market share of intermodal transport with two terminals.

\subsubsection{Air pollution external costs}

This section analyzes the variations of air pollution external costs and modal split when the initial unit air pollution external costs parameters are respectively increased and decreased by $20 \%$ (table 31 ). 


\begin{tabular}{|c|c|c|c|c|c|c|c|c|}
\hline & $\begin{array}{c}\text { Rel. ext. } \\
\text { cost } \Delta\end{array}$ & $\begin{array}{c}\text { Abs. } \\
\text { road } \\
\text { flow } \Delta\end{array}$ & $\begin{array}{c}\text { Abs. rail } \\
\text { flow } \Delta\end{array}$ & $\begin{array}{l}\text { Abs. } \\
\text { IWW } \\
\text { flow } \Delta\end{array}$ & $\begin{array}{c}\text { Abs. } \\
\text { direct } \\
\text { flow } \Delta\end{array}$ & $\begin{array}{l}\text { Abs. } \\
\text { inter- } \\
\text { modal } \\
\text { flow } \Delta\end{array}$ & $\begin{array}{c}\text { Abs. } \\
\text { inter- } \\
\text { modal } \\
\text { flow } \\
\text { with } 1 \\
\text { terminal } \\
\Delta \\
\end{array}$ & $\begin{array}{c}\text { Abs. } \\
\text { inter- } \\
\text { modal } \\
\text { flow } \\
\text { with } 2 \\
\text { terminals } \\
\Delta \\
\end{array}$ \\
\hline $\begin{array}{l}\text { IWW: } \\
+20 \%\end{array}$ & $0.71 \%$ & $0.89 \%$ & $0.81 \%$ & $-1.70 \%$ & $0.11 \%$ & $-0.11 \%$ & $0.53 \%$ & $-0.53 \%$ \\
\hline $\begin{array}{l}\text { IWW: } \\
-20 \%\end{array}$ & $-1.22 \%$ & $-1.24 \%$ & $-2.96 \%$ & $4.20 \%$ & $-0.34 \%$ & $0.34 \%$ & $-2.52 \%$ & $2.52 \%$ \\
\hline $\begin{array}{l}\text { Road: } \\
+20 \%\end{array}$ & $8.02 \%$ & $-4.64 \%$ & $4.28 \%$ & $0.36 \%$ & $0.10 \%$ & $-0.10 \%$ & $2.95 \%$ & $-2.95 \%$ \\
\hline $\begin{array}{l}\text { Road: } \\
-20 \%\end{array}$ & $-9.68 \%$ & $10.76 \%$ & $-9.31 \%$ & $-1.45 \%$ & $-0.08 \%$ & $0.08 \%$ & $-7.81 \%$ & $7.81 \%$ \\
\hline $\begin{array}{l}\text { Rail: } \\
+20 \%\end{array}$ & $9.72 \%$ & $7.27 \%$ & $-8.55 \%$ & $1.28 \%$ & $-0.16 \%$ & $0.16 \%$ & $-6.46 \%$ & $6.46 \%$ \\
\hline $\begin{array}{l}\text { Rail: } \\
-20 \%\end{array}$ & $-11.19 \%$ & $-5.01 \%$ & $5.77 \%$ & $-0.76 \%$ & $0.50 \%$ & $-0.50 \%$ & $6.86 \%$ & $-6.86 \%$ \\
\hline
\end{tabular}

Table 31: Sensitivity analysis of flows to air pollution external costs variations

As for the optimization of operational costs and $\mathrm{CO}_{2}$ emissions, the unit parameters of rail and road have the most important effects on the objective function.

Increases or decreases of the road and rail unit parameters induce the major modal split variations between road, rail and IWW transport. As for the operational cost optimization strategy, the flow exchanges happen mainly between road and rail transport and the IWW market share remains small compared to road and rail.

Similarly to the $\mathrm{CO}_{2}$ emissions optimization strategy, modifying the unit parameters of road, rail and IWW has little influence on the modal split between direct and intermodal transport.

As for the $\mathrm{CO}_{2}$ emissions optimization policy, the most important flow transfers between intermodal transport with one terminal and intermodal transport with two terminals are observed when road external costs are modified. The influence of unit rail external costs on the modal split within the intermodal market share is higher than the influence of unit rail $\mathrm{CO}_{2}$ emissions. 


\subsection{Discussion}

For environmental optimizations, rail transport has the highest market share. The market share of rail is also important for the economic optimization policy. These results should be balanced with the aggregation level of the data. Indeed, aggregating flows relatively increases the number of available rail and IWW terminals, compared to analyses at a more disaggregated level. Rail and IWW transport can therefore be used more intensively. For large-scale location problems, the demand points are usually aggregated to reduce the size of the problem and make it easier to solve. However, aggregation of data introduces errors. Errors related to the aggregation of data in transport models are not new and have been for instance discussed in Limbourg and Jourquin (2007) for the phub median problem. Further discussions on aggregation errors for locations models can be found in Francis et al. (2009).

Moreover, the all-or-nothing characteristic of the model definitely influences the results since modifications in the unit costs or emissions parameters may make one mode more competitive than another. This implies that all of the flows on a certain connection may change their mode. This change may quickly influence the modal split results since large quantities of goods are transported at the NUTS 2 level. Results of the application at the European level should therefore not be taken for granted but should provide insights on the kinds of behaviors that can be observed regarding modal splits.

The general preference for intermodal transport over direct transport is also partially explained by this aggregation level. Since more rail and IWW terminals are accessible, combining these modes together with road can more easily contribute to reduce the global impact on operational costs, $\mathrm{CO}_{2}$ emissions or air pollution external costs.

Errors related to the aggregation of data can be solved by disaggregating flows at the NUTS 3 level. Because of the number of indices related to each variable of the problem, some problems were already encountered for solving instances larger than 85 nodes. Disaggregating data implies increasing the number of nodes under study and generating larger problems that can potentially not be solved using exact methods. This opens the way to the use and development of heuristic methods. Focusing on a reduced geographical region at a lower level of aggregation can be a solution to make the balance between aggregation errors and exact resolution methods. 
Besides the aggregation level, the effects of transshipment activities are also relevant in the determination of the modal split. Results have shown the importance of transshipment operational costs on the choice between intermodal and direct transport. If operational costs are minimized, more direct transport is performed than in the environmental optimizations. Indeed, the economic benefits of transferring goods between several modes have to be balanced with the additional costs generated by the transshipment of goods. For $\mathrm{CO}_{2}$ emissions and air pollution external costs, the values of transshipment activities are low compared to the unit parameters of each mode. It results that more combinations of modes are used for reaching the optimal objective function. The low effects of transshipment activities on external costs have already been highlighted in Baccelli et al. (2001).

Economic and environmental optimizations provide different outcomes regarding the chosen intermodal chain. The economic optimization favors the "roadrail/IWW-road" combination, while environmental optimizations encourage other intermodal chains. Modeling intermodal transport as a "road-rail/IWW-road" combination therefore seems judicious from an economic point of view. This hypothesis may however reduce the adequacy of the model with reality regarding environmental perspectives.

\subsection{Conclusions}

This research has developed a new intermodal allocation model which allows for several intermodal transport chains, using a combination of up to three modes between road, rail and IWW transport. The model has been tested with experimental data at the European level. Three optimization policies and their sensitivity analysis have been evaluated: optimization of operational costs, optimization of $\mathrm{CO}_{2}$ emissions and optimization of air pollution external costs.

Results of the application the European level highlight the important market share of rail transport. Rail is the dominant mode for environmental policies and is well represented under economic optimization. The predominance of rail is explained by the structure of the model. The formulation allows the use of any mode on any leg of the intermodal path, compared to the "road-rail/IWW-road" modeling, where rail and IWW can only be used on the second leg of the intermodal chain. Moreover, the aggregation level of the data relatively increases the access to rail and IWW compared to a higher disaggregation level of data. Reaching rail 
terminals is therefore easier, which increases the rail market share. Since the model is characterized by an all-or-nothing assignment method, high aggregation levels clearly influence and may have a big impact on the modal split results. Finally, the structure of the application at the European level also influences results since most of the considered regions are located next to an intermodal terminal, which increases the potential use of rail and IWW.

Results underline the preference for intermodal than for direct transport. This outcome means that transshipment unit parameters are low enough to make a combination of modes attractive compared to the direct transport of goods. The large market share of intermodal transport is also explained by the level of aggregation of the data, which induces a larger access to the rail and IWW terminals, compared to a higher disaggregation level. This increases the potential for mode combination.

Transshipment values are important in the determination of the flow distribution. This has been observed when comparing the modal split of economic and environmental optimization policies. For economic optimization, more direct transport is used. Transshipment environmental effects are low compared to the respective unit $\mathrm{CO}_{2}$ emissions and air pollution external costs parameters of road, rail and IWW. For environmental aspects, combining several modes is therefore a competitive solution compared to direct transport.

For economic optimization policies, most of the flows follow the "road-rail/IWWroad" intermodal chain. For environmental optimization policies, flows rather follow other types of combinations. Modeling intermodal transport as a "roadrail/IWW-road" combination therefore seems judicious from an economic point of view. This hypothesis may however reduce the exactitude of the modeling regarding environmental perspectives.

Further research work should be performed to study the impact on flow distribution of errors related to data aggregation. This can be done through the development of a reduced network at a more disaggregated level. Since transshipment values influence the flow distribution between direct, intermodal transport with one terminal, and intermodal transport with two terminals, further studies confirming the values of $\mathrm{CO}_{2}$ emissions and air pollution external costs of transshipment are still needed. 


\section{PART IV}

\section{CONCLUSIONS}

This last part summarizes the general conclusions of the thesis and identifies the future research perspectives. 



\section{Chapter 8}

\section{Conclusions}

\begin{tabular}{|l|c|c|c|}
\hline \multicolumn{3}{|c|}{ 1. Introduction } \\
\hline
\end{tabular}

The purpose of this final chapter is twofold. First, it aims at summarizing the main research contributions and conclusions of the thesis. Second, it details the limitations of the performed studies, and elaborates on further research activities.

\subsection{General conclusions}

This thesis deals with freight transportation systems. It evaluates the interest of using intermodal transport as an alternative solution to road transport. The study integrates economic and environmental considerations, so as to reflect today's and tomorrow's preoccupations. Intermodal attractiveness is assessed from the economic and environmental perspectives by considering four different kinds of objectives: operational costs (economic perspective), full costs (economic and 
environmental perspective), $\mathrm{CO}_{2}$ emissions (climate change perspective) and human health external costs related to air pollution (air pollution perspective).

This research provides four main contributions:

1) First, it offers a state of the art of land transport external costs and their effects on the competitiveness of intermodal transport in relation to road.

2) Second, it develops a new intermodal bi-objective location-allocation model, which accounts for three modes of transport and intermodal nonlinear economies of scale. It also provides an application of this model to the Belgian case study to evaluate the trade-offs between economic and climate change objectives.

3) Third, it applies a simplification of the above intermodal locationallocation model to the Belgian case study, to assess the effects on flow distribution of several transport policies related to economic and air pollution objectives.

4) Finally, it generates a new intermodal allocation model which allows several intermodal transport chains. The model is tested with data on the European newtork with economic and environmental objectives to identify which combinations of modes can be considered in an intermodal path.

The results in terms of these four contributions are summarized in the following paragraphs.

1) Freight transport external costs

Results show that, in the last years, there has been an increasing interest in studying freight transport externalities. The major part of the literature on the topic involves application papers which evaluate the amount and value of transport external costs, on the basis of recognized methodological papers. An important part of the literature consists in project-related studies, which highlights not only the scientific but also the real interest of societies in better understanding these issues. Very few papers deal with the development of generic mathematical functions of external costs. However, it has been shown that these generic functions are useful since they allow determining the main factors which influence the competitiveness of a mode of transport over another one. An application of generic mathematical functions for road and rail costs has highlighted the importance of drayage operations external costs in the 
competitiveness of intermodal transport regarding road. The correct location of intermodal terminals is therefore essential for ensuring intermodal attractiveness from the economic and environmental perspectives.

\section{2) Intermodal transport and climate change}

The bi-objective intermodal location-allocation model evaluates the trade-offs between operational costs minimization and $\mathrm{CO}_{2}$ emissions minimization. The application of the model to the Belgian case study reveals that the locations of terminals are quite stable, whatever the followed policy (operational costs or $\mathrm{CO}_{2}$ emissions minimization). Terminal types and modal split between road and intermodal transport are however sensitive to the objective that is considered. The chosen policy also influences the modal split inside the intermodal market share. Results of the sensitivity analysis reveal that variations of the road parameters lead to flow transfers between road and intermodal transport. On the contrary, modifications of the rail and IWW parameters induce flow transfers between rail and IWW, within the intermodal market share. Road remains the preferred solution regarding economic objectives. An increase of the intermodal market share is observed going from cost to emission minimization. A more intensive use of intermodal transport is thus suggested for achieving the environmental objectives related to climate change.

3) Intermodal transport and air pollution

The application of the intermodal allocation model for evaluating economic and air pollution policies reveals that intermodal transport performs better than road regarding human health external costs of air pollution. Intermodal transport has indeed the largest market share under the policy which minimizes air pollution external costs. On the contrary, road transportation has the main market share under the policy which minimizes operational costs. Including additional road taxes in a policy which optimizes operational costs leads an increase of the intermodal market share compared to the single economic optimization. The intermodal market share obtained when additional road taxes are introduced is nevertheless lower than the one obtained under external costs optimization. The introduction of cleaner vehicles in the truck fleet increases the competitiveness of road over intermodal transport regarding air pollution. It restricts the potential for flow transfer from road to rail or IWW. An increased used of electricity in the rail traction mix has positive effects on the intermodal market share. IWW cost 
variations lead to flow transfers between intermodal rail and intermodal IWW transport, rather than between road and intermodal transport. This risk of flow exchange within the intermodal market had already been highlighted in the model which focuses on how intermodal transport can be useful regarding climate change impacts.

The analyses with respect to climate change and air pollution provide similar results in terms of modal split between road and intermodal transport. Indeed, compared to an economic optimization, minimizing $\mathrm{CO}_{2}$ emissions or air pollution external costs leads to a greater market share for intermodal than for road transport. The intermodal market shares under climate change and air pollution optimization are very close. The modal split within the intermodal market share is however different. Intermodal rail transport is preferred when optimizing air pollution and intermodal IWW is preferred when optimizing climate change. These variations can be explained by the scope of each model. The model focusing on climate change decides on the location of IWW terminals within a set of feasible locations, whereas the model focusing on air pollution only considers the existing terminals. Flow distribution therefore does not happen on exactly the same network. In addition, $\mathrm{CO}_{2}$ emissions for IWW are computed based on the assumption that 3,000 tonnes of goods are transported by a medium barge, while air pollution external costs are given for boats transporting goods within a range of 1,000 and 3,000 tonnes, which favors IWW in the $\mathrm{CO}_{2}$ emissions optimization. Analyses regarding climate change and air pollution both highlighted the risk of flow exchange within the intermodal market share, rather than between road and intermodal transport.

\section{4) Several intermodal chains}

The model allows choosing between direct transport and intermodal transport chains of up to three modes. The experimental results at the European level highlight that rail has an important market share in all kinds of optimizations. Intermodal transport is also preferred to direct transport. This is explained by the aggregate level of the data and by the structure of the model which allows any leg of the intermodal chain to be performed by any mode of transport. Since the NUTS 2 regions considered in the analysis are crossed by the core network corridors, the centroids are close to intermodal terminals. This also enhances the use of intermodal transport. The impact of transshipment activities on flow distribution has been underlined. From an economic perspective, results show that 
most of the intermodal flows follow the "road-rail/IWW-road" path, while other intermodal combinations own a higher market share for environmental optimizations. Modeling intermodal transport as a "road-rail/IWW-road" combination therefore seems more relevant for economic than for environmental optimizations.

\subsection{Future research perspectives}

Future research perspectives can be classified into short-term and long-term perspectives.

\subsubsection{Short-term perspectives}

Short term perspectives imply additional studies related to the intermodal location-allocation problem. The models of this thesis can be developed in several directions.

The all-or-nothing characteristic of the models could be improved by dealing with modal choice models, which do not assign the whole flows of an origindestination pair to the same mode of transport. In this way, the perception of routes by the user could be integrated on the basis of several parameters.

The data source related to the case studies can be improved. The development of data source by Eurostat is necessary for increasing the quality of the decision tools. Results of this study are based on quite old freight flows (2005 extrapolated to 2010) and variations of the demand may have been noticed since then. The economic crisis is one of the parameters that could impact the demand distribution. Indeed, it has potentially led to the restructuration of some businesses and to the disappearance or displacement of flows from one region to another. Variations of the demand between origin and destination nodes may modify the results in terms of modal split, especially when economies of scale of intermodal transport are taken into account.

The experimental data at the European level should be improved and completed to build a real European case study that can serve as the basis for policy analysis. Improved European data related to specific core network corridors can be used to calibrate and validate the results of the model on the European network. 
If economies of scale of intermodal rail transport have been modeled using dedicated nonlinear functions, intermodal IWW economies of scale have been represented using three different sizes of barges. This has been done because, as far as I know, no other formulation taking into account the different parameters of IWW costs existed in the literature. Generating formulations which account for nonlinear economies of scale of intermodal IWW transport is important to increase the coherence between intermodal rail and intermodal IWW costs. Intermodal rail and intermodal IWW transport can be better compared, which ensures a more accurate choice between the two modes.

This thesis takes into account the environmental issues related to climate change and to air pollution. However, other types of externalities can be considered in order to evaluate the attractiveness of intermodal transport in relation to road. Noise and congestion could in particular be considered as other objectives to optimize. The evaluation of noise implies nonlinear scales. The techniques used in this thesis to solve nonlinear issues could be transposed to noise, to assess its effect on intermodal and road flow distribution. The evaluation of congestion and its impact of flow distribution require the development of more dynamic models, which take the value of time into account. Externalities could also be integrated by considering general endpoint categories of impacts such as damage to human health (i.e. climate change, ozone depletion, human toxicity), damage to ecosystem diversity (i.e. acidification, eutrophication), or resource scarcity (i.e. land use, water resource depletion, resource depletion).

This study has evaluated the effects on modal split of the optimization of operational costs, of $\mathrm{CO}_{2}$ emissions, of air pollution external costs, and of operational costs with additional road taxes. The developed models can be useful to evaluate the effects on modal split of different types of policies. Other intermediate policies can be assessed such as the introduction of subsidies, the economic optimization under the internalization of external costs, a limitation of the amount of allowed externalities or the introduction of alternative fleet structures including electric, biogas or biodiesel vehicles.

The formulations of the location-allocation or allocation models have been applied to case studies with a maximum of 88 nodes. Difficulties have been encountered for solving larger problems using exact methods. The resolution of real case studies with exact methods implies the balance between disaggregation level and size of the studied geographical area. Small geographical areas can be 
solved with a higher level of precision. Larger case studies have to be studied at a more aggregate level. Solving larger instances with a higher degree of disaggregation implies the use of alternative resolution methods, such as heuristic techniques which provide good (and not necessarily optimal) solutions in reasonable computational times.

\subsubsection{Long-term perspectives}

Long-term research perspectives imply using other approaches than the single optimization of economic or environmental objectives to promote intermodal attractiveness.

Road and intermodal rail transport have been studied quite a lot in the literature and their related costs and externalities have been modeled using mathematical functions. However, intermodal IWW transport is much less considered regarding these aspects, and a specific focus on this mode can still be achieved. In particular, the modeling of IWW external costs using dedicated mathematical functions should be further developed. This could help understanding the key parameters that play a role on the competitiveness of intermodal IWW transport regarding environmental issues. Better identifying these factors is necessary to determine how to improve and expand this transportation mode.

This thesis has highlighted the risk of flow exchanges within the intermodal market share, rather than between road and intermodal transport. Indeed, results have shown that traditional policies aiming at enhancing intermodal transport (i.e. technical improvement of the different modes or introduction of road taxes) may lead to situations where rail and IWW have to compete. These outcomes demonstrate the need for newer innovative policies and initiatives which enhance the development of intermodal transport.

The expansion of the intermodal market share in relation to road is not only driven by economic and environmental costs. Other parameters such as transportation flexibility and reliability play a critical role on the decision of customers to use intermodal transport. Reliability of flows is also an important factor for intermodal transport providers which should be able to count on sufficient and regular flows to provide attractive and profitable transportation activities. The commitment of customers and service providers to flows and schedules seems important to improve intermodal attractiveness. Synchromodal 
transport can be useful to ensure more reliable flows. The development of synchromodal transport probably passes through efficient communication methods and implies the use of information technology. Further research studies focusing on the quantitative and qualitative expectations of each category of intermodal stakeholders are necessary to better identify the societal factors that contribute to intermodal attractiveness. 


\section{Bibliography}

AEA Technology Environment (2005). Clean Air For Europe (CAFE) - Damages per tonne emission of PM2.5, NH3, SO2, NOx and VOCs from each EU25 Member State (excluding Cyprus) and surrounding seas. United Kingdom: European Commission DG Environment.

Agarwal, A., Kickhöfern B. \& Nagel, K. (2015). The Internalization of Congestion and Air Pollution Externalities: Evaluating Behavioral Impacts. Paper presented at the 14th International Conference on Travel Behaviour Research, Windsor.

Aggarwal, P. and Jain, S. (2015). Impact of air pollutants from surface transport sources on human health: A modeling and epidemiological approach. Environment International, 83, 156-157.

Agora (2016). Intermodal terminals in Europe. Retrieved from http://www.intermodalterminals.eu/database, accessed September 2016.

Alumur, S. \& Kara, B. Y. (2008). Network hub location problems : The state of the art. European Journal of Operational Research, 190, 1-21.

Arnold, P., Peeters, D., Thomas, I. \& Marchand, H. (2001). Pour une localisation optimale des centres de transbordement intermodaux entre réseaux de transport : formulation et extensions. The Canadian Geographer, 45(3), 427-36.

Arnold, P., Peeters, D. \& Thomas, I. (2004). Modelling a rail/road intermodal transportation system. Transportation Research Part E, 40, 255-270.

Austin, D. (2015). Pricing Freight Transport to Account for External Costs (working paper). Washington DC: Congressional Budget Office.

Baccelli, O. et al. (2001). RECORDIT Deliverable 4: External cost calculation for selected corridors. RECORDIT, Germany

Bagienski, Z. (2015). Traffic air quality index. Science of the Total Environment 505, 606-614

Beuthe, M., Degrandsart, F., Geerts, J.-F., \& Jourquin, B. (2002). External costs of the Belgian interurban freight traffic: a network analysis of their internalization. Transport Research Part D, 7, 285-301.

Beuthe, M., Jourquin, B. \& Urbain, N. (2014). Estimating Freight Transport Price Elasticity in Multimode Studies: A Review and Additional Results from a Multimodal Network Model. Transport Reviews, 34 (5), 626-644. 
Belotti, P., Kirches, C., Leyffer, S., Linderoth, J., Luedtke, J. \& Mahajan, A. (2012). Mixed-Integer Nonlinear Optimization. Preprint ANL/MCS-P3060-1121. Argonne National Laboratory, Illinois.

Bickel, P., Friedrich, R., Droste-Franke, B., Bachmann, T. M., Gressman, A., Rabl, A., ... Tiblad, J., (2005). ExternE - Externalities of Energy - Methodology 2005 Update. Germany: IER University of Stuttgart.

Bickel, P., Friedrich, R., Burgess, A., Fagiani, P., Hunt, A., De Jong, G., ... Tavasszy, L. (2006a). Developing Harmonised European Approaches for Transport Costing and Project Assessment (HEATCO). Deliverable 5 Proposal for Harmonised Guidelines. Germany: IER University of Stuttgart.

Bickel, P., Friedrich, R., Burgess, A., Fagiani, P., Hunt, A., De Jong, G., ... Tavasszy, L.( 2006b). Developing Harmonised European Approaches for Transport Costing and Project Assessment (HEATCO). Deliverable 6 Case Study Results. Germany: IER University of Stuttgart.

Bickel, P., Friedrich, R., Link H., Stewart, L., \& Nash, C. (2006c). Introducing Environmental Externalities into Transport Pricing: Measurement and Implications. Transport Reviews: A Transnational Transdisciplinary Journal, 26 (4), 389-415.

Black, I., Seaton, R., Ricci, A., Enei, R., Vaghi, C., Schmid, S., \& Buhler, G. (2003). RECORDIT Real cost reduction of door-to-door intermodal transport - Final Report: Actions to Promote Intermodal transport.Cranfield: Cranfield University.

Bontekoning, Y.M., Macharis, C., and Trip, J.J. (2004). Is a new applied transportation research field emerging? A review of intermodal rail-truck freight transport literature." Transportation Research Part A, 38, 1-34.

Bookbinder, J. H. and Higginson, J. K. (2002). Probabilistic modelling of freight consolidation by private carriage. Transportation Research Part E: Logistics and Transportation Review, 38(5), 305-318.

Bouchery, Y. \& Fransoo, J. (2015). Cost, carbon emissions and modal shift in intermodal network design decisions. International Journal of Production Economics 164, 388-399.

Brons, M., \& Christidis, P. (2012). External cost calculator for Marco Polo freight transport project proposals. Luxembourg: Publications Office of the European Union.

Brons, M. and Christidis, P. (2013). External cost calculator for Marco Polo freight transport project proposals - call 2013 version. JRC Scientific and Policy Reports, JRC81002, Institute for Prospective and Technological Studies, Joint Research Centre, European Commission.

Bureau Fédéral du Plan (2012). Perspectives de l'évolution de la demande de transport en Belgique à l'horizon 2030. Bruxelles : Bureau Fédéral du Plan. 
Caris, A., Limbourg, S., Macharis, C., van Lier, T., \& Cools, M. (2013). Integration of Inland Waterway Transport in the Intermodal Supply Chain: a Joint Research Agenda. Proceedings of the PIANC-SMART Rivers Conference 2013. Liege, Belgium.

Caris, A., Macharis, C. \& Janssens, G. K. (2008). Planning problems in intermodal freight transport: accomplishments and prospects, Transportation Planning and Technology, 31, 277-302.

Caris, A., Macharis, C., \& Janssens, G. K. (2012). Corridor network design in hinterland transport systems. Flexible Services and Manufacturing Journal, 24, 294-319.

Caris, A., Macharis, C. \& Janssens, G. K. (2013). Decision support in intermodal transport: A new research agenda. Computers in Industry, 64, 105-112.

Carreira, J., Santos, B.F., \& Limbourg, S. (2012). Inland Intermodal Freight Transport Modelling. 40th ETC - European Transport Conference, Glasgow, UK.

CE Delft (2011).STREAM international freight 2011: Comparison of various transport modes on an EU scale with the STREAM database. Commissioned by: Dutch Ministry of Infrastructure and the Environment.

Central Commission for the Navigation of the Rhine (2014). Inland navigation in Europe Market observation 2014. Tech. rep., CCNR, Strasbourg.

Chaabane, A., Ramudhin,A., Paquet,M. (2012). Design of sustainable supply chains under the emission trading scheme. International Journal of Production Economics, 135 (1), $37-49$.

Cheung, R. K., \& Chen, C.-Y. (1998). A Two-Stage Stochastic Network Model and Solution Methods for the Dynamic Empty Containeur Allocation Problem. Transport Science, 32(2), 142-162.

Chen, G., Govindan, K. \& Golias, M. M. (2013).Reducing truck emissions at container terminals in a low carbon economy: Proposal of a queuing-based bi-objective model for optimizing truck arrival pattern. Transportation Research Part E, 55, 3-22.

Costabile, F., Allegrini, I. (2008). A new approach to link transport emissions and air quality: An intelligent transport system based on the control of traffic air pollution. Environmental Modelling \& Software 23, 258-267.

Cravioto, J., Yamasue, E., Okumura, H., \& Ishihara, K. N. (2013). Road transport externalities in Mexico: Estimates and international comparisons. Transport Policy, 30, 63-76.

Cruz, C. \& Montenon, A. (2016). Implementation and impacts of low emission zones on freight activities in Europe: Local schemes versus national schemes. Transportation Research Procedia, 12, 544-556. 
Cullinane, K., Toy, N. (2000). Identifying influential attributes in freight route/mode choice decisions: a content analysis. Transportation Reseach Part E, 36, 41-53.

Danielis, R. \& Marcucci, E. (2007). Attribute cut-offs in freight service selection. Transportation Research Part E, 43(5), 506-515.

de Leeuw, F. A. A. M., Moussiopoulos, N., Sahm, P., Bartonova, A. (2001). Urban air quality in larger conurbations in the European Union. Environmental Modelling \& Software, 16, 399-414.

Delucchi, M. A. \& McCubbin D. R. (2010). External Costs of Transport in the U.S. In A. de Palma, R. Lindsey, E. Quinet \& R. Vickerman (Eds), A Handbook of Transport Economics pp. 341-368. United Kingdom: Edward Elgar Publishing.

Demir, E. (2012). Models and Algorithms for the Pollution-Routing Problem and Its Variations (Unpublished doctoral dissertation). University of Southampton, United Kingdom.

Devos, S., Cox, B., van Lier, T., Nawrot, T. S. \& Putman, K. (2016). Effect of the shape of the exposure-response function on estimated hospital costs in a study on non-elective pneumonia hospitalizations related to particulate matter. Environment International, 94, 525-530.

DINALOG (2013). Synchromodal Transport. Retrieved from http://www.dinalog.nl/en/themes/synchromodal_transport/, accessed October 2016.

Dullaert, W., \& Zamparini, L. (2013). The impact of lead time reliability in freight transport: A logistics assessment of transport economics findings. Transport Research Part E, 49, 190-200.

EEA - European Environment Agency (2010). Load factors for freight transport. Retrieved from http://www.eea.europa.eu/data-and-maps/indicators/load-factors-forfreight-transport/load-factors-for-freight-transport-1, accessed January 2014.

EEA, (2013a). Air pollution fact sheet 2013 Belgium. European Environment Agency, Copenhagen.

EEA (2013b). Emissions of primary PM2.5 and PM10 particulate matter. Retrieved from http://www.eea.europa.eu/data-and-maps/indicators/emissions-of-primary-particles-and5/assessment-3

EEA (2014). Costs of air pollution from European industrial facilities 2008-2012 - an updated assessment. European Environment Agency, Copenhagen.

Emisia (2015). COPERT data for Belgium, Retrieved from http://emisia.com/products/copert-data 
Ernst, A.T. \& Krishnamoorthy, M. (1998). Exact and heuristic algorithms for the uncapacitated multiple allocation p-hub median problem. European Journal of Operational Research, 104(1), 100-112 .

European Commission (2001). Real Cost Reduction of Door-to-door Intermodal Transport RECORDIT. Tech. rep., European Commission, Directorate General DG VIIRTD, $5^{\text {th }}$ Framework Programme, Brussels.

European Commission (2004)._Directive of the European Parliament and of the Council on intermodal loading units. Retrieved from http://eurlex.europa.eu/LexUriServ/LexUriServ.do?uri=COM:2004:0361:FIN:EN:PDF, accessed April 2013.

European Commission (2007). Commission Staff Working Paper - Annex to the Communication from the Commission to the Council and the European Parliament Towards a rail network giving priority to freight $\{\mathrm{COM}(2007) 608$ final $\}$ \{SEC(2007) 1324\} \{SEC(2007) 1325\}. Retrieved from http://eur-lex.europa.eu/legalcontent/EN/TXT/?uri=CELEX:52007SC1322, accessed November 2016.

European Commision (2008). Communication from the Commission to the European Parliament, the Council, the Economic and Social Committee and the Committee of the Regions of 8 July 2008 "Strategy for the internalisation of external costs" [COM(2008) 435 final - Not published in the Official Journal]. Retrieved from http://europa.eu/legislation_summaries/transport/transport_energy_environment/tr0007 en.htm, accessed November 2012.

European Commission (2011). White Paper: Roadmap to a single European transport area - Towards a competitive and resource efficient transport system. COM, Brussels.

European Commission (2012). EU Transport in figures - Statistical pocketbook 2012. COM, Brussels.

European Commission (2015). National Emission Ceilings. Retrieved from http://ec.europa.eu/environment/air/pollutants/ceilings.htm, accessed February 2016.

European Commission (2015a). Road transport: Reducing $\mathrm{CO}_{2}$ emissions from vehicles (2015). Retrieved from http://ec.europa.eu/clima/policies/transport/vehicles/index_en.htm, accessed February 2016.

European Commission (2015b). Commission refers Belgium and Bulgaria to court and gives Sweden a final warning over poor air quality. Retrieved from http://europa.eu/rapid/press-release_IP-15-5197_en.htm, accessed January 2016.

European Commission (2015c). Healthcare expenditure by function, 2012. Retrieved from http://ec.europa.eu/eurostat/statistics- 
explained/index.php/File:Healthcare_expenditure by function,_2012_\%25_of_current health_expenditure) YB15.png, accessed January 2016.

European Commission (2015d). National Emission Ceilings. Retrieved from http://ec.europa.eu/environment/air/pollutants/ceilings.htm, accessed January 2016.

European Commision (2016). Infrastructure - TEN-T - Connecting Europe - Corridors. Retrieved from http://ec.europa.eu/transport/themes/infrastructure/ten-tguidelines/corridors_en, accessed October 2016.

European Commission (2016b). TENTec Interactive Map Viewer. Retrieved from http://ec.europa.eu/transport/infrastructure/tentec/tentec-portal/map/maps.html, accessed October 2016.

European Commission (2016c). EU Climate Action. Retrieved from http://ec.europa.eu/clima/citizens/eu/index_en.htm, accessed October 2016.

European Commission (2016d). Public finances and macroeconomic development. Retrieved from http://ec.europa.eu/economy finance/eu/public finances/index en.htm, accessed January 2016.

European Parliament (2016). Fact Sheets on the European Union: free movement of goods. $\quad$ Retrieved from http://www.europarl.europa.eu/atyourservice/en/displayFtu.html?ftuId=FTU 3.1.2.html, accessed December 2016.

European Policy Center (2016). Policy Areas: the four freedoms. Retrieved from http://www.europeanpolicy.org/en/european-policies/single-market.html, , accessed December 2016.

European Railway Agency (2011). Guide for the application of Technical Specifications for Interoperability (TSIs). Retrieved from http://www.era.europa.eu/DocumentRegister/Documents/IU-TSI-Guide.pdf, accessed March 2013.

Europaforum (2009). Transport ferroviaire européen : un grand pas vers un système de signalisation harmonisé. $\quad$ Retrieved from http://www.europaforum.public.lu/fr/actualites/2009/07/ertms/index.html, accessed March 2013.

Eurostat (2013). Répartition modale du transport de fret. Retrieved from http://epp.eurostat.ec.europa.eu/tgm/table.do?tab=table\&init=1\&language $=$ fr\&pcode $=$ ts dtr220\&plugin=1, accessed September 2015

Eurostat (2014). Train movements, by type of vehicle and source of power. Retrieved from http://appsso.eurostat.ec.europa.eu/nui/show.do?dataset=rail_tf_traveh\&lang=en, accessed August 2015. 
Eurostat (2015). Modal split of freight transport. Retrieved from http://ec.europa.eu/eurostat/tgm/refreshTableAction.do?tab=table\&plugin=1\&pcode=tsd tr220\&language $=$ en, accessed August 2015.

Eurostat (2016). Répartition modale du transport de fret. Retrieved from http://appsso.eurostat.ec.europa.eu/nui/submitViewTableAction.do, accessed December 2016.

Eurostat (2016a). Train-movements, by type of vehicle and source of power. Retrieved from http://appsso.eurostat.ec.europa.eu/nui/show.do?dataset=rail_tf_traveh\&lang=en, accessed December 2016.

Eurostat (2016b). Modal split of freight transport. Retrieved from http://appsso.eurostat.ec.europa.eu/nui/show.do?dataset=tran hv frmod\&lang=en, accessed December 2016.

Eurostat (2016c). Navigable inland waterways, by waterways type. Retrieved from http://appsso.eurostat.ec.europa.eu/nui/show.do?dataset=iww_if_infrastr\&lang=en, accessed March 2016.

Fan, Y. (2013). The design of a synchromodal freight transport system - Applying synchromodality to improve the performance of current intermodal freight transport system (Unpublished master's thesis). Delft University of Technology, the Netherlands.

Farahani, R. Z., Hekmatfar, M., Arabani, A. B. \& Nikbakhsh, E. (2013). Hub location problems: A review of models, classification, solution techniques, and applications. Computers \& Industrial Engineering, 64, 1096-1109.

Forkenbrock, D. J. (1999). External costs of intercity truck freight transport. Transport Research Part A, 33, 505-526.

Forkenbrock, D. J. (2001). Comparison of external costs of rail and truck freight transport. Transport Research Part A, 35, 321-337.

Francis, R. L., T. J. Lowe, M. B. Rayco and A. Tamir (2009). Aggregation Error for Location Models: a Survey and Analysis. Annals of Operations Research, 167, 171-208.

Garcia-Menendez, L., Martinez-Zarzoso, I. \& De Miguel, D.P (2004). Determinants of mode choice between road and shipping for freight transport evidence for four Spanish exporting sectors. Journal of Transport Economics and Policy, 38 (3), 447-466.

Gathon, H.- J. (2013). Gestion Publique et Economie des Transports. Syllabus, HEC Ecole de Gestion de l'Université de Liège, Liège.

Ghane-Ezabadi, M. \& Vergara, H.A. (2016). Decomposition approach for integrated intermodal logistics network design. Transportation Research Part E, 89, 53-69. 
Gimeno, D., Bültmann,U., Benavides, F. G., Alexanderson, K., Abma F. I., UbaldeLópez, M., Roelen, C. A. M., Kjeldgård, L., Delclos, G. L. (2014). Cross-national comparisons of sickness absence systems and statistics: towards common indicators. The European Journal of Public Health, 24, 4, 663-666.

Google Maps (2016). Google Maps. Retrieved from https://www.google.be/maps?source=tldso, accessed October 2016.

Grosso, M. (2011). Improving the competitiveness of intermodal transport: applications on European corridors. Unpublished doctoral thesis. University of Antwerp:Antwerp.

Hoen, K.M.R, Tan, T., Fransoo, J. C. \& van Houtum G. J. (2010). Effect of carbon emission regulations on transport mode selection in supply chains. Working paper. Technische Universiteit Eindhoven, Eindhoven.

Hoen, K.M.R, Tan, T., Fransoo, J. C. \& van Houtum G. J. (2014). Effect of carbon emission regulations on transport mode selection under stochastic demand. Flexible Services and Manufacturing Journal, 26, 170-195.

Hoffrichter, A., Miller, A. R., Hillmansen, S., \& Roberts, C. (2012). Well-to-wheel analysis for electric, diesel and hydrogen traction for railways. Transport Research Part D, 17, 28-34.

Hystad, Villeneuve, P. J., Goldberg, M. S., Crouse, D. L., Johnson, K (2015). Exposure to traffic-related air pollution and the risk of developing breast cancer among women in eight Canadian provinces: A case-control study. Environment International 74, 240-248.

Iannone, F. (2012). The private and social cost efficiency of port hinterland container distribution through a regional logistics system. Transportation Research Part A, 46, 1424-1448.

INFRAS/IWW (2004). External Costs of Transport: Update study. Zürich/Karlsruhe : University of Karlsruhe.

Ishfaq, R. \& Sox, C. (2011). Hub location-allocation in intermodal logistic networks. European Journal of Operational Research, 210, 213-230.

Janic, M. (2007). Modelling the full costs of an intermodal and road freight transport network. Transport Research Part D, 12, 33-44.

Janic, M. (2008). An assessment of the performance of the European long intermodal freight trains (LIFTS). Transportation Research Part A, 42, 1326-1339.

Janic, M., \& Vleugel, J. (2012). Estimating potential reductions in externalities from railroad substitution in Trans-European freight transport corridors. Transport Research Part D, 17, 154-160. 
Jeroslow, R. G., Lowe, J.K. (1984). Mathematical programming at Oberwolfach II, chap. Modelling with integer variables. Springer, Berlin, 167-184.

Jourquin, B. (2005). A multi-flow multi-modal assignment procedure on large freight transportation networks. Studies in Regional Science, 35(4), 929-946.

Jourquin, B. (2016). Calibration and Validation of Strategic Freight Transportation Planning Models with Limited Information. Journal of Transportation Technologies, 6, 239-256.

Jurion, B. (2013). Economie Politique 4ème edition. Louvain-la-Neuve: De Boeck.

Kim, N. S., \& van Wee, B. (2011). The relative importance of factors that influence the break-even distance of intermodal freight transport systems. Journal of Transport Geography, 19, 859-875.

Kimms, A. (2006). Economies of Scale in Hub \&: Spoke Network Design Models: We Have It All Wrong. In Morlock, M., Schwindt, C., Rautmann, N. \& Zimmermann, J. (Eds), Perspectives on Operations Research : Essays in honor of Klaus Neumann (pp. 293-317). Gabler Publishing, Wiesbaden.

Kirby, H., Hutton, B., McQuaid, R. W., Raeside, R., \& Zhang, X. (2000). Modelling the effects of transport policy levers on fuel efficiency and national fuel consumption. Transport Research Part D, 5, 265-282.

Konings, R., Kreutzberger, \& E., Maras, V. (2013). Major considerations in developing a hub-and-spoke network to improve the cost performance of container barge transport in the hinterland: the case of the port of Rotterdam. Journal of Transport Geography, 29, 63-73.

Kreutzberger, E. (2010). Lowest Cost Intermodal Rail Freight Transport Bundling Networks: Conceptual Structuring and Identification. European Journal of Transport and Infrastructure Research, 10 (2), 158-180.

Larranaga, A. M., Arellana, J. \& Afonso Senna, L. (2016). Encouraging intermodality: A stated preference analysis of freight mode choice in Rio Grande do Sul. Transportation Research Part A, in Press.

Leveque, P. \& Roso, V. (2002). Dry Port concept for seaport inland access with intermodal solutions. Masters thesis.

Limbourg, S. and Jourquin, B. (2009). Optimal rail-road container terminal locations on the European network. Transportation Research Part E, 45(4), 551-563.

Limbourg, S. \& Jourquin, B. (2010). Market area of intermodal rail-road container terminals embedded in a hub-and-spoke network. Papers in Regional Science, 89 (1), 135-154. 
Lin, C.-C., Chiang, Y.-I. \& Lin, S.-W. (2014). Efficient model and heuristic for the intermodal terminal location problem. Computers \& Operations Research, 51, 41-51.

Lozhkina, O., Lozhkin, V. N. (2015). Estimation of road transport related air pollution in Saint Petersburg using European and Russian calculation models. Transportation Research Part D, 36, 178-189.

Macharis, C. and Bontekoning, Y.M. (2004). Opportunities for OR in intermodal freight transport research: A review." European Journal of Operational Research 153, 400-416.

Macharis, C. \& Pekin, E. (2009). Assessing policy measures for the stimulation of intermodal transport: a GIS-based policy analysis. Journal of Transport Geography, 17, 500-508.

Macharis, C., Van Hoeck, E., Pekin, E., \& Van Lier, T. (2010). A decision analysis framework for intermodal transport: Comparing fuel price increases and the internalization of external costs. Transport Research Part A, 44, 550-561.

Macharis, C., Vereecken, L. and Verbeke, A. (2002) The possibilities of bundling in Belgium. Paper presented at the Congress on Freight Transport Automation and Multimodality, Delft, the Netherlands, May 2002

Maibach, M., Schreyer, C., Sutter, D., Van Essen, H. P., Boon, B. H., Smokers, R., ... Bak, M. (2008). Handbook on estimation of external costs in the transport sector Produced within the study Internalization Measures and Policies for All external Cost of Transport (IMPACT). Delft : CE Delft.

Martí, J. M. C., Tancrez, J. S., Seifert, R. W. (2015). Carbon footprint and responsiveness trade-offs in supply chain network design. International Journal of Production Economics, 166, 129-142.

Mathisen, T. A. \& Sandberg-Hanssen, T.-E. (2014). The academic literature on intermodal transport. Transportation Research Procedia, 3, 611-620.

Mayeres, I., Proost, S., Vandercruyssen, D., De Nocker, L., Int Panis, L., Wouters, G., \& De Borger, B. (2001). The External Costs of Transport - Final Report. Belgium: Sustainable Mobility Programme, Federal Office for Scientific, Technical and Cultural Affairs.

Meers, D. \& Macharis, C. (2014). Are additional intermodal terminals still desirable? An analysis for Belgium. European Journal of Transport and Infrastructure Research, 14 (2), 178-196.

Merchan, A. L., Belboom, S. \& Léonard, A. (2016). BRAIN-TRAINS: Integrating the LCA methodology in an interdisciplinary project. Proceedings of the 5th international conference on Life Cycle approaches. 
Michiels, H., Mayeres, I., Int Panis, L., De Nocker, L., Deutsch, F., \& Lefebvre, W. (2012). $\mathrm{PM}_{2.5}$ and $\mathrm{NO}_{\mathrm{x}}$ from traffic: Human health impacts, external costs and policy implications from the Belgian perspective. Transport Research Part D, 17, 569-577.

Moliner, E., Vidal, R., \& Franco, V. (2013). A fair method for the calculation of the external costs of road traffic noise according to the Eurovignette Directive. Transport Research Part D, 24, 52-61.

Mostert, M., Caris, A. \& Limbourg, S. (2017a). Intermodal network design: A three-mode bi-objective model applied to the case of Belgium. Flexible Service and Manufacturing Journal, In Press. https://doi.org/10.1007/s10696-016-9275-1

Mostert, M., Caris, A. \& Limbourg, S. (2017b). Road and intermodal transport performance: the impact of operational costs and air pollution external costs. Research in Transportation Business and Management, In Press. https://doi.org/10.1016/j.rtbm.2017.02.004

Mostert, M. \& Limbourg, S. (2016). External costs as competitiveness factors for freight transport: a state of the art. Transport Reviews, online.

Mulley, C. \& Nelson, J. D. (1999). Interoperability and transport policy: the impediments to interoperability in the organisation of trans-European transport systems. Journal of Transport Geography, 7, 93-104.

Musso, A. \& Rothengatter, W. (2013). Internalization of external costs of transport-A target driven approach with a focus on climate change. Transport Policy, 29, 303-314.

Nayes, E., \& Arnold, P. (2010). Evaluation des coûts externes liés au transport en Région Wallonne. Namur: Direction générale opérationnelle de l'agriculture, des ressources naturelles et de l'environnement.

Newton, S. (NEA Transport Research and Training; OSC; MKMETRIC) (2009). Deliverable 7. Freight Flows final. Worldnet Project (Worldnet. Worldwide Cargo Flows) Deliverable 7.

Niérat, P. (1997). Market area of rail-truck terminals: pertinence of the spatial theory. Transport Research Part A, 31 (2), 109-127.

Notteboom, T. \& Rodrigue, J. P. (2009). Inland Terminals, Regions and Supply Chains.

Odgaard, T., Kelly, C., \& Laird, J. (2005). Developing Harmonised European Approaches for Transport Costing and Project Assessment (HEATCO). Deliverable 1 Current Practice in project appraisal in Europe - Analysis of country reports. Denmark: COWI A/S. 
OECD (2005). OECD Glossary of Statistical Terms - Stated preference pricing methods Definition. Retrieved from http://stats.oecd.org/glossary/detail.asp?ID=6575, accessed April 2013.

Ortúzar, J.D.D., Cifuentes, L.A., \& Williams, H. C. W. L. (2000). Application of Willingness-to-Pay Methods to Value Transport Externalities in Less Developed Countries. Environment and Planning A, 32, 2007-2018.

Ortúzar, J.D.D. \& Willumsen, L.G. (2011). Modelling transport. Chichester: Willey.

Perez L., Trüeb S., Cowie H., Keuken M.P, Mudu P., RagettliM.S., Sarigiannis D.A., Tobollik M., Tuomisto J., Vienneau D., Sabel C. \& Künzli N. (2015). Transport-related measures to mitigate climate change in Basel, Switzerland: A health-effectiveness comparison study. Environment International, 85, 111-119.

Pérez-Martínez, P. J., \& Vassallo-Magro, J.M. (2013). Changes in the external costs of freight surface transport In Spain. Research in Transport Economics, 42, 61-76.

Pham, V. (2013). The liberalization of rail transport in the European Union. Economics Honors Papers. Economics Department of Connecticut College.

Pigou, A. C. (1920). The Economics of Welfare. London: Macmillan.

Port Autonome de Liège (2016). Retrieved from http://www.portdeliege.be/fr/trilogiport$\underline{3 \mathrm{~d}}$, accessed September 2016.

Port of Antwerp (2015). 2015 Faits et chiffres - Le port en chiffres. Port of Antwerp, Belgium.

Port of Ghent (2017). Cargo traffic: figures and statistics: seagoing + inland navigation. Port of Ghent, Belgium.

Port of Zeebrugge (2017). Evolution container traffic. Retrieved from http://www.portofzeebrugge.be/en/node/496, accessed 18 April 2017.

Preiss, P. and Klotz, V. (2007). Description of updated and extended draft tools for the detailed site-dependent assessment of external costs - Technical Paper No. 7.4 - RS 1b of NEEDS Project. Universität Stuttgart, Germany.

Promotie Binnenvaart Vlaanderen (2015). Periskal Easy Voyage Planning. Retrieved from http://pbv.periskal.com/\#Pages/EasyVoyagePlanning.xaml, accessed June 2015.

Promotie Binnenvaart Vlaanderen (2016). Periskal Easy Voyage Planning. Retrieved from http://pbv.periskal.com/\#Pages/EasyVoyagePlanning.xaml, accessed October 2016.

PWC (2003). Faire le choix du transport fluvial: l'avis des entreprises - Enquête Voies Navigables de France. PWC, France. 
Racunica, I. \& Wynter, L. (2005). Optimal location of intermodal freight hubs. Transportation Research Part B, 39, 453-477.

Rangaiah, G. (2009). Multi-objective optimization: techniques and applications in chemical engineering. Advances in process systems engineering. World Scientific.

Ravibabu, M. (2013). A nested logit model of mode choice for inland movement of export shipments: A case study of containerised export cargo from India. Research in Transportation Economics, 38(1), 91-100.

Ricardo-AEA (2014). Update of the Handbook on External Costs of Transport. United Kingdom: Ricardo-AEA.

Ricci, A., \& Black, I. (2005). The Social Costs of Intermodal Freight Transport. Research in Transport Economics, 14, 245-285.

Rodrigue, J.-P., Comtois, C., \& Slack, B. (2006). The Geography of Transport Systems. New York: Routledge.

Roso, V., Woxenius, J. \& Lumsden, K. (2009). The dry port concept: connecting container seaports with the hinterland. Journal of Transport Geography, 17, 338-345.

RTBF (2014). DP World acquiert le terminal à conteneurs Trilogiport de Liège. Retrieved from https://www.rtbf.be/info/regions/detail_dp-world-acquiert-le-terminal-aconteneurs-trilogiport-de-liege?id=8341688, accessed May 2017.

Sansom, T., Nash, C. A., Mackie, P. J., Shires, J., \& Watkiss, P. (2001). Surface Transport Costs and Charges: Final Report. United Kingdom: Institute for Transport Studies, University of Leeds.

Santos, B.F., Limbourg, S., Carreira, J.S. (2015). The impact of transport policies on railroad intermodal freight competitiveness the case of Belgium. Transportation Research Part D: Transport and Environment, 34, 230-244.

Schilk, G. \& Seemann, L. (2012). Use of ITS technologies for multimodal transport operations - River Information Services (RIS) transport logistics services. Procedia Social and Behavioral Sciences, 48, 622-631.

Schmid, S. A., Bickel, P., \& Friedrich, R. (2001). RECORDIT Real cost reduction of door-to-door intermodal transport - Deliverable 4 External cost calculation for selected corridors. Germany: IER University of Stuttgart.

Sen, A. K., Tiwari, G., Upadhyay V. (2010). Estimating marginal external costs of transport in Delhi. Transport Policy, 17, 27-37.

Sirikijpanichkul, A., Van Dam, K. H., Ferreira, L. \& Lukszo, Z. (2007). Optimizing the Location of Intermodal Freight Hubs: An Overview of the Agent Based Modelling 
Approach. Journal of Transportation Systems Engineering and Information Technology, 7 (4), 71-81.

Smith, T. W., Axon, C. J., Darton, R.C. (2013). The impact on human health of carrelated air pollution in the UK, 1995-2005. Atmospheric Environment, 77, 260-266.

Sörensen, K., Vanovermeire, C. \& Busschaert, S. (2012). Efficient metaheuristics to solve the intermodal terminal location problem. Computers \& Operations Research, 39, 20792090 .

Sörensen, K. \& Vanovermeire, C. (2013). Bi-objective optimization of the intermodal terminal location problem as a policy-support tool. Computers in Industry, 64, 128-135.

SteadieSeifi, M., Dellaert, N.P., Nuijten, W., Van Woensel, T., \& Raoufi, R. (2014). Multimodal freight transport planning: A literature review. European Journal of Operational Research, 233, 1-15.

Tainio, M. (2015). Burden of disease caused by local transport in Warsaw, Poland. Journal of Transport \& Health, 2, 423-433.

te Loo, R. (2009). A methodology for calculating $\mathrm{CO}_{2}$ emissions from transport and an evaluation of the impact of European Union emission regulations. Unpublished master's thesis. Eindhoven University of Technology, the Netherlands.

Terminal Container Athus (2017). Transport de containers import-export. Retrieved from http://www.tca.be/fr/transport-de-containers, accessed $18^{\text {th }}$ April 2017.

The Intermodal Container Web Page (2013). Retrieved from http://www.mattsplace.com/intermodal/part1/sea_containers1.htm, accessed February 2013.

Troch F., Vanelslander, T., Sys, C., Stevens, V., Verhoest, K., Mostert, M., Tawfik, C., Limbourg, S., Merchan, A., Belboom, S., Léonard, A. (2015). BRAIN-TRAINS Transversal assessment of new intermodal strategies - Deliverable 1.3: Scenario development. University of Antwerp, Belgium.

UNECE United Nations Economic Commission for Europe (2015). The Air Convention and its Protocols. Retrieved from http://www.unece.org/environmentalpolicy/conventions/envlrtapwelcome/the-air-convention-and-its-protocols/theconvention-and-its-achievements.html, accessed January 2016.

UNIFE (2016). EU financing for rail. Retrieved from http://www.unife.org/topics/21.html , accessed September 2016.

United Nations (2001). Terminology on combined transport. Tech. rep., United Nations, Geneva. 
UNFCCC United Nations Framework Conference on Climate Change (2016). Paris Agreement - Status of Ratification. Retrieved from http://unfccc.int/paris_agreement/items/9444.php, accessed December 2016.

Van Essen, H. P., Boon, B.H., Maibach, M., \& Schreyer, C. (2007). Methodologies for external cost estimates and internalization scenarios - Discussion paper for the workshop on internalization on March 15, 2007. Delft: CE Delft.

Van Essen, H. P., Boon, B. H., Schroten, A., Otten, M., Maibach, M., Schreyer, C., ... Pawlowska, B. (2008). Internalization measures and policy for the external cost of transport - Produced within the study Internalization Measures and Policies for all external cost of Transport (IMPACT) - Deliverable 3. Delft: CE Delft.

van Klink, H.A. \& van den Berg, G. (1998). Gateways and intermodalism. Journal of Transport Geography, 6, 1-9.

van Lier, T., \& Macharis, C. (2010). Transport of goods to and from the centre of Brussels: using the port to improve sustainability. In Macharis C. and Melo, S. (Eds.), Multiple views on City Distribution: a state of the art (pp. 176 - 199). Cheltenham: Edward Elgar Publishing.

van Lier, T. $(20$ 14). The development of an external cost calculator framework for evaluating the sustainability of transport solutions (Unpublished doctoral dissertation). Vrije Universiteit Brussel, Belgium.

van Lier, T, Macharis, C. (2014). Assessing the environmental impact of inland waterway transport using a LCA approach - the case of Flanders. Research in Transportation Business \& Management, 12, 29-40.

Verhetsel, A., Kessels, R., Blomme, N., Cant, J., \& Goos, P. (2013). Location of Logistics Companies: a Stated Preference Study to Disentangle the Impact of Accessibility. Unpublished manuscript.

Verweij, K. (2011). Synchronic modalities - Critical success factors. In P. J. van der Sterre (Ed.), Logistics yearbook edition 2011. Rotterdam: Feico Houweling.

Viapass (2015). Viapass for hgvs. Retrieved from http://www.viapass.be/en/aboutviapass/viapass-for-hgvs/

Vrenken, H., Macharis, C. \& Wolters, P. (2005). Intermodal transport in Europe. Brussels: EIA

Wang, F., Lai, X., Shi, N. (2011). A multi-objective optimization for green supply chain network design. Decis.SupportSyst.51,262-269. 
Wendt, C. (2009). Mapping European healthcare systems: a comparative analysis of financing, service provision and access to healthcare. Journal of European Social Policy, $19,432-445$.

World Health Organization (2014). 7 million premature deaths annually linked to air pollution. Retrieved from http://www.who.int/mediacentre/news/releases/2014/airpollution/en , accessed December 2015.

Woxenius, J. (2007). Generic Framework for Transport Network Designs: Applications and Treatment in Intermodal Freight Transport Literature. Transport Reviews, 27(6), 733-749.

Xia, T., Nitschke, M., Zhang, Y., Shah, P., Crabb, S, Hansan, A. (2015). Traffic-related air pollution and health co-benefits of alternative transport in Adelaide, South Australia. Environment International 74, 281-290.

Yamada, T., Russ, B. F., Castro J., Taniguchi, E. (2009). Designing Multimodal Freight Transport Networks: A Heuristic Approach and Applications. Computers in Industry, 64(2), 146-154.

Yevdokimov, Y. V. (2000). Measuring economic benefits of intermodal transportation. Transportation Law Journal, 27(3), 439-452.

Zhang, M. (2013). A Freight Transport Model for Integrated Network, Service and Policy Design - Zhang (Unpublished doctoral dissertation). Delft University, the Netherlands.

Zhang, M., Janic, M., Tavasszy, L. (2015). A freight transport optimization model for integrated network, service, and policy design. Transportation Research Part E, 77, 6176.

Zhang, M. \& Pel, A. J. (2016). Synchromodal hinterland freight transport: Model study for the port of Rotterdam. Journal of Transport Geography, 52, 1-10.

Zhang, M., Wiegmans, B. \& Tavasszy, L. (2013). Optimization of multimodal networks including environmental costs: A model and findings for transport policy. Computers in Industry, 64, 136-145. 